This dissortation has been

microflimed exactly as recolved $\quad 67-16,272$

DITMARS Jr., Walter Earl, 1923-

A COMPARATIVE STUDY OF PHEOPHYTIN a AND OF PHEOPHYTIN $\underline{b}$ MONOLAYERS.

The Ohio State University, Ph.D., 1967

Chemistry, physical

University Microfilms, Inc., Ann Ārbor, Michigan 


\title{
A COMPARATIVI STUDY OF PHEOPHYTIN a AND OF PHEOPHYTIN b MONOLAYERS
}

\author{
DISSERTATION
}

\section{Presented in Partial Fulfillment of the Requirements for the Degree Doctor of Philosophy in the Graduate School of The Ohio State University}

Walter Sarl DitmarB Ir., B.Sc., M.Sc.

The Ohio State University

$196 ?$

Approved by

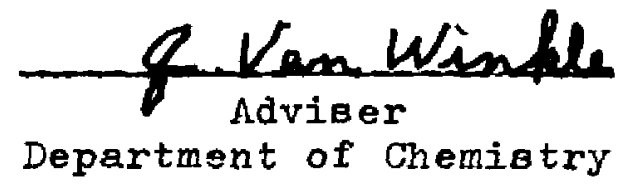




\section{ACKNOWLEDGMENTS}

I wish to thank my adviser. Professor Quentin Van Winkle, for his continued interest and oupport in initiating and bringing to fruit the research reported herein. It is an understatement to say that without his unusual courage of moral conviction and high standards for academic performance this work could not have come into being.

I wish to acknowledge the assistance of the members of the Chemistry Department Machine and Glassblowers Shops in construction of various pieces of apparatus used in the research. I am indebted to H.F. Blanck Jr., P. Kullavanijaya, and J. Larry for ossistance in calculations of the osciallator and dipole strengths of the visible and ultraviolet light absorption of the chlorophylls and several of their derivatives.

I wish to thank $\mathrm{H} . \mathrm{F}$. Blanck $\mathrm{Jr}$, , and $\mathrm{J}$. Larry for assistance in performing the work on the spectroscopic and stability studies, and for many stimulating discussions.

I am especially appreciative for the support my family has given me, and for the patience shown in the hardships endured to accomplish this work. 
This work was generously supported by grants from the National Science Foundation and the National Institutes of Health. 
VITA

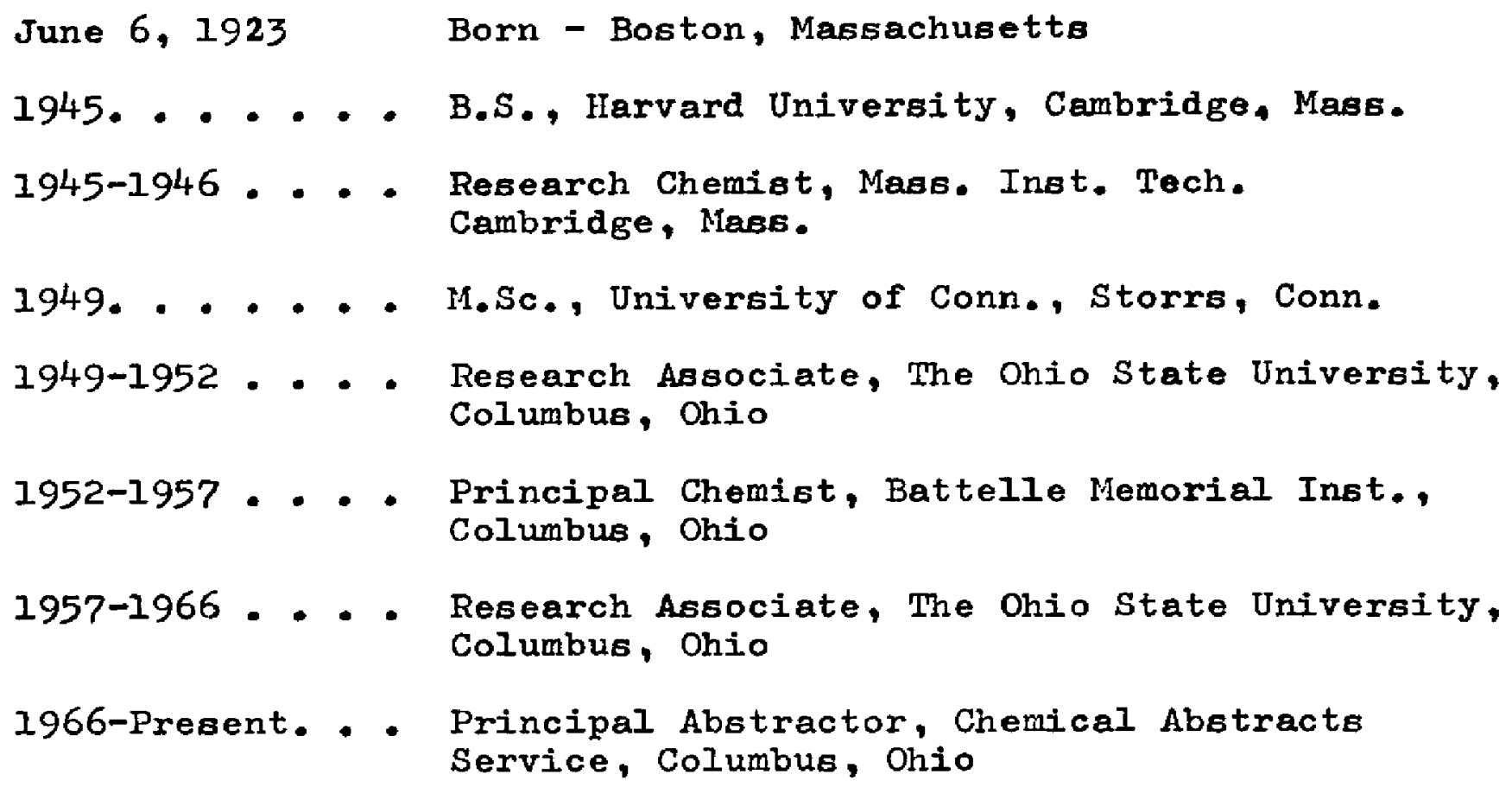

\section{PUBLICATIONS}

"The Vapor Pressure of Inorganic Substances VII. Iron between $1356^{\circ} \mathrm{K}$ and $1519^{\circ} \mathrm{K}$ and cobalt between $1363^{\circ} \mathrm{K}$ and $1522^{\circ} \mathrm{K} . "$

J.W. Idwards, H.I. Johnston, and W.E. Ditmars, Jr. JACS 73 4729 (1951).

"The Vapor Pressure of Inorganic Substances $\mathrm{K}$. Diseociation Pressures of Iithium hydroxide between $650^{\circ}$ and $800^{\circ} \mathrm{K} . " 1$ W.E. Ditmars, Jr. and H.L. Johnston. JACS 751830 (1953). "The Vapor Pressures of Inorganic Substances II. Titanium between $1587^{\circ}$ and $1764^{\circ} \mathrm{K}$ and copper between $1143^{\circ}$ and $1292^{\circ} \mathrm{K} . "$ J.W. Edwards, H.L. Johnston, and W.E. Ditmars, Jr. JACS 75 2467 (1953). 
PUBLICATIONS

"Current generator cell." J. McCallum, T.B. Johnson, W.E. Ditmars, Jr., and L.D. McGraw. U.S. 2,979,553, April 11, 1961.

"Alkaline Voltaic Cells having anodes of $\mathrm{Nb}, \mathrm{V}$, or Mo." J. McCallum and W.E. Ditmars, Jr. U.S. 2,986,592, May 30, 1961. "Electrical Concurrent Generating Cells." J. McCallum, T.B. Johnson, W.E. Ditmars, Jr., and L.D. McGraw. U.S. 3,033,910, May 8, 1962.

"Current Generator Cell." J. McCallum, T.B. Johnson, W.E. Ditmars, Jr., and L.D. McGraw. U.S. 3,093,512, U.S. 3,093,513, U.S. 3,093,514, June 11, 1963.

"Heterogeneity of the interaction of DNA (deoxyribonucleic acid) with acriflavine." R.K. Tubbs, W.E. Ditmars, Jr., and Q. Van Winkle. J. Mol. Biol. 9 545-57 (1964).

"A Comparative Study of Pheophytin a and Pheophytin b Monolayers." W.E. Ditmars, Jr. and Q. Van Winkle, submitted to the Journal of Physical Chemiatry, 1967.

FIEIDS OI STUDY

Major Fields: Undergraduate: Chemistry, Mathematics Graduate: Physical Chemistry

Surface Chemistry Professor Quentin Van Hinkle 
CONTENTS

ACKNOWLEDGMENTS. . . . . . . . . . . . . . ..$\cdot \cdot$

VITA

iv

TABLES

.. . . . . . . . . . . . . . . . . . .

viii

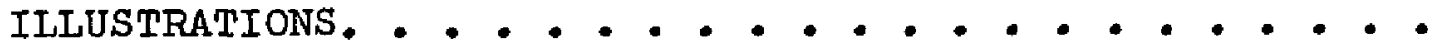

$\mathbf{x i}$

ABBREVIATIONS AND STMBOLS. . . . . . . . . . . . .

xii

Page

INTRODUCTION . . . . . . . . . . . . . . . . . .

The Chlorophylls in Vivo..............

Statement of Problem . . . . . . . . . . . .

LITERATURE SURVEY. . . . . . . . . . . . . . . .

EXPERTMENTAL . . . . . . . . . . . . . . . . . .

Reagents, General Procedures, and

General Facilities. . . . . . . . . . . .

Preparation of the Chlorophylls and

their Derivatives.................

Spectroscopic Measurements . . . . . . . . . 30

Oscillator Strengths ................. 31

Constituent Analysis . . . . . . . . . . . 32

Monolayer Apparatus . . . . . . . . . . . . 39

Monolayer Procedures . . . . . . . . . . . . 45

Experimental Accuracy - Spectroscopic

Experimental Accuracy - Monolayer

Monolayer Stability. . . . . . . . . . . 76

Surfaces Pressures and Surface Potentials. . . . 83

Monolayer Model. . . . . . . . . . . . . 96 
CONTENTS (Conta.)

Page

SUMMARY

122

APPENDIX A. CHEMICAL AND PHOTOCHEMICAL STABILITY

TESTS OF THE CHLOROPHYLLS AND SEVEKAI

DERIVATIVES IN VARIOUS SOLVENTS. • . • 127

INTRODUCTION . . . . . . . . . . . . 128

EXPERIMENTAL . . . . . . . . . . . . . 129

RESULTS AIND DISCUSSION . . . . . . . . . . 135

Chemical Stability ... . . . . . . 135

Photochemical Stability. ......... 145

SUMMARY .................. 174

APPENDIX B. VISIBIE ABSORPTION SPECTRA OF THE CHLOROPHYLIS AND SEVERAI DERIVATIVES IN

VARIOUS SOLVENTS ............ 180

INTRODUCTIOH . . . . . . . . . . . . . 181

RESULTS AIND DISCUSSIONJ . . . . . . . . . 186

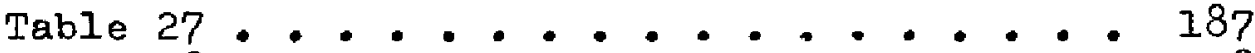

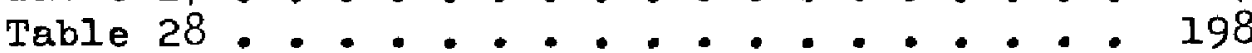

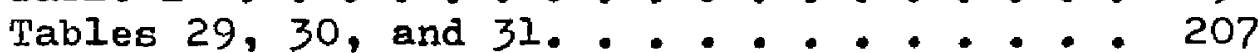

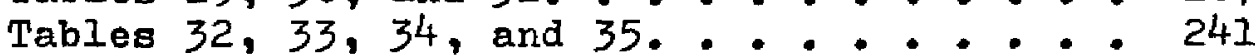

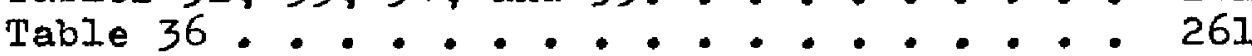

SUMMARY .................. 271

BIBLIOGRAPHY • . . . . . . . . . . . . . . . 277

vii 
TABLES

Table

Page

1. Comparison of the spectral Parameters of this Research With Those of the Chlorophyll Derivatives of Holt. . . . . . . . 28

2. Optical Density Values and Wavelengths for the $0.99 \times 10^{-5} \mathrm{M}$ Solutions, and Values of the Denominator Determinants Used for Component Correlation . . . . . . . . . . 35

3. Comparison of the Visible Absorption Parameters of the Chlorophylls in Ethyl Ether. . . . . 54

4. Visible Absorption Parameters of the Pheophytins . . . . . . . . . . . 60

5. Estimated Uncertainties in Band Peak Positions and Band Cut-Offa ............... 65

6. Estimated Errors in Oscillator and Dipole Strengths Arising from Uncertainties in Choice of Band Cut-Offs............. 66

7. Procedural Errors in the Area Per Molecule . . 70

8. Percentage Variations in $\sigma$ calculated from Observed Variations in $\Delta V$.......... 74

9. Stability Tests on Chlorophyll a Monolayers. . - 77

10. Stability Tests on Pheophytin Monolayers at Air-Water Interfaces............... 80

11. Surface Pressure and Surface Potential Values for Pheophytin $a$ and $b$ at $\mathrm{pH}=4.0$ and

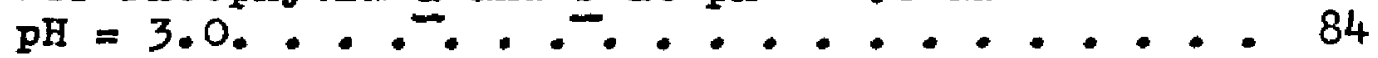

12. Average Compressibilities of ph a, ph b, chl a,
and chl b Monolayers - - - -89

13. Effect of $\mathrm{pF}$ on $(\mu / D) \cos \theta$ for ph..... .91 viii 


\section{TABLES (Contd.)}

Table

14. Variation of Monolayer Molecule Characteriatics With Angle of Tilt $(\theta) . . . . . . . . . . .109$

15. Areas Per Molecule and Free Areas Per Monolayer Unit at the Start of Transition . . . . . . I15

16. Initial Energy Absorption of Solutions in the Photochemical Experiments . . . . . . . 131

17. Description of the Systems in Chemical Stability Tests.................... 136

18. Chemical Stability of Chlorophyll a in Benzene Solutions................... 139

19. Chemical Stability of the Chlorophylls and the Pheophytins in Various Solvents .... . . . 140

20. Systems Used in Low Light Intensity Photobleaching Tests............... . . 146

21. Photobleaching Behavior at Low Light Intensities, chl a, chl b, al chI a, al ph 2 , and ph a. . 149

22. Photobleaching Behavior at Low Light Intensities, chI a................... 152

23. Systems Used in High Light Intensity Photobleaching Tests . . . . . . . . . . . 156

24. Photobleaching Behavior at High Light Intensities. Benzene Solutions . . . . . . . . . . 161

25. Photobleaching Behavior at High Light Intensities. Solvents Different than Benzene . . . . . . 162

26. Apparent Quantum Yield in the Initial Period of Photodecomposition . . . . . . . . 167

27. Band Peak Wavelengths and Wave Numbers of the Chlorophylls and Several Derivatives in Various Solventa. . . . . . . . . . . . 188 
TABLES (Contd.)

Table

28. The Change of Band Peak Wave Numbers With Change of Solvent in Reference to Ethyl Ether. . . . 199

29. Oscillator Strengths of the Chlorophylls and Several Derivatives in Various Solvents... . 208

30. Dipole Strengths of the Chlorophylls and Several Derivatives in Various Solvents . . . 220

31. Changes in Oscillator and Dipole Strengths With Change of Solvent in Reference to Ethyl Ether ................... 229

32. Spectroscopic Parameters of the Chlorophylls and Several Derivatives in Various Solvests . . 242

33. Ratios of Peak Absorbances, Oscillator Strengths, and Dipole Strengths ............ 244

34. The Change of Band Peak Wave Numbers With Change of Substituent in the Same Solvent......., 248

35. Changes in Oscillator and Dipole Strengths With Change of Substituent in Ethyl Ether. . . . . 251

36. Distances Between Band Peaks. . . . . . . . . 262 


\section{ILLUSTRATIONS}

Figure

Page

1. Chlorophyll a and Chlorophyll b. . . . . . 3

2. Surface Pressure and Surface Moment Versus

Molecular Area for Pheophytin a... . . . 85

3. Surface Pressure and Surface Moment Versus

Molecular Area for Pheophytin b. . . . 86

4. Molecular Model of Chlorophyll b . . . . . . 97

5. Close Packed Arrangement in a Pheophytin

Monolayer ................. 103

6. Variations in $\Delta \mathrm{V}$ With $\sigma \mathrm{ph} \underline{\mathrm{e}} \mathrm{pH}=3.0 . . . .117$ 


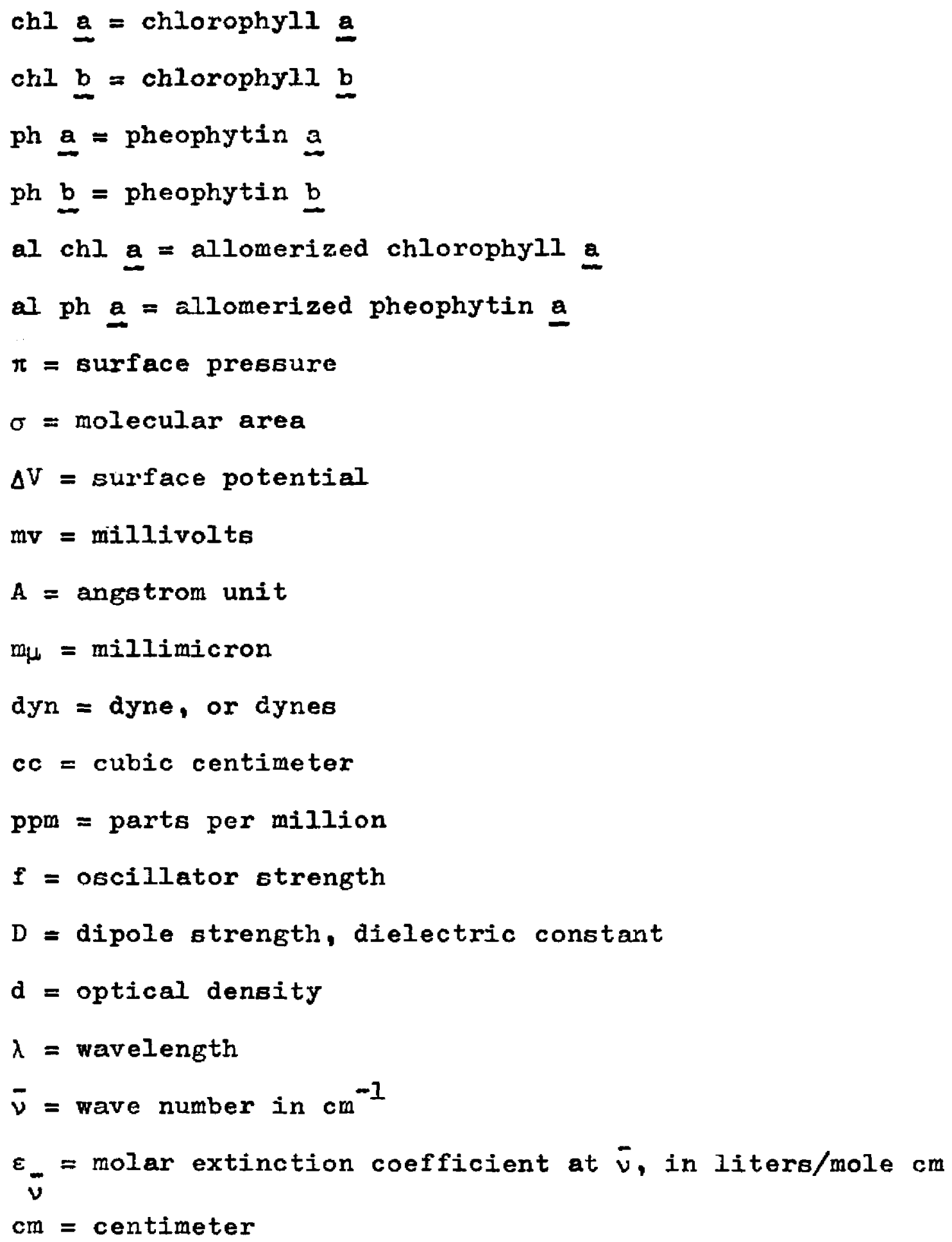




\section{ABBREVIATIONS AND SYMBOLS (Contd.)}

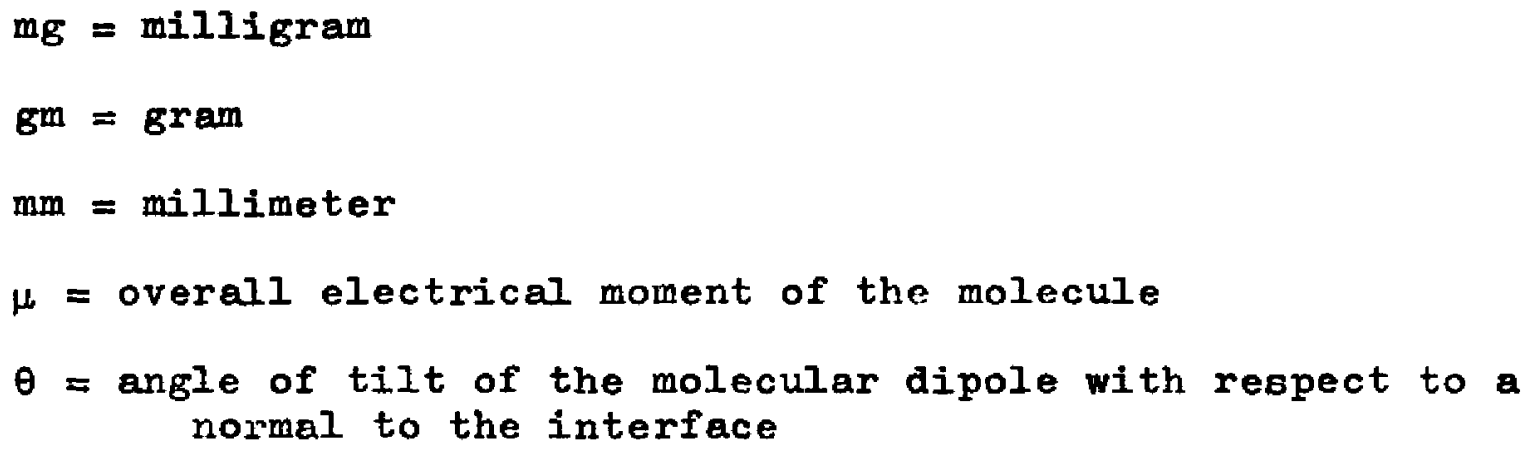




\section{INTRODUCTION}

The Chlorophylls in Vivo

There is good evidence, principally from light and electron microscopy studies, that the photoconversion apparatus (the chloroplast) of most photosynthesizing organiams has a highly ordered lamellar structure [1], [2]. The layers appear to be comprised of paired membranes joined at their ends to form closed disci. These discs are spaced regularly apart in a matrix, and are in ordered stacks. Differences in reaction with various chemical reagents have shown that the discs probably have a higher concentration of lipids, while the matrix is higher in proteins. Light-microscopic and fluorescence-microscopic evidence indicate that the chlorophyll is concentrated in the stacks of discs and absent in the matrix [2], [3]. Exposure of the discs to silver nitrate solution in light results in oilver deposits on the discs as revealed by electron microscopy. Since chlorophyll can reduce ałlver nitrate photochemically, the ailver coating of the discs can be taken as further evidence that the chlorophyll is bound in the discs. Calculations, using the dimensions and number of discs, and the amount of chlorophyll present in the chloroplast, suggest that the chlorophyll could be present in the form of non-crystalline monolayers at the 
Interfaces of the discs and the matrix. Coneiderations of this type led to the generally aseumed model of monomolecular chlorophyll lylng between relatively thick layers alternately high in concentration of lipids and aqueous proteins, or at essentially an oil-water interface. As a consequence of their heterophilic nature the chlorophyll molecules will probably be oriented with the phytol group in the oil phase. Such orientation will reault in electrical polariaation of the interface. The direction and degree of polarization will depend on the normal (to the plane of the interface) component of the dipole moment of chlorophyll, and the constituents contiguous to the chlorophylls at the phase boundaries. In the former instance, a change in substituent pattern on the chlorin ring may be expected to alter the effective interfacial moment. AB shown in Figure 1 change of the $-\mathrm{CH}_{3}$ group of chl a to the -CHO group of chl $\underline{b}$ should produce a different resultant molecular moment, and perhaps a significantly different contiguous molecular environment. Definition of the actual composition of the chlorophyllcontaining interfacial regions in vivo remains a matter of continuing research interest. It is generally thought, however, that intimately associated with chlorophyll at the interface there are at least three other primary constituents: lipoproteins, lipides, and carotenold pigments. These constituents play several roles in the primary conversion process. From a general functional view the most important roles would be: (a) stabilization 


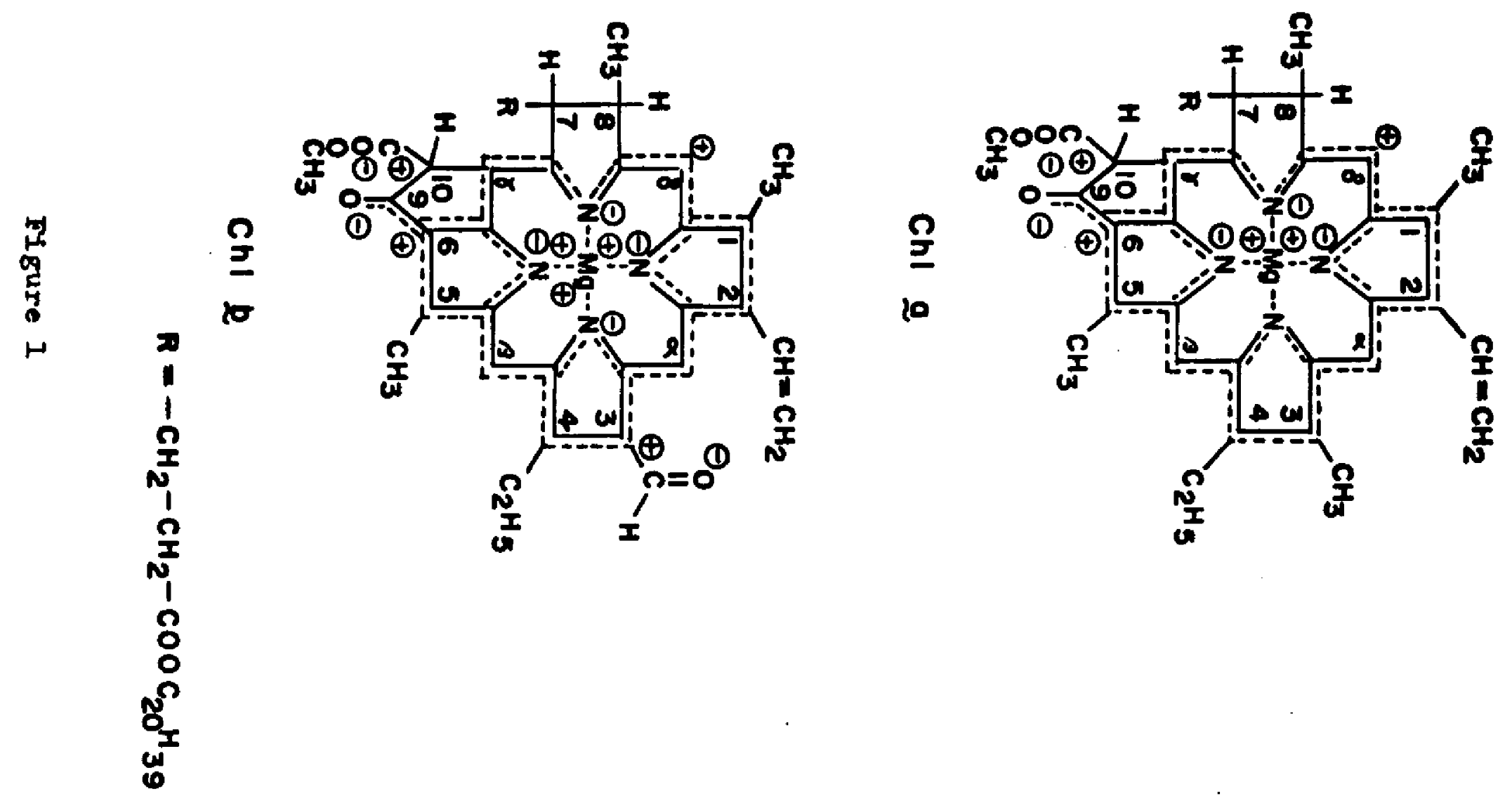


and protection of the chlorophyll monolayer, (b) provision of phase boundaries that can allow for efficient transfer and conversion of the light energy absorbed by the chlorophyll, and (c) provision for separated (by the chlorophyll monolayer) phases that can allow for efficient utilization of the converted energy (i.e., a chemical oxidant, and a chemical reductant).

Statement of Problem

As a step toward an understanding of the complex interfacial syetems in vivo, information on the properties of oriented monolayers of the chlorophylls and their derivatives at simple air-water interfaces may be expected to be of value. The properties of interest include chemical and photochemical stability, surface presaure ( $\pi$ ) vo. molecular area $(\sigma)$ behavior, surface potential $(\Delta V)$ vs, $\sigma$ behavior, and spectral properties. The property of stability is of first concern, since only measurements on films of intact compounds can be regarded as significant.

It has been rather generally known that the chlorophylls and their derivatives are quite labile orgenic molecules. In particular, gross photodecomposition of chlorophyll in solution, resulting in destruction of the chlorin ring, has often been noted. Until only recently, there appeared to be less general arareness of the ease of intact ring derivative formation, chemically and photochemically, both in solutions and in monolayers. 
In 1961 G. Colmano [4] showed that the chlorophylls are chemically unstable at ordinary air-distilled water interfaces, and in benzene solutions prepared under normal laboratory conditions. In monolayers significant decomposition occurs within the first five minutes after spreading, under conditions of dim, diffuse lighting. Some retardation of decomposition is obtained if the $p H$ of the aqueous phase is maintained at about 8.0 . W. D. Bellamy, G. L. Gains, Jr., and A. G. Tweet in 1963 [5] confirmed Colmano's findings, and showed further that decomposition of the monolayer is also lessened in nearly total darkness. Results of the exploratory phases of this work vere in agreement with these findings, and will be discussed subsequently. We find that, although pheophytin formation (where the central $\mathrm{Mg}$ atom is replaced by two hydrogen atoms) is inhibited, a process that is identified as essentially allomerization (oxidation at the isocyclic ring betreen the $\gamma$ and 6 positions of the chlorin ring) continues to occur. The rate is inhibited considerably when the chl a monolayer is under an atmosphere of nitrogen containing about $40 \mathrm{ppm}$ of $\mathrm{O}_{2}$.

We find that, at air-water interfaces, the pheophytine undergo a process identified as allomerization unless the $\mathrm{pH}$ of the aqueous phase is maintained at less than about 5.0. The monolayers are then stable, in the absence of light, or in dim, diffuse green light (i.e., at wavelengths absorbed only slightly by the molecules), for periods of six hours or more. In view of these findinge, a quantitative, comparative study of the $\pi-\sigma$ 
and $\Delta V-\sigma$ behavior of $p H a$ and $p H \underline{b}$ monolayers at air-water interfaces was undertaken.

Knowledge of the absolute values of $\sigma$ will depend on knowledge of the absolute purity of the samples. While there has been increasing agreement between different reseirohes in recent years, absolute purity remains a problem of continued research interest. Study of conditions required for obtalning and maintaining highly purified samples constituted an important phase of this work. 


\section{IITERATURE SURVIY}

A number of otudies of chlorophyll and pheophytin monolayers have been reported over the past 30 years. These will be reviewed briefly in historical order.

W. Sjoerdsma, in 1936 [67, studied the $\pi-\sigma$ behavior of 3 to 1 mixturee of $\operatorname{chl}$ a: $\operatorname{chl}$ b spread at air-0.1N $\mathrm{H}_{2} \mathrm{SO}_{4}$, air-0.01 $\mathrm{N} \mathrm{H}_{2} \mathrm{SO}_{4}$, alr-water, and $\mathrm{CO}_{2}$-water interfaces. He reportB that the $\pi$ - $\sigma$ behavior at the first three interfaces were identical within experimental error, while in the fourth system the force-area curve was shifted to about 7 per cent larger molecular areas. Limiting molecular areas ( $\sigma$ extrapolated to $\pi=0$ ) of about $124 \mathrm{~A}^{2}$, and collapse areas of about $30 \mathrm{~A}^{2}$, at $\pi \sim 26 \mathrm{dyn} / \mathrm{cm}$, were observed. No information on film homogeneity, sample purity, or film atability was given. It seems certain that on the acid substrates the chlorophylls were converted to the pheophytins.

A. IIughes, in $1936[7]$, summarizes the results of $\pi-\sigma$ and $\Delta V-\sigma$ studies of $\operatorname{chl}$ a and chl $\underline{b}$ monolayers at air-pH $=7.0-7.5$ buffer interfaces. Limiting areas of $132 \mathrm{~A}^{2}$ for chl $a$, and $137 A^{2}$ for chl b were found. Film collapse was observed between $80-90 A^{2}$. Over the range of area studied the surface potential of chl a increased from $300 \mathrm{mv}$ to $375 \mathrm{mv}$ on compresiton, while that for chl b increased from 250 to $300 \mathrm{mv}$. If the pH of the 
aqueous substrate was made less than 6.0 , a sharp increase in $\Delta V$ was obeerved, and attributed to the formation of pheophytin. Alkali was reported to have little effect on the properties of the films. No information on ample purity or film homogeneity was given.

I. Langmuir and V. J. Schaefer, in 1937 [8], otudied chlorophyll monolayers at air-water interfaces where the $\mathrm{pH}$ of the subphase was varied from 3.0 to 10.0 . Surface viscosities as a function of surface pressure and pH are reported. Multilayers of up to 600 layers in thickness were prepared and the conditions leading to fluorescence investigated. No information on aample purity, film stability, or film homogeneity was given.

In 1937, A. E. Alexander [9] made a comparative study on the $\pi-\sigma$ and $\pi-\Delta V$ behavior of a variety of porphyrin derivatives, including $\operatorname{ch} \mathbf{l}$ a and $\operatorname{chl} \underline{b}$, at atr-pH $=7.3$ buffer interfaces. By use of the dark-field ultramicroscope method the chlorophyll films were found to be homogeneous at large areas. Limiting areas of $135 \mathrm{~A}^{2}$ and $138 \mathrm{~A}^{2}$ for chl $\mathrm{a}$ and chl $\mathbf{b}$ respectively were found. The areas, at a collapse pressure of about $28 \mathrm{dyn} / \mathrm{cm}$, were $80 \mathrm{~A}^{2}$ for $\mathrm{chl} a$ and $76 \mathrm{~A}^{2}$ for chl b. Over the range of areas studied the surface potential of chl a increased from 300 to $385 \mathrm{mv}$ on compression, while that of chl b rose from 250 to $300 \mathrm{mv}$. At pH's less than 6.0 the surface potentials rose sharply; the effect was attributed to the formation of pheophytin. It was ouggested without elaboration that the $\pi$ - $\sigma$ behavior of 
the pheophytins was quite aimilar to that of the chlorophylls. No information on sample purity was given, and no indication was given of problems of chemical or photochemical instability. E. A. Hanson, in 1939 [10], studied ethyl chlorophyllide and chlorophyll monolayers at air-water interfaces. Ifimiting areas of $70 \mathrm{~A}^{2}$ for the chlorophyllide (at $\mathrm{pH}=5.4$ ), and of $106 \mathrm{~A}^{2}$ for chlorophyll (at $\mathrm{pH}=4.1$ ) were found. Thus, the phytol tail increases the area occupied by about $36 \mathrm{~A}^{2}$. Hanson reported that chlorophyll is not converted into pheophytin at $\mathrm{pH}=4.1$ which appears to be in variance with the work of Hughes [7] and Alexander [9], and is not corroborated by the reoults of this research. Hanson further reports that the surface requirement and compressibility increase with increasing $\mathrm{pH}$, effects which are ascribed to increasing degree of hydration. No indication was made of problems of stability, or film homogeneity.

In eeveral papers published in the years 1954 through 1957 , E. E. Jacobs and co-workers report studies on the visible absorption spectra of ethyl chlorophyllide and chlorophyll monolayers [11], [12], [13]. Monolayers were prepared by spreading a solution containing a known amount of pigment onto a given area of air-water interface. No $\pi$ - $\sigma$ or $\Delta V-\sigma$ data were reported, and no information on film stability or homogeneity was given. The work bhowed that the main red absorption band is ohifted oignificantly to the red for both chlorophyll and 
chlorophyllide monolayers, in comparison to its position in dilute solution spectra. Such red shifts are observed for chlorophyll In vivo. The band shifts were greater for the chlorophyllide and closely resembled shifts observed for the pigment microcrystals. In 1959, H. J. Trurnit and G. Colmano studied chl a and chl b monolayers at air-water and oil-water interfaces [14]. They reported $\ddot{\pi}-\sigma$ data at air-distilled water interfaces and absorption epectra at both air-distilled water and oil-distilled water interfaces. Considerable attention was given to sample preparation, and epectroscopic criteria for sample purity are presented. Limiting areas for chl a ranged from 103 to $130 \mathrm{~A}^{2}$, depending on the chlorophyll sample used and the spreading solvent. Use of acetone as apreading solvent, for example, appeared to result in a loss of chlorophyll to the aqueous phase and therefore gave a smaller apparent area per volecule. For chl b the range was from 211 to $140 \mathrm{~A}^{2}$. Collapse preesuies for chl a ranged from 26 to $29 \mathrm{dyn} / \mathrm{cm}$ and the areas at collapse from 54 to $73 \mathrm{~A}^{2}$; for $\operatorname{chl} \mathrm{b}$ the ranges were from 30 to $42 \mathrm{dyn} / \mathrm{cm}$, and from 51 to $54 \mathrm{~A}^{2}$. Detailed consideration was given to spectral changes of chlorophyll films in comparison to spectra in dilute solutions. The most marked changes found were: (a) a shifting of all bands to longer wavelengths, (b) the shrinkage of the blue absorption band of chl a to the extent that it almost disappeared within the blue satelitite band, and (c) the shrinkage of the blue satellite band of chl $\underline{b}$ to the extent of almost disappearing in the blue band. By redissolving the films in solvent after experiment, and 
recording the solution epectra, the changes observed for the films were deduced to be due primarily to changes in the physical state of the molecules. In a later report [4] (referred to above), where film stability was discussed, it is stated that measurements were generally completed within about 15 minutes after opreading of the filme. In that time period degradation to the extent of perhaps only 10 per cent had occurred, which lends some support to the conclusion regarding the spectral changes observed in the films.

In the period from 1963 through 1965 W. D. Bellamy, G. L. Gains, Jr., and A. G. Tweet reported a number of studies on monolayers of chl $\underline{a}$ and $\mathrm{ph}$ a at ges-water interfaces, [57, [15], [16], [17], [18], [19]. Measurements, using highly sophisticated instrumentation, were carried out under controlled, inert atmospheres, filtered lighting (or total darkness), and with the pH of the aqueous aubphase maintained at 8.0 . The chl a samples were apparently of high purity, as indicated by the spectral parameters of dilite solutions. The pheophytin a, however, appeared to be of lesser quality (comparisons with this work are made in the discussion of sample purity). Numerous tests were made to assess the chemical and photochemical stability of the monolayers. It was generally concluded that, in the absence of light, the monolayers remained stable for times sufficient for meaningful experiments on their chemical and physical properties. Main band absorbance, for both $\mathrm{ph}$ a and chl a films, was reported 
to decrease only a fow per cent in 2 hours in the absence of light. Degradation of chl a was also determined in terms of change of the following absorption band peak ratios: Blue/Blue satellite

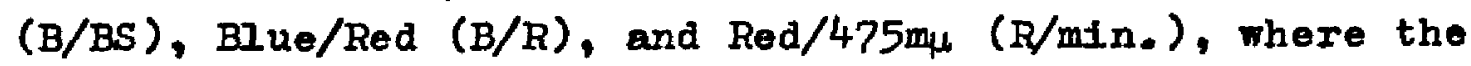
denominator in the last ratio refers to the optical density of the absolute minimum in the pure absorption epectrum. In typical experiments, for monolayers ipread for two hours in darkness, decreases of 7 per cent in $B / B S$ and 45 per cent in $R /$ min. were observed, with $B / R$ apparently remainting unchanged. Although it is difficult to decide on the actual amount of degradation from peak ratio changes, we estimate, from similar type experiments, that the changes reported represent from 5 to 15 per cent decomposition. This estimate would appear to be in line with the general conclusion of the authors.

In the first report of Bellamy et al $[5], \pi-\sigma, \Delta V-\sigma$, and absorption spectral data for chl a and ph a monolayers are given. No information on film homogeneity was reported. Experimental accuracy in $\sigma$ wes indicated to vary from \pm 8 per cent to \pm 3 per cent, depending largely on sample purity. The limiting areas were, for chl a, $125 \mathrm{~A}^{2}$, and for ph a, $109 \mathrm{~A}^{2}$. Chl a monolayers collapsed at $22-23 \mathrm{dyn} / \mathrm{cm}$, at a molecular area of about $77 \mathrm{~A}^{2}$, while $\mathrm{ph}$ a monolayers collapsed at about $11.0 \mathrm{dyn} / \mathrm{cm}$ and $90 \mathrm{~A}^{2}$. For $\mathrm{chl} \mathrm{a}, \Delta \mathrm{V}$ varied from 230 to $310 \mathrm{mv}$ over the range $120-85 \mathrm{~A}^{2}$; for ph a, the increase was from 545 to $590 \mathrm{mv}$ in the range 105 to $90 \mathrm{~A}^{2}$. The absorption spectra of the monolayers are 
compared with earlier work [11], [12], [13], [14], Similar changes, in comparison to the spectra of dilute solutions, were found. The absorption spectra of both ph a and chl a monolayers are reported to be essentially independent of molecular area over most of the otable mechanical range of pressures.

On the basis of the experimental results and considerations of molecular dimensions, a monolayer model was proposed. It was suggested that the monolayer comprises a liquid film conforming to Langmuir's theory [20] of liquid expanded monolayers. ${ }^{\dagger}$ The molecules are anchored to the water surface by the ester linkages, a configuration suggested earlier by Hughes [7] and Alexander [9]. The chlorin heads and the phytol tails, in a folded configuration rising above the water surface, are interspersed in a randomly oriented array. The planes of the chlorin heads are tilted at an angle of $35^{\circ}$, or less, with respect to a normal to the interface. On the basis of the relatively small change of surface moment with molecular area, it was concluded that there is no major change in the configuration of the polar groups with respect to the water surface as the filmo are compressed. Following the inftial report, Bellamy, Gains, and Tweet reported studies on: a) fluorescence of chl a monolayers [15],

The theory was originally proposed for straight chain hydrocarbons with hydrophilic polar head groups. Monolayers of these substances were visualized as essentially duplex films with the hydrocarbon tails tending to form a coherent liquid phase above the water surface, and the polar heads tending to form a gaseous film, within the water surface, and occupy all the avallable interfacial area. 
b) angular dependence of fluorescence from chl a in monolayers [16], c) interaction between chl a and fatty alcohol molecules in mixed monomolecular films [17], d) fluorescenco quenching and energy transfer in monomolecular films containing chlorophyll [18], and e) interaction botween chl a and vitamin $K$, in monomolecular films [19]. A brief summary of the results follows.

Fluoreacence in pure chl a monolayers is strongly concentration quenched; relative fluoreecence yield increases nearly 1000-fold when the pigment molecules are effectively separated by a two-dimensional diluent. The intensity of fluorescence emission was found to be significantly dependent on the angle of detection with respect to the plane of the interface. nn the basis of the proposed monolayer model, the results were interpreted to show that the transition moment of the red fluorescence, lying in the plane of the chlorin ring, makes an angle of $20^{\circ}$ or less with the plane of the water surface. Quenching of the fluorescence of chl a in monolayers by copper pheophytin a, a non-fluorescent chlorophyll dexivative, was measured as a function of quencher concentration. Energy transfer is detected through the quenching. Since the nature of the description of energy transfer depenas on the distances between chromophores, both undiluted and highly diluted chl a monolayers were studied. The results were discussed theoretically with appropriate modification of available theories. Chl a and oleyl alcohol form nearly ideal two-dimensional solutions up to chlorophyll mole fraction of at least 0.2 . 
Chlorophyll is essentially insoluble in stearyl alcohol monolayers. Chl a-oleyl alcohol monolayers gave collapse preasures that depended cn the composition, while chl a-stearyl alcohol monolayers collapsed at the collapse pressure of $\mathrm{chl}$ a at all compositions. Oleyl, but not stearyl, alcohol produces significant wave length shifts to the blue in both the absorption and emisBion epectra of $\operatorname{chl}$ a monolayers. Oleyl alcohol, as a diluent, increases the fluorescence yield of chl a but stearyl alcohol does not. The wavelength shifts with dilution are evidence that chlorophyll-chlorophyll interactions, as well as chlorophyllwater interactions [5], are responsible for the red shift observed in the spectra of chl a monolayers.

Vitamin $K_{1}$ (a quinone) quenches the fluorescence of chl a both In diluted (by oleyl alcohol) and undiluted mixed monolayers. The quenching is interpreted as arising from collisional interaction, possibly requiring a preferred orientation between pigment molecule and quencher. Vitamin $K_{2}$ and chl a form non-ideal twodimensional solutions; departures from ideality are small.

M. Rosoff and C. Aron, in 1965, report a study [21] of the conversion of $\operatorname{chl} \underline{a}$ to $\mathrm{ph}$ a in monolayers at air-pH $=4.0$ buffer interfaces. They indicate that the properties of ph a monolayers at $\mathrm{pH}=8.0$ are the same as at $\mathrm{pH}=4.0$ which is in variance with the results of this work. The $\pi-\sigma$ data at $\mathrm{pH}=8.0$ of Rosoff and Aron do not agree well with that reported by Bellamy et al [5]. At given values of $\pi$, the $\sigma$ values reported by former authors are about 7 per cent greater for $\operatorname{chl} \underline{a}$, and 
about 5 per cent smaller for ph a. Because of the lower compressibility found by Rosoff and Aron, they consider the chl a and ph a monolayers to be of the liquid condensed type rather than liquid expanded as assumed by Bellamy et al [5]. These discrepancies may relate to variations in sample purity or problems in obtaining completely opread monolayers. Rosoff and Aron give no information on these points, nor do they give information on the otability of ph a films at $\mathrm{pH}=8.0$.

No systomatic study of ph $b$ appears to have been reported. 


\section{EXPERTMENTAL}

Reagents, General Procedures, and General Facilities

AIl solvente and reagenta used were C.P. analytical grade as received from the manufacturer. In the chlorophyll preparation work, monolayer studies, and in some of the spectroscopic determinations the colvents were used without further treatment. For work under controlled atmospheres (in sealed Blove enclosures) all solvents, except the ethyl ether, were degassed by evaporation and agitation under racuum. The benzene was twice recrystallized to about one half its original volume, and arfed by storage (for more than 3 days) over calcium hydride ponder. It was filtered under a pure nitrogen atmosphere $\left(\mathrm{O}_{2}<30 \mathrm{ppm}\right.$, $\mathrm{CO}_{2}<3$ ppm, $\mathrm{H}_{2} \mathrm{O}$ vapor $<1$ ppm), with predesiccated materials and apparatus, into a special pyrex vacuum evaporation vessel, and subequently degassed. Where it was dosired to obtain exceptIonally high purity benzene, the following technique was necessary. The already purified benzene wes put into a otoppered flask, under pure nitrogen atmoophere, which contained a mixture of $\mathrm{CaH}_{2}$ and high grade (Woelm) chromatography alumina. The calcium hydride removed adsorbed water from the alumina, as evidenced by an initial, vigorous evolution of gas. Nonaqueous polar molecules in the benzene were then adsorbed on the 
activated alumina. With the doubly recrystallized and degassed cyclohexane it was oufficient to pass the cyclohexane through an alumina column and then store over $\mathrm{CaH}_{2}$. Attempting to dry a solution of chlorophyll $\left(10^{-5} \mathrm{M}\right)$ in benzene directly with $\mathrm{CaH}_{2}$ resulted primarily in 108 s of the chlorophyll by adsorption on the $\mathrm{CaH}_{2}$. Ethyl ether oolutions, prepared and used for quantitative measurements, were handled in closed polyethylene bags. The atmosphere within was saturated with ether vapor. This procedure reduced error due to solvent evaporation to less than 1 per cent.

In the exploratory work on the chemical stability of chl a monolayers several additives to the monolayers were examined. The $a-L-l e c i t h i n$ was the high purity grade obtained from the Fluka Chemical Manufacturing Co., Buche, Switzerland. The phytol was the $C$ grade product obtained from the California Corporation for Biochemical Research, Los Angeles. The $\beta$-carotene was obtained from the Eastman Kodak Co. These chemicala were used without further purification except for removal of adsorbed or dissolved gases $\left(\mathrm{O}_{2}\right.$ and $\left.\mathrm{CO}_{2}\right)$ and water before being put into solution. All apreading solutions were made with highly purified benzene, except for those containing the a-I-lecithin. These latter solutions were made from dry, CP ethyl ether with 10 vol. per cent absolute alcohol which was needed to dissolve the lecithin crystals. The ethyl alcohol was thoroughly degased (to remove $\mathrm{O}_{2}$ and $\mathrm{CO}_{2}$ ) before use. 
The buffer solutions were made with distilled water and reagent grade chemicals. The Bolutions were made more concentrated than used and subsequently diluted volumetrically. For mork under controlled atmospheres degassing (to remove dissolved $\mathrm{O}_{2}$ ) was done by allowing the solutions to equilibrate (in the monolayer trough) with the controlled atmosphere for at least 15 hours before opreading the monolajer. The aurfaces of all aqueous solutions were cleaned by suction at the surfaces through a capillary frior to transfer to the monolayer trough. Double recryatallization of the Baker'B reagent grade phthalate salt, used to prepare the $0,025 \mathrm{M}$ buffer eciutions, had no detectable influence on the experimental accuracy of the monolayer runs (see below). Within experimcntal error, increase or decrease of buffer concentration by a factor of four had no effect on monolayer properties. Use of a citrate, instead of a phthalate, buffer did not affect the results.

Double distilled demineralized water (specific resistance $1.1 \times 10^{6} \mathrm{ohm} \mathrm{cm}$ ) was used in chlorophyll preparation. Water used in monolayer work was single distj?] sd (specific resistance $8.0 \times 10^{5} \mathrm{ohm} \mathrm{cm}$ ). For work under controlled atmospheres the water was degassed (to remove $\mathrm{O}_{2}$ and $\mathrm{CO}_{2}$ ) by bubbling (through a fritted glass disk, which also provided for atirring of the water) with high purity nitrogen for at least 18 hours before use. The apparatus consisted essentially of a twelve liter round bottom pyrex flask with auitable glass inlets, stopcocks, ground glass joints, etc., to permit filling, emptying, and 
degassing without the water contacting anything other than clear Blass surfaces, and short sections of cleaned, heavy :r.1. (5/32 in.) Tygon tubing. The high purity nitrogen $\left(\mathrm{O}_{2} \sim 30 \mathrm{ppm}\right.$, $\mathrm{CO}_{2} \sim 3 \mathrm{ppm}$ as received in the tank) was passed through a fritted glass bubble trap with acid chromous chloride oolution [22] (to remove $\mathrm{O}_{2}$ ), an $8 \mathrm{~N} \mathrm{NaOH}$ solution (to remove $\mathrm{CO}_{2}$ and acid bpray) and finally through a trap filled with glass-wool (to remove spray) before being passed into the distilled rater.

Experiments under controlled atmosphere were conducted in conventional aealed glove boxea with gasketted airlocks and suitable outlets for the nitrogen lines, recirculation purificetion oystem, distilled water, eystem for testing oxygen content, vacuum-trap system for removal of water and cleailing the gaswater interface before spreaaing the monolayer, etc. The atmosphere box used for preparaticn of speciel spectroscopic solutions had a recirculation puification system. The nitrogen in the box, kept at a slight positive pressure with respect to atmospheric, was continously pumped through (a) an activated charcoal column, (b) condensation traps (filled with fine copper screen to increase burface area) refrigerated to liquid nitrogen temperature, and (c) a tube filled with 200-mesh copper gauze squares heated to about $400^{\circ} \mathrm{C}[23]$, in that order. The oxygen content, during experimental work, averaged $\leq 20 \mathrm{ppm}$. When experimental resulte showed that control of polar molecule concentrations was insufficient for working with very high purity solutions, specially designed (to provide maximum surface 
exposure and good circulation) containers with CP KOH pellets and (separately) with anhydrous magnesium perchlorate were installed within the box. The amount of condensable materials collecting in the liquid nitrogen traps per unit time was considerably reduced.

Deliberate introduction of gaseous impurities (e.g. wet and dry $\mathrm{CO}_{2}$, wet and dry $\mathrm{O}_{2}$ ) into the chlorophyll solutions was done within the atmosphere box. The gases were carefully purified and, where intended, saturated with pure water vapor waing conventional techniques. The addition of water vapor alone was done by bubbling pure nitrogen saturated with water vapor from degassed distilled water.

The system for terting oxygen content consisted essentially of a trap containing a piece of dry, yellow phosphorus with freshly cut ourfaces. At $30 \mathrm{ppm}$ of oxygen a fairly heavy evolution of phorphorous pentoxide amoke is observabie in a sow moving dry nitrogen gas stream. At less than $10 \mathrm{ppm}$ the smoke is no longer observable [24].

Sample weighings were made with a Sartorius microbalance to at least $\pm 0.005 \mathrm{mg}$. In adiition to usual care to achieve great cleanliness, the apparatus and glassware used in controlled atmosphere work were thoroughly desiccated and flushed with pure nitrogen before use. Operations with the chlorophylls or their derivatives were carried out in low intensity diffuse green light. Commercially available transparent green plexiglass in $1 / 4$ inch thicknesses, or greater was used for light filter. This 
particular plastic trangmite light almost entirely in the region of the green minimum of the chlorophyll-a absorption spectrum, and reduced the problem of photobleaching of samples greatly. Dilute solutions of chlorophyll-a when viewed in this green light, appear as colorless as water, and show no observable fluoreacence.

The crystalline chlorophyll samples were predesiccated and degassed with a liquid nitrogen trap under high vacuum for 2 to 6 days at $25^{\circ} \mathrm{C}$ before use. The preparations of allomerized chlorophyll-a were carried out under controlled atmosphere conditions.

Monolayer experiments were carried in a constant temperature laboratory maintained at $20^{\circ} \mathrm{C} \pm 1^{\circ}$. The laboratory air was maintained at 1 ess than 50 per cent relative humidity, and was continuously circulated through dust-removing filters and an activated charcoal air purifier to remove ourface active vapors.

Preparation of the Chlorophylla and their Derivatives

Crystaline samples of chlorophyll a and chlorophyll b were prepared by a method similar to that used by E. E. Jacobe, A. E. Vatter, and A. S. Holt $[1 I] \bullet^{\dagger}$ Variations will be described. All operations were carried out at $4^{\circ} \mathrm{C}$ and very low light intensities. Humidity level was considerably below saturation.

This work confirms the results of Jacobs et al [11] on the otability of the crystalifne material. After 36 months of otorage in the dark at $4^{\circ} \mathrm{C}$ there was no trace of decomposition, as determined by visible ipectra measurements. 
The work was carried out so that a minimum of time elapsed during transfer of the chlorophylle from the fresh spinach leaves to the mixed cryetalline mat in the first phase of the procese, and during the chromatographic separation through to the final crystallization of the pure products.

The spinach was carefully trimmed of all stems, and only the freshert, greenest leaves used. Prior to blending with acetone, the selected leaves were thoroughly washed with cold water to remove dirt and juices from the cut portions. Following blending, all insoluble material was filtered out through a Hy-Flo Supercell (cleaned diatcmaceous earth) pad. The first effluent (about 10 per cent of the total liquid volume) contained no chlorophyll and, hence, was discarded. The insoluble material and filter pad were washed with fresh acetone in order to obtain all the chlorophyll.

The chlorophyll pigments were trensferred to a petroleum ether (boiling range $30^{\circ}-60^{\circ}$ ) aolution, having about $1 / 10$ the volume of the initial acetone folution, in the following manner. Portions of the initial acetone solution (twice the volume of the petroleum ether) were shaken in a separatory funnel. Then twice as much distilled water as acetone was slowly added and gently shaken. In this way very little chlorophyll was lost in colloidal form to the aqueous phase. The chlorophyll is oolubilized in the petroleum ether phase by the acetone in that phase. Consequently, the use of too large a ratio of distilled water to acetone in transfer step can reault in the formation 
of pigment crystals (particularly toward the end of the tranefer process) and greater amounts of colloidal chlorophyll dispersed in the aqueous phase. In the operation of washing the petroleum ether solution of chlorophyll with 80 vol. per cent aqueous methanol solution, it is important to have oufficient volume of petroleum ether so that all the chlorophyll remains in oolution (due to the presence of methanol in the petroleum either phase). If this is not done, removal of the precipitated carotenols by filtration cannot be carried out. In most of the washing and transfer procedures, where two phases are present, mixing in the Beparatory funnel should be done gently. Otherwise, very stable, fine emulsions can be formed that can cause much loss of time in obtaining the final product.

Confectioner's $10 \mathrm{X}$ sugar with 3 per cent cornstarch was used for chromatography. It was pretreated as follows to remove moisture and other volatile materials: (a) heated at $90^{\circ} \mathrm{C}$ in an oven in a large, open crystallizing dish for about 10 hours, (b) evacuated for $11 / 2$ to 2 hours, while still hot after removal from the oven, through a liquid nitrogen trap with a two etage mechanical pump. It was siftod with a triple stage flour sifter, directly before uee in the column, into anhydrous reagent grade petroleum ether $\left(30^{\circ}-60^{\circ} \mathrm{C}\right)$. The column was packed from elurries of the sugar in petroleum ether. The packed sugar was thoroughly washed with petroleum ether. These treatments provided for uniform and channel-free packing, and excellent adsorption and elution characteristics for the pigments. Pressure (with high 
purity nitrogen) was used, rather than suction, since it provided a more uniform flow. The first, and last $1 / 10$ of the chlorophylla solution was diacarded. The chlorophyll-b was removed from the column by elution with acetone; the first and last $1 / 10^{\prime} s$ were discarded.

During chromatography the only colored bands observed were the $\operatorname{chl} \underline{a}$ and $\operatorname{chl} \underline{\mathrm{b}}$ bands. Ultraviolet illumination of the column did not reveal any fluorescence from colorless bands. No odors were ever detected from the sugar, of from the final crystals (see below).

Crystallization of the chlorophylls was done by coreful vacuum removal of solvent on a distilled water surfece. In some batches, a small amount of amorphous residue $(<5$ per cent of the material) was left on the diatilled water surface, indicating that impurities, which may have been picked up from the sugar, were separated out during crystallization. The final crystalline aggregates were vacuum dried tlırough a liquid nitrogen trap for about 1 week. The chlorophyll-a crystal aggregates were dark purplish blue in color with dull metallic lustre. The chlorophyll-b crystal aggregates were dark rich green in color with high metallic lustre. While there were variations from one batch of spinach to another, about one gram of chlorophyll-a, and one-half gram of chlorophyll-b was obtained from $20 \mathrm{lbs}$. of whole opinach plants.

The pheophytins were prepared as follows: to $100 \mathrm{cc}$ of $10^{-5} \mathrm{M}$ acetone solutions of the chlorophylls in a $500 \mathrm{ml}$ 
separatory funnel was added 5 ce of degaseed 10 per cent (by vol.) HCl solution. After a minute with shaking, about $90 \mathrm{cc}$ of benzene or ethyl ether were added. Then about $200 \mathrm{ml}$ of distilled water was added slowly (to inhibit fine emulsion formation upon phase separation) to transfer the pheophytin to the benzene (or ether) phase. The benzene (or ether) solution was subsequently washed with eight $150 \mathrm{ml}$ portions of disililed water to remove all acid and acetone. This was done with care so that little or no pigment was loet (in the form of fine aroplets) in the water phases. Finally, the solution was diluted to $100 \mathrm{ml}$ in a volumetric flask. Three nethods were tried for the preparation of allomerized chlorophyll... While only one was considored to give satisfactory resulte, it is of interest to compare all three. A $100 \mathrm{ml}$ of $10^{-5}$ Moluticn of chlorophyl1-a in degassed CP methanol was the starting solution in all cascs. In all instances the following procedures were followed. The chlorophyll solution was placed in a $500 \mathrm{ml}$ volumetric flack provided with a tight-sealing, standard taper, Teflon-Eleeved stopper. Oxygen gas, which had been passed through a long column of Ascarite then through several large surface area traps cooled to dry ice-alcohol bath temperature, was bubbled through the methanol solution for 30 minutes with agitation. The flask was sealed with an oxygen atmosphere within and allowed to stand in the dark, at room temperature for more than 18 hours. About $80 \mathrm{ml}$ of benzene (or ether) was then added to the solution in a separatory funnel. Then a procedure identical with that for pheophytin was followed 
to attain the final benzene (or ether) solution. In the first instance nothing was added to the methanol eolution. The absorption spectrum was almost identical in every detail with that of pure chlorophyll in a wet benzene. Constituent analysis (seo below) of the spectral data showed 98.2 per cent chlorophyll-a, 0.2 per cent allomerized chlorophyl1-a, and 1.6 per cent unknown. In tive second instance about $50 \mathrm{mg}$ lanthanum chloride per 100 cc methanol solution was used. In this instance a definite chemical change occurred. However, there were aignificant intensity increases at $555 \mathrm{~m}$ and $505 \mathrm{~m} \mu$ in the absorption spectrum which showed that the oxidation reaction was complicated by oimultaneous loss of magnssium. This wovld indicate that the dissolution of lanthanum chloride in the methanol resulted in the formation of sufficient hydrogen ion for replacement of the magnesium in the chlorophyl1. Constituent analysis showed 6.9 per cent chlorophyJl-a, 66.6 per cent allomerized chlorophyll-a, 24.4 per cent pheophytin-a, and 2.1 per cent unknown.

In the last instance magnesium was dissolved in the methanol (before making up the chlorophyll solution) to give a solution of magnesium methoxide (about $10 \mathrm{mg} \mathrm{Mg} / 100 \mathrm{ml}$ methanol). The spectrum of the product showed no gross complications and closely resembled that of fraction number two reported by $A$. $S$. Holt [25]. The method of preparation wes similar to that used by Holt to obtain pure fraction 2 .

In Table 1 are compared the spectroscopic parameters of 
Table 1

Comparison of the Spectral Parameters of This Research

With Those of the Chlorophyll Derivatives of

Holt, $25^{\circ} \mathrm{C}$, Solvent is Ethyl Ether

\begin{tabular}{|c|c|c|c|c|c|c|c|c|c|}
\hline Compound & $\lambda_{\mathrm{R}}^{\mathrm{c}}$ & $\lambda_{B}$ & $\lambda_{\mathrm{BS}}$ & $B / R^{d}$ & $B / B S^{d}$ & $B / 505^{d}$ & $R / \min d, e$ & $\mathrm{R}_{1 / 2}$ & $\mathrm{~B}_{1 / 2}$ \\
\hline Chlorophyl1-a & 660.0 & 428.1 & 408.0 & 1.29 & 1.57 & 64 & 109 & 17.0 & 38.0 \\
\hline Pheophytin-a & 667.0 & 408.5 & 393.8 & 2.03 & 1.23 & 10.5 & 18.1 & 26.6 & 51.8 \\
\hline $\begin{array}{l}\text { Allomerized } \\
\text { Chlorophyl-a }\end{array}$ & 653.0 & 417.0 & 392.0 & 2.00 & 2.00 & 58.7 & 49.9 & 21.6 & 36.6 \\
\hline $\begin{array}{l}\text { Allomerized } \\
\text { Pheophlytin-a }\end{array}$ & 670.3 & 399.8 & & 2.77 & & 18.0 & 19.2 & 20.5 & 40.7 \\
\hline Fraction $1^{b}$ & 670 & 420 & & 2.71 & & 43.3 & 17.3 & $(46)$ & (55) \\
\hline Fraction $2^{b}$ & 652 & 417 & $(400)$ & 1.88 & & $(50)$ & 67 & $(22)$ & $(35)$ \\
\hline Fraction $3^{b}$ & 660 & 429 & 411 & 1.4 & 1.47 & 59 & 65 & $(20)$ & $(37)$ \\
\hline
\end{tabular}

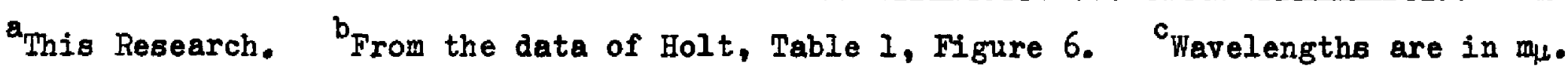

${ }^{d}$ Ratios of optical densities. The minimum occurs in the neighborhood of $470 \mathrm{~m} / \mathrm{s}$. 
Holt [25] and this research. Data on chl a, ph a, and al ph a are included to illustrate the differences from Holt'B fractions. The numbers in parentheses were estimated from Figure 6 of Holt. In the absence of molar extinction coefficient data, it is not possible, by comparison, to decide on absolute pigment purity, which will depend not only on the presence of pigments absorbing in the visible, but on the presence of colorless impurities. This matter is discussed subsequently.

From a comparison of the parameters available, it seems likely that the al chl a of this work was probably less pure than the fraction 2 of Holt. This is evidenced by the smaller $R /$ min ratio and the larger $B_{1 / 2}$ value (width of the main blue band at $1 / 2$ peak optical density) of this research. Since the spectrum of the al chl a of this work showed a small "tail" on the long wave length side of the main red band, extending over the region occupied by the main red band of Holt's fraction 1 , it seems reasonable to suppose that a small amount of this compound was present in our sample. This view is also supported by the fact that the $B / R$ ratio of this work is about 6 per cent larger than that of Holt's fraction 2. If it is assumed that the red molar absorption coefficients of fractions 1 and 2 are about equal, then we estimate, from the magnitude of the absorbance of the red "tail" of our spectrum, that our sample may have had from 5 to 10 per cent impurity. This will introduce some uncertainty in the constituent analysis method, discussed Bubsequently. 
The allomerized pheophytin-a (here, we mean allomerized chlorophyll-a where the $\mathrm{Mg}$ atom has been replaced by two hydrogens, es in pheophytin-a) was prepared in the aame manner as pheophytin-a, only starting with a solution of allomerized chlorophyll-a.

Spectroscopic Measurementa

Visible absorption spectra measurements were made with a Cary 14 recording spectrophotometer run on automatic slit control over a scanning range of $750 \mathrm{m \mu}$ to $350 \mathrm{m \mu}$ at $5 \mathrm{~A} / \mathrm{sec}$. For a typical chlorophyll spectrum manual variation of the slit widths to about \pm 10 per cent of the automatic setting produced only negligible differences in optjcal densities at a given wavelength. The accuracy of the instrument was usually \pm 0.002 unit of optical density but occasionally was as low as \pm 0.006 . These errors were gensrally small compared to those from other sources (to be discussed subsequently). The accuracy in wavelength was generally better than $\pm 0.5 \mathrm{~m} \mu$. Corrections for scattering and fluorescence were estimated to be negligible. The Beckman pyrex absorption cells were modified by sealing No. 9 standard taper outer joints on the tops. The cells could then be stoppered with ground glass, polyethylene, or Teflon-sleeved stoppers. The rate of leakage ${ }^{\dagger}$ of impurity

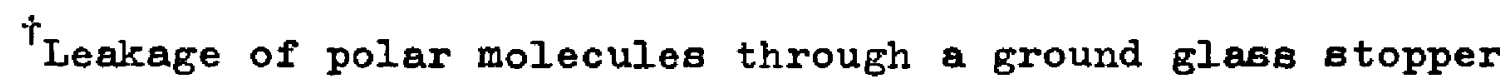
was sufficiently rapid that within a period of 10 to 15 minutes in ordinary laboratory air the chlorophyll spectrum of a dry solution could be observed to be changing in a manner characteristic for the addition of polar molecules. 
molecules $\left(\mathrm{H}_{2} \mathrm{O}, \mathrm{O}_{2}, \mathrm{CO}_{2}\right.$, etc., $)$ through the stoppered joint was in the order: ground glass $\gg$ polyethylene $\gg$ Teflon sleeve. The use of Teflon-sleeved stoppers was absolutely essential when highly purified solutions were being measured. In fact, as a supplementary precaution, the cells were often kept in a vacuum desiccator (in darkness) filled with pure nitrogen until just before scanning.

All cells were calibrated with respect to a control cell and individual cell corrections over the scanning range determined. Procedural errors were estimated to have introduced an uncertainty of \pm 3 per cent or less in concentrations of the pigments. Crystalline samples were re-desiccated at $25^{\circ} \mathrm{C}$ under vacuum through a liquid nitrogen trap at least two days before weighing. Weighing was done at $20^{\circ} \mathrm{C}$, where the relative humidity was 50 per cent or less. Spectra measurements were made at $25^{\circ} \mathrm{C}$ and concentrations corrected for temperature change.

Oscillator Strengths

The oscillator strengths were determined [26], [27] with

$$
f=\frac{2303 \mathrm{mc}^{2}}{\pi \mathrm{Ne}^{2}} \int \varepsilon_{\bar{\nu}} \mathrm{d} \bar{v}=4.318 \times 10^{-9} \int \varepsilon_{\bar{v}} \mathrm{~d} \overline{\bar{v}}
$$

$$
D=\frac{2303}{N} \frac{3 h c}{8 \pi^{3} e^{2}} \int \varepsilon_{\bar{v}} \mathrm{~d} \bar{v} / \bar{\nu}=3.980 \times 10^{-20} \int \varepsilon_{\bar{\nu}} \mathrm{d} \bar{v} / \bar{\nu},
$$


where $\mathrm{m}=9.1072 \times 10^{-28} \mathrm{gm}, c=2.99776 \times 10^{10} \mathrm{~cm} / \mathrm{Bec}$, $\mathrm{N}=6.0254 \times 10^{23} \mathrm{~mole} \mathrm{e}^{-1}, \mathrm{e}=-4.8023 \times 10^{-10} \mathrm{e.s.u.}$, $h=6.6238 \times 10^{-27} \mathrm{erg} \mathrm{sec}, \bar{v}=$ wave number in $\mathrm{cm}^{-1}$, and $\varepsilon_{\bar{\nu}}=$ molar extinction coefficient at $\bar{\nu}$.

An ott type 30 compensating polar planimeter was used for measurement of areas under the curves. Errors in measurement were negligible compared to those from other sources to it discussed subsequently.

Constituent Anaiysis

In early phases of this work, observations on the variations of the absorption spectra of dilute solutions of chl a indicated that mixtures of several intact ring derivatives can be rather easily formed under normal laboratory conditions (results are summarizod in Appendix A). Similar observations were made, for example, by F.P. Zscheile and coworkers [28], [29], whose classical work on chlorophyll purity established the values of the optical density ratios $B / R, R / 505$ (for chl a), $R / 520$ (for $\operatorname{chl} \underline{b}$ ), and $R / \min$ as criteria for aample purity. Variations of these ratios, and increses of main band half-widths have been used as an indication of degradative reactions (for example references [4] and [5]). No work appears to have been reported estahilishing what mixtures of products are usually formed under normal laboratory conditions leading to degradation. Under usual conditions, 
oxygen, water vapor, and carbon dioxide are present to interact. Water and carbon dioxide can interact to cause pheophytinization (for example, reference [2] p. 452), while the cyclopentanone ring is readily attacked by oxygen (for example, reference [2] pp. 400, 462, 1773-1774). This suggested that mixtures of intact ring derivatives, under normal laboratory conditions, would arise primarily from processes of pheophytinization and allomerization. Although Holt [25] showed that allomerization can result in at least thres products, he found that fractions 1 and 3 can both be converted into fraction 2. Under circumstances leading to formation of several derivatives, fraction 2 is the predominant product $(70-80$ per cent). When water is present to give hydroxyl ions, fraction 2 is formed in preference to fraction 1. This evidence euggests that allomerization, occuring under most laboratory conditions, will lead primarily to products having the expanded isocyclic ring structure of Holt's fraction 2. Allomerization under laboratory conditions will give products having a hydroxyl group on the $\mathrm{C}_{10}$ atom rather than a methoxy group as obtained in methanol solutions. This difference in substitution does not give rise to significant differences in the visible absorption spectrum [25].

It was assumed, in the absence of extensive light activation and where water, carbon dioxide, and oxygen are present, that chl a could give mixtures of al chl $a$, ph $\underline{a}$, and al ph $a$. Similarly al chl a could degrade to al ph a, and ph a to al ph a. In dilute solutions (total concentration the order of $10^{5} \mathrm{M}$ ), 
where the solvent is wet benzene or ethyl ether, mixtures of derivatives are likely to be non-interacting. The absorption spectra at given wavelengths were assumed, therefore, to be additive. Consequently, the optical density of a mixture is giver. by

$$
\mathrm{d}=\log I_{0} / I=\left(\varepsilon_{1} C_{1}+\varepsilon_{2} C_{2}+\cdots-\cdots\right) 1,
$$

where $\varepsilon_{i}=$ the molar extinction coefficient for the $i^{\text {th }}$ absorbing component, $C_{i}=i t s$ concentration, and $I=$ the path length. If there are $n$ components, then $n$ sinultaneous equations for the densities at $n$ different wave lengthe are needed to solve for the Cn's. Solutions can be obtained by the method of determinants. To minimize the effect of small errors, wavelengths in the regions of the naxila of the main red and blue bands were chosen. The optical densities of the four components (i.e. chl a, al chl a, al ph a and ph a) at a concentration of $0.99 \times 10^{-5} \mathrm{~F}$, and the values of the denominator determinants are given in Table 2. It is desirable to calculate the unknown concentrations from at least two different sets of simultaneous equations to reduce the possibility of spurious correlations. The solvents used were reagent grade, saturated with water, and having dissolved oxygen and carbon dioxide in amounts probably $\geq 10^{-5}$ in.

From application of the method to a large number of solutions containing various amounts of the a derivatives, an uncertainty of \pm 5 per cent or less was found when the prinary components were $\operatorname{ch} 1 \underline{a}, \mathrm{ph} \underline{a}$, and al ph $\underline{a}$. If large percentages 


\section{Table 2}

Optical Density (d) Values and Wavelengths for the $0.99 \times 10^{-5} \mathrm{M}$

Solutions, and Values of the Denominator Determinants

Used for Component Correlation

A. For Benzene $\left(\mathrm{H}_{2} \mathrm{O}, \mathrm{O}_{2}, \mathrm{CO}_{2}\right)$ Solutions

\begin{tabular}{|c|c|c|c|c|c|}
\hline $\begin{array}{l}\text { Wave Compou } \\
\text { length } \\
\text { mul }\end{array}$ & Chl. a & $\begin{array}{l}\text { Allom. } \\
\text { Ch1. a }\end{array}$ & $\begin{array}{l}\text { Allom. } \\
\text { Pheo. a }\end{array}$ & Pheo. a & \multirow{4}{*}{$=$ Determinant $A=-96.8686 \times 10^{-3}$} \\
\hline $\begin{array}{l}667.5 \\
405.0 \\
427.5 \\
415.0\end{array}$ & $\begin{array}{l}0.723 \\
0.569 \\
0.840 \\
0.633\end{array}$ & $\begin{array}{l}0.226 \\
0.652 \\
0.646 \\
0.907\end{array}$ & $\begin{array}{l}0.282 \\
0.989 \\
0.283 \\
0.720\end{array}$ & $\begin{array}{l}0.501 \\
0.902 \\
0.465 \\
1.088\end{array}$ & \\
\hline $\begin{array}{l}\text { Compou } \\
\text { Wave } \\
\text { length } \\
\text { m } \mu\end{array}$ & Chl. a & $\begin{array}{l}\text { Al1om. } \\
\text { Ch1. }\end{array}$ & $\begin{array}{l}\text { Allom. } \\
\text { Pheo. a }\end{array}$ & Pheo. a & \\
\hline $\begin{array}{l}405.0 \\
662.5 \\
427.5 \\
415.0\end{array}$ & $\begin{array}{l}0.569 \\
0.696 \\
0.840 \\
0.633\end{array}$ & $\begin{array}{l}0.652 \\
0.343 \\
0.646 \\
0.907\end{array}$ & $\begin{array}{l}0.989 \\
0.182 \\
0.283 \\
0.720\end{array}$ & $\begin{array}{l}0.902 \\
0.329 \\
0.465 \\
1.088\end{array}$ & \\
\hline
\end{tabular}


Table 2 (Contd.)

\section{B. For Ethyl Ether $\left(\mathrm{H}_{2} \mathrm{C}, \mathrm{O}_{2}, \mathrm{CO}_{2}\right)$ Solutions}

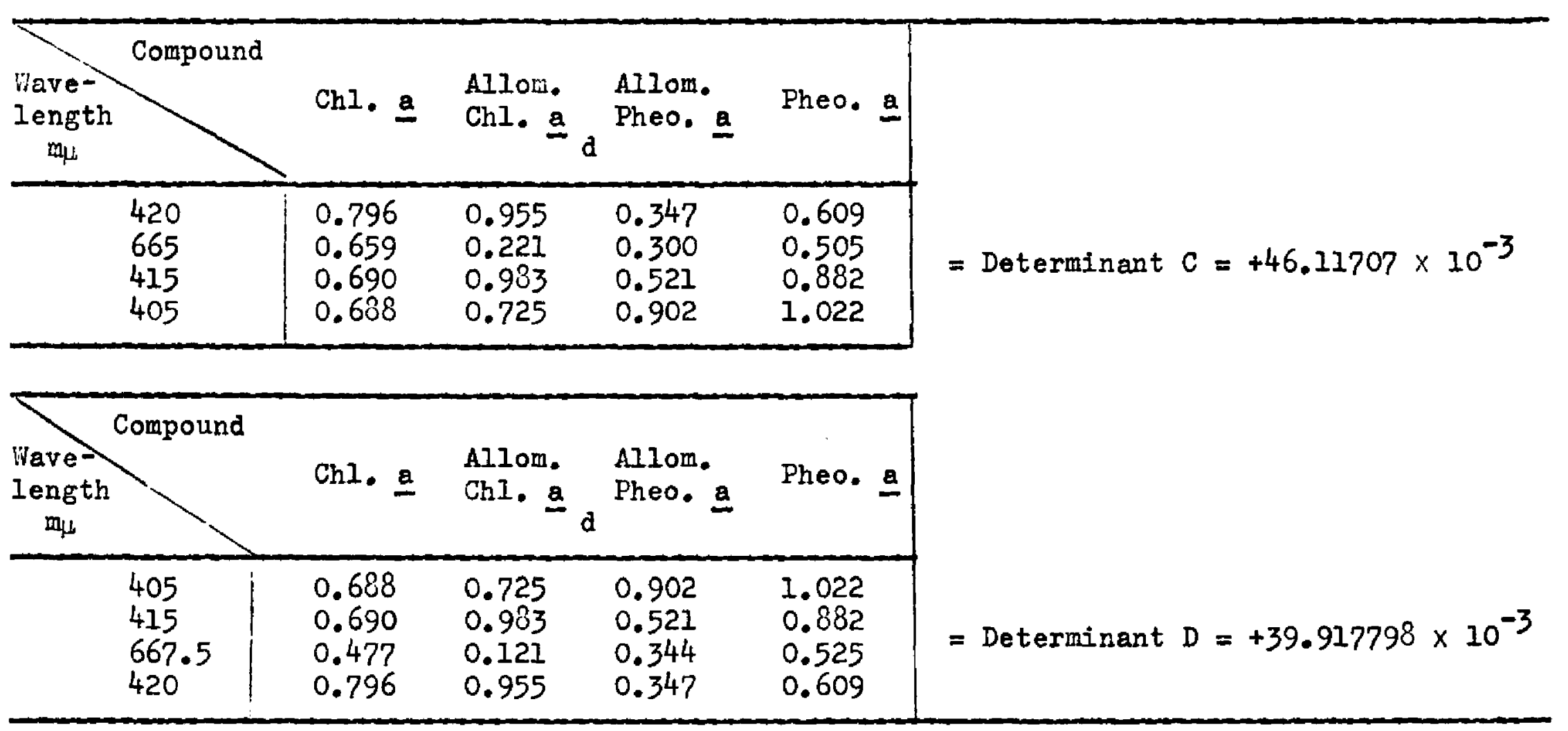


of al chl a were present uncertainties as large as \pm 10 per cent were sometimes found. In many instances study of the whole spectrum provided for resolution of the uncertainties. If extensive photobleaching had occurred, as evidenced by rise in the minimum of the opectrum, it was not possible to obtain good correlations. Products arising from rupture of the chlorin ring are formed.

The accuracy of this method of analyois depends on the purity of the four original pigmente used to obtain the characteristic optical densities, and the absence of different intact ring derivatives in the solution to be analyzed. The purities of the chl a and ph a components were high, and are discussed subsequently. As stated previously, the allomerized compounds probably had a few per cent of a second constituent present as impurity. This could account for some of the observed uncertainties. It seems more likely, however, that small amounts of intact ring derivatives, different than the four components used for analysis, were being encountered. The surprisingly good correlations found are evidence that most of the oxidized intact ring products had the expanded isocyclic ring structure.

The percentage decomposition of $\mathrm{ph} \underline{\mathrm{b}}$ in the monolayer stability tests was roughly estimated by determining the change in the ratio ( $B / B S$ ) of the peak optical densities of the blue and blue satellite bands. The basis for this was as follows. Partial allomerization of ph a causes a significant increase in absorption in the region of the blue satellite peak of 
ph $a$, and a corresponding decrease in the blue peak. A decrease in the ratio $B / B S$ is observed. This ratio for ph b was also observed to decrease significantly under the same monolayer or solution conditions that led to allomerization of ph a. Other changes in the visible absorption spectrum were similar to those occurring for ph a on partial allomerization. The wavelength of the main red band shifted to the red and the main blue band shifted to the blue. The half widths of the main red and blue bands increased, which is good evidence for the presence of a mixture of different intact ring chlorin derivatives. Under conditions providing for monolayer stability the spectral parameters showed little or no change. These observations were taken as indirect evidence that allomerization of ph $\underline{b}$ in monolayers or solutions occurred, when it occurred for ph a. Consequently, the change of B/BS was used as a crude estimation of degree of allomerization of ph b. It must be clearly emphasized that the evidence for allomerization of ph $\underline{b}$ is quite indirect. It seems certain, however, that different intact ring products were formed.

Under identical conditions of testing, the B/BS ratio of ph b was found to change in fairly constant proportion to the

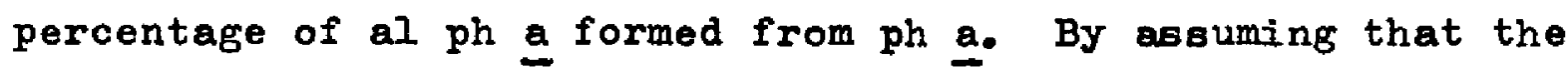
rate of decomposition of $\mathrm{ph}$ a and $\mathrm{ph}$ b were roughly equivalent, the percentage change of ph $b$ could be calculated from the change in $B / B S$. 
The percentage recovery of ph $\underline{b}$ was estimated from knowledge of the anount spread, and comparison of the peak optical densities of the red, blue, and blue satellite bands with those from a solution of known concentration of pure pigment. Since peak optical densities vary with change of substitution on the chlorin ring, this procedure can give, at best, only rough qualitative values.

Monolayer Apparatus

The Wilhelmy plate method [30], [3]], with une uf a Christian Becicer chainomatic enalytical balance (accuracy, $\pm 0.2 \mathrm{mg}$ ), was used to measure surface pressure. The balance was modified by putting a hole through the floor beneath one of the arms to allow for attachment of the plate. This was done with suitably formed glass rods, and a specially constructed clamp with Teflon jaws. Stops were placed under the pans to prevent accidental vertical motion. In use, vertisal motion tes the order of $0.06 \mathrm{~mm}$.

Change of surface tension, which is related directly to the amount of water drawn up on the sides of the plate, was determined directly from the change of weight on the balance arm. A 20 foot long optical arm was used for zeroing. A circular, front surface galvanometer mirror was mounted on the beam balance above the fulcrum. The light source was a zirconium arc point source which was focused on the mirror with an achromatic 
condensing lens to give a sharp, undistorted image on the distant scale.

The Langmuir trough was heavily coated with Fisher Scientific Company's white purified parafin (m. p. $65^{\circ}-70^{\circ} \mathrm{C}$ ). of a number of paraffins evaluated, this material was the only one that did not give off significant amounts of surface active impurities in the experimental periods. The cleaned trough, with the buffer solutions used, gave off, in a period of eight hours under the conditions of experimental testing, impurities that could have introduced the following maximum positive errors in $\pi: 0.05 \mathrm{dyn} / \mathrm{cm}$ in the range $210 \mathrm{~A}^{2} \geq 0 \geq 155 \mathrm{~A}^{2}, 0.10 \mathrm{dyn} / \mathrm{cm}$ in the range $150 \mathrm{~A}^{2} \geq \sigma \geq 130 \mathrm{~A}^{2}$, and $0.20 \mathrm{dyn} / \mathrm{cm}$ in the range $125 A^{2} \geq \sigma \geq 100 A^{2}$. Since the testing periods were uaually five hours, or less, smaller errors than indicated were probably introduced.

The trough edges and the barriers were machined from Teflon which, with suitable weights on the barriers, provided good gasket-like seals at the barrier-edge intersections. With the pheophytin monolayers, however, at high surface pressures, spreading of the water (which was maintained at a height of about $6 \mathrm{~mm}$ above edge level) onto the Teflon-edge surfaces occurred. This could be prevented by applying a very thin film of paraffin onto the Teflon from petrileum ether solution. The movable barrier was motor driven, and could be run at different speeds. 
Both the vibrating disk [32], [33], and the ionizing air electrode [33], [34] methods were used to measure surface potential. Both methods gave the same results within experimental accuracy. The latter method was used almost exclusively because of the greater ease, flexibility, and range of surface scanning.

The vibrating disk apparatus was constructed with the use of a 25-vatt high fidelity, floating magnetic core, loud speaker driver, which was suitably mounted and run by a Jackson Model No. 652 audio frequency oscillator. The polished, circular gold plated electrode was attached to the driver mouth through a two-inch long, 1/8-inch diam. bakelite rod which was bolted to the center of a two mil thick spring steel circular diaphragm. Signal transformation (i.e. alternating current to alternating voltage) was made with the use of a 30-megohm, lownoise resistor, manufactured by the Victoreen Instrument Co. The resistor consisted essentially of a deposited carbon element sealed in a glass envelope which contained an inert gas. The potential balancing and measuring systems were conventional. A specially constructed coaxial cable (45:1 ratio insulation diam. to conductor diam., $7 \mathrm{~mm}$ as average separation distance from conductor to shielding braid), having a very low capacity grounding loss of signal, was used to bring the signal into the amplifier.

A General Radio type 1231-B amplifier and null detector, in conjunction with a G.R. type 1231-P5 wave filter, was used to 
amplify the signal. The signal was detected with a Dumont type 208-B high-gain oscilloscope. The total gain was about 50,000 . The ionizing air electrodes were made by electrodepositing poJonium 210, and then a very thin (0.05-0.15 mil) layer of gold onto circular platinum diske with platinum lead wires. The gold plating insured against the occurrence of flaking off of the polonium. The direct current signal was detected by amplification with a Cary Model 31 Vibrating Reed Electromete:. ihe instrument was used, as recommended by the manufacturer, with a shielded, Victoreen 10,000 meg-ohm resistor installed between the input and feedback terminals. This allows for continuous measurement or detection of small currents. The output oignal was led into a Sargent Model MR recorder, so that the ourface potential variations could be recorded continuously, or balanced to a null point with the external potential balancing system. Since sensitivity of detection was limited only by the height of the electrode from the water surface, its determination provided for direct reading of the ourface potential changes on the recorder chart. The electrode was provided with a mounting stand that allowed for complete scanning of the water surface. As a consequence, it was a simple matter to determine ourface heterogeneity of the monolayer, patches of ourface impurities during the initial cleaning processes, and the presence, or absence, of leaking (i.e., of the compressed monolayer) past the movable and fixed barrier bars. A saturated calomel electrode, a clean silver wire, or a clean platinum wire 
could be used interchangeably as opposing electrode without affecting the values of $\Delta v$.

Use of a polonium electrode, in contrast to the vibrating disc electrode, requires care in preventing the $\alpha$-pariicles, and the high energy ions, from causing significant decomposition of the monolayer. Thus, in exploratory tests with the apparatus, it was very soon discovered that reduction of the surface potential $^{\dagger}$ (from 100 to $150 \mathrm{mv}$ ) rapidly occurred if the electrode was allowed to remain in position over a particular area, or if it was positicned too close to the surface during scanning motion. It seemed likely that primarily decomposition reactions occurred. Consequently, the polonium electrode was positioned e. about $1 \mathrm{~cm}$ from the water surface during measurements, and positioned entirely off the surface during equilibration periods and measurement of surface pressure. At the rather great distance of the electrode from the surface, the marnitude of the measured potential was not affected if proper control of humiaity was maintained. The signal rise time was increased slightly, however, because of the smaller current flow across the air gap. Measurements were carried out within a heavy plywood enclosure, having suitable ports, windows, and adjustable legs for leveling. The inside was painted black and then coated with paraffin wax. The outside was covered with layers of [35].

${ }^{\dagger}$ Similar changes have boen observed for protein monolayers 
83-3 Netic foil, and where additional ohielding was needed Co-Netic AA foil was used. These ferromagnetic foils are manufactured by the Perfection Mica Company in Chicago Illinois. They are characterized by a high efficiency in ecreening out both magnetic and electrostatic fields. Because of their thinness $(0.004$ to 0.005 inch) and dead softness, they can be easily applied in most shielding problems. During experiments the relative himidity within the enclosure wis held to abovt 100 per cent with the aid of large sheets of chromatography paper dipped in beakers of water. After a monolayer had been spread, the cabinet was effectively closed off from the laboratory during the measurement period.

A Gilmont precision micropipetburet with micrometer drive was used in spreading the monolayers. It was a direct reading instrument with an ascuracy of $\pm 0.001 \mathrm{cc}$ for most liquids. In use with ethyl ether solutions, however, the accuracy was probably $\pm 0.003 \mathrm{cc}$. The instrument was used with a luer fitting and number 27 hypodermic needle. The ether solutions contacted only glass, the Teflon gasket, and the stainless steel needle. To prevent accumulation of pigment on the needle tip, due to solution creep while delivering solution to the water surface, 
the tip was touched to the water surface immediately after delivery.

\section{Monolayer Procedures}

Both benzene and cthyl ether were tried as spreading solvents. The latter was adopted since homogeneously spread films could be obtained more easily from it. The ether was C.P. reagent grade and used from freshly opened containers without further purification. It was tested for aurfare residue by spreading various amounts of pure solvent onto a clean water surface and determining changes of surface pressure and surface potential upon compression. To get measurable changes over the whole rarge of trough area about three times as much solvent as used in spreading pheophytin had to ve used. Then the amount of change that would have occurred, using one third the amount of solvent was calculated. The results showed that maximum positive errors in $\pi$ of: $0.05 \mathrm{dyn} / \mathrm{cm}$ in the range $210 A^{2} \geq \sigma \geq 155 \Lambda^{2}, 0.10 \mathrm{dyn} / \mathrm{cm}$ in the range $150 A^{2} \geq \sigma \geq 130 A^{2}$, and $0.20 \mathrm{dyn} / \mathrm{cm}$ in the range $125 \mathrm{~A}^{2} \geq \sigma \geq 100 \mathrm{~A}^{2}$ could have been introduced. The need for rather unusual care in spreading the pheophytin monolayers was first evidenced by large variations in $\Delta V$ (as great as $\pm I 50 \mathrm{mv}$ ) over the surface after spreading. This heterogeneity did not diminish in stand periods of five hours, nor did it diminish significantly on compression of the film. Incompletely spread films showed smaller values of $\pi$ and $\Delta V$ at 
given values of $\sigma$, in comparison with homogeneous monolayers. The following procedure was found to give satisfactory results. A $10^{-4} \mathrm{M}$ solution of the pigment was added dropwise in increments of about $0.005 \mathrm{cc}$ every 6 to 10 seconds. The drops were distributed evenly over the surface. The amount of pigment added was ouch that the initial total surface area was from 40 to $80 \mathrm{~cm}^{2}$ greater than that corresponaing to the start of measurable changes of surface pressure. The initial area per molecule was from 230 to $245 \mathrm{~A}^{2}$. This procodure appeared to provide a suitable avoidance of undesirable piaton oil effects of the spreading solvent, while allowing for a uniform molecular distribution with the absence of three dimenBional aggregation.

A well spread monolayer showed variations in $\Delta V$ of $\pm 20 \mathrm{mv}$ or less at $\pi<1.0 \mathrm{dyn} / \mathrm{cm}$, and $\pm 2 \mathrm{mv}$ at higher compression. These variations were reproducible on decompression and recompression, provided that the collapse prossure had not been greatly exceeded. If the film had been collapsed, lower surface potentials and greater variations in $\Delta V$ were observed at all areas. Variation of electrode area from about $0.8 \mathrm{~cm}^{2}$ to $0.07 \mathrm{~cm}^{2}$ did not reveal Bignificant differences in magnitude of potential variation in homogeneous monolayers. Scanning with the smaller electrode, however, gave a Ereater number of fluctuations,

tIt was observed that the slight rippling of the water surface, due to spreading from the droplet, had ceased after these time periods. 
but primarily at molecular areas for $\pi \leq 1.0 \mathrm{dyn} / \mathrm{cm}$. From these observations it cannot be concluded that the ultimate in monolayer homogeneity was achieved. However, the areas found at collapse and experimental reproducibility indicate that the films must have been at least 95 per cent mono-molecular. This is discussed subsequently.

Use of a spreading peg ${ }^{\dagger}$ (wire, slide, etc.,), which provides for smooth, even flow of the spreading solution onto the water surface, was extensively investigated in this work. While providing for some improvement toward lessened heterogeneity, it proved to be a minor factor. As observed at $\pi \sim 0.10 \mathrm{dyn} / \mathrm{cm}$, homogenously spread films were more easy to obtain at low pH's than at high pH's.

The procedures for testing the stability of various monoleyers at air-water, or nitrogen ( $\left.\leq 100 \mathrm{ppm} \mathrm{O}_{2}, \leq 10 \mathrm{ppm} \mathrm{CO}_{2}\right)-$ water interfaces were as follows. The monolayers were spread at areas per molecule $\left(\geq 240 A^{2}\right)$ corresponding to pressures less than about $0.10 \mathrm{dyn} / \mathrm{cm}$. Some monolayers were subsequently compressed. After the test period, a portion of the monolayer was compressed onto a large clean glass plate wetted with the same aqueous substrate used during the test. The pigment on the plate was then collected with the use of solvent in a hypodermic syringe) into a known volume of reagent grade

${ }_{\text {This }}$ technique was developed by H.J. Trurnit and coworkers in several of their surface chemistry researches. For example, see reference [14]. 
solvent (i.e. benzene, or ethyl ether), and analyzed spectroscopically as described above. All of the apparatus (glassware, and nickel tongs) used in transferring the monolayer were thoroughly clean and wetted with the test aqueous substrate. It was unlikely, therefore, that the pigment contacted any surface other than the test aqueous substrate.

On the basis of the areas of the plate and the final aqueous substrate area in the trough, it was estimated that a naximura of 80 per cent \pm 10 per cent of total pigment could be recovered. In practice, an average of about 57 per cent was recovered with variations from 49 to 90 per cent. Excessive mechanical losses of pigment probably occurred durinc removal of the plate from the trough and subsequent transfer to solution, Bince the whole operation had to be carried out quite rapidly so that drying of the glassware did not occur. When the latter occurred, spurious observations of chemical instability were sometimes made. The reason for this is not known, although interaction with the glass or dried (or concentrated), salt may have been an important fector.

Microscope cover glasses, $0.15 \mathrm{~mm}$ thick and $128 \mathrm{~mm}$ working perimeter, were used as tilhelmy plates. Thin tantalum and platinu: sheets were tried, but were found not to preserve a zero contact angle.

At air-distilled water interfaces, in exploratory phases of the work, little problem was encountered in obtaining and maintaining zero contact angle on the glass slides, even on 
decompression of the monolayers. The conventional cleaning treatment, using hot chromic acid solution, followed by rinsinr and storing in distilled water was found suitable. Spreading of the monolayer could be done with the slide in position in the water ourface. Considerable difficulties, however, were encountered in obtaining and maintaining zero contact angle with the pheophytins on low $\mathrm{pH}$ buffer substrates.

It was necessary to etch ${ }^{\dagger}$ the glass slides slightly in hot $\left(-80^{\circ} \mathrm{C}\right)$ solution of Haenosol (Meineche and Co., Inc.) and tri-sodium phosphate. Following etching, the slides were rinsed thoroughly in hot, then cold distilled water, and stored under distilled water, the $\mathrm{pH}$ of which had been adjusted with HCI near to that of the experimental substrate. This procedure usually provided for an initial zero contact angle when the slide was in position during spreading of the monolayer.

Lack of reproduribility of results and a fortunate observation of a color change in the olide after a run quickly led to the observation that the pigments were adsorbing strongly on the wet glass. The adsorption occurred primarily at low $(<1.0 \mathrm{dyn} / \mathrm{cm})$ surface pressures, and was uneven if the olide was present during spreading. It was necessary, therefore, to insert the slide after the monolayer had been spread. By

†Etching, or roughening a surface is known to decrease contact angle of surface active solutions on solids [36]. 
observation of surface potential changes (after insertion), and epectroscopic analysis ${ }^{\dagger}$ of the amount of adsorbed pigment it was establiched that 75 per cent or more of the adsorption occurred at $\pi \sim 0.10 \mathrm{dyn} / \mathrm{cm}$. Nevertheless variable additioral adsorption occurred upon compression and accounts for part of the reported experimental uncertainty (see below).

Correction of surface concentration for every run was made for the adsorption on the glass. Since adsorption occurred so strongly, it wes asiumed that the area of the glass plate was not accessible to the monolayer in calculation of area per molecule.

The procedures of etching the slide and installing it after spreading always insured a zero contact angle initially and during compression. Alnost invariably, howsver, the contact angle increased froil zero (ise below) on decompression. Consequently, only surface pressure values obtained on compression were considered reliable.

Glass slides that had been thoroughly cleaned gave no water breaks when wetted (i.e. water spread evenly over the whole surface). They showed menisci, when inserted verticelly into a clean water surface, that rose sharply and curved in parallel to the plane of the alides. Different clean slides of the same dimensions, or the same glass slide recleaned and used on different occasions required the same counterbalancing weight,

The spectra did not reveal any signs of chemical degradation for the pigments which had been adsorbed. 
within a fow milligrams, when inserted into a clean water surface under identical experimental conditions. Neither the counterbalancing weight, nor the appearance of the menisci changed during a stand period of 18 hours in a clean water surface. When a milligram of weight was added, or subtracted from the counterbalancing arm, the slides were vertically displaced out of, or into the water surface by a small distance (determined by the deflection of the light beam of the ocale). For different clean slides of the sare dimensions, in clean water surfaces, the displacements were identical, viz. $12 \mathrm{mn} \pm 1$. The preceeding observations were considered to be good evidence that zero contact angle had been obtained.

In monolayer runs with the pheophytins at low pH substrates, compression of the monolayers did not give rise to changes in behavior or the slides. On decompression, however, the vertical displacements, described above, were usually drastically reduced (e.F. 3 to $4 \mathrm{mul}$ ), and the line of contact of the water to the plate wes often observed to be uneven, giving a crinkled appearance. These phenomena clearly indicated an increase of contact angle from zero, and hysteresis of wetting. Calculated surface pressures, at various areas on decompression, were erratic; values were obtained that were both larger and smaller than those obtained on compression.

The change in slide behavior was considered to arise primarily from additional slight interaction of the pheophytins with the wet glass at the water contact line. In most of the 
runs, it was observed that the surface potentials on decompression were consiatently lower by a few millivolts (2 to $10 \mathrm{mv}$ ) at given areas, which showed that the surface concentration of pigment had been reduced. Since the film heterogeneity had not increased, as evidenced by potential scanning over the ourface, it did not appear that any film collapse had occurred. When no slide was present, repeated compression and decompression did not result in a change of surface concentration, as evidenced by surface notential values. If the film area had been reduced below one corrsesponding to about $90 \mathrm{~A}^{2}$ at $\mathrm{pH}=4.0$, and about $100 \mathrm{~A}^{2}$ at $\mathrm{pH}=3.0$, surface potential values decreased with time and an increase in surface heterogeneity occurred, which indicated film collapso.

Barrier motion was $\leq 0.3 \mathrm{~mm} / \mathrm{sec}$, corresponding to about $9 \mathrm{~A}^{2} / \mathrm{molecule/minute}$ or les3. After an area change, corresponding to about 4 per cent of the total area per molecule, the film was allowed to equilibrate from 5 to 10 minutes. More rapid and continuous barrier motions often resulted in increased surface heterogeneity and transient hysteresis effects in both pressure and potential.

Experimental Accuracy Spectroscopic Data

The primary uncertainty in the measured spectral parametere lies in the uncertainty of the absolute purity of the pigments. Accuracy of the monolayer data also depends on pigment purity, but other factors are involved and will be discussed subsequently. 
Preparations of different batches of chlorophyll crystals were made until the visible spectral parameters from batch to batch were reproducible to within about \pm 3 per cent. This amount of variation was the maximum found in weighing and volumetric procedures. Use of a magnesium sulfate column in this laboratory [37], for chromatographic purification and separation for completely different preparations of the chlorophylls, gave cryotals the spectral parameters of which agreed to within better thar \pm 1 per cent with those irom the method described in this work. A comparison is given in Table 3 of the visible absorption apectral parameters of the chlorophylls of this research and those of the following authore:

a) H.H. Strain et al [38], b) W.D. Bellamy et al [5],

c) F.P. Zscheile et al [28], d) J.H.C. Smith et al [39],

e) H.J. Trurnit et al [14], f) H.J. Perkins et al [40], G) D.G. Harris et al [29], and h) A.S. Holt et al [41]. Apart from the problems of allomerization, pheophytin formation, removal of water from the chlorophyll crystals, and photodecomposition, separation of the xanthophylls and carotenols (which absorb in the blue region), and colorless impurities from the chlorophylls by chromatography have currently been emphasized as problems. $†$ In terms of variation of the visible absorption parameters given in Table 2 , the following

\footnotetext{
iFor example, references $[38],[40]$, and $[42]$.
} 
Table 3

Comparison of the Visible Absorption Parameters of the Chlorophylls in Ethyl Ether

\begin{tabular}{|c|c|c|c|c|c|c|c|c|c|c|}
\hline Reference ${ }^{a}$ & $\begin{array}{l}{ }^{\varepsilon} \text { Red } \times 10^{-4} \\
\text { liters } \\
\text { mole cm }\end{array}$ & ${ }_{m_{\mu}}^{\lambda}$ & ${ }_{m_{\mu}}^{\lambda_{B}}$ & $\begin{array}{l}\lambda_{B S} \\
m_{\mu}\end{array}$ & $\mathrm{B} / \mathrm{R}$ & $\mathrm{B} / \mathrm{BS}$ & $R / \min ^{b}$ & $\begin{array}{l}R / 505 \\
\text { for a } \\
R / 520 \\
\text { for b }\end{array}$ & $\begin{array}{l}R_{1 / 2} \\
m_{\mu}\end{array}$ & $\begin{array}{l}B_{1 / 2} \\
m_{4,4}\end{array}$ \\
\hline \multicolumn{11}{|c|}{ Chlorophyll a (M.11. 393.5) } \\
\hline This & $8.63 \pm$ & 660.0 & 428.1 & 408.0 & 1.290 & 1.573 & 109 & 46 & 17.2 & 33.2 \\
\hline Research & $0.20^{\mathrm{c}}$ & \pm 0.1 & \pm 0.3 & $\pm 0.3 \pm$ & 0.007 & \pm 0.018 & \pm 13 & \pm 4 & $\pm 0.2 \pm$ & \pm 0.3 \\
\hline (38) & 8.63 & 660.5 & 428.1 & & 1.295 & & & & & \\
\hline $\begin{array}{l}(5) \\
(28) \\
(39)\end{array}$ & $\begin{array}{l}8.40 \\
9.10 \\
9.00\end{array}$ & $\begin{array}{l}661 \\
660.0 \\
662\end{array}$ & $\begin{array}{l}427 \\
429 \\
430\end{array}$ & $\begin{array}{l}410 \\
410\end{array}$ & $\begin{array}{l}1.280 \\
1.32 \\
1.30\end{array}$ & $\begin{array}{l}1.59 \\
1.58 \\
1.54\end{array}$ & $\begin{array}{r}98 \\
114\end{array}$ & $\begin{array}{l}46 \\
52.4\end{array}$ & $\begin{array}{l}{[15]^{d}} \\
18.5\end{array}$ & 38 \\
\hline $\begin{array}{l}(14) \\
(40)\end{array}$ & {$[6.61]^{\mathrm{d}}$} & $\begin{array}{l}660.9 \\
660.0\end{array}$ & $\begin{array}{l}427.7 \\
428\end{array}$ & 409.0 & $\begin{array}{l}1.32 \\
1.29\end{array}$ & 1.57 & 63 & & 17.3 & 38.9 \\
\hline $\begin{array}{l}(29) \\
(41)\end{array}$ & $\begin{array}{l}(8.70)^{e} \\
8.55 \\
\pm 0.18\end{array}$ & $\begin{array}{l}660.0 \\
660.0\end{array}$ & $\begin{array}{l}429.0 \\
427.8 \\
\pm 0.3\end{array}$ & $\begin{array}{l}410.0 \\
408\end{array}$ & $\begin{array}{l}1.33 \\
1.33\end{array}$ & 1.57 & 105 & $\begin{array}{l}53 \\
53.9 \\
\pm 1\end{array}$ & 18 & 39 \\
\hline
\end{tabular}


Table 3 (Contd.)

\begin{tabular}{|c|c|c|c|c|c|c|c|c|c|c|}
\hline Reference $^{a}$ & $\begin{array}{l}\varepsilon_{\text {Red } \times 10^{-4}} \\
\text { liters } \\
\text { mole } \mathrm{cm}\end{array}$ & ${ }_{m_{1-1}}^{\lambda_{R}}$ & $\lambda_{B}$ & $\begin{array}{l}\lambda_{\mathrm{BS}} \\
\mathrm{m}_{\mu}\end{array}$ & $B / \mathrm{R}$ & $\mathrm{B} / \mathrm{BS}$ & $\mathrm{R} / \min ^{\mathrm{b}}$ & $\begin{array}{l}R / 505 \\
\text { for a } \\
R / 520 \\
\text { for b }\end{array}$ & $\begin{array}{l}\mathrm{R}_{1 / 2} \\
\mathrm{~m}_{\mu}\end{array}$ & $\begin{array}{l}\mathrm{B}_{1 / 2} \\
\mathrm{~m}_{\mu}\end{array}$ \\
\hline \multicolumn{11}{|c|}{ Chlorophyll b (M.W. 907.5) } \\
\hline $\begin{array}{l}\text { This } \\
\text { Research }\end{array}$ & $\begin{array}{r}5.09 \\
+\quad 0.10\end{array}$ & 641.8 & 452.3 & 427.5 & $\begin{array}{r}2.81 \\
\pm \quad 0.01\end{array}$ & 2.71 & 22.9 & 18.0 & 16.1 & 21.2 \\
\hline $\begin{array}{l}(38) \\
(28) \\
(39)\end{array}$ & $\begin{array}{l}5.69 \\
5.15 \\
5.61\end{array}$ & $\begin{array}{l}642.0 \\
642.5 \\
644\end{array}$ & $\begin{array}{l}452.5 \\
453 \\
455\end{array}$ & $\begin{array}{l}430 \\
430\end{array}$ & $\begin{array}{l}2.84 \\
3.00 \\
2.31\end{array}$ & $\begin{array}{l}2.92 \\
2.78\end{array}$ & 21 & 28.9 & 17.0 & 22 \\
\hline $\begin{array}{l}(29) \\
(14)\end{array}$ & $\begin{array}{c}(4.97)^{\mathrm{e}} \\
5.21\end{array}$ & $\begin{array}{l}642.5 \\
642.4\end{array}$ & $\begin{array}{l}453 \\
452.7\end{array}$ & $\begin{array}{l}423.5 \\
420.4\end{array}$ & $\begin{array}{l}2.98 \\
3.00\end{array}$ & 2.72 & 23.9 & & 16.3 & 22.2 \\
\hline
\end{tabular}


major changes (with reference to pure chlorophyll) occur in the contamination problems stated above.

Allomerization.-For chl $a$, the peak vavelengths of the main red $\left(\lambda_{R}\right)$ and blue $\left(\lambda_{B}\right)$ bands are shifted significantly to the blue. The red molar extinction coefficient $\left(\varepsilon_{R}\right)$ decreases about 40 per cent, with the result that the ratio of the feak optical densities of the blue to the red band (B/R) increases from 1.29 to 2.00. Similar changee nay occur for chl b. Pheoplytinization.--For both chl a and chl b, $\lambda_{R}$ Bhifts significantly to the red, while $\lambda_{B}$ shifts significantly to the blue. For chl $a, \varepsilon_{R}$ decreases by about 40 per cent and $B / R$ increases from 1.29 to 2.03 ; in chl $b \varepsilon_{R}$ decreasea by about 38 per cent and $B / R$ increases from 2.81 to 4.89 . The appearance of the green bands at about $505 \mathrm{~m}_{\mathrm{l}}$ (for chl a) and at about $520 \mathrm{~m}_{\mu}$ (for chl b) results in a decrease of $\mathrm{R} / 505$ from 46 to 4.52 , and a decrease of $\mathrm{K} / 520$ from 18.0 to 2.97 . Correspondingly large decresses in the $\mathrm{R} / \mathrm{min}$ ratios occur. The blue half width $B_{1 / 2}$ of chl a increases from 38.2 to $51.8 \mathrm{~m} \mu$; Ior chl $\underline{b}$ there is a decrease from 21.2 to $16.2 \mathrm{~m} \mu$. If chl a and chl b samples had varying amounts of the allomerized producti and/or the pheophytins, both the red and blue half widths would be increased, and the ratio $B / B S$ would be smaller.

Water of hydration.--It is possible that from $1 / 2$ to 2 molecules of water could be present in imperfectly desiccated

${ }^{t}$ See discussion on constituent analysis. 
crystals [41], [43]. This would have the effect primarily of lowering the molar extinction coefficients if the ary molecular weights were used for calculation.

Photodecomposition.--In general, light activation of the chlorophylls in dilute solutions, when oxygen is present, can result in decomposition where products are formed derived from rupture of the chlorin ring. Decreases of $\mathrm{R} / \mathrm{min}, \mathrm{R} / 505$, and $R / 520$ occur, there is a lowering of $E_{R}$, and both blue and red half widths increase. If the decomposition products interacted specifically with the chlorophyllo, shifts in the band peak wavelengths might also be expected to occur.

Xanthophy11s and carotenols.--As impurities absorbing in the blue and green regions, their presence would increase $B / R$ and $B_{1 / 2}$. Both $\varepsilon_{R}$ and $R /$ min would be reduced. Colorless impurities.--In general, if the impurities are noninteracting, a decrease of $\varepsilon_{R}$ without change of $B / R$ would be expected. If they interacted specifically with the chlorophylls in dilute solution, changes in other parameters could occur, shifts in band peak wavelengths and increase of half widths would perhaps be most predominant.

The value of the red molar absorption coefficient provides the best criterion for absolute purity. Knowledge of the other parameters discussed is important in helping to decide which type of impurities might be present. There is considerable variation in the reported values of $\varepsilon_{R^{*}}$ Differences in technique in determining total 
chlorophyll, and procedural errors could give rise to both positive and negative deviations in $\varepsilon_{R^{*}}$ In this work, large positive deviations were observed unless special precautions were taken to prevent evaporation of the ether. It seems reasonable to calculate average values of $\varepsilon_{R}$ as a basis for estimating absolute pigment purity. Uning the values in Table 3 (except that for chl a reported by Trurnit et el [14]) and the values obtained independently in this laboratory [37] which were nearly the same as in this research, the average for chl a is $8.70 \times 10^{4}$ liters/mole $\mathrm{cm}$, and for $\mathrm{chl} \mathrm{b}, 5.25 \times 10^{4}$ liters/ mole $\mathrm{cm}$. The corresponding averaged deviations are $\pm 0.17 \times 10^{4}$ and $\pm 0.21 \times 10^{4}$ liters/mole $\mathrm{cm}$. On this basis, the chl a of this work is estimated to have had an impurity of about $I$ per cent, and chl $\underline{b}$ about 3 per cent. These impurity levels are within the range of reproducibility of the spectral parameters of different chlorophyll preparations of this work. It Beems reasonable to conclude that the calculated average values of $\varepsilon_{R}$ may be very close to those for the 100 per cent pure chlorophylls.

The recent careful work of Perkins and Roberts [40] showed that the limiting value of $B / R$, for extremely pure chl $a$, is probably 1.29. This value was also found in this research, and in other work in this laboratory [37].

The research of Zscheile and co-workers [28], [29] showed that the values of the $R / 505$ and $R / 520$ ratios are very sensitive for detection of traces of pheophytins as impurities. However, 
so also are the half widths and the values of $R / m i n$. Since our values of these latter parameters are equal to, or better than those reported by Zscheile and Comar [28], it seems likely that our slightly lower values of $R / 505$ and $R / 520$ signifies the presence of only very small amounts of pheophytins.

As shown in Table 3, there is considerable variation in $B / R$ for chl b. The other work in this laboratory [37] gave a value of 2.83 , in close agreement with our 2.81. Since several factors can avcount for an increase in $B / R$, it is not possible to decide what the causes of the discrepancies are. The lower values are more characteristic of chlorophyll preparations done in recent work with improved methods, and probably can be conBidered to be more reliable.

In this work, the $\mathrm{R} /$ min values were high and the half width values were low. This is regarded as evidence that the main impurities present were colorless and inert toward the chlorophylls. Further evidence on the last point is that both chl a and chl b gave the typical dry spectra (see Appendix B) that occurs in inert solvents free from polar impurities. In Table 4 are compared the visible absorption parameters of the pheophytins of this work and those reported by the following authors: a) F.P. Zscheile et al, [28],

b) J.H.C. Smith et al, [39], c) A.S. Holt et al, [41], and d) W.D. Bellamy, et al, [5].

The pheophytins were prepared from solutions of the pure chlorophylls by volumetric procedures (see above). Consequently, 
Table 4

Visible Absorption Parameters of the Pheophytins

\begin{tabular}{|c|c|c|c|c|c|c|c|c|}
\hline Reference & $\begin{array}{c}\text { Red Molar } \\
\text { Absorption Coefficient } \\
\varepsilon_{\mathrm{R}} \times 10^{-4}\end{array}$ & $\lambda_{\mathrm{R} \max }$ & $\lambda_{B \max }$ & $B / R$ & $\mathrm{R} / \mathrm{min}$ & $R / 505^{a}$ & $R_{1 / 2}^{R}$ & $\underbrace{B}_{1 / 2}$ \\
\hline \multicolumn{9}{|c|}{ Pheophytin a (M. H. 871 ), ethyl ether } \\
\hline This Research & $5.30 \pm 0.16$ & 667.0 & 408.5 & 2.03 & 13.1 & 4.52 & 16.6 & 51.8 \\
\hline $\begin{array}{l}(28) \\
(39) \\
(41)\end{array}$ & $\begin{array}{l}5.14 \\
5.55 \\
5.10\end{array}$ & $\begin{array}{l}665.0 \\
667 \\
666\end{array}$ & $\begin{array}{l}410 \\
408.5 \\
408.5\end{array}$ & $\begin{array}{l}2.14 \\
2.07 \\
2.10\end{array}$ & $\begin{array}{r}18 \\
\sim 23\end{array}$ & $\begin{array}{l}4.38 \\
4.37 \\
4.44\end{array}$ & $\begin{array}{l}17.0 \\
16.5\end{array}$ & \\
\hline \multicolumn{9}{|c|}{ Pheophytin $a_{\text {, benzene }}$} \\
\hline This Research & 5.42 & 670.2 & 414.3 & 2.03 & 19.2 & 4.97 & 18.4 & $47 \cdot 9$ \\
\hline$(5)$ & 4.88 & 669 & 414 & 2.06 & 16.3 & 4.65 & 19.0 & 50 \\
\hline \multicolumn{9}{|c|}{ Pheophytin b (M.W. 385.2), ethyl ether } \\
\hline This Research & $3.18 \pm 0.10$ & 654.3 & 433.2 & 4.89 & 7.33 & 2.97 & 16.0 & 16.2 \\
\hline $\begin{array}{l}(28) \\
(39) \\
(41)\end{array}$ & $\begin{array}{l}3.27 \\
3.73 \\
3.30\end{array}$ & $\begin{array}{l}653 \\
655 \\
654.8\end{array}$ & $\begin{array}{l}433 \\
434 \\
432\end{array}$ & $\begin{array}{l}5.32 \\
5.15 \\
5.26\end{array}$ & $\begin{array}{l}8.0 \\
\sim 10\end{array}$ & $\begin{array}{l}2.92 \\
2.96 \\
3.0\end{array}$ & $\begin{array}{l}16.0 \\
17.0\end{array}$ & $\begin{array}{l}22.0 \\
18.0\end{array}$ \\
\hline
\end{tabular}

The ratio is that of the optical densities of the peaks of the main red band and the second green band. The latter for pheophytin b occurs at $522.1 \mathrm{~m}, \mathrm{c}$ 
some of the same contamination problems are to be considered for the pheophytins. These include the possible presence of:

a) allomerized impurities, b) xanthophylis and carotenols,

c) products from photodecomposition, and d) colorless impurities. In the preceding discussion on the purity of the chlorophyllo, evidence was presented that indicated that the chl a of this work may have had 1 per cent non-interacting, colorless impurity, while the chl b may have had 3 per cent. The eame type and percentage imiurities would be expected in the pheophytins. The volumetric procedure used in their preparation could have introduced a maximum concentration error of \pm 3 per cent. This will be reflected in the values of $E_{\mathrm{R}^{*}}$

In terins of the spectral parameters shown in Table 4, the presence of xanthophyils and carotenols, and the occurrence of photodecomposition will have the same effecte as r.jscussed above. Allomerization of ph a produces the following changes (see Table 1). The main rea band yeais is shifted to the red, while the main blue band is shifted to the blue. $\varepsilon_{R}$ decreases about 30 per cent and $B / R$ increases from 2.03 to 2.77 . The $\mathrm{R} / \mathrm{min}$ values remain about the same, while the $\mathrm{R} / 505$ value increases from 4.52 to 6.5 . The $R_{1 / 2}$ value increases from 16.6 to 20.5 , while the $B_{1 / 2}$ decreases from 51.8 to 40.7 . Similar type changes appear to occur in the allomerication of ph b. Contamination of the pheophytins by small amounts of the allomerized pheophytins will increase both the blue and red halfwidths. 
To estimate absolute purity of the pheophytins of this work, the same procedure is used as for the chlorophylls. From the ethyl ether data, the average value of $\varepsilon_{R}$ for $p h$ a is $5.27 \times 10^{4}$ liters/mole cm, while for ph b it is $3.37 \times 10^{4}$ liters/mole $\mathrm{cm}$. The corresponding average deviations are $\pm 0.15 \times 10^{4}$ and $\pm 0.18 \times 10^{4}$ liters/mole $\mathrm{cm}$. Using the average values of $\varepsilon_{R}$, the indicated impurity in the ph a of this work is $O$ per cent, while in ph $\underline{b}$ it is 5.6 per cent. Taking into account our estimated \pm 3 per cent concentration uncertainty, these impurity levels are within the range of expected impurity content derived from the pure parent chlorophylls. This ouggeste that the average values of $\varepsilon_{R}$ for the pheophytins may also be very close to those for the 100 per cent pure compounds. Perkins and Roberts [40] report a value of 2.08 for $B / R$ for ph a in ethyl ether. This is the same as the average of the values shown in Table 4. Lower values of $B / R$ would be indicative of greater freedom from xanthophyll and carotenol impurities. This should also be accompanied by smaller values of $B_{1 / 2}$. Since there are no values for comparison, the aignificance of the variations is not clear. For ph $\underline{b}$ our value of $B / R$ is significantly lower than the average, viz., 4.89 versus 5.15. The lower value is accompanied by a significantly smaller value of $\mathrm{B}_{1 / 2}$ - These facts indicate higher purity in terms of freedom from xanthophylls and carotenol impurities. There is good agreement for the $R /$ min values for the ethyl ether data. The values shown for Holt and Jacobs [41] were 
estimated from small scale molar extinction curves and may be too large. The values of $R / 505$ and $R / 522$ for etinyl ther also agree well.

Comparison of the data for benzene shows considerable differences between $\varepsilon_{R}, R / \min$, and $R / 505$ values. The higher values in this work, particularly of $\varepsilon_{R}$ which is close to that for ethyl ether, are indicative of higher purity. Since the values of $B / R$ and the half widths are close, the sample of Bellamy et a.l, [5] would appear to have contained colorless impurities.

The data available shows that the half width values of this work are 10 , and that the $R /$ min and $R / 505$ values are high. This is evidence for absence of allomerized producte, and of other pigments absorbing in the visible. It is concluded therefore that the impurities that may have been present in the samples of this work were colorless, and derivel from the parent chlorophyll samples.

In the preceding discussions it was estimated that the chlorophyllo were from 97 to 99 per cent pure, and the pheophytins from 94 to 99 per cent pure. It was concluded that the impurities present were probably colorless and non-interacting. The presence of these impurities will cause uncertainties in values of intensity, but not in values of band peak positions and band cut-offs (i.e. positions of minima or inflections between bands chosen in order to evaluate values of $f$ and $D$ ). 
Errors in the positional values were considered to depend primarily on the choosing of the values so that band overlap would be correctly compensated for. They are givan in Table 5. The letters refer to peak designations, and are far red (FR), red (R), blue (B), blue satellite (BS), ultraviolet (UV), and the small protuberance appearing or the red side of the main blue band $\left(B_{1}\right)$ in, for exemple, the dry, nonpolar solvents. The percentage errors are in terms of the total values of energy in $\mathrm{cm}^{-1}$. The choosing of positional values was uased primarily on empirical observations of band shape symmetries, and change of these symmetries with change of solvent and substitution. Almost all peaks and cut-offs were chosen on plots of $d$ (or $d / \bar{v}$ ) versus $\bar{\nu}$. In the higher enorgy regions, selection from d versus $\lambda$ curves leajs to considerable inaccuracy. Uncertainties in the integrated $f$ and $D$ values depend on both the presence of impurities in the original amples, and on choosing cut-offs between bands so that the band overlap areas are correctly compensated for. Estimated errors arising from the latter source are given in Table 6. lise aditional letter designations are orange (O), yellow (Y), and green (G). The subscript "T" refers to the total value for the particular band, and was included since in some solvents band splitting was 
Table 5

Eetimated Uncertainties in Band Peak Positions and Band Cut-Offs

\begin{tabular}{lcc}
\hline Quantity & Probable Error Range \pm & Maximum Error Range \pm \\
\hline FR Peaks & $0.2 \%$ & $0.5 \%$ \\
BS Peaks & $0.2 \%$ & $0.5 \%$ \\
WV Peaks & $0.3 \%$ & $0.7 \%$ \\
(Error in other peak positions is less than $0.2 \%$, except for $B_{1}$ which could be relatively \\
high) & $0.3 \%$ & $0.7 \%$ \\
FR Cut-off & $0.3 \%$ & $0.7 \%$ \\
FR--R Cut-off & $0.2 \%$ & $0.7 \%$ \\
B--BS Cut-off & $0.2 \%$ & $0.8 \%$ \\
BS--UV Cut-off & $0.2 \%$ & $0.7 \%$ \\
WV--UV Cut-off & $0.2 \%$ except for $B_{1}$ which could be relatively \\
(Error in other cut-off positions is less than &
\end{tabular}


Tabie 6

Estimated Errors in Oscillator and Dipole

Strengths Arising From Uncertainties

in Choice of Band Cut-Offs

\begin{tabular}{lrr}
\hline \multicolumn{1}{c}{ Quantity } & Probable Error Range & Maximum Error Range \pm \\
\hline$f\left(B_{T}\right)$ or $f(B+B S)$ & $2 \%$ & $5 \%$ \\
$f\left(B S_{T}\right)$ & $4 \%$ & $10 \%$ \\
$f\left(O_{T}\right)$ & $<1 \%$ & $3 \%$ \\
$f(Y)$ & $1 \%$ & $4 \%$ \\
$f\left(G_{T}\right)$ & $<1 \%$ & $3 \%$ \\
$f\left(R_{T}\right)$ & $<1 \%$ & $2 \%$ \\
$f\left(U V_{T}\right)$ or $f\left(B S+U V_{I}\right)$ & $3 \%$ & $8 \%$ \\
$f\left(R_{T}+O_{T}+Y_{T}\right)$, or & & \\
$f\left(R_{T}+O_{T}+Y_{T}+G_{T}\right)$ & $<1 \%$ & $2 \%$ \\
\hline
\end{tabular}

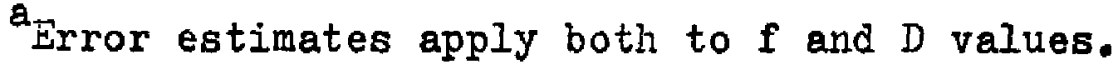


observed. The per cent uncertainties are in reference to the total calculated values.

Experimental Accuracy - Monolayer Data

The presence of a few per cent of non-chlorin derivative impurities could result in either $a$ negative or positive error in the absolute area per molecule of the pheophytins. This would depend on the surface requirement per molecule of the impurity. Two extreme cases would be: a) the impurity was twice as great as that of the pheophytin. In the former case, the calculated total number of pheophytin molecules would be too large; then the calculated area per molecule would be too small by a per cent corresponding to the per cent impurity present. In the latter case, the calculated area per nolecule would be too large by a per cent corresponding to the per cent impurity present. From this vien, the uncerteinties in $\sigma$, due to the presence of colorless impurities, are estimated to ve \pm 1 per cent for $\mathrm{ph} a$, and \pm 3 per cent for ph $\underline{b}$. The impurity percentages are taken to be those derived from the parent chlorophylls. Spectroscopic analysis of the pigment solutions used for spreading the monolayers showed that they each contained about 5 per cent intact ring chlorin derivative. Use of the determinantal method showed the impurity in ph a to be al ph a. The direction of change of the spectral parameters for the ph $b$ solution indicated that the impurity was al ph b (see above). 
Calculation of the change in $B / B S$ ratio was made to estimate percentage impurity.

In a test on the atability of an al ph a monolayer, it was observed that the surface potential had the same sign as that of ph a and was of the same magnitude. ${ }^{\dagger}$ This was considered evidence that the molecular orientation of the chlorin heads at the interface was quite similar. The molecular surface requirements of the two compounds would not be expected to be greatly different. It seems probable therefore that the presence of 5 per cent allomerized pheophytin in pheophytin monolayers would cause less than \pm 5 per cent uncertainty in $\sigma$. A reasonable estimate of maximum error is \pm 5 per cent.

The uncertainties in $\sigma$ arising from the presence of impurities, represent constant limits in the experimental accuracy. The variations in the data points that were observed in different runs are a measure of the procedural errors. These were determined in the manner described below.

The data for each run were smoothed graphically. For each system, points were first taken from the curves of all runs, ${ }^{\dagger}$ and averaged at given values of $\sigma$. Comparison was made of the deviations of each run from the averages of $\Delta V$ and $\pi$ over the

tThe heterogeneity of monolayer was such that a definitive estimate of the average value of the-surface potential could not be made.

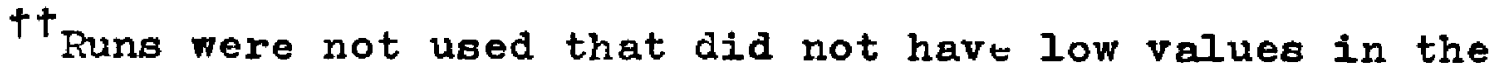
variation of $\Delta V$ over the surface at given values of $\sigma$ (i.e. $\pm 30 \mathrm{mv}$ or less at $\pi<1$. 0 , and \pm 4 mv or less at higher compressions). 
whole range of $\sigma$. Runs were rejected whose deviations in $\Delta V$ and $\pi$ were not consistent in sign and magnitude, or showed significantly different per cent deviations at different values of $\sigma$. The types of internal Inconsistencies observed were considered indicative of either accidental contamination with fairly large amounts of polar surface active impurities during the run, or adsorption of unusually large amounts of pigment on the glass slide during compression. In the first instance, deviations in $\pi$ were more positive than in $\Delta V$, and usually increased with decreasing $\sigma$. In the second instance the deviations morkedly decreased with decreasing $\sigma$. This type of behavior was less frequent than the first type. Average values and deviations were recalculated, and comparison again made of deviations. The new set of average values differed only a few per cent from the first set, deviations vere considerably smaller, and nearly all internal discrepanciea were eliminated.

The deviations were es follows: $\pm 0.04 \mathrm{dyn} / \mathrm{cm}$ for the range $0.10 \mathrm{dyn} / \mathrm{cm} \leq \pi \leq 0.50 \mathrm{dyn} / \mathrm{cm}, \pm 0.20 \mathrm{dyn} / \mathrm{cm}$ for the range $0.50 \mathrm{dyn} / \mathrm{cm} \leq \pi \leq 2.00 \mathrm{dyn} / \mathrm{cm}$, and $\pm 0.40 \mathrm{dyn} / \mathrm{cm}$ for $\pi \geq 2.0 \mathrm{dyn} / \mathrm{cm}$. These deviations are averaged over the range of $\pi$ shown, and represent average values for all systems. The corresponding average per cent deviations in $\sigma$ for all aystems are shown in Table 7. The average over all ranges and systems is \pm 3.1 per cent.

The major sources of error were considered to be:

1) differences in adsorption of small amounts of pigment on the 
Table $?$

Procedural Errors in the Area Per Molecule

\begin{tabular}{|c|c|c|}
\hline System & $\begin{array}{l}\text { Range of } \pi \\
\text { dyn/cri }\end{array}$ & $\begin{array}{c}\text { Average Percent Deviation } \\
\text { of } \sigma \text { in the Range }\end{array}$ \\
\hline ph $a, p H=3.0$ & 0.15 to 0.50 & \pm 4.7 \\
\hline $\mathrm{ph} \mathrm{a}, \mathrm{pH}=3.0$ & 0.50 to 2.25 & \pm 3.5 \\
\hline $\mathrm{ph} \underline{\mathrm{a}}, \mathrm{pH}=3.0$ & 2.25 to 11.04 & \pm 1.2 \\
\hline $\mathrm{ph} \underline{\mathrm{a}}, \mathrm{pH}=4.0$ & 0.10 to 0.41 & \pm 5.0 \\
\hline $\mathrm{ph}$ a, $\mathrm{pH}=4.0$ & 0.41 to 1.60 & \pm 4.0 \\
\hline $\mathrm{ph} \underline{\mathrm{a}}, \mathrm{pH}=4.0$ & 1.60 to 12.85 & \pm 0.9 \\
\hline $\mathrm{ph} \underline{\mathrm{b}}, \mathrm{pH}=3.0$ & 0.20 to 0.60 & \pm 2.3 \\
\hline $\mathrm{ph} \underline{\mathrm{b}}, \mathrm{pH}=3.0$ & 0.60 to 2.63 & \pm 3.6 \\
\hline $\mathrm{ph} \underline{\mathrm{b}}, \mathrm{pH}=3.0$ & 2.63 to 8.03 & \pm 1.7 \\
\hline $\mathrm{ph} \underline{\mathrm{b}}, \mathrm{pH}=4.0$ & 0.10 to 0.50 & \pm 4.2 \\
\hline ph b, $\mathrm{pH}=4.0$ & 0.50 to 1.84 & \pm 4.5 \\
\hline $\mathrm{ph} \underline{\mathrm{b}}, \mathrm{pH}=4.0$ & 1.84 to 8.25 & \pm 1.6 \\
\hline
\end{tabular}


glase slide during monolayer compression, 2) uncertainties in the amount of pigment spread, and 3) introduction of varying trace amounts of contaminante during a run. The first source of error can explain in part the tendency for decrease of magnitude of error at smaller values of $\sigma$.

The amount of pigment adsorbed was determined after each run. All values of $\sigma$ were calculated on the basis that all adsorption on the glass occurred before compression. Where additional edsorption had occurred on compression, the calculated values of $\sigma$ would be too large at low pressures, but would be correct at high pressires. Comparison of the sulall decreases in $\Delta V$ at given values of $\sigma$, obseived on decompression in most runs, showed that variations of about \pm 1.8 per cent occurred. This is a good indication of the variation in percentage adsorption on the giasis.

Uncertaintiea in the amount of pigment spread would be reflected in variations of $\sigma$ at all values of $\pi$. It seems reasonable to suppose that the variations of $\sigma$ at high values of $\pi$ reflect error from this source. These values range from 0.9 per cent to 1.7 per cent, and are conej.stent with the magnitude of the errors that could have arisen from the estimated inaccuracy of the spreading micropipetburet, and from the estimated error in the volumetric procedures in preparing the pheophytins.

F.C. Goodrich [44], in work with mixed monolayers, points out that the presence of small amounts of surface contaminants, 
accidentally introduced onto the substrate surface, can expand the low pressure regions without having appreciable effect on the high pressure regions. This may be related to the phenomena of small amounts of non-polar ofls diseolved in monolayers (reference [31], P. 156). The areas are more expanded at low pressures than at high pressures, since compression of the film reduces the solubility of the oil and it is squeezed out. It seems possible then that variable trace emounts of non-polar impurities in pheophytin monolayers could give rise to errors in $\sigma$ in the low pressure regions which would not be reflected in the high pressure region. The magnitude of the errors would be from \pm 1.0 to \pm 2.0 per cent. The runs which were rejected on the basis of surface contamination showed positive deviations in $\pi$ at high pressures. The impurities in these cases were evidently not squeezed out of the film on compreseion.

If significant variations in incompleteness of spreading had occurred, it seems likely that this would have been reflected in the errors in $\sigma$ at all molecular areas. Errors in monomolecular pigment concentration, however, could be related to other more probable sources. The degree of incomplete spreading, therefore, must have been nearly the same in every run. Residual variation in $\Delta V$ over the ourface (from $\pm 2 \mathrm{mv}$ to $\pm 4 \mathrm{mv}$ ) at small areas per molecule was observed in every run. These variations, in part, were probably due to the presence of trace amounts of impurities. They are also evidence that some of the pigment was consistently present in small three dimensional 
aggregates in every run. Film collapse occurred at molecular areas from 10 to 15 per cent larger than the smallest posiible area per molecule calculated from molecular dimensions (see below). This is evidence that the percentage of pigment in the form of three dimensional aggregates must have been gmall. A reasonable maximum estimate is 5 per cent.

The average deviations in $\Delta V$ for all systems were: $\pm 9 \mathrm{mv}$ in the range $0.10 \mathrm{dyn} / \mathrm{cm} \leq \pi \leq 0.50 \mathrm{dyn} / \mathrm{cm}, \pm 9 \mathrm{mv}$ in the range $0.50 \mathrm{dyn} / \mathrm{cm} \leq \pi \leq 2.00 \mathrm{dyn} / \mathrm{cm}$, and $\pm 7 \mathrm{mv}$ for $\pi \geq 2.00 \mathrm{dyn} / \mathrm{cm}$. The corresponding percentage variations in $\sigma$ are shown in Table 8. These values egree well with the deviations in $\sigma$ calculated from observed variations in $\pi$. Unlike the latter values they do not ehow a tendency to decrease with decrease of $\sigma$. This indicates that surface potentials remained sensitive to the presence of impurities which could have been squeezed out of the film on compression, as suggested above.

The surface potential (in $\mathrm{mv}$ ) can be related [45], [46] to the vertical component of the overall electrical moment, $\mu \cos \theta$, of the monolayer molecule and its associated counterion by

$$
\Delta V=4 \pi 300 \times 10^{3} \mathrm{n} \mu / D \cos \theta
$$

where $\mathrm{n}=$ the number of monolayer molecules per $\mathrm{cm}^{2}, \theta=$ the angle of tilt of the dipole with respect to a normal to the interface, and $D=$ the interfacial dielectric constant which includes the effects of re-orientation and re-distribution of 
Table 8

Percentage Variations in o Calculated from Observed Deviations in $\Delta V$

\begin{tabular}{|c|c|c|}
\hline System & $\begin{array}{l}\text { Rance of } \pi \\
\text { dyn/cli }\end{array}$ & $\begin{array}{c}\text { Average Percent Variation } \\
\text { of } \sigma \text { in the Range }\end{array}$ \\
\hline $\mathrm{ph}$ a, $\mathrm{pH}=3.0$ & $0.15 \leq \pi \leq 0.50$ & \pm 2.4 \\
\hline ph $a, p H=3.0$ & $0.50 \leq \pi \leq 2.25$ & \pm 2.6 \\
\hline $\mathrm{ph} a, \mathrm{pH}=3.0$ & $2.25 \leq \pi \leq 11.04$ & \pm 3.0 \\
\hline ph a, $\mathrm{pH}=4.0$ & $0.10 \leq \pi \leq 0.41$ & \pm 2.3 \\
\hline $\mathrm{ph} a, \mathrm{pH}=4.0$ & $0.41 \leq \pi \leq 1.60$ & \pm 2.1 \\
\hline ph a, pH $=4.0$ & $1.60 \leq \pi \leq 12.85$ & \pm 2.3 \\
\hline $\mathrm{ph} b, \mathrm{pH}=3.0$ & $0.20 \leq \pi \leq 0.60$ & \pm 3.2 \\
\hline $\mathrm{ph} \mathrm{b}, \mathrm{pH}=3.0$ & $0.60 \leq \pi \leq 2.63$ & \pm 3.5 \\
\hline $\mathrm{ph} b, \mathrm{pH}=3.0$ & $2.63 \leq \pi \leq 8.03$ & \pm 3.3 \\
\hline $\mathrm{ph} \mathrm{b}, \mathrm{pH}=4.0$ & $0.10 \leq \pi \leq 0.50$ & \pm 3.3 \\
\hline $\mathrm{ph} b, \mathrm{pH}=4.0$ & $0.50 \leq \pi \leq 1.84$ & \pm 3.0 \\
\hline $\mathrm{ph} b, \mathrm{pH}=4.0$ & $1.84 \leq \pi \leq 8.25$ & \pm 2.8 \\
\hline
\end{tabular}


water molecules. In general $\mu$ and $D$ can not be determined independently. With this formula the value of $\mu / D$ is given in Debye units $\left(1 \times 10^{-18}\right.$ e.s.u. $\left.\mathrm{cm}\right)$. The overall average deviation in $\mu / D$ was determined to be 0.03 Debye unit. 


\section{RESULTS AND DISCUSSION}

Monolayer Stability

In Table 9 are summarized representative results of exploratory stablifty tests on chl a monolayers at air-water and nitrogen (30-50 ppm $\mathrm{O}_{2}, 3-10 \mathrm{ppm} \mathrm{CO}_{2}$ )-water interfaces. The percentage variations, shown with per cent products formed, represent the uncertainties in total percent chlorophyll calculated. Their magnitudes are in the range of the order estimated for the accuracy of the analytical method. The differences from run to run, however, indicate that products other than al chl a, ph $a$, and al ph a were formed. The ourprisingly good correlations found, however, signify that the percentages of such products were small.

The tests showed that increase of $\mathrm{pH}$ greatly reduced the total rate of decomposition. Pheophytin formation was progresBively inhibited as $\mathrm{pH}$ was increased, but apparently never entirely eliminated. With increase of $\mathrm{pH}$, the amount of allomerization that occurred, relative to the amount of pheophytinization, increased. Increase of $\mathrm{pH}$ to 8.0 and above inhibited the rate of allomerization.

Decrease of oxygen concentration in the gas phase decreased the rate of allomerization. This factor had significantly less effect than increase of $\mathrm{pH}$. This ouggests that 
Table 9

Stability Tests on Chlorophyll a Monolayers

\begin{tabular}{|c|c|c|c|c|}
\hline $\begin{array}{l}\text { Run } \\
\text { Number }\end{array}$ & $\mathrm{pH}$ & $\begin{array}{l}\text { Time, } \\
\text { Hours }\end{array}$ & Per Cent Products Formed & $\begin{array}{l}\text { Per Cent } \\
\text { Decomposition } \\
\text { Per Hour }\end{array}$ \\
\hline \multicolumn{5}{|c|}{ Air-Water Interface } \\
\hline $90^{a}$ & 6.2 & 0.42 & $\begin{array}{c}1.9 \% \text { al chl a, } 28.6 \% \text { ph a } \\
3.2 \% \text { al ph a, } \pm 1.5 \%\end{array}$ & $84 \%$ \\
\hline $338^{a}$ & 9.1 & 4.5 & $11.3 \%$ al chl $\mathrm{a}, \pm 1.5 \%$ & $2.5 \%$ \\
\hline \multicolumn{5}{|c|}{ Nitrogen-Water Interfase } \\
\hline $187^{a}$ & 5.3 & 1.0 & $\begin{array}{c}0.9 \% \text { al chl a, } 79.7 \% \text { ph a } \\
1.0 \% \text { al ph } a, \pm 0.5 \%\end{array}$ & $81.6 \%$ \\
\hline $182^{a}$ & 7.0 & 1.0 & $1.1 \%$ al chl a, $9.3 \%$ ph $a, \pm 2.7 \%$ & $13.1 \%$ \\
\hline $183^{a}$ & 7.0 & 18.0 & $\begin{array}{r}24.8 \% \text { al chl a, } 42.9 \% \text { ph a } \\
13.0 \% \text { al ph a, } \pm 4.3 \%\end{array}$ & $4.7 \%$ \\
\hline $202^{b}$ & 7.4 & 18.0 & $\begin{array}{r}33.2 \% \text { al chl a, } 7.1 \% \text { ph a } \\
22.1 \% \text { al ph a, } \pm 3.8 \%\end{array}$ & $3.7 \%$ \\
\hline $207^{a}$ & 8.1 & 15.0 & $\begin{array}{r}12.4 \% \text { al chl a, } 7.5 \% \text { ph a } \\
3.0 \% \text { al ph a, } \pm 0.0 \%\end{array}$ & $1.5 \%$ \\
\hline
\end{tabular}


Table 9 (Contd.)

\begin{tabular}{|c|c|c|c|c|}
\hline $\begin{array}{l}\text { Run } \\
\text { Number }\end{array}$ & $\mathrm{pH}$ & $\begin{array}{l}\text { Time, } \\
\text { Hours }\end{array}$ & Per Cent Products Formed & $\begin{array}{l}\text { Per Cent } \\
\text { Decompo日ition } \\
\text { Per Hour }\end{array}$ \\
\hline $197^{\mathrm{a}}$ & 8.9 & 18.0 & $12.6 \%$ al chl $a, 3.3 \%$ al ph $a, \pm 1.0 \%$ & $0.9 \%$ \\
\hline $192^{a, c}$ & 7.0 & 1.0 & $\begin{array}{l}\text { 12. } 0 \% \text { al chl a, } \pm 1.5 \% \\
\text { traces of ph a and al ph a }\end{array}$ & $13.1 \%$ \\
\hline $200^{a, d}$ & 7.1 & 1.0 & $\begin{array}{r}1.4 \% \text { al chl a, } 4.1 \% \text { ph a } \\
2.0 \% \text { al ph a, } \pm 3.0 \%\end{array}$ & $10.6 \%$ \\
\hline $203^{b, d}$ & 7.1 & 21.0 & $\begin{array}{r}31.4 \% \text { al chl a, } 23.6 \% \text { ph a } \\
15.9 \% \text { al } \mathrm{ph} \text { a, } \pm 2.3 \%\end{array}$ & $3.5 \%$ \\
\hline $205 A^{b, e}$ & 7.4 & 20.0 & $\begin{array}{r}17.9 \% \text { al chl a, } 44.4 \% \text { ph a } \\
11.0 \% \text { al ph a, } \pm 4.0 \%\end{array}$ & $3.9 \%$ \\
\hline
\end{tabular}

$a_{\text {Surface pressure }} \leq 0.10 \mathrm{~d} y \mathrm{n} / \mathrm{cm}$.

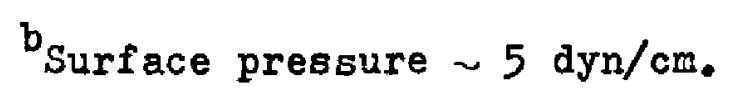

$c_{50 \%}$ trans $\beta$ carotene in the monolayer.

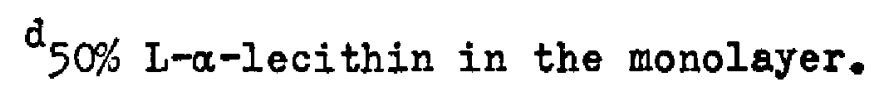

$e_{50 \%}$ phytol in the monolayer. 
polarization of the chlorin heads, through apecific interactions with the aqueous substrate, may be an important factor in inhibiting oxidation.

The presence of $\beta$ carotene, lecithin, or phytol in the monolayer, and compresiston of the monolayer had little effect on the total rate of decomposition. The presence of $\beta$ carotene and lecithin appeared to promote the occurrence of aifomerization over pheophytinization. Phytol appeared to have the reverae effect.

In Table 10 are summarized the results of stability tests on pheophytin monolaycrs. The percentage variations shown for ph $a$ and al ph a represent the uncertainties in the total per cent calculated for these compounds. They signify the inherent uncertainties in the method of analyois and the posaible presence of unknown chlorin derivatives.

Decreace of $\mathrm{pH}$ to below 5.0 gave a marked decrease in rate of allomerization for both $p h a$ and ph $b$ monolayers. Monolayers of al ph a did not appear to undergo any changes. The decrease in rate for ph $a$, in the range $5.0 \leq \mathrm{pH} \leq 9.1$ is approximately linear, the slope being -3.7 per cent/hour/pH unit. The line intersecto zero per cent decomposition at $\mathrm{pH}=4.8$. At $\mathrm{pH}<5.0$, the rates of decomposition level out to low values that are Independent of $\mathrm{pH}$. This ouggests that the decomposition did not occur when the monolayers were in darkness.

Tests showed that when pheophytin monolayers were exposed to direct green lighting much greater changes occurred than when 
Table 10

Stability Tests on Pheophytin Monolayers at Air-Water Interfaces

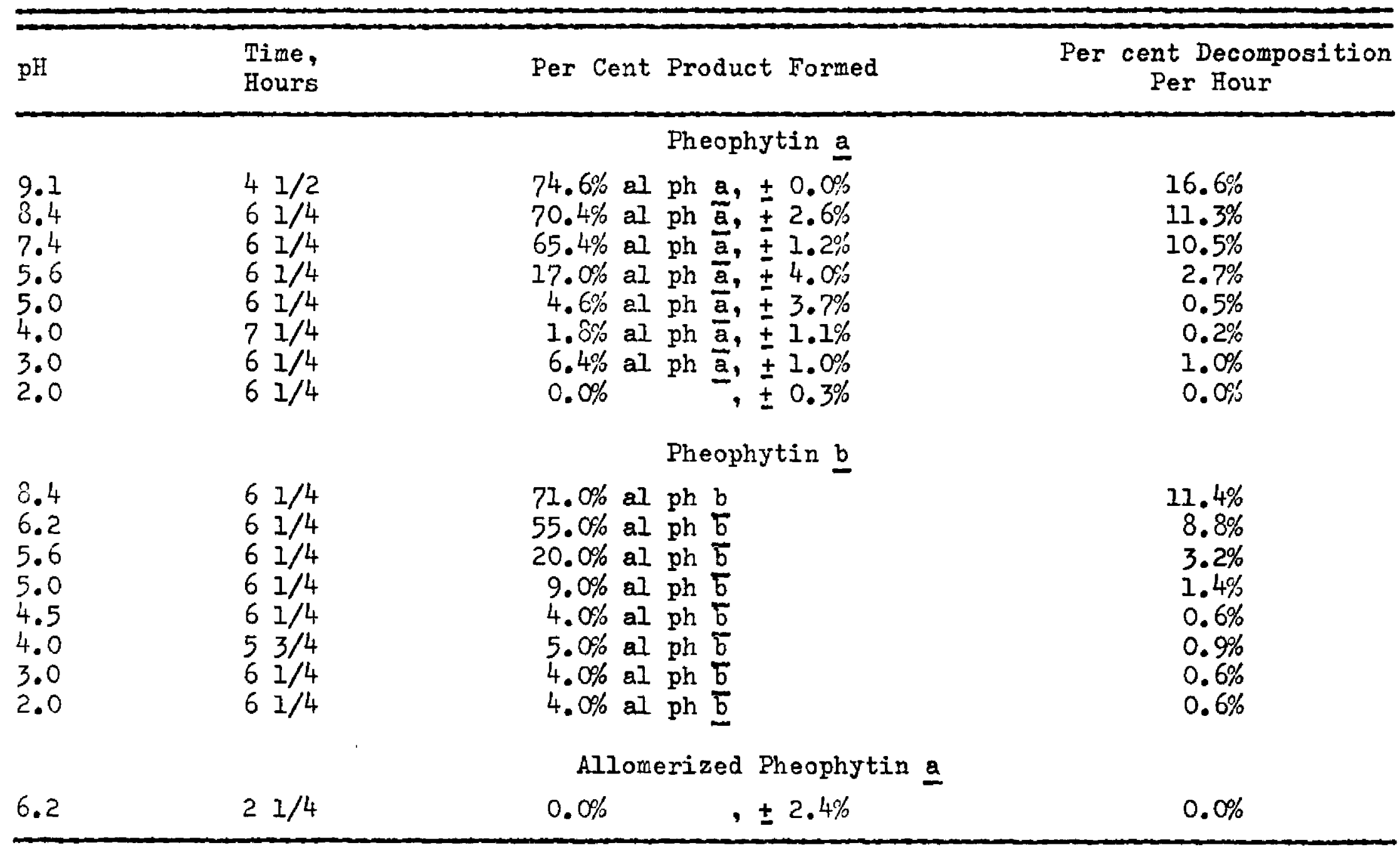


the lighting was of very low Intensity and diffuse, ${ }^{\dagger}$ as used in epreading. During collection of the monolayers, it was necesoary to use direct, low inteneity green lighting for short periods (5-7 minutes). The procedures, lighting, and ise periode were very uniform from run to run. It seems quite likely, then, that photoactivated decomposition can account for the constant small percentages of decomposition producte found at pH's less than 5.0. Since direct illumination was not used during measurement of curface pressure and surface potential, It is probable that the films remained intact during the test periods $(\sim 5$ hours $)$.

The stablization of the pheophytins against allomerization is incerpreted as arising from salt formation with the entry of one or more protons into the center of the chlorin ring. Protons, in the center of the chlorin ring, can act as strong electron acceftors. Such action, transmitted to the cyclopentanone ring would decrecse tts electron density. This would increase the potenciel barrier in the first step of the allomerization process. If there existed unintorrupted conjugation between the constituent in the center of the ring, the $\pi$ electron system of the chlorin head, and the cyclopentanone

$t_{W . D .}$ Bellamy et al [5] measured the changes in optical absorption of ph a monolayers in situ that had been strongly illuminated. They found not only a general decrease in optical densities, but also a rather large increase in $B / R$ ratio. We have found that partial allomerization was accompanied by an increase in $\mathrm{B} / \mathrm{R}$. It seems possible that photoactivation can cause some allomerization. 
ring, the increase of potential barrier could be quite large. In support of this suggested interpretation, it is interesting to note that the rate of allomerization of $\operatorname{ch} \underline{a}$ at air $-\mathrm{pH}=9.1$ buffer interfaces is about 6.5 -fold olower than the rate for ph a under identical conditions. The magnesium atom can be visualized as decreasing electron density in the cyclopentanone ring in the same manner as the protons in pheophytin. I.t seems certain that the pheophytins at $\mathrm{pH}=9.0$ are present as the free bases. The;e may be minor differences in interaction with the aqueous substrate between the chlorophylls and the pheophytins. Such differences wolld probably be small in comparison to the perturbing effect of tile presence of the magnesium atom. The strong perturbing effect of acid on the visible absorption spectra of some of the chlorins hes been studied [47] and attributed to salt formation in the manner suggested above. A. Neuberger and J. Scott [48] prosent evidence that the closely related porphyrin derivatives can exist in mono- anc di-protonated forms. The results of etuaies on the effect of acid on the visible absorption spectra of the pheophytins in this work are given in Appendix B. Salt formation is a reversible process, as evidenced by the restoration of the free base spectrim when the acid is washed out of the colvent with water.

Addition of protons to the center of the chlorin ring of ph a tends to make its spectrum resemble that of the more centrally symmetric chl a. The main red and blue peaks are shifted toward wavelengths characteristic of chlorophyll, and 
the green bands at about $505 \mathrm{~m}_{\mu}$ and $535 \mathrm{~m}_{\mu}$, charaoteristic of pheophytin, ere greatly diminished in intensity. Simiiar type changes occur with al ph a.

Surface Presaures and Surface Potentials

The surface pressure and surface potential data are summarized in Table 11 and Figures 2 and 3. The monolayers rere mechanicelly stable at all values of $\sigma$ ehown. If the films were compressed to areas per molesule smaller than those shown, ourface pressures and surface potentials decreased with time. This was considered evidence of fj.Im collapse.

A study ras made of the change of surface potential on repeated compression and decompression down to and below the area corresponding to mechanical stability. If the area per molecule had not been reduced below about 5 per cent of that of the mechanical stability limit, the surface potentials were unchanged on decompression. This indicated that the changes occurring in the film on collapse were reversible on decompresBion. If the area had been reduced to below about 15 pir cent of that of the mechanical stability limit, changes in the film occurred that were not reversible in a period of an hour, on decompression. The heterogeneity was increased as evidenced by increase of variation of Burface potential over the surface. This indicated that, where extensive film collapse had occurred, three dimensional aggregates of the monolayer molecules were 
Table 11

Surface Pressure $(\pi)$ and Surface Potential $(\Delta V)$ Values for Pheophytin $\mathrm{a}$ and $\mathrm{b}$ at $\mathrm{pH}=4.0$ and $\mathrm{pH}=3.0$

\begin{tabular}{|c|c|c|c|c|c|c|c|c|}
\hline \multirow{3}{*}{$\begin{array}{c}\text { Area } \\
\text { Per } \\
\text { Molecule }(\sigma) \\
\mathrm{A}^{2}\end{array}$} & \multicolumn{4}{|c|}{ Pheophytin a } & \multicolumn{4}{|c|}{ Pheophytin b } \\
\hline & \multicolumn{2}{|c|}{$\mathrm{pH}=3.0$} & \multicolumn{2}{|c|}{$\mathrm{pH}=4.0$} & \multicolumn{2}{|c|}{$\mathrm{pH}=3.0$} & \multicolumn{2}{|c|}{$\mathrm{pH}=4.0$} \\
\hline & $\frac{\pi}{\mathrm{dyn} / \mathrm{cm}}$ & $\begin{array}{c}\Delta V \\
\text { millivolts }\end{array}$ & $\frac{\pi}{\operatorname{dyn} / \mathrm{cm}}$ & $\begin{array}{c}\Delta \mathrm{V} \\
\operatorname{millivolts}\end{array}$ & $\stackrel{\pi}{\mathrm{dyn} / \mathrm{cm}}$ & $\begin{array}{c}\Delta V \\
\text { millivolts }\end{array}$ & $\begin{array}{c}\pi \\
\mathrm{dyn} / \mathrm{cm}\end{array}$ & $\begin{array}{c}\Delta V \\
\text { millivolts }\end{array}$ \\
\hline $\begin{array}{l}100 \\
105 \\
110 \\
115 \\
120 \\
125 \\
130 \\
135 \\
140 \\
145 \\
150 \\
155 \\
160 \\
165 \\
170 \\
175 \\
180 \\
185 \\
190 \\
195 \\
200 \\
205 \\
210\end{array}$ & $\begin{array}{r}11.04 \\
9.50 \\
8.00 \\
6.56 \\
5.30 \\
4.10 \\
3.05 \\
2.25 \\
1.50 \\
1.05 \\
0.80 \\
0.63 \\
0.50 \\
0.42 \\
0.37 \\
0.30 \\
0.27 \\
0.23 \\
0.20 \\
0.17 \\
0.15\end{array}$ & $\begin{array}{l}561 \\
553 \\
544 \\
536 \\
527 \\
517 \\
508 \\
497 \\
486 \\
476 \\
464 \\
454 \\
442 \\
431 \\
420 \\
409 \\
398 \\
388 \\
379 \\
369 \\
361\end{array}$ & $\begin{array}{r}12.85 \\
10.46 \\
8.25 \\
6.24 \\
4.35 \\
2.80 \\
1.60 \\
1.04 \\
0.68 \\
0.50 \\
0.41 \\
0.36 \\
0.31 \\
0.27 \\
0.24 \\
0.21 \\
0.18 \\
0.16 \\
0.14 \\
0.12 \\
0.10\end{array}$ & $\begin{array}{l}597 \\
586 \\
573 \\
561 \\
548 \\
535 \\
521 \\
508 \\
492 \\
480 \\
463 \\
450 \\
436 \\
424 \\
412 \\
401 \\
387 \\
377 \\
367 \\
358 \\
349\end{array}$ & $\begin{array}{l}8.03 \\
6.92 \\
5.83 \\
4.90 \\
4.02 \\
3.30 \\
2.63 \\
2.10 \\
1.64 \\
1.29 \\
1.01 \\
0.83 \\
0.70 \\
0.60 \\
0.50 \\
0.45 \\
0.35 \\
0.30 \\
0.25 \\
0.20\end{array}$ & $\begin{array}{l}423 \\
415 \\
407 \\
398 \\
390 \\
381 \\
372 \\
364 \\
355 \\
347 \\
339 \\
330 \\
322 \\
314 \\
306 \\
298 \\
290 \\
283 \\
275 \\
269\end{array}$ & $\begin{array}{l}8.25 \\
6.35 \\
4.90 \\
3.65 \\
2.62 \\
1.84 \\
1.27 \\
0.98 \\
0.75 \\
0.62 \\
0.50 \\
0.40 \\
0.35 \\
0.30 \\
0.29 \\
0.25 \\
0.23 \\
0.18 \\
0.15 \\
0.12 \\
0.10\end{array}$ & $\begin{array}{l}434 \\
422 \\
410 \\
399 \\
387 \\
377 \\
364 \\
354 \\
342 \\
333 \\
322 \\
313 \\
303 \\
295 \\
286 \\
279 \\
271 \\
263 \\
257 \\
249 \\
244\end{array}$ \\
\hline
\end{tabular}




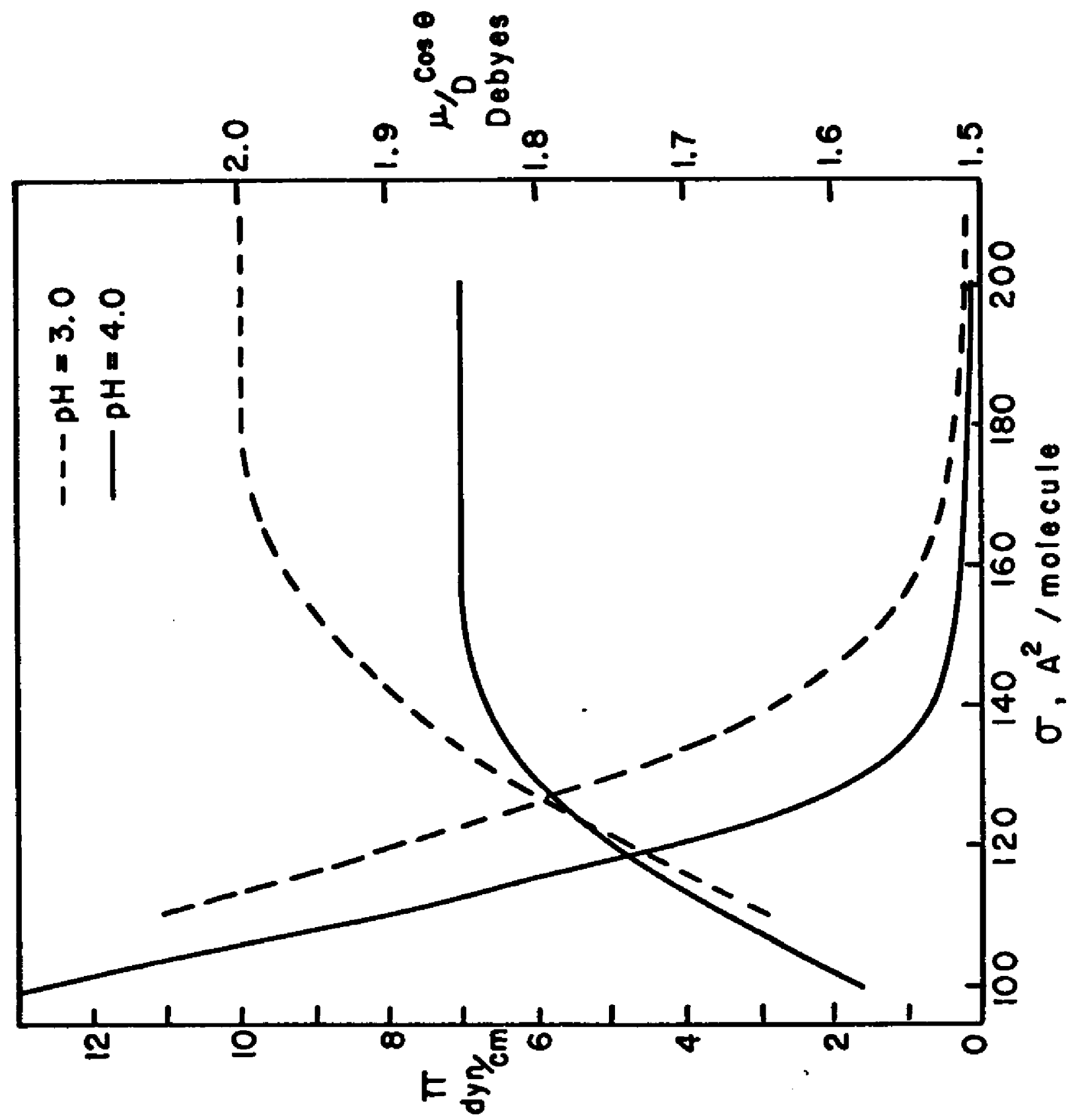

Tigure 2

Surface Pressure and Surface Moment Versus Molecular Area for Pheophytin a 


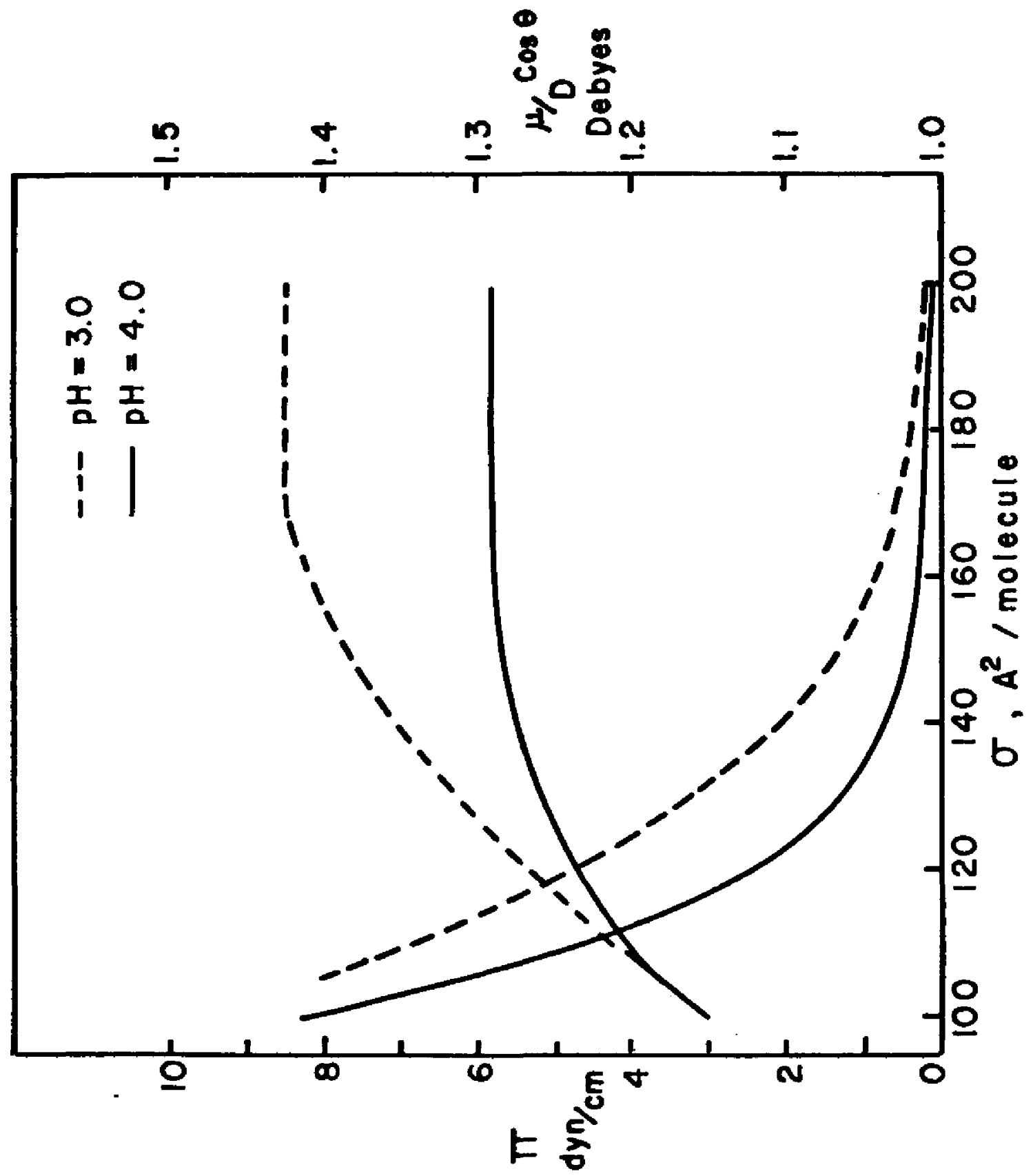

Figure 3

Surface Pressure and Surface Moment Versus Molecular Area for Pheophytin b 
formed that had a high potential energy barrier against respreadIng.

The surface potentials are positive in sign. The wost reasonable orientation to account for this is one in which the esters groups are anchored in the water phase, and where the phytol tails and the major portion of the chlorin heads are elevated into the air phase. ${ }^{\dagger}$ In such a configuration the ester groups, which are the most hydrophilic parts of ire molecule, can interact otrongly with the water Burface and provide for spreading (for example, reference [45], p. 93). The ester groups, anchored in the water surface, would make a positive contribution to the ourface moment. This might range from 0.5 to 0.2 Debye unit depending on orientation (for example, reference [36], p. 72). With the ester groups in the water surface, the chlorin head will be oriented with the cyclor pentanone ring toward the water surface. This group probably represents the negative ond of the overell dipole moment of the head. The total dipole moment of the whole molecule will be a sum of the component parts. In the configuration suggested, the moments of the head and the ester groups will both be positive toward the air phase, and will add to give an overall moment greater than that of an ester group, as observed. For given values of $\pi$ above $1.0 \mathrm{dyn} / \mathrm{cm}$, decrease of $\mathrm{pH}$ from 4.0 to 3.0 results in an average increase in $\sigma$ of

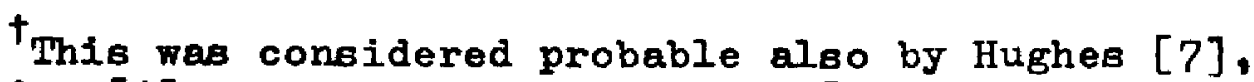
Alexander [9], and W.D. Bellamy et al [5]. 
11 per cent for ph $\underline{a}$, and 8 per cent for ph b. The expansion below $1.0 \mathrm{dyn} / \mathrm{cm}$ averages about 13 per cent. Comparison with the data given by W.D. Bellamy et al [5], shows that the values of $\sigma$ for ph a average about 20 per cent larger at $\mathrm{pH}=4.0$ than at $\mathrm{pH}=8.0$, at Given values of $\pi$ above $1.0 \mathrm{dyn} / \mathrm{cm}$.

Table 12 shows the average compressibilities $\left(C_{B}\right)$ for ph a, ph b, chl, $a$, and chl b monolayers at several pH's and ranges of $\pi$. Comparison is made with data from the work of W.D. Bellory et al [5], A.E. Alexander [9], and H.J. Trurnit and G. Colmeno [14]. $C_{B}$ decreases with increase of $\pi$; the effect is more pronounced for the pheophytins at 10\% pH's than for the other syatems. For the pheophytins, decrease of $\mathrm{pH}$ results in an increase of $C_{B}$ in a given range of $\pi$. This does not appear to be the case for the chlorophylls. At $\mathrm{pH}=8.0$, the $\mathrm{C}_{\mathrm{s}}$ valuee for chl a are greater than those of ph a in both pressure ranges; in the two lower ranges, they are close to those of ph a at $\mathrm{pH}=4.0$. In a given precoure range and at a given $\mathrm{pH}$, the $\mathrm{C}_{\mathrm{s}}$ values of the $b$ compounds are consistently larger than those of the a compounds.

In the range $2.0 \mathrm{dyn} / \mathrm{cm} \leq \pi \leq 8.0 \mathrm{dyn} / \mathrm{cm}$, the $\sigma$ values of ph a average 9 per cent larger than those of ph $\underline{b}$ at $p H=3.0$. In the same $\pi$ range at $\mathrm{pH}=4,0$, the $\sigma$ values of $\mathrm{ph}$ a average 7 per cent larger than those of ph b. From the data of Alexander [9], the $\sigma$ values of chl a average 7 per cent larger than those of $\mathrm{chl} \mathrm{b}$ in the range $3.0 \mathrm{dyn} / \mathrm{cm} \leq \pi \leq 20.0 \mathrm{dyn} / \mathrm{cm}$. The work of Trurnit and Colmano [14] shows that the values of 


\section{Table 12}

Average Compressibilities, $c_{s}=\frac{1}{1 / 2\left(\sigma_{1}+\sigma_{2}\right)} \frac{\sigma_{1}-\sigma_{2}}{\pi_{2}-\pi_{1}}, \mathrm{~cm} / \mathrm{dyn}$

of ph $\underline{a}, \mathrm{ph} \underline{b}, \operatorname{chl} \underline{a}$, and chl $\underline{b}$ Monolayers

\begin{tabular}{|c|c|c|c|c|c|c|}
\hline \multicolumn{2}{|c|}{ Reference } & $\frac{\text { Compound }}{\text { ph a }}$ & $\frac{\mathrm{pH}}{3.0}$ & \multicolumn{2}{|c|}{$\begin{array}{l}\text { Range of } \pi \\
\mathrm{dyn} / \mathrm{dm}\end{array}$} & $\mathrm{C}_{\mathrm{B}}, \mathrm{cm} / \mathrm{dyn}, \times 10^{2}$ \\
\hline $\begin{array}{l}\text { This } \\
\text { This } \\
\text { This } \\
\text { This } \\
\text { This } \\
\text { This } \\
\text { This } \\
\text { This }\end{array}$ & $\begin{array}{l}\text { Research } \\
\text { Research } \\
\text { Research } \\
\text { Research } \\
\text { Research } \\
\text { Research } \\
\text { Research } \\
\text { Research }\end{array}$ & $\begin{array}{l}\text { ph } \frac{a}{a} \\
\text { ph } \\
\text { ph } \frac{a}{a} \\
\text { ph } \\
\text { ph } \frac{b}{b} \\
\text { ph } \frac{b}{b} \\
\text { ph } \frac{b}{b} \\
\text { ph }\end{array}$ & $\begin{array}{l}3.0 \\
3.0 \\
4.0 \\
4.0 \\
3.0 \\
3.0 \\
4.0 \\
4.0\end{array}$ & $\begin{array}{l}1.0 \\
3.0 \\
1.0 \\
3.0 \\
1.0 \\
3.0 \\
1.0 \\
3.0\end{array}$ & $\begin{array}{r}-\quad 3.0 \\
=\quad 10.0 \\
=\quad 3.0 \\
=\quad 10.0 \\
=\quad 3.0 \\
=\quad 8.0 \\
=\quad 3.0 \\
=\quad 8.0\end{array}$ & $\begin{array}{l}5.1 \\
3.1 \\
4.6 \\
2.2 \\
8.0 \\
4.5 \\
6.5 \\
3.2\end{array}$ \\
\hline & $\begin{array}{l}(5) \\
(5) \\
(5) \\
(5) \\
(5)\end{array}$ & $\begin{array}{l}\text { ph } \frac{a}{a} \\
\text { ph } \frac{a}{\text { chl }} \\
\text { chl } \frac{a}{a} \\
\text { chl } \frac{a}{a}\end{array}$ & $\begin{array}{l}8.0 \\
8.0 \\
8.0 \\
8.0 \\
8.0\end{array}$ & $\begin{array}{r}1.0 \\
3.0 \\
1.0 \\
3.0 \\
10.0\end{array}$ & $\begin{array}{r}-3.0 \\
=\quad 10.0 \\
-\quad 3.0 \\
=\quad 10.0 \\
=\quad 20.0\end{array}$ & $\begin{array}{l}2.7 \\
1.4 \\
3.8 \\
2.0 \\
1.7\end{array}$ \\
\hline & $\begin{array}{l}(9) \\
(9) \\
(9) \\
(9) \\
(9) \\
(9)\end{array}$ & $\begin{array}{l}\operatorname{chl} \frac{a}{\cos } \\
\operatorname{chl} \\
\operatorname{chl} \\
\operatorname{chl} \\
\operatorname{chl} \\
\operatorname{chl} \\
\operatorname{ch}\end{array}$ & $\begin{array}{l}7.3 \\
7.3 \\
7.3 \\
7.3 \\
7.3 \\
7.3\end{array}$ & $\begin{array}{r}1.0 \\
3.0 \\
10.0 \\
1.0 \\
3.0 \\
10.0\end{array}$ & $\begin{array}{l}-\quad 3.0 \\
=\quad 10.0 \\
=\quad 20.0 \\
=\quad 3.0 \\
=\quad 10.0 \\
=\quad 20.0\end{array}$ & $\begin{array}{l}2.2 \\
1.9 \\
1.8 \\
3.5 \\
2.7 \\
2.1\end{array}$ \\
\hline
\end{tabular}


Table 12 (Contd.)

\begin{tabular}{|c|c|c|c|c|c|}
\hline Reference & Compound & $\mathrm{pH}$ & $\operatorname{Ran}$ & $\begin{array}{l}\text { of } \pi \\
\mathrm{n} / \mathrm{cm}\end{array}$ & $C_{B}, \mathrm{~cm} / \mathrm{dyn}, \times 10^{2}$ \\
\hline (14) & $\operatorname{chl} \underline{a}$ & distilled $\mathrm{H}_{2} \mathrm{O}$ & 1.0 & -3.0 & 3.5 \\
\hline$(14)$ & $\operatorname{chl} \underline{a}$ & distilled $\mathrm{H}_{2} \mathrm{O}$ & 3.0 & -10.0 & 2.1 \\
\hline$(14)$ & $\operatorname{chl} \underline{a}$ & distilled $\mathrm{H}_{2} \mathrm{O}$ & 10.0 & -20.0 & 1.9 \\
\hline$(14)$ & $\operatorname{chl} \mathrm{b}$ & distilled $\mathrm{H}_{2} \mathrm{O}$ & 1.0 & $-\quad 3.0$ & 4.1 \\
\hline$(14)$ & $\operatorname{chl} \underline{b}$ & distilled $\mathrm{H}_{2} \mathrm{O}$ & 3.0 & -10.0 & 2.6 \\
\hline (14) & $\operatorname{chl} \mathrm{b}$ & distilled $\mathrm{H}_{2} \mathrm{O}$ & 10.0 & -20.0 & 2.4 \\
\hline
\end{tabular}


$\sigma$ for chl a average 9 per cent greater than those for chl $\underline{b}$, In the same pressure range.

Plots of $\mu / D \cos \theta$ versus $\pi$ are linear, for $\pi$ greater than about $1.0 \mathrm{dyn} / \mathrm{cm}$ up to the collapse pressures, for the pheophytins at low pH's. The elopes, with units of Debye/dyn/cm, are -0.030 , $-0.017,-0.032$, and -0.020 for $\mathrm{ph} \underline{\mathrm{b}}-\mathrm{pH}=3.0, \mathrm{ph} \underline{\mathrm{b}}-\mathrm{pH}=4.0$, ph $\underline{a}-\mathrm{pH}=3.0$, and $\mathrm{ph} \underline{\mathrm{a}}-\mathrm{pH}=4.0$, respectively. In the same ranges of $\pi$, the value of $\mu / D \cos \theta$ averages 0.08 Debye greater at $\mathrm{pH}=3.0$ than at $\mathrm{pH}=4.0$ for $\mathrm{ph} \underline{b}$, and 0.09 Debye larger for ph a. For $\pi<1.0 \mathrm{dyn} / \mathrm{cm}$, the average difference is about 0.14 Debye for both ph a and ph b. Comparison with the data of W.D. Bellamy et al [5] ohows the following for ph a.

\section{Toble 13}

Effect of $\mathrm{pH}$ on $\mu / \mathrm{D} \cos \theta$ for $\mathrm{ph} \underline{\underline{a}}$

\begin{tabular}{lrc}
\hline $\mathrm{pH}$ & $\pi, \mathrm{dy} / \mathrm{cm}$ & $\mu / D \cos \theta$, Debye units \\
\hline 8.0 & 1.0 & 1.52 \\
8.0 & 10.0 & 1.41 \\
4.0 & 1.0 & 1.82 \\
4.0 & 10.0 & 1.64 \\
\hline
\end{tabular}

The Burface moments average 18 per cent greater at $\mathrm{pH}=4.0$ than at $\mathrm{pH}=3.0$.

The expansion of the films, the increase of compressibilities, and the increase of the values of the surface moment with decrease of $\mathrm{pH}$ are evidence for salt formation, with entry 
of one or two protons into the center of the chlorin ring. The amount of expansion of the pheophytin monolayers was relatively amall in coinparison to that observed for fully ionized stralght chain amines (for example, reference [36], p. 226). This suggests that the degree of ionic dissociation of the pheophytins was probably quite small. Close association of the charged heads and their counterions would aleo account for the relatively gmall increase of $\mu / D \cos \theta$. J.T. Davies developed an equation for estimation of the pressure ariaing from coulombic repulsion for films of oymmetrical long chain ions (reference [36], p. 231, [49]). The development is based on the theory of the diffuse electrical double layer of J. Gouy. For the equation to be useful, the counterions must be distributed diffusely beneath the charged monolayer, and the dipole moment associated with head group must not undergo orientation changes with change of $\sigma$. To evaluate the possibility for using the equation, one assumes a constant value for $\mu / D \cos \theta$, and calculates (reference $[36]$, p. 78 )

$$
\left.\Delta V_{\text {meas. }}-4 \pi 300 \times 10^{3} \sigma^{-1} \times 10^{16} \mu / D \cos \theta=\psi_{0}, \quad 5\right)
$$

where $\theta$ and $D$ are as previously described. It is assumed now that $\mu$ relates only to the dipole moment of the head group. The term $\psi_{0}$ (in mv) giver the contribution of the ionic double layer to the surface potential. If the surface dipoles do not reorient, and if there is no specific association and change of 
specific assoctation of the counterions with the monolayer on compression, $\downarrow_{0}$ should increase in a characteristic fashion with decrease of $\sigma$. Bxploratory calculations for the pheophytins at low $\mathrm{pH}$ with equation 5) showed a decrease in calculated $\psi_{0}$ with decrease of $\sigma$. This was considered further indication that the degree of ionic dissociation was small.

If compression changed the angle of tilt ( $\theta$ ) of the chlorin heads with respect to a normal to the interface, a decrease of $\theta$ would be exisoted. This rould have the effect of increasing the contribution of the dipole moment of the head, to the total molecular moment. If there were no ion effects, plots of $\mu / D \cos \theta$ versus $\sigma$ would show an increase of $\mu / D \cos \theta$ as $\sigma$ decreased. This was not observed. A reasonable czplanation is that, on compression, the angle of tilt remained essentially constant, and an increase in the relative vertical displacement (vertical staggering, see below) between monolayer molecules occurred, accompanica by a slight increase of ionic association (decrease of separation between charged heads and counterions). $†$ According to Davies' theory for simple ionized monolayers, the surface pressures and the surface potentials, at given values of $\sigma$, should increase with decrease of salt concentration in the bulk aqueous phase. Decrease of salt concentration increases the mean thickness of the ionic double layer, which results in an increase in $\psi_{0}$ and Intermolecular coulombic repulsions.

The value of $\mathrm{D}$ is assumed to be independent of compression, see below. 
Experiments with pheophytin monolayers were made to teat the effect of change of buffer salt concentration. Concentrations were made from 2 to 4-fold smaller than normally used $(0.025 \mathrm{M})$. Within experimental accuracy, no differences in $\pi-\sigma$ and $\Delta V-\sigma$ behavior were found. This was considered further evidence that separation between charged heads and counterions was small.

Measurements were made with both ph a and ph b monolayers at $\mathrm{pH}=4.5$. Areas per molecule and surface moments, at given values of $\pi$, were smaller at $\mathrm{pH}=4.5$ than at $\mathrm{pH}=4.0$ by about I $1 / 2$ per cent on the average. This is proportionately much less change than was observed in decreasing the $\mathrm{pH}$ from 4.0 to 3.0 . Two different effects must have been involved. The results of the monolayer stability tests showed that decomposition either ceased, or leveled out to a nearly constant low value, at a $\mathrm{pH}$ between 4.0 and 5.0 . This can be interpreted to mean that all of the monolayer molecules must have become mono-protonated in that $\mathrm{pH}$ range. Since salt formation in monolayer can be regarded as similar to a neutralization process in solution, it is reasonable to expect that, near the point of 100 per cent conversion, the percentage change in composition per unit change in $\mathrm{pH}$ would be small. The relatively small changes in $\pi-\sigma$ and $\mu / D$ cos $\theta-\sigma$ behavior between $\mathrm{pH}=4.0$ and 4.5 can be attributed to the completion of mono-protonation of the monolayer. The differences observed, when the $\mathrm{pH}$ was decreased from 4.0 to 3.0 , can then be viewed as arising from some degree of di-protonation at the lower $\mathrm{pH}$. 
Comparison of the values of $\mu / D \cos \theta$ for ph $\underline{a}$ and $p h \underline{b}$ shows that significant differences exist over the range of $\sigma$. At $\mathrm{pH}=4.0$, in the range $200 \mathrm{~A}^{2} \geq \sigma \geq 140 \mathrm{~A}^{2}, \Delta \mu / D \cos \theta$ is constant and equal to 0.56 Debye. In the range $140 \mathrm{~A}^{2} \geq \sigma \geq 100 \mathrm{~A}^{2}, \Delta \mu / D \cos \theta$ decreases from 0.56 to 0.43 Debye. At pH $=3.0$, a constant difference of 0.58 Debye, in the range $200 A^{2} \geq \sigma \geq 160 A^{2}$, 1s found, while $\Delta \mu / D$ cos $\theta$ decreases from 0.58 to 0.42 Debye in the range $160 \mathrm{~A}^{2} \geq \sigma \geq 110 \mathrm{~A}^{2}$.

The variations in $\Delta \mu / D \cos \theta$ are small compared to the differences themselves. This suggests that the lower values of $\mu / D$ cos $\theta$ for ph $b$ result largely from the presence of the carbonyl group at the 3-position on the chlorin ring. At this position its group moment will, on the average, be negative toward the air phase, and therefore decreases the total moment of the molecule.

The decreases in $\Delta \mu / D \cos \theta$ are very similar at both pH's, and reflect the fact that the $\mu / D \cos \theta$ values of $\mathrm{ph} b$ show amaller decrease with decrease of $\sigma$ than those of ph $\underline{a}$. This smaller decrease for the ph $b$ monolayers indicates that compresaion, above about $1.0 \mathrm{dym} / \mathrm{cm}$, to the collapse configuration reaults in a smaller increase in relative vertical otaggering, and thus a amaller decrease in $\mu / D \cos \theta$ due to increase of Lonic association as suggested above. If the collapse configuration for both ph a and ph bonolayers involves about the same degree of relative vertical staggering among molecules, which is reasonable to suppose, then below $1.0 \mathrm{dyn} / \mathrm{cm}$ the $\mathrm{ph} \underline{\mathrm{b}}$ monolayers 
would on the average have a greater degree of relative vertical displacement among molecules than the ph a monolayers.

From the Burface potential data of Alexander [9], an average value for $\Delta \mu / D \cos \theta$ of 0.25 Debye, between chl a and chl $\underline{b}$, was calculated. This was for the range $128 A^{2} \geq \sigma \geq 90 A^{2}$, and was nearly constant. The absolute values of $\mu / D \cos \theta$, in this area range, decreased from 1.08 to 0.94 Debye for chl a, and from 0.85 to 0.68 Debye for $\mathrm{chl}$ b. The corresponding pressure coefficients of $\mu / D \cos \theta$ were -0.007 Debye/dyn/cm for chl a and -0.011 Debye/dyn/cm for chl b.

The values of $\Delta_{k} / D \cos \theta$ between ph $a$ and ph $\underline{b}$ are larger than that between chl a and chl b. This could be due to relative differences in the angles of tilt of the chlorin heade, and differences in degree of ionic association between the pheophytins.

Monolayer Model

In Figure 4 is shown a molecular model of chl b based on known atomic radii and bond angles. The scale used was about $0.83 \mathrm{~A} /$ inch. The diameter of the central covalent magnesium atom was taken to be $2.8 \Lambda$.. The chlorin ring positions are ohown clockwise in the figure. The carbonyl group, at the three position, is at the top left, and the ethyl group, at the four position, is at the top right. If the chlorin head were rotated clockwise in the figure so that the vinyl group was at 11 o'clock and the carbonyl group at 1 o'clock, this would represent the probable orientation of the head at the air-water interface. 


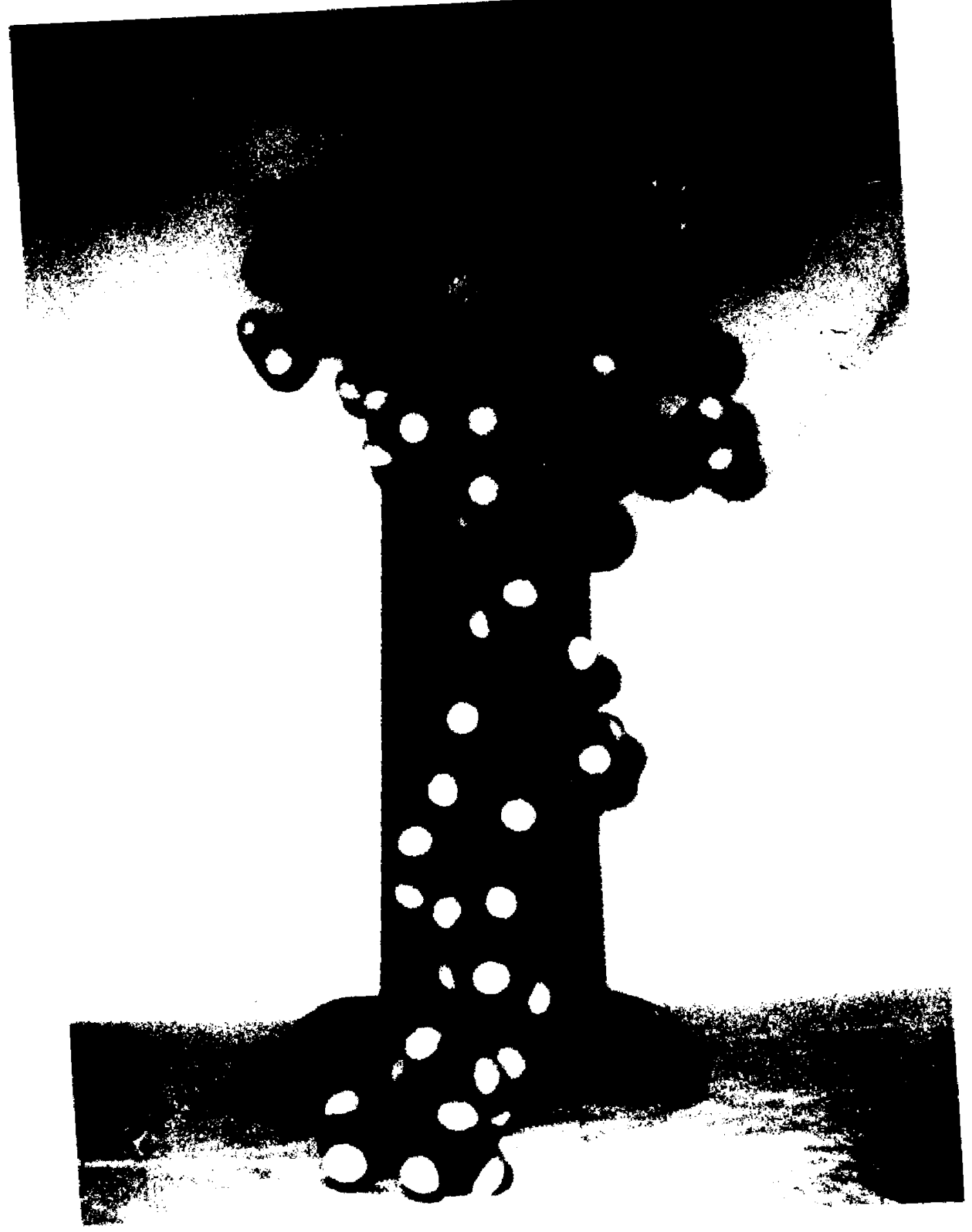

Figure 4

Molecular Model of Chlorophyll b 
The area of the chlorin plane without substituents corresponds to about $108 \mathrm{~A}^{2}$, as determined from the pic..int model. This assumes the plane to be square; the measured dimension of a side corresponds to about 10.4 The area calculated this way agrees very well with estimates $\left(100-110 \mathrm{~A}^{2}\right)$ given by Rabinowitch (reference [2], p. 448).

The substituents on the chlorin ring extend the area of the plane considerably, and in a fairly uniform manner. Calculation of the dimensions of length in the substituted chlorin plane along various axes passing through the center gave the following: axis between the midpoints of the 3,4 and 7,8 positions--13.7 $\mathrm{A}^{\dagger}$ (b) axis between the midpoints of the 1,2 and 5,6 positions--I3.3A; (c) axis through the carion atoms at the $\beta$ and 6 methine bridges--12.4A, and (d) axis through the carbon atoms at the $\alpha$ and $\gamma$ methine bridges--12.8A. With the ester groups oriented in the aqueous phase, as suggested above, the axis passing through the $\beta$ and $\delta$ methine bridges would be nearly parallel to the plane of the interface. If change of angle of tilt $(\theta)$ of the chlorin plane, with respect to a normal to the interface, involved only a simple folding movement of one plane with respect to the other, the $\beta-\delta$ axis would remain nearly paraliel to the interface at all values of $\theta$. In this case, the greatest extension of length of the chiorin plane in the

\footnotetext{
The extension in length of the chlorin head due to the $-\mathrm{CH}_{2}-\mathrm{CH}_{2}-\mathrm{C}-$ group at the 7 position is approximately equal to that due to an ethyl group.
} 
Interface would be close to $12.4 A$, for $\theta$ less than about $68^{\circ}$. Since the exact orlentation of the chlorin head, with ester groups immersed, is not known it seems reasonable to select the average of the lengths, $13.1 \mathrm{~A}$, for purposes of calculation. Using this average value and assuming the plane to be square, the total area of the plane is $172 \mathrm{~A}^{2}$.

The thickness of the chlorin plane will depend on the projections of the substituents from the plane of the head. With the prcsent model this was determined to be $4.5 \Lambda$. As an approximation, the chlorin head can be represented by a rigid, rectangular parallelepiped with the dimensions

$13.1 \mathrm{~A} \times 13.1 \mathrm{~A} \times 4.5 \mathrm{~A}$.

Estimates of chlorin head aize, from results of $x$-ray measurementв, gave $15.48 \Lambda \times 15.62 A \times 3.9 \Lambda$. (Reference [2], pp. 448-449). Although these dimensions do not agree well with those calculated above, the differences in calculated area of the chlorin plane projected on the interface are not more than $2 n^{2}$, for $\theta \leq 55^{\circ}$. M. Calvin (reference [1], p. 172) gives lengths in the substituted chlorin plane ranging from 12 to $15 \Lambda$, but does not estimate the area of the plane.

When fully extended, the length of the phytol chain is about $20 \mathrm{n}$. In the folded configuration with the chlorin head in the monolayer it can extend about $5 \mathrm{~A}$ above the head. The diameter of the extended phytol chain is about $5.8 \mathrm{~A}$, as determined from the present model. This value allows for motion 
of the methyl groups around the axis of the chain, artaing from rotational motions within the chain. The corresponding excluded area is $26 A^{2}$. This represents the least projected area, or Burface requirement for the phytol group in pheophytin monolayers. It is the area that would be expected for the most closely packed state in the monolayer.

Hanson suggested that the phytol group had a surface requirement of about $36 \mathrm{~A}^{2}$ in chlorophyll monolayers at zero compression (reference [10] and reference [2], p. 449). This was based on a comparison of the limiting areas of ethyl chlorophyllide monolayers at $\mathrm{pH}=5.4$, and chlorophyll monolayers at $\mathrm{pH}=4.1$. At these $\mathrm{pH}^{\prime} \mathrm{s}$ the monolayere were probably not stable. Larger values for the apparent phytol ourface requirement could have been calculated by comparison with chlorophyll at high $\mathrm{pH}^{\prime} \mathrm{B}$, since the limiting areas wore greater. To assi.gn a value for the surface requirement of phytol, it was necessary to assume that the heads of the chlorophyllide and chlorophyli molecules had the same angle of tilt with respect to a normal to the interface. If the angle of tilt of chlorophyll had been greater, the calculated surface requirement for phytol would have been smaller than $36 \Lambda^{2}$, or vice versa. Unfortunately no surface potential data appears to have been taken, so that the assumption could not be more clearly evaluated. It does not seem possible to decide from Hanson's work whether or not use of $26 \Lambda^{2}$, in calculation of minimum areas per molecule, will give rise to significant errors. It is likely, however, that any 
uncertainties will be in the direction of estimating too small an area per molecule.

It is possible to describe certain features of the monolayers in terms of molecular dimensions and the surface moment characteristics of the molecules. In the considerations that follow, it is assumed that the chlorin head is approximated by a rigid, rectangular parallelepiped, and the phytol tail by a long flexible cylinder.

With the ester groups oriented in the water phase, one of the lower edges of the chlorin head will be negative with respect to the other, due to the presence of the cyclopentanone ring. The counterion, associated with the head, will tend to be located as far as possible from the ester groups and the cyclopentanone ring to minimize repulsion. A probable arrangement is one in which the plane of the chlorin head is tilted ${ }^{\dagger}$ at some angle between $0^{\circ}$ and $60^{\circ}$ from the normal, and the counterion located slightly beneath, and slightly to one side of the positively charged head center. Close packing of monomolecular units in such an orientation would require that the chlorin heads lie approximately in rows of parallel planes, alternate rows being displaced both horizontally and vertically to minimize

tTilting of the head would allow for closer approach of the charged head center and the counterion. It would also increase the area excluded by each pheophytin molecule (Bee below) which would allow more space for, and greater oeparation between counterions. The phthalate anion is quite bulky with an average excluded area of about $24 \Lambda^{2}$. 
repulsion. ${ }^{\dagger}$ The direction of the electrical moments in alternato rows would be essentially congruous in such an orientation. Each phytol tail would have four nearest neighbor chlorin heads, and each chlorin head would have four nearest neighbor tails.

A scale, schematic view of an idealized arrangement in the plane of the interface is given in Figure 5. The rectangles represont cross-sectional projections of the heads. The angle of tilt of the head is taken to be $42^{\circ}$ from the normal, so that the effective thickness of the head represents $6 \mathrm{~A}$ instead of 4.5A. The closed circles represent projections of the tails, and the dashed circles drawn inside the head area represent the counterions. The crosses on the long side of the heads represent the ester groups, while the crosecs on the short side of the heads represent the cyclopentanone rings. These are not drawn to scale. The area excluded by the ester groups and the cyclopentanone ring is about $36 \mathrm{~A}^{2}$. This is close to one half the area excluded by the entire head, which is $79 \mathrm{~A}^{2}$. As drawn in Figure 5, the average area available to each molecule is about $130 A^{2}$.

The ouggested arrangement represents a highly ordered array of both the heads and the tails. It is visualized that an ordering of this type prevails throughout the film down to surface pressures where it is proposed that a transition in order takes place (bee below). It is not to be inferred, however,

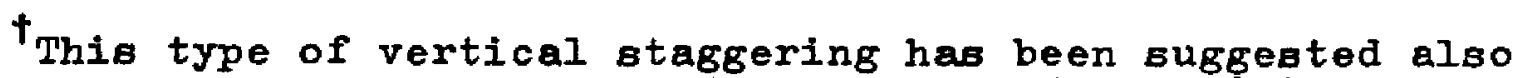
for bymmetrical long chain ions (reference [36], p. 80). 


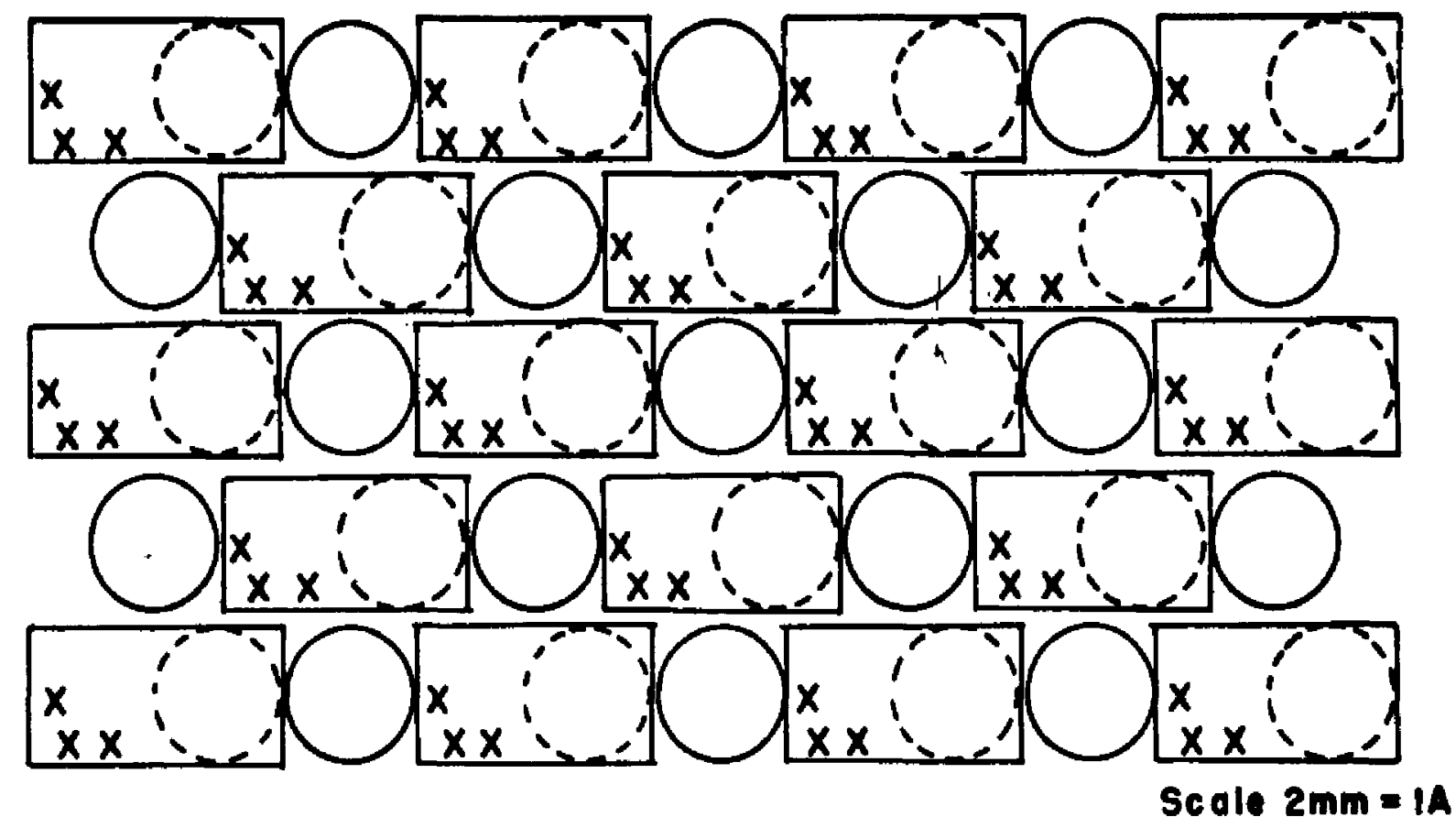

Figure 5

Close Packed Arrangement in a Pheophytin

Monolayer (Scale $2 \mathrm{~mm}=1 \mathrm{~A}$ ) 
that at high pressures all the chlorin heads of the film, in their average positions, have their planes parallel. Thermal motion of the molecules is likely to result in differences of orientation of large regions of molecules in the film without significantly increasing the average repulsion pressures.

The cohesive pressure within the monolayer will be due primarily to dispersion interactions between the hydrocarbon parts of the molecules. These interactions will increase continuously with compression, roughly in proportion to the minus 6ixth powers of the various intermolecular distances. Where local ordering prevails, head-tail and head-head interactions will be large and tail-tail interactions small. Dispersion interactions are approximately additive in all directions. For the heads the interactions will be greater along axes parallel. to the head planes, since the electronic oscillations along the $\pi$-bond paths in the planes of the heads will give rise to larger oscillating dipoles than will arise from motions normel to the head plane. Head-head interactions, therefore, will be favored by parellel orientations of the planes of the heads.

The net coulombic interactions in the film are repulsive and will give rise to a positive pressure. The predominant interactions are probably interionic, so that repulsions will vary approximately as the reciprocal of intercharge distances. Vertical displacement into the water surface, of the molecules in alternate rows, will reduce repulsion not only be increasing distances between charges, but also by allowing for the 
interposition of more water molecules between charges. This will increase the effective dielectric constant and reduce the repulsive interaction onergies. Partial submersion of molecules into the water surface will be opposed primarily by the work of hydrophobic immersion of the hydrocarbon parts of the molecules. ${ }^{+}$

Because of the highly complicated cooperative interactions occurring in pheophytin monolayers, a definitive calculated estimate of depths of immersion can not be made. Estimates have been mede, Lowever, for simple long chain ions (reference [36], p. 80). A typical depth might be around 3A.. This would entail the immersion of 2 or $3-\mathrm{CH}_{2}-$ groups. It seeme reasonable to suppose that 3 to $5 \mathrm{~A}$ is of the right order for the depth of immersion of the ester groups for the pheophytins.

The kinetic motions of the tails will make the main contribution to she thermal pressure of the films. Since the phytol eroups extend only about 5A above the planes of the heads, it can be seen from Figure 5 thet the motion of the tails will be quite restricted in a close packed array. The restriction will be greater, the greater the angle of tilt of the heads, at a given area per molecula. Assume that the film is expanded

${ }^{\dagger}$ slight decreases in cohesive interactions between heads, due to increased relative depths of submersion, will be offet by decreases in intermolecular distances. Head-tail interactions, between nearest neighbors, will probably not be decreased by increase of relative immersion. The reason is that the part of the tails, which rise some $5 \mathrm{~A}$ above the heads, will be brought into the film on immersion. 
from $130 A^{2}$ per molecule to $150 A^{2}$, and the same molecular arrangement and angle of tilt of the head persists as depicted in Figure 5. Then, with the molecules centered in their T-Bhaped cella, the increase in average accessible free area, ${ }^{\dagger}$ per head or tail, is from about $13 A^{2}$ to about $23 A^{2}$. The proportionate increase of free area to excluded area is clearly greater for the tails. Because of their flexibility the tails will be able to undertake a greater degree of thermal motion than the rigid heads.

In expansion from the most close packed state to $150 \mathrm{~A}^{2}$, the average separation between adjacent molecules increases only by about 1.5A. Intermoleculsx coulombic repulstons will still be significant, so that local ordering of the heads would be expected to persist. Motions of a molecular unit as a whole, then, would be confized largely to translatory oscillations about the center of its cell.

For the smallest excluded dimensions given in Figure 5, and with the molecules centered in their cells, the smallest area per molecule at which free rotation (about an axis normal to the interface) could occur is about $24 \mathrm{OA}^{2}$. Since configurational fluctuations will occur wherein one, or two nearest neighbors of a particular molecule will not be centered in their cells, free rotation could occur at smaller areas per molecule

Here, this is assumed to be the area available for the head, or tail to move about in, with all nearest neighbors remaining motionless. 
than $24 O A^{2}$. Where free rotations set in, the $\pi-\sigma$ behavior would reveal discontinuities in $C_{B}$ which are characteristic of orderdisorder transitions (reference [31], p. 109). Such discontinuities were observed, but at areas per molecule where free rotation of whole molecular units would be improbable (see below). For ph a at $\mathrm{pH}=3.0$, for example, the slope of $\mathrm{C}_{\mathrm{s}} \mathrm{vs} \sigma$ started to increase discontinuously at about $150 \mathrm{~A}^{2}$. For this system, assume that the angle of tilt is $42^{\circ}$, then the average free area per molecule is $45 \mathrm{~A}^{2}$. Free rotation of a whole molecular unit could just occur if all its nearest neighbors simultaneously moved away from their cell centers to positions where they were contiguous with their nearest neighbors. A fluctuation of this type, however, seems highly improbable.

With the head and tail folded together, and the plane of the head perpendicular to the water surface, the smallest excluded area per molecule is about $90 \mathrm{~A}^{2}{ }^{t}$ This is the smallest area that should be observed, if the entire film is monomolecular, and if the ester groups are oriented in the water surface as suggested. Calculation of the excluded area, using head dimenBions estimated from $x$-ray data and Hanson's suggested surface requirement for phytol, gives about $96 \mathrm{~A}^{2}$.

If the chlorin heads were inverted into the water surface, an area per molecule of $75 \mathrm{~A}^{2}$ or less might be observed. It is

'In the most close packed molecular array, there would be interstitial spaces unoccupied by the monolayer molecules. This corresponds to about $5 \mathrm{~A}^{2}$ per molecule, and is included in the value of $90 A^{2}$. 
probable that the oign of the surface potential would be reversed. To attain this configuration considerable work would be required for hydrophobic immersion of the hydrocarbon parts of the head.

In the collapse region, where it appeared that some sort of reversible process was occurring, it is conceivable that a configurational fluctuation could result in a vectorial reversal of some of the chlorin heads, without their complete immersion. Such a reversal would result in a reduction in average occupied area by about 16 per cent. The phytol tail would be elevated further into the air phase. Attractive coulombic interactions between the ester groups and the cyclopentanone ring with neighboring head centers could occur. These would tend to compensate for the removal of the ester groups from the water surface. The surface potential would decrease with decrease of $\sigma$, and the slope $0 \hat{\mu} \mu / D \cos \theta$ versus $\sigma$ would increase sharply, which was observed. Apparent reversibility was observed at calculated areas per molecule down to about 5 per cent less than the area determined at the limit of mechanical otability. This corresponds to an inversion of about 16 per cent of the chlorin heads, if the suggestion for the process is correct. With head and tail folded together and largely elevated above the water surface, an increase of angle of tilt will increase the smallest excluded area and reduce the overall electric moment of the wonolayer. In Table 14 are 111 ustrated the changes for several values of $\theta$. A value of 1.50 Debye 
is taken for $\mu / D$, and it is assumed that $D$ remotins constant.

Table 14

Variation of Monolayer Molecule Characteriatics with Angle of Tilt $(\theta)$

\begin{tabular}{ccc}
\hline$\theta$, Degrees & $\begin{array}{c}\text { Smallest } \\
\text { Excluded Area, } \mathrm{A}^{2}\end{array}$ & $\mu / \mathrm{D}$ cos $\theta$, Debyes \\
\hline 0 & 90 & 1.50 \\
20 & 94 & 1.41 \\
31 & 100 & 1.29 \\
37 & 105 & 1.20 \\
42 & 110 & 1.11 \\
60 & 149 & 0.75 \\
\hline
\end{tabular}

$a_{\text {This includes }} 5 \mathrm{~A}^{2}$ to allow for interstitial areas between molecules in the closest packed state.

The area per molecule, where film collapse began, increased with decrease of $\mathrm{pH}$ for both $\mathrm{ph}$ a and $\mathrm{ph} b$. This can be related to an increase in the average angle of tilt of the chlorin heads as shown in Table $14 .^{+}$Increase of tilt would not only reduce the vertical component of the dipole of the head, but it would also allow for closer association between charged heads and counterions. This would produce a rather significant decrease in the overall electric moment, which would be consistent with the relatively small increase in $\mu / D \cos \theta$.

tIt is possible that the larger areas at $\mathrm{pH}=3.0$ could have resulted from a partial penetration of counterions into the monolayer. However, pheophytin monolayers spread on unbuffered $\mathrm{HCl}$ solutions at $\mathrm{pH}=3.0$ and 4.0 showed the same behavior, within experimental accuracy, as on buffered substrates. No differences were observed between citrate and phthalate buffers. 
It was suggested above that di-protonation occurred at $\mathrm{pH}=3.0$. From the vierpoint of the present monolayer model, the degree of di-protonation must have been rather small. If it had been large, the average angle of tilt of the heads would have been great, and much larger increases in the areas at collapse would have been observed. Alternatively, a large degree of ai-protonation could have been accompanied by a relatively great depth of submersion of alternate rows of heads, e.g. 7 or 8A. Close association of immersed head centers and their counterions would have greatly diminished the overall electric moment. However, a rather large work of hydrophobic immersion would have been required. Further, a large increase of extent of relative vertical displacement, in contrast to increase of average angle of tilt, would have brought the film closer to the collapse configuration. In this case, it seems likely that greater decreases in collapse pressures should have been observed. If di-protonation had been accompanied by penetration of counterions into the monolayer, compression would have decreased the extent of penetration (reference [36], p. 295). The value of $\mu / D \cos \theta$, then, would probably have increased rather than decreased.

If D changed with compression, it would be due primarily to re-orientation of specifically associated water molecules. Adam (reference [45], p. 30) points out that reorientation and redistribution of specifically associated water molecules is often independent of compression. Consideration of the relative 
sizes of water molecules and the pheophytins shows that this is probably true for the pheophtyin monolayers. The largest excluded area of a water molecule can be taken as the cross Bectional area of the widest cylinder of revolution around one of the axes of rotation. This is approximately 3.OA ${ }^{2}$. The area excluded by the ester groups and the cyclopentanone ring is about $36 A^{2}$, and will remain constant at all areas per molecule. Clearly, twelve primary waters of hydration could be essociated with these groups and not be remoriented on compression. Using the longest dimension of the water molecule, it is estimated that the greatest thickness, which two hydrated protons could impart to the center of the chlorin head, is about 4.34 . This is slightly less than the value of $4.5 \mathrm{~A}$ estimated for the side chain substituents. It seems unlikely, therefore, that one or two prinary waters of hydration at the center of the ring would undergo appreciable rearrangement on compression.

Decrease of separation between head centers and counterions, suggested to explain the decrease of $\mu / D \cos \theta$ on compression, could involve some re-orientation of water molecules. From the following order of magnitude considerations, this effect would appear to be small. In the calculations, no attempt is made to account for the polarization of the chlorin heads, the counterions, or the water molecules. The interaction between a head and its counterion is assumed to be independent of the neighboring heads and counterions. The dielectric constants used, were estimated for the reorientation of water 
molecules in electric fields of one sign originating from one source (reference $[36], p .142$ ). In the monolayer region between the charged heads and counterions, there could exist cooperative field effects that would reduce the orienting effect of a single charge center. Thus, the dielectric constants used in the calculations may be considerably smaller than those actually occurring in the film.

Assume that the separation between the charge centers of the heads and the counterions is $8 \mathrm{~A}$, and that a layer of water is effectively interposed. The field strength, at half the distance of separation, due to a mono-valent ion would be [50]

$$
\frac{4.8 \times 10^{-10}}{16 \times 10^{-16}}=3 \times 10^{5} \text { esu } \mathrm{cm}^{-1} \text {, }
$$

At this field strength the water molecules would be highly oriented, and would have an estimated dielectric constant of about 7. Using this value and a typical change of $\mu / D \cos \theta$ (e.g. 0.30 Debye), a decrease in ionic separation of

$$
\frac{0.30 \times 10^{-18} \times 7}{4.8 \times 10^{-10}}=0.44 \times 10^{-8} \mathrm{~cm}
$$

is calculated. Using one half the new distance of separation, $7.56 \mathrm{~A}$, a field strength of $3.4 \times 10^{5} \mathrm{esu} \mathrm{cm}^{-1}$ is found, giving an estimated dielectric constant of about 6.5 . The changes in

tDavies and Rideal use a vaj.ue as large as 80 in calculation of the electric moments between heads and counterions in completely ionized films (reference [36], p. 70 ). 
relative distance and dielectric constant are both small. On this bases, then, decrease in distance between head and counterion would not be accompanied by significant rearrangements of water molecules. Using the value of 7 fur the dielectric constant and $8 \mathrm{~A}$ for separation, the electric moment for the ion pair is

$$
\frac{4.8 \times 10^{-10} \times 8 \times 10^{-8}}{7}=5.5 \text { Debyes }
$$

This is sor.ewhat too large and reflects the approximations used in the calculations, and the likelihood that, on the average, separation of charges was considerably smaller than assumed. In this latter case, the rearrangements of water molecules would be of even less significance than indicated.

The areas per woleculd, where collanse begins to occur, are similar for the ph $\underline{a}$ and ph $\underline{b}$ systems. Collapse pressures for the ph b systems, however, are significantly smaller. At surfaces pressures greater than about $1.0 \mathrm{dyn} / \mathrm{cm}$, the compressibilities of the b systems are greater than those of the a systems, resulting in smaller areas per molecule at given values of $\pi$. These phenomena can be related to the presence of the 3-position carbonyl group on the ph b head units. As compression on the film is increased the molecules approach a clcse packed ordered array with increasing degree of relative vertical displacement between alternate rows of molecules. In the vertical staggering arrangement, internolecular configurations 
are possible where there are ion-dipole attractions between neighboring positively charged head centers and 3 -position carbonyl groups. An arrangement might be one in which the heads of the molecules, which are more deeply immersed in the aqueous phase, are rotated slightly around an axis perpendicular to the plane of the head so that the carbonyl groups are brought closer to the plane of the water surface. Increase of degree of relative vertical staggering by compression can increase ion-dipole attractions. These interactions, not present in the ph a monolayers, will contribute to the cohesive pressure and tend to promote relative vertical displacement. Consequently, less compressional work is required to reduce fillu area and reach the collapse configuration.

As shown in Figures 2 and 3 , there are distinct related changes in $\pi-\sigma$ and $\mu / D$ cos $\theta-\sigma$ behavior in the neighborhood of 1.0 $\mathrm{dyn} / \mathrm{cm}$. Above about $1.0 \mathrm{dyn} / \mathrm{cm}$, the compressibilities were characteristic of cohering films, $\mu / D$ cos $\theta$ decreased linearly with incroase of $\pi$, and surface potentials were uniform over the surface. In Table 15 are given the areas per molecule where plots of $\mathrm{C}_{s}$ versus $\sigma$ start to show discontinuities with increase of $\sigma$, and where plots of $\mu / D \cos \theta$ versus $\pi$ cease to be linear with decrease of $\pi$. The values of $\sigma_{f / 2}$, which represent the approximate average free area accessible to a head or tail, are one half the difference between the average of the transition areas and the smallest excluded areas, $\sigma_{o}$. These latter values are calculated using the angles of tilt shown in Table 14; 
Table 15

Areas Per Molecule and Free Areas Per Monolayer Unit at the Start of Transition

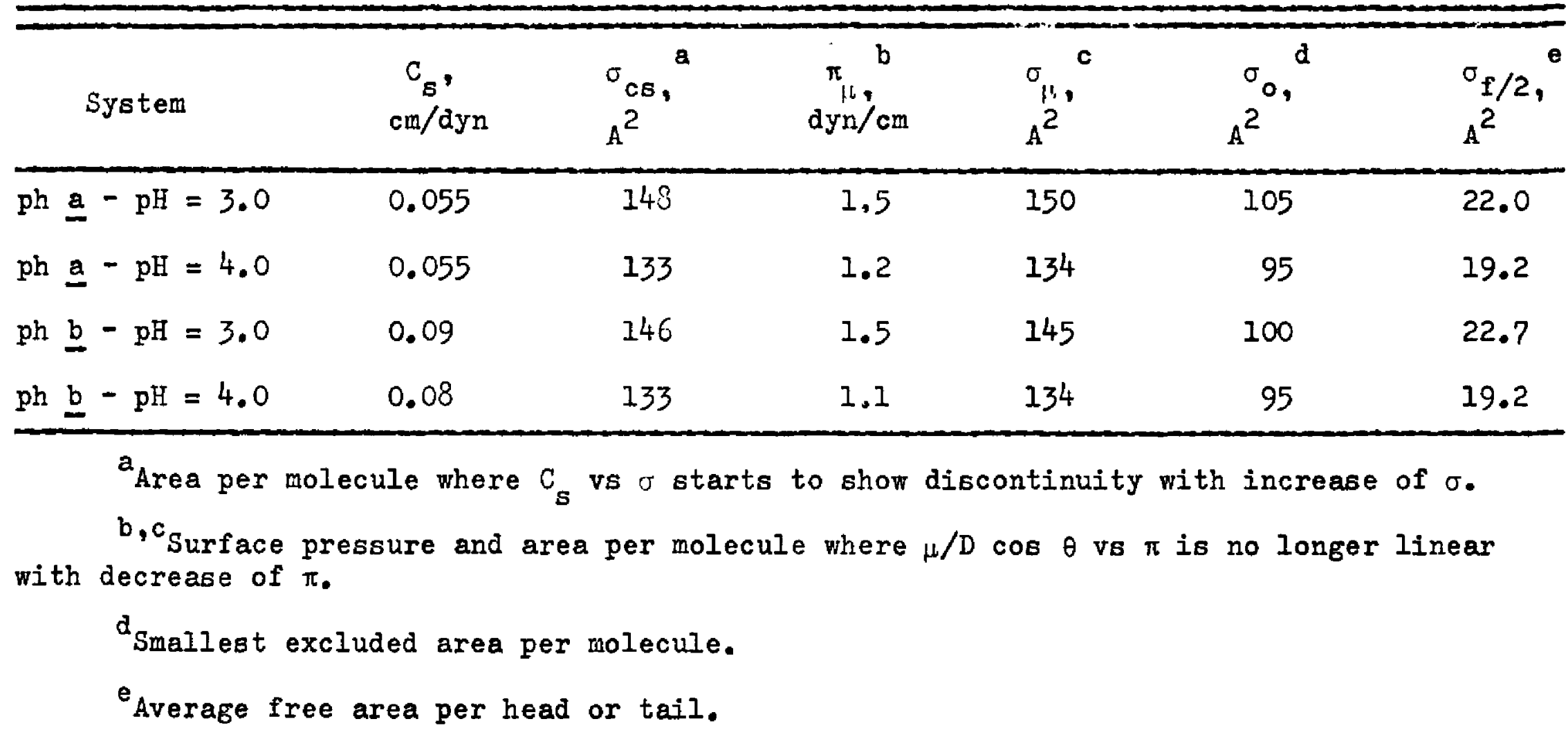


the $5 \mathrm{~A}^{2}$ for interstitial area is included in the free area. The average value of $\sigma_{f / 2}$ for all four systems $i s 20.3 \Lambda^{2}$ with average deviations of $\pm 1.6 \mathrm{~A}^{2}$.

At pressures less than the values shown in Table 15, reproducible small fluctuations in surface potentials over the surface were observed, ${ }^{\dagger}$ and the surface pressures tended to level out to constant low values in a muiner similar to that observed for fluid type surface films of high polymers [51]. These phenomena indicaie that the observed transitions involved a change in the state of ordering in the films. t' The close agreenent in the average free area, per head or tail, suggests tilat the transitions for the different systens arose from the sane cause. The magnitude of the frec area per unit is almost as large as the srallest excluded area of the phytol tail. It seems reasonable to suggest that the changes ill film behavior were due primarijy to significant increases in the kinetic motions of some of the phytol tailes $t+i$

$i^{i}$ These corresponded to an average difference in surface moment of about 0.12 Debye in different regions of the surface, or about \pm 0.06 Debye from the average values shown in Figures $z$ and 3. Väriations in $\Delta V$ for a typical run are shown in Fígure 6.

${ }^{+}$It is poseible that impurities could have produced part of the pressure in the regions of large molecular area. How ever, the consistency and reproducibility of the behavior for well spread films rules out the presence of impurities as the primary explanation.

${ }^{+}+{ }^{+}$D.J. Crisp [51] suggested, similarly, that the expanded Low pressure regions for high polymers arose from the onset of kinetic motions of the hydrocarbon chains. The transition in 


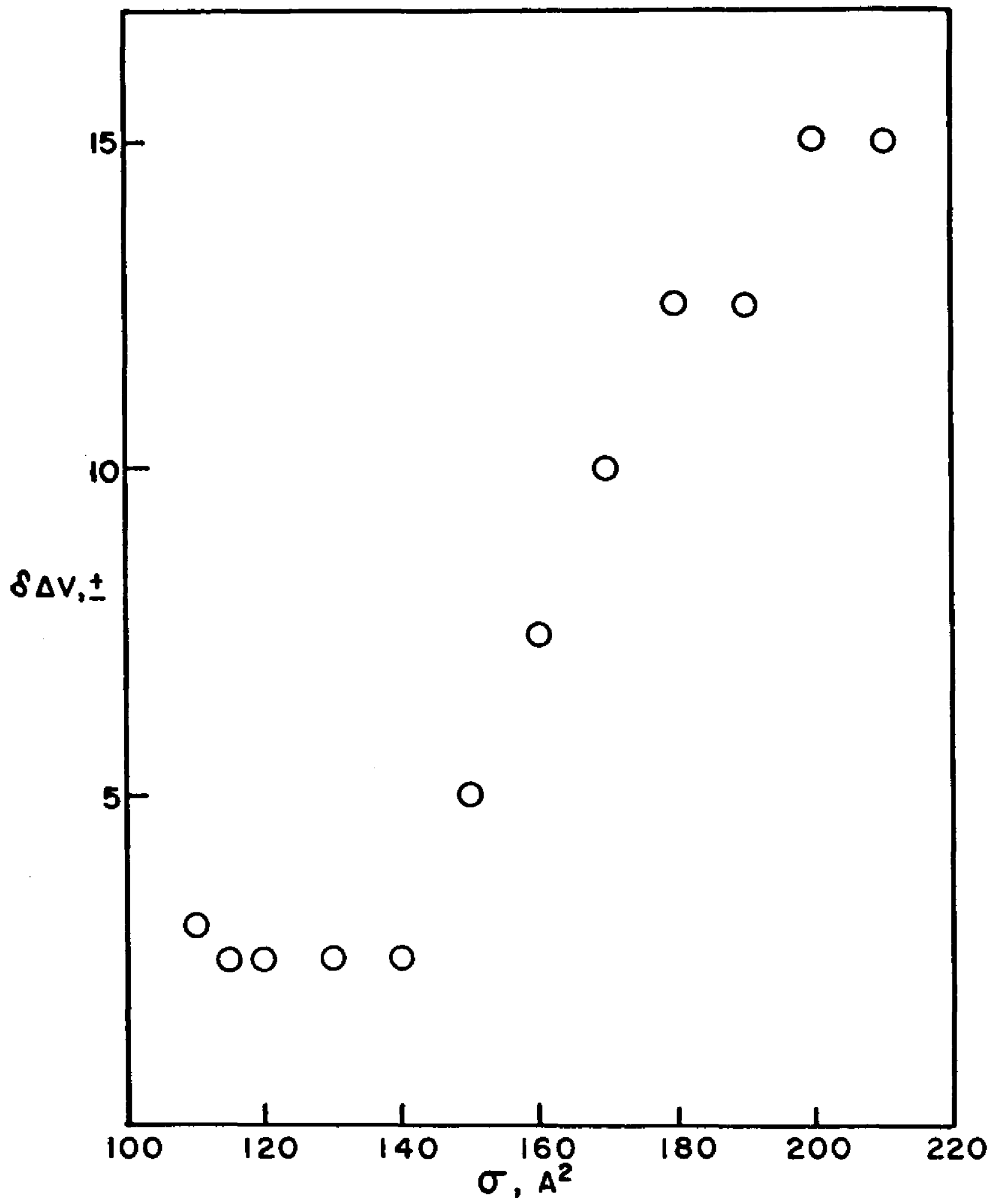

Figure 6

Variations in $\Delta V$ with $\sigma$ $\mathrm{ph} \underline{\mathrm{a}}-\mathrm{pH}=3.0$ 
The thawing out of thermal motion with decrease of $\pi$ would produce regions in the film of different states of order. The occurrence of measurable fluctuations in surface moment over the surface suggests that the regions coexisting in equilibrium were macroscopic in size. The regions where the notions of the tails were largely frozen out ${ }^{\dagger}$ would preserve the type of ordering suggested in Figure 5. Compression of the films at high pressures, then, would involve relatively large increases in vertical steggering, and relatively small decreases in average intermolecular distances to allow for closer packing.

In the regions of relatively greater disorder, each molecular unit would have a significantly larger average free area than in the ordered regions to allow for the greater degree of kinetic agitation. For example, assume that the average area per molecule in the regions of order increase relatively little on expansion of the film, and that 50 per cent of the wolecules

the intermediate liquid region for straight chain monolayers has been ascribed to the gradual liberations of thermal motions (reference [33], p. 134, [52]). Extremely high compressibilities are found in these transitions, and often heterogeneity in surface potential [20].

tIn discussion of the condensing effect of cholesterol on straight chain fatty acids in mixed monolayers, Adan (reference $[45], p .70)$ suggests that the rigid heads of the cholesterol molecules, which are not undergoine oscillations, exert a mechanical interference with the oscillatory motions of the long chains. A similar interference can be visualized for the chlorin heads on the phytol tails. At small interunit distances, dispersion interactions between heads and tails will be large and tend to make the tails lie as close as possible to, and extended along one of the nearest neighbor heads. 
are disordered at an overall average molecular area of $175 A^{2}$. For the $\mathrm{ph} \stackrel{\mathrm{A}}{-} \mathrm{pH}=3.0$ system, the average free area per molecule in the disordered regions would be about $50 A^{2}$ greater than in the ordered regions. With greater free areas per molecule, the probability of rotation of entire molecules about an axis normal to the interface would be increased. Intermolecular configurations would then occur where numbers of phytol chains were interacting. Because of the concerted kinetic motions among the cirains, average distances between chain units would remain relatively small. Their dispersive interactions would therefore nake a significant contribution to the cohesive pressure.

To eccount for the variations in surface moment it is suggested that in the disorcared regions of the film, where the molecules on the avertige have a larger socessible free area than in the ordered regions, there is a decrease in the extent of relative vertical stargering between molecules accompanied by a slight increase in the separation between charged heads and their counterions. This would produce a small increase in overall surface monent in comparison to that in the ordered regions and could thus account for the fluctuations in surface potential observed. With a larger accessible free area per molecule, lateral coulombic repulsions would be reduced. This reduction in repulsion would lead to a decrease in relative vertical displacement of the nolecules since displacement of some of the molecules into the water surface requires a positive 
work of hydrophobic immersion of the hydrocarbon parts of the molecule.

If the commonly observed free area, at which tranaitions in the behavior of surface moment and compressibility became apparent, corresponds to a sort of critical area per molecule, where the balance of negative cohesive pressure and positive thermal and repulaive pressures is such as just to damp out the random wagging motions of the phytol tails, then a decrease in critical area with increase of temperature might be expected, along with an increase in the measured surface pressure at the start of transition. The transition that is suggested to explain the phenomena can not be considered to be a regular first order transition, primarily because a constant surface pressure was never attained, and the transition from one regime of behavior to the other is not at all sharp.

At equilibrium, with coexisting ordered and disordered regions,

$$
\pi_{k i n}^{\alpha}+\pi_{c o h}^{\alpha}+\pi_{r e p}^{\alpha}=\pi_{k i n}^{\beta}+\pi_{c o h}^{\beta}+\pi_{r e p}^{\beta}=\pi_{\text {meas }}
$$

where $\alpha=$ region of disorder, $\beta=$ region of order,

$$
\pi_{k i n}=\pi_{k i n}^{\text {mol }}+\pi_{k i n}^{\text {tails }}, \pi_{c o h}^{\beta}=\pi_{c o h}^{\text {heads-heads }}+\pi_{c o h}^{\text {heads-tails }},
$$

and

$$
\pi_{\mathrm{coh}}^{\alpha}=\pi_{\mathrm{coh}}^{\text {heads-heads }}+\pi_{\mathrm{coh}}^{\text {heads-tails }}+\pi_{\mathrm{coh}}^{\operatorname{tails}-\operatorname{tail}_{s}}
$$


The following inequalitiea exist:

$$
\begin{aligned}
\pi_{r e p}^{\beta}> & \pi_{r e p}^{\alpha}, \pi_{c o h}^{\beta}>\pi_{c o h}^{\alpha}, \pi_{k i n}^{\beta, m o l}>\pi_{k i n}^{\alpha, \text { mol }}, \\
& \pi_{k i n}^{\alpha, t_{\text {tails }}} \gg \pi_{k i n}^{\beta, \text { tails }}
\end{aligned}
$$

If the transition was regular first order, then for a given temperature with $\pi_{\text {meas }}=$ constant, the average free areas per molecule in both the ordered and disordered regions would remain essentially constant with change in film area, and each of the terms in equation 6) would remain constant. Since $\pi_{\text {meas }}$ was not constant, particularly in the first part of the transition region with decreasing compression, it seems likely that secondary configurational changes occurred in both the ordered and disordered regions. In the disordered phase such a secondary change might be the gradual freeing of the rotational motions of the molecular units as a whole, while in the ordered phase it might be the liberation of rocking motions of the chlorin heads. The presence of secondary configurational changes might be further revealed in an alteration of shape of the transition region with change of temperature, particularly in the initial part. Thus an increase of temperature might be expected to broaden the transition region. 


\section{SUTMARY}

A study has been made of the stability of chl $\underline{a}$, ph $\underline{a}$, ph $\underline{b}$, and al ph $a$ monolayers at air-water interfaces, and chl a monolayers at nitrogen-water interfaces. To avoid photodecomposition, the monolayers must be kept in darkness, or under very low intensity, diffuse green light. Ph a and ph b monolayers are stable at air-water interfaces if the pH of the aqueous substrate is 4.5 or less. Al ph a monolayers are stable at air-unbuffered water interfaces. At $\mathrm{pH}^{\prime} \mathrm{s}$ greater than $4.5, \mathrm{ph}$ a and ph b monolayers undergo a chemical change that appears to be essentially allomerization. The rate of change increases approximately linearly with $\mathrm{pH}$ above 5.0 , with a slope of 3.7 per cent/hour/pH unit. Chl a monolayers at air-water interfaces rapidly undergo both pheophytinization and allomerization at $\mathrm{pH}=6$. At $\mathrm{pH}=9$ pheophytinization is inhibited, but allomerization of chl a occurs at a rate of about 2.5 per cent/hour. Under a nitrogen atmosphere (30-50 ppin $\left.\mathrm{O}_{2}\right)$ and at $\mathrm{pH}=9.0$, allomerization of chl $\mathrm{a}$ is reduced to about 0.9 per cent/hour.

Since it was possible to obtain chemical stability of ph a and ph $\underline{b}$ monolayers at low $\mathrm{pH}$, a quantitative study of the surface pressure $(\pi)$ and surface potential $(\Delta V)$ as a function 
of area per molecule $(\sigma)$ was made at $20^{\circ} \mathrm{C}$, on $\mathrm{pH}=4.0$ and $\mathrm{pH}=3.0$ substrates. At $\mathrm{pH}=4.0$, as $\sigma$ was varied from 200 to $100 \mathrm{~A}^{2}, \pi$ changed from 0.10 to $12.85 \mathrm{dyn} / \mathrm{cm}$ and $\Delta \mathrm{V}$ increased

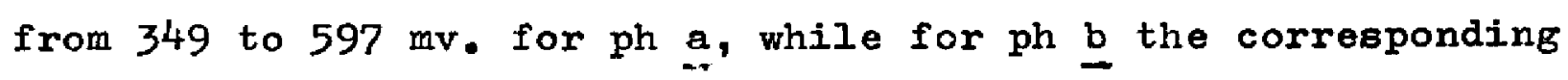
changes were 0.10 to $3.25 \mathrm{dyn} / \mathrm{cm}$ and 244 to $434 \mathrm{mv}$. For ph a at $\mathrm{pH}=3.0$ and for $\sigma$ in the range $210-110 \mathrm{~A}^{2}, \pi$ varied from 0.15 to $11.04 \mathrm{dyn} / \mathrm{cm}$ and $\Delta V$ increased from 361 to $561 \mathrm{mv}$. For $\mathrm{ph} \underline{b}$ at $\mathrm{pH}=3.0$, as $\sigma$ was varied from 200 to $105 \mathrm{~A}^{2}, \pi$ changed from 0.20 to $8.03 \mathrm{dyn} / \mathrm{cm}$ and $\Delta \mathrm{V}$ increased irom 269 to $423 \mathrm{mv}$. If the films were compressed to values of $\sigma$ smaller than those recorded above, surface pressures and surface potentials decreased with time. This was considered as evidence of film collapse.

The positive sign of the surface potentials is indicative of a molecular orientation in which the ester groups are anchored in the water surface, and the major portion of the chlorin head and the phytol tail are elevated into the air phase. The smaller values of the surface potentials for ph $b$ are visualized as arising primarily from the presence of the -CHO group at the 3-position on the chlorin ring. At this position its group moment will on the average be negative toward the air phase, and therefore decrease the total moment of the molecule. For given values of $\pi$ above $1.0 \mathrm{dyn} / \mathrm{cm}$, decrease of $\mathrm{pH}$ from 4.0 to 3.0 results in an average increase of $\sigma$ of about $91 / 2$ per cent. Conparison with the results of studies of ph a on $\mathrm{pH}=8$ substrates shows that $\sigma$ averaces about 20 per cent 
larger at $\mathrm{pH}=4.0$ than at $\mathrm{pH}=3$, for given values of $\pi$ above 1.0 dyn/cm. This expansion at the low pH's suggests that salt formation occurs with the entry of one or two protons into the center of the chlorin ring. Protonation would increase the repulsion between molecules and thus result in larger area per molecule at a given value of the film compression. Salt formation would be expected to affect the electronic distribution in the molecule and therefore alter its susceptibility to allomerization. Thus protonation of the pheophytins can be visualized as resulting in a decrease of electron density in the isocyclic ring, thereby increasing the potential barrier in the first step of an oxidation process.

For both ph a and $\mathrm{ph} b$ monolayers at $\mathrm{pH}=4.0$ and 3.0 , the effective surface moinents, $(\mu / D) \cos \theta$, of the molecules decrease linearly with increase of $\pi$ above about $1.0 \mathrm{dyn} / \mathrm{cm}$. At smaller surface pressures, the surface moment, averaged over the film area, is essentially constant with sinall reproducible fluctuations appearing over the surface of the ronolayer. The change in behavior of surface moment is accompanied quite closely by a change in the character of the averare compressibility. At compressions less than $1.0 \mathrm{dyn} / \mathrm{cm}$, the compressibility is characteristic of a gaseous film, while at Ereater pressures it is characteristic of a liquid expanded film. It is suggested that these phenomena signify an order-disorder transition occurring in the region of surface pressures near $1.0 \mathrm{dyn} / \mathrm{cm}$. 
A simple monolayer model is discussed which is based on the dimensions of the molecules and the characteristics of their packing together at different states of compression. A reasonable interpretation can be given for most of the observed characteristics of the monolayers. 'The essential features of the model are as follows. At surface pressures above about $1.0 \mathrm{dyn} / \mathrm{cm}$, the molecules are packed in a highly ordered array of local extent. To account for the decrease of $(\mu / D)$ cos $\theta$ with incres:e of $\pi$, it is suegested that molecules in alternate lows undergo an increase in relative vertical displ dcement with respect to the plane of the interiace. This relative motion would be expected to lessen intesmolecular repulsion and decreace the distance of separation of some of the monolayer molecules and their counterions. At surface pressures Jess than ahout $1.0 \mathrm{dyn} / \mathrm{cm}$ it is suggested that regions of order and disorder coexist throughout the film. The disordered regions are characterized by a relatively greater degree of thermal motion of the phytol tails and a smaller degree of relative vertical stagGering among the molecules, as compared to the ordered regions. These features could account for the greater compressibility and the fluctuations in surface moment over the surface in the lov pressure regine.

A spectroscopic method is presented for the analysis of intact chlorin ring decomposition products of chl a in dilute benzene or ethyl ether solutions. It is applicable to 
126

noninteracting mixtures where the components are ch l a, al chI $a, p h \underline{a}$, and al ph $\underline{a}$, or any other mixtures of these components. From application of the method to arm: number of solution samples from chemical, photochemical, and monolayer stability tests, it is found that allomerization andor pheophytinization are the predominant degradation reactions forming intact chlorine ring derivatives under many usual laboratory conditions. 
APPENDIX A

CHEMICAL AND PHOTOCHEIICAI STABILITY TESTS ON THE CHLOROPHYLLS AND SEVERAI DERIVATIVES II VARIOUS SOLVENTS 


\section{INTRODUCTION}

During the work on preparation of th, chlorophylls and their derivatives, it became evident that decomposition of the materials in solution could occur quite readily under normal laboratory conditions. Since it was necessary to obtain pure compounds and to store them under conjitions in which they would remain iniajt, chemical and photochemical stability studies were undertaken. The objectives were too obtain a qualitative evaluation of the various types of solvents used in this work and to intercompare the behavior of the different compounds. 


\section{EXPERIMENTAI}

In all tests decomposition was evaluated by weasuring the changes in the visible absorption spectra. Chemical stability was determined simply by storing the different solutions $\left(1 \times 10^{-5} \mathrm{M}\right.$, or $\left.1 \times 10^{-4} \mathrm{M}\right)$ in stoppered flasks for various time periods in the dark. Illumination at low light intensities was done with either a 15-watt "Daylight" fluorescent lamp, or a 100-watt tungsten lamp. Solution samples, in stoppered pyrex absorption cells (volume, $4.0 \mathrm{cc}$ ) were exposed directly to the light, or through various filters. Condensing lenses were not usc.d. In some experimenta, where apparatus was not available to measure light intensity, comparisons were made with different samples placed at eçual distances from the light source. Illumination at high light intensities was done with a looo-watt tungsten projection lamp uiing suitable condensing and focusing lenses. The light was passed through an eight inch column of water in a flat ended pyrex cylinder and then through one or more Corning heat resistant glass filters. The Corning filters used were as follows:
a) 5-60, transwitting in the blue region;
b) 4-64, transmitting in the green region;
c) 2-59 and 2-64, both transmitting in the red, and 
d) 1-69, 1-57, and 1-59, transmitting in the visible and absorbing in the infrared and ultraviolet.

In Table 16 are shown the initial rates of absorption of energy of some of the solutions used in the photochemical experiments. The designations high, and low under the heading "Light Source" refer to the 1000-watt tungsten laipg and the 15-watt fluorescent lanp, respectively. Energy and quanta absorbed were calculated from light intensities measured with an Eppley thermopile. Calculations were made as follows: per cent transmissions of the various filters were applied at wavelength intervals to relative energies of the source which resulted in a relative energy incident to tho sample vs wavelength. The absorption spectra data for ch orophyll and related derivatives were chanfed fron $d$ vs $\lambda$ to per cent absorbed vs $\lambda$. The relative incident tnergies and the absorption curves were combined for each compound. The areas under the resulting curve were measured with a planimeier. Using the measured energy values the relative energy values were changed to absolute energies. The relative energy vs $\lambda$ emission of the "Daylight" fluorescent source was taken from "Electrical Illumination," J.0. Kraehenbuel, Wiluy (1951). The relative energy vs $\lambda$ emission of the 1000-watt tungsten source was calculated from data in the RCA Tube Handbook and 'Measurements of Radiant Energy," W. E. Forsythe, MeGraw-IIill (1937). By comparison of neasured energies in various regions of the spectrum and relative energies from above references the 
Table 16

Initial Energy Absorption of Solutions

in the Fhotochemical Experiments

\begin{tabular}{|c|c|c|c|c|c|}
\hline System & $M\left(x \quad 10^{5}\right)$ & $\underset{\left(m_{4}\right)}{\text { Spectral Range }}$ & $\begin{array}{c}\text { Filters } \\
\text { Light Source }\end{array}$ & $\begin{array}{l}I_{\text {abs } / \mathrm{sec}} \\
(\mathrm{ergs} / \mathrm{sec}) \\
\times 10^{-5}\end{array}$ & $\begin{array}{l}\text { Quanta } \\
\times 10^{-16}\end{array}$ \\
\hline ph a - ether & 1.00 & $\begin{array}{l}750-350 \\
750-625 \\
625=575 \\
575=475 \\
475-350\end{array}$ & $\begin{array}{c}1-56 \\
\text { High }\end{array}$ & $\begin{array}{l}3.3 \\
0.9 \\
0.5 \\
1.1 \\
0.9\end{array}$ & $\begin{array}{l}9.1 \\
3.0 \\
1.4 \\
2.8 \\
1.8\end{array}$ \\
\hline ph $\underline{b}-$ ether & 1.00 & $\begin{array}{l}750-350 \\
750-625 \\
625=575 \\
575=475 \\
475=350\end{array}$ & $\begin{array}{l}1-56 \\
\text { Hi gh }\end{array}$ & $\begin{array}{l}4.0 \\
0.7 \\
0.4 \\
1.3 \\
1.6\end{array}$ & $\begin{array}{r}10.4 \\
2.2 \\
1.3 \\
3.5 \\
3.4\end{array}$ \\
\hline al ph $\underline{a}$ - ether & 1.00 & $\begin{array}{l}750-350 \\
750-625 \\
625=575 \\
575=475 \\
475-350\end{array}$ & $\begin{array}{l}1-56 \\
\text { High }\end{array}$ & $\begin{array}{l}2.5 \\
0.8 \\
0.2 \\
0.8 \\
0.7\end{array}$ & $\begin{array}{l}6.9 \\
2.6 \\
0.7 \\
2.1 \\
1.5\end{array}$ \\
\hline $\operatorname{chl} \underline{a}-$ ether & 1.15 & $\begin{array}{l}750-350 \\
750-625 \\
625=575 \\
575=500 \\
500-350\end{array}$ & $\begin{array}{l}1-56 \\
\text { High }\end{array}$ & $\begin{array}{l}4.4 \\
1.4 \\
1.0 \\
0.8 \\
1.3\end{array}$ & $\begin{array}{r}12.3 \\
4.5 \\
3.0 \\
2.1 \\
2.7\end{array}$ \\
\hline
\end{tabular}


Table 16 (Contd.)

\begin{tabular}{|c|c|c|c|c|c|}
\hline System & $\begin{array}{l}\text { Conc. } \\
M\left(x 10^{5}\right)\end{array}$ & $\underset{\left(m_{\mu}\right)}{\operatorname{Spectral}}$ & $\begin{array}{l}\text { Filters } \\
\text { Light Source }\end{array}$ & $\begin{array}{l}I_{\text {abs } / \mathrm{sec}} \\
(\mathrm{ergs} / \mathrm{sec}) \\
\times 10^{-5}\end{array}$ & $\begin{array}{l}\text { Quanta abs/sec } \\
\times 10^{-16}\end{array}$ \\
\hline chl b-ether & 0.94 & $\begin{array}{l}750-350 \\
750-625 \\
625-575 \\
575-500 \\
500-350\end{array}$ & $\begin{array}{l}1-56 \\
\mathrm{H}_{-\mathrm{Gh}}\end{array}$ & $\begin{array}{l}4.7 \\
0.9 \\
0.8 \\
0.8 \\
2.2\end{array}$ & $\begin{array}{r}12.5 \\
2.7 \\
1.9 \\
1.9 \\
6.0\end{array}$ \\
\hline chl a - benzene & 1.00 & $750-640$ & $\begin{array}{c}2-64+1-56 \\
\text { High }\end{array}$ & 0.5 & 1.5 \\
\hline chl a - benzene & 1.00 & $750-610$ & $\begin{array}{c}2-59+1-56 \\
\text { High }\end{array}$ & 1.0 & 3.3 \\
\hline chl a - benzene & 1.00 & $525-375$ & $\begin{array}{c}5-60+1-56 \\
\text { High }\end{array}$ & 0.7 & 1.6 \\
\hline chl a - pyridine & 1.15 & $\begin{array}{l}750-350 \\
750-625 \\
625-575 \\
575=500 \\
500-350\end{array}$ & $\begin{array}{c}1-56 \\
\text { Hish }\end{array}$ & $\begin{array}{l}4.8 \\
1.6 \\
0.9 \\
0.5 \\
1.8\end{array}$ & $\begin{array}{r}13.5 \\
5.4 \\
2.9 \\
1.4 \\
3.9\end{array}$ \\
\hline chl $\underline{b}$ - pyridine & 0.94 & $\begin{array}{l}750-350 \\
750-625 \\
625-575 \\
575-500 \\
500-350\end{array}$ & $\begin{array}{c}1-56 \\
\text { High }\end{array}$ & $\begin{array}{l}5.6 \\
1.0 \\
0.8 \\
0.8 \\
3.1\end{array}$ & $\begin{array}{r}14.9 \\
3.2 \\
2.3 \\
2.2 \\
7.2\end{array}$ \\
\hline
\end{tabular}


Table 16 (Contd.)

\begin{tabular}{|c|c|c|c|c|c|}
\hline System & $\begin{array}{l}\text { Conc. } \\
M\left(x \quad 10^{5}\right)\end{array}$ & $\begin{array}{c}\text { Spectral Range } \\
\left(m_{\mu}\right)\end{array}$ & $\begin{array}{l}\text { Filters } \\
\text { Light Source }\end{array}$ & $\begin{array}{l}I_{\text {abs/sec }} \\
(\text { ergs/sec }) \\
\times 10^{-5}\end{array}$ & $\begin{array}{l}\text { Quanta }{ }_{a b s / \mathrm{sec}} \\
\times 10^{-16}\end{array}$ \\
\hline \multirow{2}{*}{$\begin{array}{l}\text { al chl a - } \\
\text { pyridine }\end{array}$} & 0.57 & $750-350$ & $1-56$ & 2.5 & 6.8 \\
\hline & & $\begin{array}{l}750-625 \\
625-575 \\
575=500 \\
500-350\end{array}$ & High & $\begin{array}{l}0.8 \\
0.4 \\
0.2 \\
1.0\end{array}$ & $\begin{array}{l}2.6 \\
1.3 \\
0.6 \\
2.2\end{array}$ \\
\hline \multirow{2}{*}{ al ph $\frac{a}{\text { pyridine }}-$} & 0.55 & $750-350$ & $1-56$ & 2.1 & 5.6 \\
\hline & & $\begin{array}{l}750-625 \\
625-575 \\
575=500 \\
500-350\end{array}$ & High & $\begin{array}{l}0.5 \\
0.2 \\
0.7 \\
0.7\end{array}$ & $\begin{array}{l}1.6 \\
0.7 \\
1.9 \\
1.4\end{array}$ \\
\hline $\operatorname{chl} a-\operatorname{wet} \mathrm{CCI}_{4}$ & 1.00 & $\begin{array}{l}750-350 \\
750-625 \\
625-575 \\
575-500 \\
500-350\end{array}$ & $\begin{array}{l}\text { Water } \\
\text { Low }\end{array}$ & $\begin{array}{l}0.016 \\
0.003 \\
0.002 \\
0.001 \\
0.010\end{array}$ & $\begin{array}{l}0.041 \\
0.011 \\
0.006 \\
0.003 \\
0.022\end{array}$ \\
\hline $\operatorname{chl}$ a $-\mathrm{dry} \mathrm{CCl}_{4}$ & 1.00 & $\begin{array}{l}750-350 \\
750-625 \\
625-575 \\
575-500 \\
500-350\end{array}$ & $\begin{array}{l}\text { Water } \\
\text { Low }\end{array}$ & $\begin{array}{l}0.020 \\
0.004 \\
0.002 \\
0.001 \\
0.013\end{array}$ & $\begin{array}{l}0.052 \\
0.013 \\
0.007 \\
0.004 \\
0.028\end{array}$ \\
\hline chl a - benzene & 1.00 & $750-610$ & $2-\underset{\text { Iow }}{59}+1-69$ & 0.002 & 0.006 \\
\hline
\end{tabular}


approximate temperature of the tungsten source was determined to be $3070^{\circ} \mathrm{K}$

The energy absorbed in each indicated region was converted to quanta absorbed by using an average wavelength absorbed in each region. The total number of quanta absorbed was obtatned by adding the number of quanta in each region.

Frrors could include source tenjerature, thermopile measurements, area of exposure measurements, reflection, transmission, plctting, and area measurenent. Possible total error in values could be as high as \pm 45 per cent; however, the probable error in intercomparison between runs should be $\$ 15$ per cent or perhaps less.

All values calculated are for the indicated solutions in 1 cin absorption cells containing $4 \mathrm{cc}$ of solution.

The only difference between the low inteasity wet and dry calculations for chl a in $\mathrm{CCl}_{4}$ is that the iry series was run slightly closer to the source.

Details of each experimental syotem are given in the tables describing the systems. 
RESULTS AND DISCUSSION

Chemical stability

In Table 17 are given descriptions of some representative systems studied in the chemical stability tests. If no decomposition occurred it is stated in this table. Tables 18 and 19 give the results where decomposition was encountered. To facilitate tabulation the following abbreviations for the solvents are used throughout: $A c=$ acetone, $\mathrm{py}=$ pyridine, $\mathrm{bz}-\mathrm{D}=$ dry benzene, $E=$ ethyl ether, $E H C l=$ ethyl ether saturated with dry $\mathrm{HCl}$ gas, $\mathrm{EHClH}_{2} \mathrm{O}=2$ parts ethyl ether +3 parts ethyl ether saturated with concentrated aqueous HCl solution, $\mathrm{bz}-\mathrm{H}_{2} \mathrm{O}=$ wet benzene (i.e. $\left[\mathrm{H}_{2} \mathrm{O}\right]>10^{-5} \underline{M}$ ), ary cyclohexane $=$ cyclo-D, dry carbon tetrachloride $=\mathrm{CCl}_{4}-\mathrm{D}$, wet carbon tetrachloride $=\mathrm{CCl}_{4}-\mathrm{II}_{2} \mathrm{O}$, and $11 / 2$ per cent py-pet. $=11 / 2$ per cent (by volume) of pyridine in petroleum ether.

With reference to the ary benzene solutions, the absorption of polar molecules, such as water, has the effect of decreasing $B / R,{ }^{+}$and increasing both $B / 505$ and $R / m i n$ as shown for the control runs in Table 17. In the long storage period of 7 months, leakage of water through the plastic stopper seals

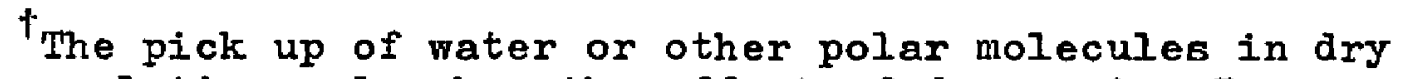
benzene solutions also has the effect of decreasing $\Omega_{1 / 2}$ $\mathrm{B}_{1 / 2}$ 
Table 17

Description of the Systems in Chemical Stability Tests

\begin{tabular}{|c|c|c|}
\hline $\begin{array}{l}\text { System. } \\
\text { Run No. }\end{array}$ & $\begin{array}{l}\text { Storage } \\
\text { Time }\end{array}$ & Remarks ${ }^{d}$ \\
\hline $\begin{array}{l}\operatorname{chl} a, b z-D \\
2351\end{array}$ & 7 Months $^{a}$ & Solution was prepared under $\mathrm{N}_{2}$ atmosphere. \\
\hline chl $a, b z-D$ & 7 Months $^{a}$ & $\begin{array}{l}\text { Solution was prepared under } \mathrm{N}_{2} \text { atmosphere, and } \\
\text { then saturated with dry } \mathrm{O}_{2} \text { gas. }\end{array}$ \\
\hline $\begin{array}{l}\operatorname{chl} a, b z-D \\
235 B\end{array}$ & 7 Months $^{\mathrm{a}}$ & $\begin{array}{l}\text { Solution was prepared under } \mathrm{N}_{2} \text { atmosphere, ahd } \\
\text { then saturated with dry } \mathrm{CO}_{2} \text { gas. }\end{array}$ \\
\hline $\begin{array}{l}\operatorname{chl} a, b z-H_{2} O \\
234 d\end{array}$ & 7 Months & $\begin{array}{l}\text { Solution was prepared under } \mathrm{N}_{2} \text { atmosphere, and } \\
\text { then saturated with } \mathrm{H}_{2} \mathrm{O} \text { and } \mathrm{O}_{2} \text {. }\end{array}$ \\
\hline $\begin{array}{l}\operatorname{ch} 1 \text { a, bz }-D \\
232 D\end{array}$ & 12 Hours & $\begin{array}{l}\text { Under } \mathrm{N}_{2} \text { atmosphere, the chl a was evaporated } \\
\text { onto a pyrex dish, allowed to stand for } 12 \text { hours, } \\
\text { then redissolved in dry benzene. }\end{array}$ \\
\hline $\begin{array}{l}\operatorname{chl} a, b z-D \\
230 c \text {, }\end{array}$ & 4 Hours & $\begin{array}{l}\text { Under } \mathrm{N}_{2} \text { atmosphere, a stream of } \mathrm{CO}_{2} \text { saturated } \\
\text { with } \mathrm{H}_{2} \mathrm{O} \text { was blown over dried amorphous chl a } \\
\text { before redissolving in dry benzene. }\end{array}$ \\
\hline $\begin{array}{l}\mathrm{ch} 1 \mathrm{a}, \mathrm{bz}-\mathrm{D} \\
234 \mathrm{~A}\end{array}$ & 4 Hours & $\begin{array}{l}\text { Under } \mathrm{N}_{2} \text { atmosphere, a stream of } \mathrm{O}_{2} \text { saturated } \\
\text { with } \mathrm{H}_{2} \mathrm{O} \text { was blown over dried amorphous chl a } \\
\text { before redissolving in dry benzene. }\end{array}$ \\
\hline
\end{tabular}


Table 17 (Contd.)

\begin{tabular}{|c|c|c|}
\hline $\begin{array}{l}\text { System, } \\
\text { Run No. }\end{array}$ & $\begin{array}{l}\text { Storage } \\
\text { Time }\end{array}$ & Remarks ${ }^{d}$ \\
\hline $\begin{array}{l}\operatorname{chl} a, A c^{b} \\
\operatorname{chl} a, I I / 2 \% \text { py-pet. }{ }^{b}\end{array}$ & $\begin{array}{l}2 \text { Months } \\
18 \text { Months }\end{array}$ & No decomposition. \\
\hline$\frac{\operatorname{chl}}{287}$ a, $\mathrm{py}^{\mathrm{b}}$ & 11 Days & No decomposition. \\
\hline al chl a, py ${ }^{b}$ & 2 Days & No decomposition. \\
\hline${ }_{290^{-}}$ & II Days & \\
\hline ph $a, E^{b}$ & 129 Days & No decomposition. \\
\hline $\mathrm{ph}$ a, $\mathrm{EHCl}^{\mathrm{b}}$ & 7 Days & No decomposition. \\
\hline $\mathrm{ph}$ a, $\mathrm{EHCl} \mathrm{H}_{2} \mathrm{O}^{\mathrm{b}}$ & 9 Days & No decomposition. \\
\hline al ph $\mathrm{a}, \mathrm{EHCl}^{\mathrm{b}}$ & 7 Days & No decomposition. \\
\hline al $\mathrm{ph} \underline{\mathrm{a}}, \mathrm{py}^{\mathrm{b}}$ & 11 Days & No decomposition. \\
\hline al ph $\underline{a}, E^{b}$ & 125 Days & No decomposition. \\
\hline $\begin{array}{l}\mathrm{ChI} b, A c^{b} \\
273 A^{-}\end{array}$ & 2 Years & \\
\hline
\end{tabular}


Table 17 (Contd.)

\begin{tabular}{|c|c|c|}
\hline $\begin{array}{l}\text { System, } \\
\text { Run No. }\end{array}$ & $\begin{array}{l}\text { Storage } \\
\text { Time }\end{array}$ & Remarks $d$ \\
\hline $\operatorname{chl} \underline{b}, E^{b, c}$ & 132 Days & No decomposition \\
\hline${ }_{288}^{c h l}$ b, py & 9 Days & \\
\hline $\operatorname{chl}_{284 \mathrm{~A}} \mathrm{~b}, \mathrm{bz}-\mathrm{H}_{2} \mathrm{O}^{\mathrm{b}}$ & & $\begin{array}{l}\text { This solution was obtained from } 288 \text { by washing } \\
\text { out the pyridine with distilled } \mathrm{H}_{2} \mathrm{O}\end{array}$ \\
\hline ph b. $E^{b}$ & 132 Days & No decomposition. \\
\hline $\mathrm{ph} \underline{b}, \mathrm{EHCl}^{\mathrm{b}}$ & 6 Days & No decomposition. \\
\hline $\mathrm{ph} b, \mathrm{EHCl} \mathrm{H}_{2} \mathrm{O}^{\mathrm{b}}$ & 8 Days & No decomposition. \\
\hline $\operatorname{ph}_{286}^{b}, \mathrm{py}^{\mathrm{b}}$ & 11 Days & \\
\hline
\end{tabular}

The solution picked up polar molecules $\left(\mathrm{H}_{2} \mathrm{O}\right)$ during the storace period.

b The solution was prepared in normal laboratory atmospheres.

${ }^{c} \mathrm{Chl}$ a, in ether, stored for a similar period, also showed no decomposition.

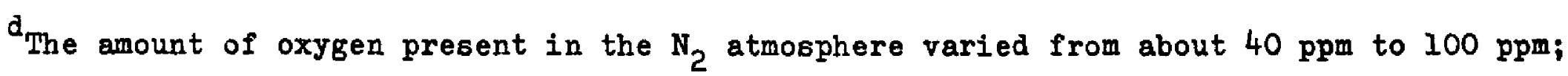
the amount of $\mathrm{CO}_{2}$ was estimated to be about $10 \mathrm{ppm}$. 
Table 18

Chemical Stability of Chlorophyll a

in Benzene Solutions

\begin{tabular}{|c|c|c|c|c|c|c|c|c|}
\hline $\begin{array}{l}\text { System, } \\
\text { or Run No. }\end{array}$ & $\mathrm{B} / \mathrm{R}$ & $\mathrm{B} / 505$ & $R / \min$. & $\% \operatorname{chl} \underline{a}$ & $\% a r$ chl a & $\%$ ph $\underline{a}$ & $\% \mathrm{PBP}{ }^{b}$ & $\%$ Unknown ${ }^{c}$ \\
\hline Control, ${ }^{a}$ bz-D & 1.336 & 52.1 & 66 & 100.0 & & & & \\
\hline Control, ${ }^{a} \mathrm{bz}_{-} \mathrm{H}_{2} \mathrm{O}$ & 1.261 & 55.7 & 107 & 100.0 & & & & \\
\hline $235 \mathrm{~A}$ & 1.27 & 60 & 89 & 95.2 & 1.6 & & 1.1 & 2.1 \\
\hline $232 C$ & 1.27 & 40 & 58 & 92.2 & 3.0 & & 2.8 & 2.0 \\
\hline $235 B$ & 1.26 & 55 & 87 & 94.6 & 2.5 & & 1.1 & 1.8 \\
\hline $234 \mathrm{C}$ & 1.28 & 17 & 17 & 73.3 & 13.2 & & $10.5^{\mathrm{d}}$ & 3.0 \\
\hline $232 \mathrm{D}$ & 1.35 & 15 & 12 & 56 & 14 & 5 & $20^{d}$ & 5 \\
\hline $230 \mathrm{C}$ & 1.48 & 14 & 29 & 39 & 6 & 40 & 2 & 13 \\
\hline $234 \mathrm{~A}$ & 1.28 & 12 & 12 & 49.5 & 17.2 & 9.4 & $13.7^{\mathrm{d}}$ & 10.2 \\
\hline
\end{tabular}

This refers to solutions of pure chl a.

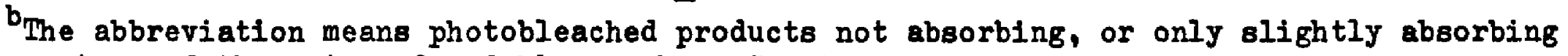
in the regions of the main red and blue peaks. See text.

This represents the uncertainties found in the determinantal correlations, and is indicative of the presence of unknown intact ring chlorin compounds.

$d_{\text {See text. }}$ 
Table 19

Chemical Stability of the Chlorophylls and the Pheophytins in Various Solvents

\begin{tabular}{|c|c|c|c|c|c|c|c|c|}
\hline $\begin{array}{l}\text { System, } \\
\text { or Run No. }\end{array}$ & ${ }_{\mathrm{R}}^{\lambda_{\mathrm{R}}}$ & $\begin{array}{l}\lambda_{B} \\
\mathbf{m}_{\mu}\end{array}$ & $\mathrm{B} / \mathrm{R}$ & $\mathrm{B} / \mathrm{BS}$ & $\mathrm{B} / 505$ & $\mathrm{R} / \mathrm{min}$. & $\begin{array}{l}\mathrm{R}_{1 / 2} \\
\mathrm{~m}_{\mu}\end{array}$ & $\mathrm{B}_{1 / 2}$ \\
\hline $\begin{array}{l}\text { Control, }{ }^{a} \text { l } 1 / 2 \% \text { py-pet. } \\
8, \text { chl a }\end{array}$ & $\begin{array}{l}663.7 \\
663.0\end{array}$ & $\begin{array}{l}434.5 \\
431.6\end{array}$ & $\begin{array}{l}1.169 \\
1.237\end{array}$ & $\begin{array}{l}1.327 \\
1.486\end{array}$ & $\begin{array}{l}54.8 \\
42\end{array}$ & $\begin{array}{l}94 \\
47\end{array}$ & & \\
\hline $\begin{array}{l}\text { Control, py } \\
290, \mathrm{ph} \text { a }\end{array}$ & $\begin{array}{l}669.3 \\
671.0\end{array}$ & $\begin{array}{l}414.6 \\
406.0\end{array}$ & $\begin{array}{l}2.21 \\
2.7\end{array}$ & & & $\begin{array}{l}13.4 \\
10.0\end{array}$ & $\begin{array}{l}20.4 \\
21.6\end{array}$ & $\begin{array}{l}44.9 \\
37.4\end{array}$ \\
\hline $\begin{array}{l}\text { Control, Ac } \\
273 \mathrm{~A}, \mathrm{chl} \mathrm{b}\end{array}$ & $\begin{array}{l}645.5 \\
645.6\end{array}$ & $\begin{array}{l}456.6 \\
457.3\end{array}$ & $\begin{array}{l}2.85 \\
2.91\end{array}$ & $\begin{array}{l}2.52 \\
2.46\end{array}$ & $\begin{array}{l}47.6^{b} \\
43.4\end{array}$ & $\begin{array}{l}17.4 \\
16.0\end{array}$ & $\begin{array}{l}20.1 \\
20.7\end{array}$ & $\begin{array}{l}25.9 \\
26.3\end{array}$ \\
\hline $\begin{array}{l}\text { Control, py } \\
288, \text { chi b }\end{array}$ & $\begin{array}{l}655.2 \\
641.4\end{array}$ & $\begin{array}{l}474.0 \\
461.0\end{array}$ & $\begin{array}{l}3.10 \\
5.8\end{array}$ & $\begin{array}{l}2.57 \\
2.4\end{array}$ & & $\begin{array}{r}11.6 \\
4.5\end{array}$ & & $\begin{array}{l}25.4 \\
35.4\end{array}$ \\
\hline $\begin{array}{l}\text { Control, bz- } \mathrm{H}_{2} \mathrm{O} \\
284 \mathrm{~A}, \mathrm{chl} \mathrm{b}\end{array}$ & $\begin{array}{l}646.2 \\
633.6\end{array}$ & $\begin{array}{l}457.9 \\
446.8\end{array}$ & $\begin{array}{l}2.67 \\
4.9\end{array}$ & $\begin{array}{l}2.81 \\
2.2\end{array}$ & & $\begin{array}{r}20.4 \\
5.1\end{array}$ & & $\begin{array}{l}21.8 \\
35.2\end{array}$ \\
\hline $\begin{array}{l}\text { Control, py } \\
286, \mathrm{ph} \text { b }\end{array}$ & $\begin{array}{l}656.7 \\
656.2\end{array}$ & $\begin{array}{l}438.0 \\
433.8\end{array}$ & $\begin{array}{l}4.90 \\
5.3\end{array}$ & $\begin{array}{l}2.21 \\
2.5\end{array}$ & & $\begin{array}{l}5.04 \\
4.1\end{array}$ & $\begin{array}{l}20.6 \\
22.0\end{array}$ & $\begin{array}{l}25.2 \\
22.2\end{array}$ \\
\hline al ph $a, p y$ & 671.7 & 405.8 & 3.02 & & & 8.3 & 24.4 & 39.6 \\
\hline
\end{tabular}

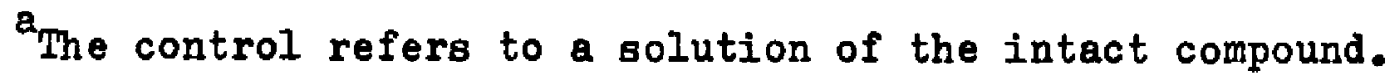

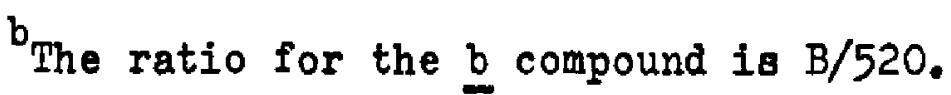


of the flasks, or desorption of water from the glass surfaces could have accounted for the partial increases in $\mathrm{R} / \mathrm{min}$ for tests $235 \mathrm{~A}$ and $235 \mathrm{~B}$, and for the decreases in $\mathrm{B} / \mathrm{R}$ for $235 \mathrm{~A}$, 232C, and 235B. The former ratio usually decreases when irreversible photobleaching has occurred, while the occurrence of allomerization and/or pheophytinization will tend to increase $B / R$. If these processes occurred in dry benzene solutions, along with pick up of polar molecules, it is possible that the ratios would not be much changed. Consequently, detection of decomposition from change of ratios alone rould be ambiguous. As will be shown subcequently, the rate of irreversible photobleaching of chlorophyll in benzene sulution containing dissolved oxygen is very much greater than the rates in polar solvents. ${ }^{\dagger}$ Consequently, brief expoeure of benzene solutions to dim diffuse light rosulted in detectable amounts of irreversible photobleaching as indicated in Table 18 . Photodecomposition results primarily in products that are derived from oxidative break up of the chlorin ring. the per cent of photobleached products was estimated from the decrease of total amount of chlorin derivatives at the end of the test period. In the instances of runs $234 \mathrm{C}, 232 \mathrm{D}$, and $234 \mathrm{~A}$, it seems likely that the high percentages of nonchlorin derivative products

IIt can be seen, in Table 17, that chl a solutions in Ac, $E$, and py showed no decomposition. These solutions had dissolved oxygen in concentrations of the order of $10^{-3} \mathrm{M}$, or greater. The amount of exposure to light was comparable to the benzene solutions. 
may have resulted from dark oxidation reactions as well as photoactivation processes.

Comparison of tests $235 \mathrm{~A}^{\dagger} 232 \mathrm{C}$, and $235 \mathrm{~B}^{\dagger}$ in Table 18

shows that, in the absence of water, a large excess of oxygen did not significantly increase the degree of decomposition. Dry $\mathrm{CO}_{2}$ has no apparent effect. This result is consistent with past work (for example, reference [2], pp. 451-453). The presence of dissolved oxygen and water together, as shown in 234C, resulied in a sicnificant increase in sinounts of allomerized chlorophyll and products forried fron the break up of the chlorin ring.

Tests $2320,230 C$, and $234 \Lambda$ show that when chlorophyll is in the dry amorphous state it is very repidly decomposed. Pheophytin formation, but not break up of the chlorin ring, is greatly enhanced by $\mathrm{CO}_{2}$ and water. These results are consistent with the findings of Zscheile and Cornar [28].

A 1:1 wixture of chl $a$ and $\beta$ carotene in benzene was prepared under $\mathrm{N}_{2}$ atmosphere and stored in the dark for 18 months. Neither the chlorophyll nor the $\beta$ carotene showed any decomposition. Under the same conditions of preparation and storage chl a alone decomposed to the extent of 5 per cent in seven

the benzene for the solutions in these runs was degassed under vacuum before use. During preparation of the solutions under controlled atmospheres, however, small amounts $\left(\leq 1.0 \times 10^{-6} \underline{I I}\right)$ of oxygen were absorbed in the benzene. 
months, and $\beta$ carotene alone underwent 80 per cent decomposition in 18 months.

In pyridine solutions ph $\underline{a}, \operatorname{chl} \underline{b}$, and $\mathrm{ph} \underline{\mathrm{b}}$ showed decomposition in relatively short time periods, while under the same conditions chl a, al chl $\underline{a}$, and al ph a vere stable. In a long storage period, however, chl a underwent a change in the $11 / 2$ per cent py-pet. solution. In all instances the changes in the spectral parameters that were found were similar to those that occur in allomerination.

Allomerization of chl $\underset{.}{b}$ Gives a principal product, presumably with the expanded isocyclic ring structure, whose main red band peak is at $63.2 \mathrm{~m}_{\mu}$ and the main blue peak at $442 \mathrm{~m}_{\mu}$ with petroleum ether as solvent (reference [2], p. 1775). This corresponds closely to the observed wavelengths of the product of run 284A in benzene shown in Table 19. The parameters of run 290 were in close egreement with those of al ph a in pyridine as shown in the table. Howevor, there were differences greater that would be expected from probable experimental error. The

It seemed probable that the decomposition was oxidation. The source of oxygen was that chemisorbed on the $\beta$ carotene crystals. Although the crystals were put under high vacuum, with a liquid nitrogen trap in the line, for 15 hours before preparing the solution under controlled atmosphere, the vacuum desiccator was not heated above room temperature. Consequentily, a considerable amount of oxygen was probably still contained in the crystals. 
product of run 290 was transferred to a wet benzene solution, the spectrum measured, and the spectral parameters compared with those of al ph a in wet benzene. Again ther was close agreement, but differences were fcund that were greater than could be accounted for by experimental error. An analysis, using the determinantal method, showed that unknown chlorin derivatives had been formed, but indicated that the major product was al ph a. These findings suggest that the main reaction in pyridine so? utions is oxidative alteration of the cyclopentanone ring with the formation of two or more different products.

The benzene solution of $284 \mathrm{~A}$ was treated with HCl solution to rewove the magnesium atom from the chlorir ring. The acid was washed out with water. The spectrum of the resulting solution was ccupared to that of the pruciuct of 286 which had been transferred to a wet banzens solution. The spectral parameters were nearly identical. This showed that the same reactions for both chl $\underline{b}$ and ph $\underline{b}$ had occurred in pyridine.

ChI $b$ in acetone proved to be quite stable. In a period

The pyridine was removed by repeated washings with distilled water. Additional treatment of the resulting benzene solution with HCl, and then renoval of the acid by washing with water, did not cause any change in the spectrum of the solution. This was good indication that washing with water had removed all the pyridine. 
of two years it appeared that only a small amount of ph $\underline{b}$ was formed.

Photochemical stability,

In Table 20 are given the descriptions of representative systems studied in low light intensity photobleaching tests. Where no decomposition cccurred it is stated in this Table. The runs to be intercoupared are spaced together; these had the same conditions of illumination. The concentrations of all solutions were about $1.0 \times 10^{-5}$ 1.

The results of the low intensity photobleaching tests are given in Pables 21 and 22 . Both the p:esence of water and $\beta$ carotene inhibited decomposition of chl a si snificantly. The result with $\beta$ carotene is consistent with the findings of H. Claes [53], and H. Clees and T. Nakayama [54]. $\beta$ carotene was not observed to uncergo any chance on photoactivation, either alone or in solution with chl a.

Brief exposure of benzene solutions to normal atmospheres before testing, or use of glass stoppers that allowed exposure during sesting, resulted in significtut increases in the amount of decomposition for chl a and $\operatorname{chl} \underline{b}$. The increase of decomposition was die to the absorption of oxycen in solution. In $\mathrm{CCl}_{4}$ solutions, comparing $P_{23}$ and $P_{24}$, it appeared that the inhibiting effect of water outweighed the effect of increasing the oxygen contert of the $\mathrm{CCl}_{4}$ solution $\left(\mathrm{P}_{23}\right)$.

Under icisntical conditions of testing al ph a and ph a 
Table 20

Systems Used in Low Light Intensity

Photobleaching Tests

\begin{tabular}{|c|c|c|c|}
\hline $\begin{array}{l}\text { System } \\
\text { Run No. }\end{array}$ & $\begin{array}{c}\text { Expose } \\
\text { Time, } \\
\text { Iours }\end{array}$ & $\begin{array}{l}\text { Light Source } \\
\text { Filters }\end{array}$ & Remarks ${ }^{c}$ \\
\hline chl $224 \mathrm{~A}, \mathrm{bz}-\mathrm{D}^{\mathrm{b}}$ & 2.5 & $F 1-3$ & Teflon stopper. \\
\hline $\begin{array}{ll}\mathrm{chl} \\
224 \mathrm{~B}\end{array}$ & 2.5 & $\mathrm{FI}-3$ & Teflon stopper. \\
\hline$\frac{\operatorname{chl} a, b z-\mathrm{H}_{2} \mathrm{O}}{231 \mathrm{~B}}$ & 1 & $\begin{array}{l}W-6 \\
1-56\end{array}$ & $\begin{array}{l}\text { Glase stopper. Solution prepared under nor- } \\
\text { mal leboratory conditions. }\end{array}$ \\
\hline $\begin{array}{l}\operatorname{chl} a, b z-H_{2} \mathrm{O} \\
231 \mathrm{~A}\end{array}$ & 1 & $\begin{array}{c}W-6 \\
1-69+4-64\end{array}$ & $\begin{array}{l}\text { Glass stopper. Solution prepared under nor- } \\
\text { mal iaboratory conditions. }\end{array}$ \\
\hline $\begin{array}{l}\text { chl a, cyclo- } \mathrm{D}^{\mathrm{b}} \\
220 \mathrm{~A}\end{array}$ & 5 & $W-12$ & Teflon stopper. \\
\hline $\operatorname{chl}_{220 \mathrm{~B}}$ a, cyclo- $\mathrm{D}^{\mathrm{b}}$ & 2 & $\mathrm{H}-12$ & $\begin{array}{l}\text { Teflon stopper. Solution was exposed briefly } \\
\text { to laboratory air before the test. }\end{array}$ \\
\hline $\begin{array}{l}\operatorname{chl} b, b z-H_{2} O^{b} \\
240 A\end{array}$ & 1.17 & $\begin{array}{l}W-6 \\
1-57\end{array}$ & Teflon stopper. \\
\hline
\end{tabular}


Table 20 (Contd.)

\begin{tabular}{|c|c|c|c|}
\hline $\begin{array}{l}\text { System } \\
\text { Run No. }\end{array}$ & $\begin{array}{l}\text { Expose } \\
\text { Time, } \\
\text { Hours }\end{array}$ & $\begin{array}{l}\text { Light Source } \\
\text { Filters }\end{array}$ & $\operatorname{Remarks}^{\mathrm{C}}$ \\
\hline $\begin{array}{l}\mathrm{chl} b, \mathrm{bz}-\mathrm{H}_{2} \mathrm{O}^{\mathrm{b}} \\
24 \mathrm{OB}\end{array}$ & 1.17 & $\begin{array}{l}W-6 \\
1-57\end{array}$ & $\begin{array}{l}\text { Teflon stopper. Solution was exposed brief- } \\
\text { ly to laboratory air before the test. }\end{array}$ \\
\hline $\begin{array}{l}\text { al } \operatorname{chl} a, b z-\mathrm{H}_{2} \mathrm{O}^{b} \\
227 \mathrm{~B}\end{array}$ & 1.25 & $F-3$ & Class stopper. \\
\hline$\underset{236 \mathrm{C}}{\mathrm{al}} \mathrm{ph}, \mathrm{bz}-\mathrm{H}_{2} \mathrm{O}^{\mathrm{b}}$ & 45.5 & $F I-3$ & Glass stonper. \\
\hline$\frac{\mathrm{ph}}{239^{-}} \mathrm{bz}-\mathrm{H}_{2} \mathrm{O}^{\mathrm{b}}$ & 48.5 & $\mathrm{FI}-3$ & Glass stopper. \\
\hline ch1 $a, b z-D^{b, d}$ & 21.6 & $\begin{array}{l}F 1-24 \\
2-59+1-69\end{array}$ & Teflon stopper. \\
\hline $\begin{array}{l}\text { chl } a+\beta C, b z-D^{b} \\
P 26,-S \equiv e \text { Remarks }\end{array}$ & 21.6 & $\begin{array}{c}F 1-24 \\
2-59+1-69\end{array}$ & $\begin{array}{l}\text { Teflon stopper. This solution was a } 1: l \\
\text { mixture chl a and } \beta \text {-carotene in dry benzene. }\end{array}$ \\
\hline $\begin{array}{l}\text { B-carotene, bz, C.P. } \\
\text { P27, See Remarks }\end{array}$ & 12.9 & $F=-24$ & $\begin{array}{l}\text { Glass stopper. The solution was prepared in } \\
\text { normal laboratory air with C.P. benzene. No } \\
\text { decomposition occurred. }\end{array}$ \\
\hline
\end{tabular}


Table 20 (Contd.)

\begin{tabular}{|c|c|c|c|}
\hline $\begin{array}{l}\text { System } \\
\text { Run No. }\end{array}$ & $\begin{array}{l}\text { Expose } \\
\text { Time, } \\
\text { Hours }\end{array}$ & $\begin{array}{c}\text { Iight Sourve } \\
\text { Filters }\end{array}$ & $\operatorname{Remarks}^{c}$ \\
\hline $\begin{array}{l}\operatorname{chl} a, \mathrm{CCl}_{4}-\mathrm{H}_{2} \mathrm{O}^{\mathrm{b}, \mathrm{d}} \\
\text { P23, See Remarks }\end{array}$ & 3 & $\begin{array}{l}\text { F1-24 } \\
\text { Water }\end{array}$ & $\begin{array}{l}\text { Teflon stopper. Distilled water was added to } \\
\text { the solution in laboratory air before the } \\
\text { test. }\end{array}$ \\
\hline $\begin{array}{l}\operatorname{chl} \text { a, } \mathrm{CCl}_{4}-\mathrm{D}^{\mathrm{b}, \mathrm{d}} \\
\mathrm{P} 24\end{array}$ & 3 & $\begin{array}{l}\text { Fl-24 } \\
\text { Water }\end{array}$ & ieflon stopper. \\
\hline
\end{tabular}

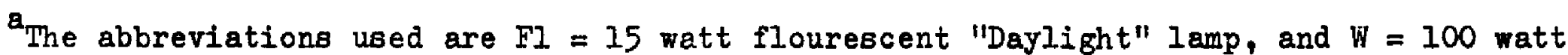
tungsten lamp. The number after the hyphen designates the distance in inches of the sample from the source.

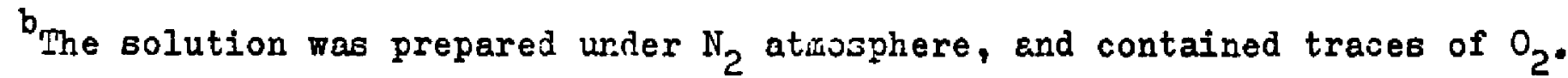

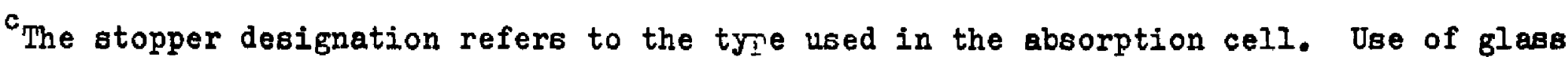
stoppers allowed leakage of $\mathrm{O}_{2}, \mathrm{CO}_{2}$, and $\mathrm{H}_{2} \mathrm{O}$ into the cell during testing, while the teflon stopper did not. Table 25.

The initial energy absorbed is shown in Table 15, and the apparent quantum yields in 
Table 21

Photobleaching Behavior at Low Iight Intensities,

chl $a, \operatorname{chl} b, a) \operatorname{chl} a, a l$ ph $\underline{a}$, and ph $\underline{a}$

\begin{tabular}{|c|c|c|c|c|c|c|}
\hline $\begin{array}{l}\text { System } \\
\text { Run No. }\end{array}$ & $\%$ Dec & $\begin{array}{c}\text { of } d \\
0\end{array}$ & $\begin{array}{r}\text { hour } \\
3\end{array}$ & $B / R^{2}$ & $B / 505^{c}$ & $\mathrm{R} / \min .{ }^{c, d}$ \\
\hline Control,,$e$ bz-D & & & & 1.42 & 64.7 & 78 \\
\hline$\frac{\operatorname{chl}}{224 A} a, b z-D$ & 16.9 & 10.9 & 15.6 & 1.50 & 6.6 & 4.4 \\
\hline Control, bz- $\mathrm{H}_{2} \mathrm{O}^{\mathrm{e}}$ & & & & 1.278 & 83.2 & 156 \\
\hline$\frac{\mathrm{chI}}{224 \mathrm{~B}^{-}}$ & 9.5 & 0.0 & 9.0 & 1.30 & 15.8 & 14.0 \\
\hline Control, bz- $\mathrm{H}_{2} \mathrm{O}$ & & & & 1.26 & 55.7 & 107 \\
\hline$\frac{\operatorname{chl} a, b z-H_{2} 0}{231 B}$ & $6+.7$ & 34.4 & 56.6 & 1.57 & 4.7 & 2.1 \\
\hline$\frac{\operatorname{chl}}{231 \mathrm{~A}}=\frac{\mathrm{a}}{\mathrm{b} z-\mathrm{H}_{2} \mathrm{O}}$ & 28.8 & 14.1 & 25.1 & 1.34 & 13.5 & 8.1 \\
\hline Control, cyclo-D & & & & 1.49 & 42.8 & 54 \\
\hline $\begin{array}{l}\text { chl a, cyclo-D } \\
220 A^{-2}\end{array}$ & 3.9 & 3.4 & 4.0 & 1.48 & 14.4 & 10.0 \\
\hline
\end{tabular}


Table 21 (Contd.)

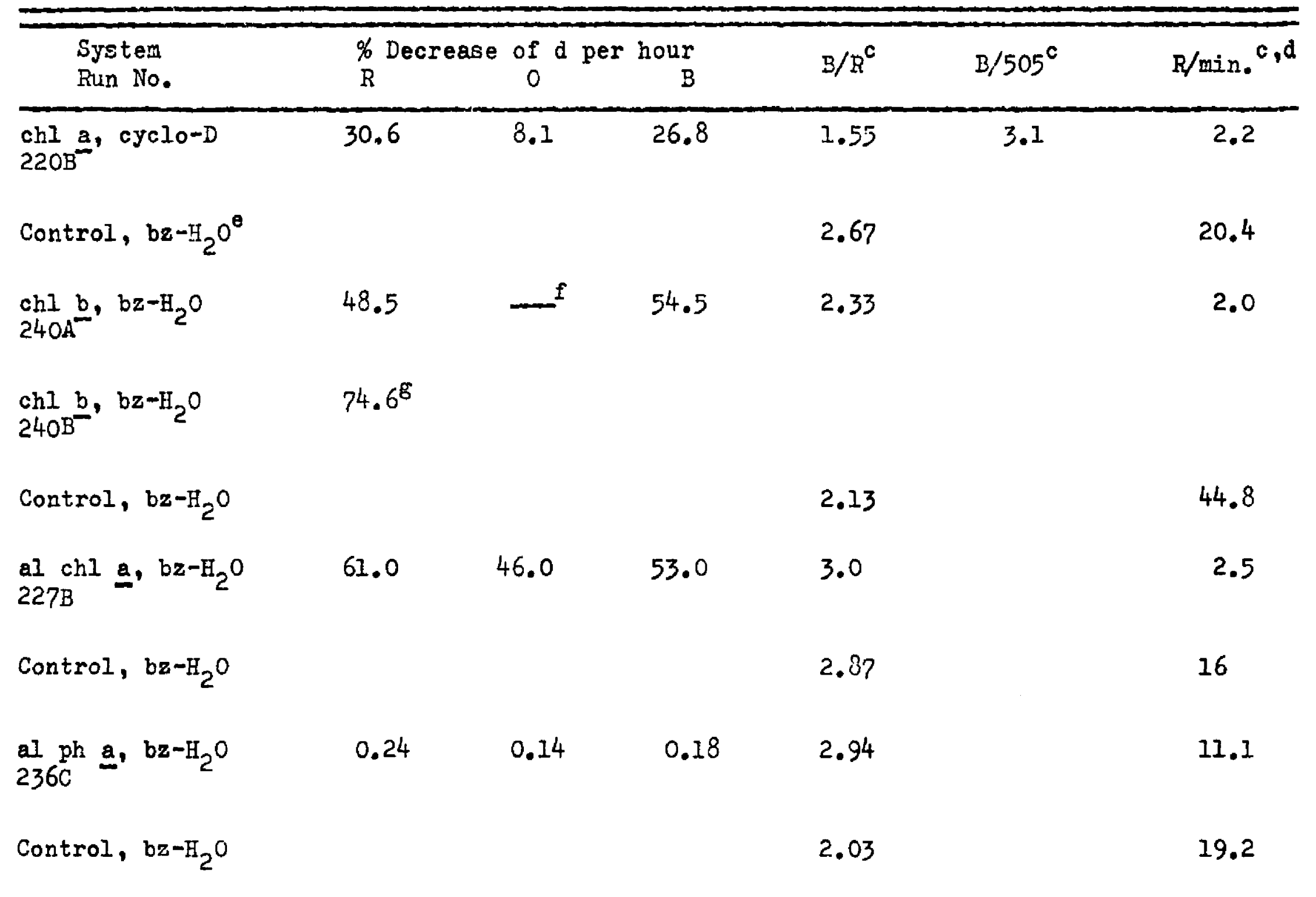


Table 21 (Contd.)

\begin{tabular}{|c|c|c|c|c|c|}
\hline $\begin{array}{l}\text { System } \\
\text { Run No. }\end{array}$ & $\begin{array}{l}\% \text { Decrease } \\
\mathrm{R}\end{array}$ & of d per hour & $B / R^{c}$ & $B / 505^{c}$ & $\mathrm{R} / \min .^{\mathrm{c}, \mathrm{d}}$ \\
\hline ph $a, b z-H_{2} \mathrm{O}$ & 0.28 & 0.26 & 2.05 & & 16.0 \\
\hline
\end{tabular}

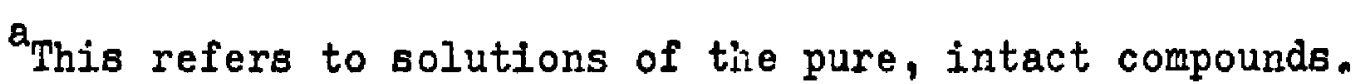

${ }^{b}$ This gives the percentage decrease of the peak optical densities for the main red, orange, and blue bands respectively.

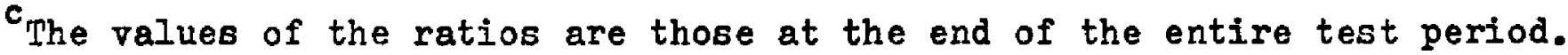

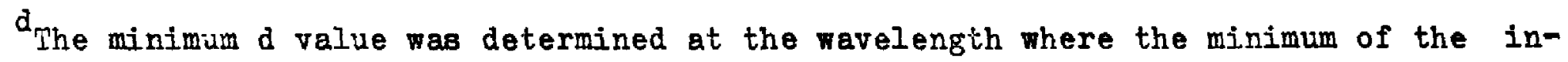
tact material occurs.

These particular control colutions were moro neurly free of dissolved $\mathrm{O}_{2}$ and $\mathrm{CO}_{2}$ than any others prepared.

$f_{A}$ product was formed that had a band marimum at $545 \mathrm{~m}_{\mu}$; this obscured the intengity change in the orange band.

Bonly the red band could be identified with reasonable certainty. 


\section{Table 22}

Photobleaching Behavior at Low Light Intensities, chl a

\begin{tabular}{|c|c|c|c|}
\hline $\begin{array}{l}\text { System } \\
\text { Run No. }\end{array}$ & $\%$ Decrease chl a per hour & $\begin{array}{c}\text { \% Total Chlorin Derivatives } \\
\text { Formed }\end{array}$ & $\%$ Other Produsts ${ }^{e}$ \\
\hline $\operatorname{chl} a, b z-D$ & $0.83^{b}$ & $42 \pm 7^{d}$ & 58 \\
\hline $\mathrm{P} 25$ & $0.75^{c}$ & & \\
\hline${ }_{\mathrm{P} 26}^{\mathrm{ch}} \underset{\mathrm{a}}{\mathrm{a}}+\beta \mathrm{C}, \mathrm{bz}-\mathrm{D}$ & $0.31^{c}$ & & \\
\hline${ }_{\mathrm{P} 23}^{\mathrm{chl}} \mathrm{a}, \mathrm{CCl}_{4}-\mathrm{H}_{2} \mathrm{O}$ & $15.0^{\mathrm{b}}$ & $17 \pm 9$ & 83 \\
\hline $\operatorname{chl} a, C_{C I}-D$ & $28.6^{\mathrm{b}}$ & $28 \pm 13$ & 72 \\
\hline
\end{tabular}

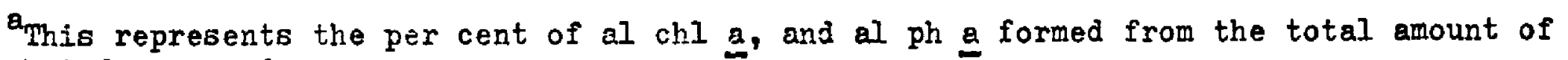
chl a that decomposed.

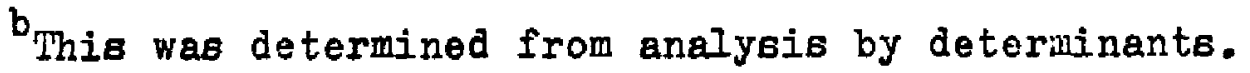

CThis value was obtained from the decrease of the main red band.

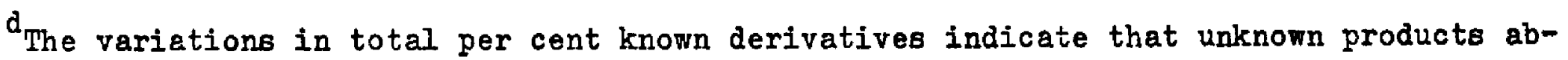
sorbing in the visible were present. visible.

This refers to decomposition products weakly absorbing, or not absorbing in the 
showed about a 230-fold lesser rate of photodecomposition than al chl a. Conparing chl a of run $224 \mathrm{~B}$ (where only trace amounts of $\mathrm{O}_{2}$ were present) to al ph a of run 236C, or to ph a of run 239 (where continuous exposure to oxygen during testing could occur) showed that the latter two compounds were essantially resistant to decomposition under conditions that would have led to complete irreversible photobleaching of $\mathrm{chl}$ a.

As shown in Table 21 photodecomposition was accompanied by a significant decrease in the ratio $R / m i n$ for all compounds. This resulted both from decrcases in the optical de:csities of the red bands and from increases in the optical densities of the minima. Photodeconposition ố $\mathrm{chl}$ a in benzene and in cyclohexane that had been exposed to normal atmospheres, and of chl b in wet benzene rcsulted in significantly larger decreases of the main red and blue bands than in the orange bands. This phenomenon and the increases in the region of the minima clearly indicate that products absorbing in the visible were formed. In the case of chl 2 , as shown in Table 21 , some of the products were identified as intact chlorin ring compounds. However, such compounds usually derived from the chlorophylls do not have their main bands in the orange, yellow, and the blue-green regions. On the other hand, phycobilin type derivatives can absorb strongly in these regions, usually with one main band (reference [2], pp. 666-667, p. 1789). This type of compound could result from the oxidative rupture of one of the methine 
bridges of the chlorin ring. A conjugated open chain of substituted pyrrole nuclei linked by $=\mathrm{CH}-$ bridges would be formed. The presence of small amounts of such compounds could account for the relatively smaller absorption changes in the region between the main red and blue bands.

In some instances it was found that photobleaching resulted in a product (or products) that gave weak absorption at $700 \mathrm{~m}_{\mu}$ and longer wavelengths. While this might have arisen from a phycobilin type compound, it is more likely that it was due to a chlcrin derivative. A.S. Holt [25] found that one of the intact ring chlorin products (i.e. fraction 1), formed from chl a under certain conditions of allomerization, had a main red band whose absorption extended to wavelengtls longer than 720 m. The isocyclic ring, which had been oxidized, was no longer intact. The formation of products of this type could account for the observed abscrption in the far red region. The major percentage of products formed in photobleaching did not absorb in the visible. These must have been derived from extensive breakup of the chlorin ring with formation of small molecules having a relatively small degree of conjugation. The process of oxidative breakup probably begins with rupture at one methine bridge, ${ }^{\dagger}$ resulting in the formation of a phycobilin type compound. It is reported that usually these

ton the basis of the recent work of R.B. Hioodward and V. Skaric [55], the bridge most likely to be attacked would be the $\delta$ methine bridge. 
compounds are quite easily decomposed by light and oxygen (for example, reference [2], p. 522). Where they aiso formed photochemically from the chlorins they would probably, in most instances, undergo extensive decomposition themselves, with the formation of products not absorbing in the visible. It is for this reason that only small amounts of phycobilin type derivatives ${ }^{\dagger}$ were usually manifested.

In Table 23 are given the descriptions of representative systems studied in the high light intensity photoactivation tests. The concentrations of all solutions were about $1 \times 10^{-5}$. All solutions were prepared under identical conditions of exposure to laboratory atmosphere, and low intensity green light. The solubilities of oxygen, carbon dioxide, and water, in all of the solvents used, we such that their concentiations were probably gieater thar that of the chlorophyll (or derivative) in eiach case. Is a consequence of the standardization in provedures, interiomparison of the various tests will have significance in regards to the effect of solvent and substituent changes on sinetic behavior. The uncertainties in per cent change of band peak optical densities were estimated from the experimental accuracy in measurement of $d$ in various regions of the spectrum. This depended on the inherent accuracy of the instrument and on the variations in the amounts of

The chlorin derivatives, in contrast to the phycobilins, have rultiple band absorption throughout the range -700 mil to $\sim 350 \mathrm{~m}$ 
Table 23

Systems Used in High Iight Intensity Photobleaching Tests

\begin{tabular}{|c|c|}
\hline System, Bun No. & Penarks $b$ \\
\hline $\begin{array}{l}\operatorname{chl} \mathrm{a}, \mathrm{bz}, \mathrm{Pl} \\
\operatorname{chl} \frac{a}{\mathrm{a}} \mathrm{bz} \text { sat'd with } \mathrm{CO}_{2}, \mathrm{P2} \\
\operatorname{chl} \mathrm{a}, \mathrm{bz} \text { sat'd with } \mathrm{CO}_{2}, \mathrm{P3}\end{array}$ & $\begin{array}{l}\text { The compositicns of the solvtions were obtained by the de- } \\
\text { terminantal method. The arerage uncertainty in the percent- } \\
\text { age of known compounds is } \pm 4 \% \text {. }\end{array}$ \\
\hline $\operatorname{chl} a, E, P 4$ & $\begin{array}{l}\text { Average uncertainty in change of } \mathrm{d} \text { is } \pm 0.8 \% \text {. The primary } \\
\text { photochemical change was probably destruction of the chlorin } \\
\text { ring. Only eme.li amounts of products were formed that ab- } \\
\text { sorbed in the visible. }\end{array}$ \\
\hline $\mathrm{ch}$ g. $\mathrm{py}, \mathrm{P} 5^{\mathrm{c}}$ & $\begin{array}{l}\text { Average uncortainty in change of d is } \pm 0.8 \% \text {. Destruction of } \\
\text { the chlorin ring occurred. As evidenced by the unequal ds- } \\
\text { creases in the bands, products absorbing in the visible were } \\
\text { formed. }\end{array}$ \\
\hline al chl a, py, $\mathrm{P}^{\mathrm{c}}$ & $\begin{array}{l}\text { Average uncertainty in change of } d \text { is } \pm 1.9 \% \text {. Destruction of } \\
\text { the chlorin ring occurred. The unequal decreases in the peaks } \\
\text { showed that products absorbing in the visible were formed. }\end{array}$ \\
\hline ph $\underline{a}, E$ & $\begin{array}{l}\text { No photodecomposition occurred in an illumination period of } \\
65 \text { minutes. }\end{array}$ \\
\hline
\end{tabular}


Table 23 (Conta.)

System Run No.

$\operatorname{Remarks}^{b}$

ph a, py, $P 8^{c}$

Average uncertainty in change of $d$ is $\pm 2.4 \%$. Extensive dark reaction, almost to completion, had occurred before the photosotivation testr. Destruction of the chlorin ring was the primary reaction. Some of the products formed absorbed in the visible.

ph $\mathrm{a}, \mathrm{EHCl}, \mathrm{P9}$

Average uncertainty in change of $\mathrm{d}$ is $\pm 1.8 \%$. Changes in the initial red band, the final blue band, the inftial blue band, and initial blue satellite band are reported, respectively. Photodecomposition resulted primarily in a product absorbing strongly at $433.9 \mathrm{~m} \mu$. This derivative was quite stable against photodecomposition.

ph a, EHCl $\mathrm{H}_{2} \mathrm{O}, \mathrm{PIO}$

Average uncertainty in change of $d=3 \pm 2.4 \%$. Same remarks as for P9. The main product absorbed strongly at $435 \mathrm{~m}_{\mu}$.

al ph a, E, PII

Average uncertainty in change of $d$ is $\pm 1.3 \%$.

al $\mathrm{ph}$ a, $\mathrm{py}, \mathrm{P} 12^{\mathrm{c}}$

Average uncertainty in change of $d$ is $\pm 2.9 \%$. Destruction of the chlorin ring occurred. The unequal decreases in the peaks showed that products absorbing in the visible were formed. 
al $\mathrm{ph}$ a, $\mathrm{EHCl}, \mathrm{Pl3}$

chl b, E, P2l

chl b, py, P15

ph b, E, P22

ph b, py, $\mathrm{P} 17^{\mathrm{c}}$
Average uncertainty in change of $\mathrm{d}$ is $\pm 2.5 \%$. A dark reaction of significant rate occurred during the test period. This reaction occurred only after photoactivation, and appeared to involve primarily decomposition of the photoformed product absorbing in the visible.

Average uncertainty in change of $\mathrm{d}$ is $\pm 1.2 \%$. A derk reaction occurred during the test period and only after photoactivation. It appeared to involve primarily the decomposition of the photoformed product aborbing in the visible.

Average uncertainty in change of $\mathrm{d}$ is $\pm 1.2 \%$. Destruction of the chlorin ring occurred. Products absorbing in the visible were formed; one of these may have been an intact chlorin ring derivative.

Average uncerteinty in change of $d$ is $\pm 0.7 \%$. A very slow dark reaction occurred aiter photoactivation, but not before.

Average uncertainty in change of $\mathrm{d}$ is $\pm 2.7 \%$. An extensive dark reaction nearly to completion, had occurred prior to photoactivation. As evidenced by the unequal decreases in the bands products absorbing in the visible were formed. A dark reaction occurred during testing. 


\begin{tabular}{|c|c|}
\hline System Run No. a & Remarks ${ }^{b}$ \\
\hline $\mathrm{ph} \underline{\mathrm{b}}, \mathrm{EHCl}, \mathrm{P} 18$ & $\begin{array}{l}\text { Average uncertainty in change of } d \text { is } \pm 3.0 \% \text { Changes in the } \\
\text { initial red band, the final orange band, the initial blue } \\
\text { band, and the final blue band are reported, respectively. A } \\
\text { rather repid dark reaction, initiated by photoactivation, oc- } \\
\text { curred during the test poriod. In the first } 30 \text { minutes of } \\
\text { photoactivation, the primary process was formation of a } \\
\text { product arsorbins strongly at } 442.5 \text { mp. Subsequently the } \\
\text { process was primacily photodecomposition of this new product. }\end{array}$ \\
\hline $\mathrm{ph}$ b, EHCl $\mathrm{H}_{2} \mathrm{O}, \mathrm{P} 19$ & $\begin{array}{l}\text { Average unceituin'y in change of } d \text { is } \pm 3.0 \% \text {. Sare remarks } \\
\text { as for } 188 \text {. The main product from photobleaching absorted at } \\
\text { about } 445.0 \mathrm{~m} \mu \text {. }\end{array}$ \\
\hline
\end{tabular}

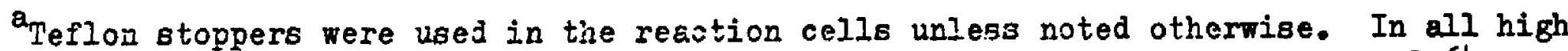
light intensity runs, a Corning 1-56 filter was used. In runs P1 and P3 a Corning 2-64 filter was used in addition. In run P2, a Corning 5-60 filter was used in addition.

bo significant dark reactions occurred in the test periods unless noted otherwise.

${ }^{A}$ A glass stopper was used in the reaction cell. 
products formed that absorbed in the visible. Estimates of the latter were made from observations on the variations in change of absorbance at the far red side of the main red band (where the chlorophyll or derivative did not originally absorb), or in the region of the absolute minimum of the initial spectrum. Uncertainties were greatest for intensity changes in the bands near which photoformed products absorbed strongly. These were usually for changes in the orange, yellow, and green bands. The average unceitainties reported are about one half as great as the largest uncertainty, and twice as great as the smallest uncertainty.

In Table 24 are eiven the results of chl a in benzene solutions, while in Table 25 are given the results of the chlorophylls and several of their derivatives in solutions other than benzene. The rates of photodecomposition, which in Table 25 are given by per cent decreases of the peak optical densities of the main red bands, are averages for all the periods of photoactivation for each run. To allow for the decrease of pigment due to the photodecomposition of preceding periods, the rates, for periods following the first, were calculated with photoactivation times decreased in proportion to the amount of the pigment present at the beginning of the particular period. With this procedure, the rates for different periods showed deviations ranging from \pm 9 per cent to \pm 32 per cent of the average values tabulated, for those tests in which there were no significant concurrent dark reactions. The average of the 
Table 24

Photobleaching Behavior at High Light

Intensities. Benzene Solutions

\begin{tabular}{|c|c|c|c|c|c|c|}
\hline $\begin{array}{l}\text { System } \\
\text { Run No. }\end{array}$ & $\begin{array}{l}\text { Total Time } \\
\text { Illuminated, min. }\end{array}$ & $\begin{array}{l}\% \text { Present } \\
\text { chl a }\end{array}$ & $\begin{array}{l}\text { After } \\
\text { al chl }\end{array}$ & $\begin{array}{l}\text { Illumination } \\
a \text { al ph a }\end{array}$ & $\begin{array}{l}\text { Other }^{a} \\
\text { Products }\end{array}$ & $\begin{array}{c}\text { Average } \% \text { Decrease } \\
\text { chl a Per Minute }\end{array}$ \\
\hline $\begin{array}{l}\operatorname{ch} 1 \mathrm{a}, \mathrm{bz} \\
\mathrm{Pl}\end{array}$ & $\begin{array}{r}5 \\
10 \\
20 \\
30\end{array}$ & $\begin{array}{l}62.0 \\
41.5 \\
25.4 \\
15.9\end{array}$ & $\begin{array}{l}11.0 \\
15.9 \\
19.0 \\
20.6\end{array}$ & $\begin{array}{r}4.8 \\
9.5 \\
11.0 \\
12.8\end{array}$ & $\begin{array}{l}22.2 \\
33.3 \\
44.6 \\
50.7\end{array}$ & 10.6 \\
\hline $\begin{array}{l}\operatorname{chl} \\
\mathrm{P} 2\end{array}$ & $\begin{array}{r}5 \\
10 \\
20\end{array}$ & $\begin{array}{l}57.5 \\
38.0 \\
18.2\end{array}$ & $\begin{array}{l}10.6 \\
=7.2 \\
19.7\end{array}$ & $\begin{array}{r}7.6 \\
10.6 \\
18.2\end{array}$ & $\begin{array}{l}24.3 \\
30.2 \\
43.9\end{array}$ & 11.1 \\
\hline $\begin{array}{l}\text { chl } \\
\text { P3 }\end{array}$ & $\begin{array}{r}5 \\
15 \\
25\end{array}$ & $\begin{array}{l}66.0 \\
34.1 \\
22.7\end{array}$ & $\begin{array}{l}11.4 \\
10.2 \\
10.2\end{array}$ & $\begin{array}{l}10.2 \\
11.4 \\
14.8\end{array}$ & $\begin{array}{l}12.4 \\
44.3 \\
52.3\end{array}$ & 8.0 \\
\hline
\end{tabular}

$a_{\text {This }}$ refers to products not absorbing, or only weakly absorbing, in the visible that result from photochemical destruction of the chlorin ring. 


\section{Table 25}

Photobleaching Behavior at High light Intensities. Solvents Different than Benzene

\begin{tabular}{|c|c|c|c|c|c|c|c|}
\hline $\begin{array}{l}\text { System } \\
\text { Run No. }\end{array}$ & $\begin{array}{l}\text { Total Tine } \\
\text { Illuminated } \\
\text { Min. }\end{array}$ & $\begin{array}{l}\% \text { Dec } \\
\mathrm{d}_{\mathrm{R}}\end{array}$ & $\begin{array}{l}\text { se Peak } \\
d_{0}\end{array}$ & $\underset{d_{B}}{O p t i c a l}$ & $\begin{array}{r}\text { Dansities } \\
d_{B S}^{b}\end{array}$ & $d_{()}$ & $\begin{array}{c}\text { Average }{ }^{\prime} \text { Decrease } \\
\text { in } \mathrm{d}_{\mathrm{R}} \\
\text { Per Min. }\end{array}$ \\
\hline $\begin{array}{l}\mathrm{chl} a, \mathrm{E} \\
\mathrm{P} 4 \\
\mathrm{P} 4 \mathrm{I}\end{array}$ & $\begin{array}{r}5 \\
10 \\
15 \\
15\end{array}$ & $\begin{array}{r}8.2 \\
16.7 \\
21.5 \\
21.2\end{array}$ & $\begin{array}{l}7.2 \\
12.5 \\
16.4 \\
17.1\end{array}$ & $\begin{array}{r}8.7 \\
17.2 \\
21.7 \\
21.9\end{array}$ & $\begin{array}{r}7.5 \\
15.9 \\
20.3 \\
19.6\end{array}$ & & 1.6 \\
\hline $\begin{array}{l}\text { Chl a, py } \\
\text { P5 }\end{array}$ & $\begin{array}{l}5 \\
10 \\
15\end{array}$ & $\begin{array}{r}8.8 \\
25.6 \\
37.4\end{array}$ & $\begin{array}{r}5.7 \\
15.0 \\
25.4\end{array}$ & $\begin{array}{r}9.1 \\
24.6 \\
35.6\end{array}$ & $\begin{array}{r}4.5 \\
14.4 \\
23.0\end{array}$ & & 2.9 \\
\hline$\frac{\mathrm{al}}{\mathrm{P} 6} \operatorname{chl} \mathrm{a}, \mathrm{py}$ & $\begin{array}{r}5 \\
10 \\
20 \\
30\end{array}$ & $\begin{array}{r}8.7 \\
13.6 \\
23.1 \\
31.1\end{array}$ & $\begin{array}{r}7.5 \\
7.7 \\
23.8 \\
20.0\end{array}$ & $\begin{array}{r}8.1 \\
12.2 \\
21.3 \\
28.0\end{array}$ & $\begin{array}{r}4.7 \\
9.1 \\
17.2 \\
20.4\end{array}$ & & 1.3 \\
\hline ph a, py & & & & & & $\left(G_{1}\right)$ & \\
\hline$P 8^{\prime}$ & $\begin{array}{r}5 \\
15 \\
35 \\
65 \\
65\end{array}$ & $\begin{array}{r}1.7 \\
4.6 \\
7.5 \\
15.1 \\
18.8\end{array}$ & $\begin{array}{r}2.4 \\
6.0 \\
9.6 \\
18.1 \\
26.5\end{array}$ & $\begin{array}{r}1.4 \\
3.1 \\
5.3 \\
9.1 \\
10.4\end{array}$ & & $\begin{array}{r}-1.2 \\
2.3 \\
8.1 \\
10.5 \\
17.4\end{array}$ & 0.27 \\
\hline
\end{tabular}


Table 25 (Contd.)

\begin{tabular}{|c|c|c|c|c|c|c|c|}
\hline $\begin{array}{l}\text { System } \\
\text { Run No. }\end{array}$ & $\begin{array}{l}\text { Total Time } \\
\text { Illuminated } \\
\text { Min. }\end{array}$ & $\begin{array}{c}\% \text { Decr } \\
d_{R}\end{array}$ & $\begin{array}{c}\text { ease Peak } \\
d_{0}\end{array}$ & $\underset{d_{B}}{\text { Optical I }}$ & $\underset{d_{B S}}{\text { Densities }^{b}}$ & ${ }^{2}()$ & $\begin{array}{c}\text { Average \% Decrease } \\
\text { in } d_{R} \\
\text { Per Min. }\end{array}$ \\
\hline ph & $\begin{array}{r}5 \\
15 \\
35 \\
65 \\
65 \\
95\end{array}$ & $\begin{array}{c}(663.9) \\
5.7 \\
16.8 \\
35.8 \\
69.2 \\
71.4 \\
86.0\end{array}$ & $\begin{array}{c}(433.9) \\
2.0 \\
-1.0 \\
-15.6 \\
-30.5 \\
-29.5 \\
-29.1\end{array}$ & $\begin{array}{c}(423.5) \\
2.9 \\
6.4 \\
13.8 \\
30.8 \\
30.8 \\
33.5\end{array}$ & $\begin{array}{c}(397.5) \\
2.0 \\
6.4 \\
12.7 \\
31.7 \\
32.2 \\
43.9\end{array}$ & & 1.5 \\
\hline ph a, $\mathrm{EHCl} \mathrm{H}_{2} \mathrm{O}$ & & $(666.0)$ & $(435.0)$ & $(415.0)$ & $(395.0)$ & & \\
\hline PIO & $\begin{array}{r}5 \\
15 \\
25\end{array}$ & $\begin{array}{l}7.9 \\
40.0 \\
59.3\end{array}$ & $\begin{array}{l}-12.9 \\
-31.9 \\
-102\end{array}$ & $\begin{array}{r}5.3 \\
21.7 \\
30.9\end{array}$ & $\begin{array}{r}4.9 \\
23.1 \\
34.7\end{array}$ & & 2.8 \\
\hline $\begin{array}{l}\text { al ph } \\
\text { PII }\end{array}$ & 65 & 3.1 & & 1.5 & & & 0.048 \\
\hline $\begin{array}{l}\text { al ph a, py } \\
\text { P12 }\end{array}$ & $\begin{array}{r}5 \\
15 \\
35\end{array}$ & $\begin{array}{l}1.7 \\
4.0 \\
7.4\end{array}$ & $\begin{array}{l}0 \\
0 \\
0\end{array}$ & $\begin{array}{l}2.1 \\
3.8 \\
6.5\end{array}$ & $\begin{array}{l}\left(G_{1}\right) \\
0 \\
0 \\
0\end{array}$ & $\begin{array}{r}\left(G_{2}\right) \\
6.1 \\
10.2 \\
14.3\end{array}$ & 0.25 \\
\hline $\begin{array}{l}\text { al ph a, EHCl } \\
\text { P13 } \\
\text { P13, }\end{array}$ & $\begin{array}{l}5 \\
10 \\
10 \\
30\end{array}$ & $\begin{array}{l}11.0 \\
14.5 \\
18.6 \\
28.3\end{array}$ & $\begin{array}{l}0 \\
3.1 \\
25.0 \\
21.9\end{array}$ & $\begin{array}{r}8.3 \\
11.4 \\
14.4 \\
22.4\end{array}$ & & & 1.2 \\
\hline
\end{tabular}


Table 25 (Contd.)

\begin{tabular}{|c|c|c|c|c|c|c|c|}
\hline $\begin{array}{l}\text { Sys tem } \\
\text { Run No. }\end{array}$ & $\begin{array}{l}\text { Total Time } \\
\text { Illuminated } \\
\text { Min. }\end{array}$ & $\begin{array}{c}\% \text { Decr } \\
d_{R}\end{array}$ & $\begin{array}{c}\text { ease Peak } \\
d_{0}\end{array}$ & $\underset{d_{B}}{\text { Optical I }}$ & $\begin{array}{r}\text { Densities } \\
d_{B S}\end{array}$ & $d()$ & $\begin{array}{c}\text { Average } \% \text { Decrease } \\
\text { in } \mathrm{d}_{R} \\
\text { Per Min. }\end{array}$ \\
\hline $\begin{array}{l}\operatorname{chl} b, E \\
\text { P21 } \\
\text { P21. }\end{array}$ & $\begin{array}{l}5 \\
10 \\
15 \\
15 \\
26\end{array}$ & $\begin{array}{r}5.0 \\
11.0 \\
16.0 \\
16.2 \\
26.6\end{array}$ & $\begin{array}{c}0 \\
0 \\
-1.1 \\
8.9 \\
25.6\end{array}$ & $\begin{array}{r}6.1 \\
11.7 \\
17.5 \\
17.1 \\
27.2\end{array}$ & $\begin{array}{r}6.1 \\
11.3 \\
16.3 \\
15.9 \\
25.4\end{array}$ & & 1.1 \\
\hline $\operatorname{chl} \underline{b}, p y$ & & & & & & $\left(G_{1}\right)$ & \\
\hline P15 & $\begin{array}{r}5 \\
10 \\
15\end{array}$ & $\begin{array}{r}4.7 \\
15.7 \\
25.3\end{array}$ & $\begin{array}{l}0 \\
3.8 \\
8.7\end{array}$ & $\begin{array}{l}11.1 \\
27.4 \\
39.2\end{array}$ & $\begin{array}{r}4.3 \\
9.1 \\
14.2\end{array}$ & $\begin{array}{l}0 \\
0 \\
0\end{array}$ & 1.9 \\
\hline $\begin{array}{l}\text { ph b, E } \\
\text { P22 }\end{array}$ & 50 & 0.7 & & 0.8 & & & 0.014 \\
\hline${ }_{\mathrm{P} 17}^{\mathrm{ph}} \underline{\mathrm{b}}, \mathrm{py}$ & $\begin{array}{r}5 \\
15 \\
35 \\
65\end{array}$ & $\begin{array}{l}0 \\
0.9 \\
2.9 \\
7.2\end{array}$ & $\begin{array}{l}0 \\
1.2 \\
1.2 \\
2.0\end{array}$ & $\begin{array}{l}1.3 \\
2.7 \\
3.8 \\
5.8\end{array}$ & $\begin{array}{l}0.6 \\
3.3 \\
4.5 \\
4.5\end{array}$ & $\begin{array}{l}(G) \\
-3.6 \\
-2.5 \\
-2.4 \\
1.2\end{array}$ & 0.08 \\
\hline $\begin{array}{l}\mathrm{ph} \\
\mathrm{PI} \mathrm{b}^{-}\end{array}$ & $\begin{array}{l}5 \\
10 \\
15 \\
20 \\
30\end{array}$ & $\begin{array}{c}(652.5) \\
11.7 \\
29.9 \\
48.7 \\
68.0 \\
82.0\end{array}$ & $\begin{array}{c}(582.5) \\
-9.4 \\
-30.1 \\
-49.0 \\
-60.1 \\
2.4\end{array}$ & $\begin{array}{c}(432.5) \\
5.5 \\
12.6 \\
20.7 \\
31.0 \\
41.7\end{array}$ & $\begin{array}{c}(442.5) \\
-4.7 \\
-12.1 \\
-20.0 \\
-23.7 \\
6.1\end{array}$ & $\begin{array}{c}(412.5) \\
0 \\
9.4 \\
13.8 \\
21.8 \\
31.7\end{array}$ & 3.2 \\
\hline
\end{tabular}


Table 25 (Contd.)

\begin{tabular}{|c|c|c|c|c|c|c|c|}
\hline $\begin{array}{l}\text { System } \\
\text { Run No. }\end{array}$ & $\begin{array}{l}\text { Total Time } \\
\text { Illuminated } \\
\text { Min. }\end{array}$ & $\begin{array}{c}\% \text { Decr } \\
d_{R}\end{array}$ & $\begin{array}{c}\text { ease Peak } \\
d_{0}\end{array}$ & $\underset{B}{\text { Optical }}$ & $\begin{array}{r}\text { Densities } \\
{ }_{\mathrm{BS}}^{\mathrm{b}}\end{array}$ & $\mathrm{d}()$ & $\begin{array}{c}\text { Average } \% \text { Decrease } \\
\text { in } \mathrm{d}_{\mathrm{R}} \\
\text { Per Min. }\end{array}$ \\
\hline P18' & $\begin{array}{l}30 \\
40 \\
50\end{array}$ & $\begin{array}{l}83.8 \\
83.8 \\
86.3\end{array}$ & $\begin{array}{r}9.4 \\
16.5 \\
34.1\end{array}$ & $\begin{array}{l}43.9 \\
49.3 \\
53.6\end{array}$ & $\begin{array}{l}12.5 \\
23.5 \\
32.5\end{array}$ & $\begin{array}{l}34.0 \\
40.5 \\
44.2\end{array}$ & \\
\hline $\mathrm{ph} \underline{\mathrm{b}}, \mathrm{EHCl} \mathrm{H}_{2} \mathrm{O}$ & & $(653.9)$ & $(598.0)$ & $(432.7)$ & $(445.0)$ & $(412.0)$ & \\
\hline $\begin{array}{l}\text { P19 } \\
\text { P19' }\end{array}$ & $\begin{array}{r}5 \\
15 \\
35 \\
35 \\
65\end{array}$ & $\begin{array}{r}2.7 \\
4.6 \\
19.8 \\
27.0 \\
61.2\end{array}$ & $\begin{array}{c}0 \\
0 \\
3.5 \\
10.5 \\
21.0\end{array}$ & $\begin{array}{r}0.7 \\
1.6 \\
6.9 \\
14.0 \\
33.8\end{array}$ & $\begin{array}{l}0.7 \\
0 \\
-6.0 \\
0 \\
6.5\end{array}$ & $\begin{array}{r}0.8 \\
1.2 \\
4.1 \\
9.8 \\
23.3\end{array}$ & 0.82 \\
\hline
\end{tabular}

a prine ouperscript in the run designation signifies that, after a period of about 10 hours in the dark at $20^{\circ} \mathrm{C}$, the spectrum of the solution was again measured.

$b_{A}$ minus sign for the recorded \% change means an increase of the band peak optical density. Numbers or symbols given in parentheses refer to band position wavelength or band at which the change in optical density was determined. 
deviations for these runs was \pm 21 per cent. The deviations for tests, where rather rapid dark reactions were occurring ( $P 13$, P17, P18, and P19) were significantly greater. The average was \pm 50 per cent.

In Table 26 are given the apparent quantum yields in the initial periods of photobleaching. The absolute uncertainty in the values may be as great as \pm 50 per cent. The relative uncertainty for intercomparison of different tests is estimated to be \pm 15 per cont or less. The quantum yields of the chlorophylis reported in Table 26 appear to be from 1.25 - to 38 -fold greater than those reported in the literature (for example, reference [2], pp. 497, 1494). The major discrepancy is for the non-polar $\mathrm{CCl}_{4}$ solutions. In $\mathrm{CCl}_{4}$ the presence of polar impurities such as water results in s:gnificant decreases in quantum yield. There is agieement with past work that quantum yields in polar solvents are significantly less than in nonpolar solventa.

Comparison of the testa in Table 24 shows the following points of interest. Within experimental error, the rate of photodecomposition of $\operatorname{chl}$ a was the same for excitation in the blue $\left(P_{2}\right)$ and in the red $\left(P_{1}\right.$ and $\left.P_{3}\right)$ absorption regions. As shown in Table 26 the initial quantum yielde were identical. $A$ large excess of $\mathrm{CO}_{2}$ in benzene appeared to have no effect on the photochemical changes. Destruction of the chlorin ring was the main photochemical reaction. Significant amounts of al chl a were also formed. It appeared that this compound 


\section{Table 26}

Apparent Quantum Yield in the Initial Period of Photoconversion

\begin{tabular}{|c|c|c|c|}
\hline \multirow{2}{*}{ System, Run No. } & \multirow{2}{*}{$\begin{array}{c}\text { Average Number of Quanta } \\
\text { Absorbed Per Second in the } \\
\text { First } 5 \text { Minute Photoactiva- } \\
\text { tion Period } \times 10^{-16}\end{array}$} & \multicolumn{2}{|c|}{ Total No. Molecules Converted } \\
\hline & & Average Total & $\begin{array}{l}\text { No. Quanta Absorbed } \\
\times 10^{3}\end{array}$ \\
\hline $\operatorname{chl}$ a, $\mathrm{CCl}_{4}-\mathrm{H}_{2} \mathrm{O}, \mathrm{P} 23$ & & & 3.2 \\
\hline $\operatorname{chl} a, \mathrm{CCl}_{4}-\mathrm{D}, \mathrm{P} 24$ & & & 9.6 \\
\hline $\operatorname{chl} a, b z-D, P 25$ & & & 2.0 \\
\hline $\operatorname{chl} a, \beta$ Car., bz $-\mathrm{D}, \mathrm{P} 26$ & & & 0.91 \\
\hline $\operatorname{ch} 1 \mathrm{a}, \mathrm{bz}, \mathrm{PI}$ & 1.0 & & 1.9 \\
\hline $\operatorname{chl} a, b z .$, Sat'd $\mathrm{CO}_{2}, \mathrm{P} 2$ & 1.1 & & 2.0 \\
\hline $\operatorname{chl} a, b z$, sat'd $\mathrm{CO}_{2}, \mathrm{P3}$ & 1.2 & & 2.0 \\
\hline $\operatorname{chl} a, E, P 4$ & 12.1 & & 0.062 \\
\hline chl a, py, P5 & 13.2 & & 0.062 \\
\hline al $\operatorname{chl} a, p y, P 6$ & 6.6 & & 0.063 \\
\hline $\operatorname{ph} \underline{a}, E$ & 9.6 & & 0.000 \\
\hline ph $\mathrm{a}, \mathrm{py}, \mathrm{P8}$ & 8.0 & & 0.017 \\
\hline $\mathrm{ph} \underline{a}, \mathrm{EHC1}, \mathrm{P9}$ & 8.9 & & 0.052 \\
\hline $\mathrm{ph}$ a, EHCl $\mathrm{H}_{2} \mathrm{O}, \mathrm{P} 10$ & 4.1 & & 0.16 \\
\hline al ph a, E, P1l & 4.7 & & 0.000 \\
\hline al ph $\underline{\mathrm{a}}, \mathrm{py}, \mathrm{P} 12$ & 5.7 & & 0.013 \\
\hline
\end{tabular}


Table 26 (Contd.)

\begin{tabular}{|c|c|c|c|}
\hline \multirow{2}{*}{ System, Run No. ${ }^{2}$} & \multirow{2}{*}{$\begin{array}{l}\text { Average Number of Quanta } \\
\text { Absorbed Per Second in the } \\
\text { First } 5 \text { Minute Photoactiva- } \\
\text { tion Period } \times 10^{-16}\end{array}$} & \multicolumn{2}{|c|}{ Total No. Molecules Converted } \\
\hline & & Average Total & $\begin{array}{l}\text { No. Quanta Absorbed } \\
\times 10^{3}\end{array}$ \\
\hline al ph a, $\mathrm{EHCl}, \mathrm{Pl3}$ & 4.6 & & 0.11 \\
\hline $\operatorname{chl} \underline{b}, E, P 21$ & 12.5 & & 0.030 \\
\hline chl b, py, P15 & 14.7 & & 0.026 \\
\hline ph $\underline{b}, E, P 22$ & 9.8 & & 0.000 \\
\hline ph b, py, P17 & 9.7 & & 0.011 \\
\hline ph $\underline{b}, \mathrm{EHCl}, \mathrm{PI} 8$ & 9.4 & & 0.10 \\
\hline $\mathrm{ph} \underline{\mathrm{b}}, \mathrm{EHCl} \mathrm{H}_{2} \mathrm{O}, \mathrm{PI} 9$ & 9.4 & & 0.023 \\
\hline
\end{tabular}

The first four runs tabulated, namely P23, P24, P25, and P26 rere lon light intensity tests. The apparent quantum yields are for time periods of 180 minutes for the first two runs, and 190 minutes for the latter tro runs. 
underwent a partial decomposition to al ph a. No ph a appeared to be formed in the testing periods.

Intercomparison of the results in Tables 24 and 25 shows the following relationships between the rates. For comparison between runs the rates are changed by factors that make the initial number of quanta absorbed for each system the same. The adjusted average rates are given in parentheses after the abbreviated designation of the system:

$$
\begin{gathered}
\text { ChI } \varepsilon, \mathrm{bz}(10.6) \gg \operatorname{chl} \text { a, } \mathrm{py}(0.22) \approx \mathrm{al} \operatorname{chl} \text { a, } \\
\operatorname{py}(0.20)>\operatorname{chl} \mathrm{a}, \mathrm{E}(0.13)
\end{gathered}
$$

The more polar solvents clearly provicied for greater photostability of chl a. This is consistent with the results on the relative cheinical stability of chl a in polar solvents. In the chl a, E system there appeared to be considerably less amounts of products formed that absorbed in the visible. For chl a, py and al chl a, py the blue satellite bands decreased significantly less than the blue and the red bands, and the orange bands decreased significantly less than the red bands. The former type of behavior, which has also been observed in past work (for example, reference [2], pp. 497-98), wight be expected where allonerization and/or pheophytinization had occurred photochemically. For both chl a and al chl a the red half widths increased with photobleaching, which is good evidence that mixtures of chlorin derivatives were being formed. The predominant direction of increase was toward the red; this is what 
would be expected for the formation of al ph a. There is evidence from past work that pheophytinization can be promoted by photoactivation (for example, reference [2], p. 493). The relatively sinall decreases of tine orange bands could have been due to formation of phycobilin type compounds absorbing in that region. This behavior is similar to that observed for the low light intensity tests.

$$
\begin{gathered}
\mathrm{Ph} \text { a, } \operatorname{EHCl}(3.3) \approx \mathrm{ph} \text { a, } \operatorname{IHClH}_{2} \mathrm{O}(2.8)>\mathrm{ph} \text { a, } \\
\mathrm{PY}(0.52) \gg \mathrm{ph} \text { a, } \mathrm{E}(0.00)
\end{gathered}
$$

Salt formation of ph a greatly incrcased the rate of photodecomposition, making it comparable to that of chl a in ether, ph a, EHCl $(2.0) \sim \operatorname{chl}$ a, $E(1.6)$. The ph a salt gave a photodecomposition product that absorbed strongly, with apparently only one main band, in the blus-green region. As suggested for chl a and chl $\underline{b}$ this nay have been a phycobilin type compound. Thile ph a in pyridine photculeached more rapidly than in ether, the rate was considerably lees than that of chl a or al chl a in pyridine, chl a, py (2.9) $\approx$ el chl a, py(2.6)> ph a, py $(0.44)$. Except in the final photobleaching period, all bands of $\mathrm{ph}$ a in pyridien decreased the same amount within experimental error. If a phycobilin type derivatives was formed, it underwent rapid decomposition to give products that did not absorb in the visible.

NI ph a, $\operatorname{EHCl}(1.2)>$ al ph a, py $(0.20)>$ al ph a,

$$
E(0.047)
$$


Salt formation of al ph a resulted in an increased rate of photobleaching like ph $a$, however less amounts of product absorbing in the visible were formed. The product absorbed primarily in the orange and yellow regions. If it was a phycobilin type derivative, it was clearly different than the one formed from ph a. The decomposition rates of al ph a and ph $\underline{a}$ in both EHCI and pyridine were comparable, al ph $\operatorname{EHCl}(1.2) \approx$ ph a, EHCl $(0.77)$, al ph a, py $(0.25)=$ ph a, py $(0.19)$. Photodecomposition of al ph a in pyridine, in contrast to ph $a$, resulted in formation of small amounts of a product absorbing in the orange and yellow regions. This product may have been similar to the one formed from al ph a in the EHCl solvent.

$$
\begin{gathered}
\text { Chl a, } \operatorname{py}(2.7)>\operatorname{chl} \text { a, } \mathrm{E}(1.6) \approx \mathrm{chl} \underline{\mathrm{b}}, \\
\operatorname{py}(1.56)>\operatorname{chl} \underline{\mathrm{b}}, \mathrm{E}(1.07)
\end{gathered}
$$

Photodecomposition of chl b in ether gave rise to significant amounts of a product absorbing in the orange region, in contrast to chl a in this solvent. The product may have been a phycobilin type compound similar to that formed from chl b in benzene solutions. If a similar product was formed from chl a in ether, it was clearly less stable than that from chl b. It is to be noted that the product formed from chl b underwent fairly rapid decomposition in the dark. In pyridine, products absorbing in the visible were forwed from both chl a and chl $\underline{b}$. Chl $b$ in py showed behavior like chl a. The blue satellite band peak decreased less than the blue band peak, the orange band decreased 
less than the red band, and the increase of the red band half width was predominantly toward the red. This behavior, similar to that for chl a, indicated that allomerized pheophytin $\underline{b}$ and a phycobilin type of derivative might have been formed photochemically.

$$
\begin{gathered}
\mathrm{Ph} \underline{\mathrm{b}}, \operatorname{EHCl}(3.2)>\mathrm{ph} \underline{\mathrm{b}}, \mathrm{EHClH}_{2} \mathrm{O}(0.82)>\mathrm{ph} \underline{\mathrm{b}}, \\
\operatorname{py}(0.073)>\mathrm{ph} \underline{\mathrm{b}}, \mathrm{E}(0.013)
\end{gathered}
$$

Salt formation of ph $\underline{b}$, similar to ph a and al ph $a$, resulted in an increased rate of photodecomposition that was comparable to $\operatorname{chl}$ b, $\operatorname{chl} \mathrm{b}, \mathrm{E}(0.83) \approx \mathrm{ph} \underline{\mathrm{b}}, \mathrm{EHClH}_{2} \mathrm{O}(0.82)$. The ph b salt, like the ph a salt, gave rise to a product with one main band absorbing strongly in the blue green region. The effect was greatest in the FHCl solvent. The product formed from the ph $\underline{\mathrm{b}}$ salt was apparently much less stable photochemically and chemically than the ose formed from the ph a salt. All the pheophytin salts had roughly the same rates, ph b. EHCl $(1.6)>$ al ph a, EHCl (1.2) > ph a, EHCl $(0.77)$. The increase in rate of photodecomposition of ph $b$ in pyridine over ether was relatively less than the increase for ph a, ph a, py $(0.27)>$ ph $\underline{b}$, $\mathrm{py}(0.066)>\mathrm{ph} \underline{\mathrm{b}}, \mathrm{E}(0.01 \mathrm{I})>\mathrm{ph} \underline{\mathrm{a}}, \mathrm{E}(0.00)$. The rate of $\mathrm{ph} \underline{\mathrm{b}}$ relative to chl b in pyridine was significantly smaller than for the corresponding a compounds, chl b, py(1.25)> ph b, py(0.03). Photodecomposition of ph $\underline{b}$, in pyridine, like al ph $a$ 
gave ribe to a product absorbing in the orange, yellow, and green regions that, similarly, may have been a phycobilin type derivative. 


\section{SUMMARY}

The results, which were reproducible and found to be internally consistent, are in general agreement with past work (for example, reference [2], $\mathrm{pp} .400,495)$. They have shown that, for maintaining intact pigments, it is desirable to exclude dissolved oxygen ${ }^{\dagger}$ and to use dim, diffuse green light (that is not strongly absorbed) when preparing and working with solutions of the chlorophylls and their intact ring derivatives. This is particularly true for the magnesium containing derivatives in non-polar solvents, and for solutions of the pheophytin salts. Allowing the pigments to beccine dry, in the amorphous form, results in rapid degradation even under essentially inert atmosfheres.

Folar solvents provide for greater photochemical stability against oxidative processes for the chlorophylls than inert solvents such as benzene, carbon tetrachloride, and cyclohexane. With the exception of basic organic solvents, polar solvents also provide for greater chemical stability. It seems likely that the protective action arises from specific solvating

tThere is evidence in past work (for example, reference [2], pp. 486,501) that, when there is no dissolved oxygen, and if ultraviolet and violet light are excluded, chlorophyll does not undergo photodecomposition in acetone and methanol solutions. 
interactions. Such interactions could be effective either through displacement of specifically associated oxygen, or steric hinderance of the interaction of oxygen, or through electronic inductive effects that increased, the potential barrier in the first step in an oxidative attack. In the latter case specific interactions at the magnesium atom and the cyclopentanone ring would be expected to be of grentest importance. In the case of the inert solvents, such as benzene or $\mathrm{CCl}_{4}$, specific interactions at ihese sites vould be unlikely, since their interactions would be limited largely to dispersion interactions, and in addition, for benzene, weak $\pi$-electron charge transfer interactions.

In either inert or pclar solvents the apparent quantum yield of irreversible photobleaching is quite small. Several types of mecharisms have been put forward to explain this (for example, refererce [2], pp. 499, 501, 1493). In the first type of mechanisin, it is postulated that electronic excitation of chlorophyll leads essentially to the forination of a longlived activated state of the chlorophyll. The chlorophyll in this state reacts with molecular oxygen in an almost completely reversible manner, yielding only small anounts of irreversibly oxidized chlorophyll. In the second instance, it is sugeested essentially that excitation of the chlorophyll results primarily in a photosensitized oxidation of solvent molecules. In view of the facts that rather extensive photodecomposition occurred when relatively small amounts of dissolved oxygen was present, 
and that the rate of irreversible photobleaching reaches a maximum at relatively small concentrations $\left(-1 \times 10^{-5} \mathrm{M}\right)$ of dissolved oxygen (reference [2], p. 1493), mechanisms of the first type secm more plausible.

The use of pyriaine as a solvent (containing traces of water and dissolved oxygen) resulted in rather rapid chemical reaction of chl $\underline{b}, \mathrm{ph} \underline{a}$, and $\mathrm{ph} \underline{\mathrm{b}}$. $\operatorname{Chl} \mathrm{e}$, in the presence of pyridine, reacted much more slowly. The reactions in every case appeared to involve prinarily oxidative alteration of the cyclopentanone ring. Al chl a and al ph a were stable in pyridine. These results are in agreement with past work on the effect of basic organis solvents (for example, reference [2], pp. 1730-1781, 1799-1801, 1804). It has been suggested that the primary reaction, with primary or secondary amines, is cleavage of the cyclopenterche ring between the 9 and 10 carbon atoms with a hydrogen atom being added in the 10 position and the amide residue in the 9 position (reference [2], pp. 1780-1781).

Comparing the change of photochemical stabilities in going from ether to pyridine, the pheophytins showed greater increases $(-5$ - fold $)$ in rates of decomposition than the chlorophylls $(\sim 1.5$ - fold). The absolute rates of the pheophytins, however, were significantly smaller than those of the chlorophylls and al chl a. Past work has shown that pyridine forms solvates with the chlorophylls, the allonerized chlorophylls, and the pheophytins (roference [2], p. 1803). The fact that the 
solvating interactions had greater perturbing effects on the pheophytins indicates that the mode of solvation was different for the pheophytins than for the compounds with the central magnesium atom. It has been suggested for the muiallo-porphyrin derivatives that the pyridine, acting as an electron donor, interacts with the vacant orbitals of the central metal atom [56]. Such an interaction would not be pcssible for the pheophytins.

The proophytins in all solvents were much more photochemically stakle than the chlorophylls and al chl a. When converted to the salt form, with audition of protons to the center of the ring, their photochemical stability decreased to that of the chlorophylls. Salt formation, lowever, did not appear to jecrease chemical stability in contrast to complexation with pyridine. The marked differences in behavior of the magnesiun-containing compounds and the pheophytin salts on the one hand, and the free pheophytin bases on the other hand are clearly related to the differences in perturbing effects of the substituents of the center of the chlorin ring. The differences in the perturbing effects of pyridine on $\mathrm{ph} a$ and $\mathrm{ph} b$ compared to that of salf formation, suggests that the former effect was relatively greater on the ground electronic state, while the latter effect was relatively greater on the excited state. Alteration of the substituent pattern of the isocyclic ring has significantly less effect on photochemical behavior. Thus, chl a and al chI a decomposed at about the same rates in 
pyridine, and the rates of al ph $\underline{a}$ and ph a were comparable in that solvent. The corresponding salts underwent about the same rate of plotodecomposition in ether.

Three types of decomposition products were encountered. The first type were intact chlorin ring compounds that absorbed strongly in the red and blue regions, characteristically of the chlorins. These compouncis spprared to be mostly allomerized, or allomerized pheophytin derivatives. The second type of product abscrbed stroncly, with apparently one main band, in the orange, yellow, or blue-green regicis where the usual derivatives of the chlorophylls have bands of relatively low intensity. It was suggested that these products may have been phycobilin type compounds, which can have fairly extensive conjugated double bond systems and are known to absorb in the visible. Compounds of this type, which are themselves chemically and photochemicaliy unstable, could be $f$,rmed by the oxidative rupture of a bond at one of the methine bridges of the intact chlorin ring. The third type of product did not absorb at all, or at least only very weakly, in the visible. These products must have had relatively short conjugated double bond systems. They would be formed by extensive oxidative break up of the chlorin ring, probably starting from a phycobilin type derivative.

The chemical stability of the ph a and ph b salts in ethyl ether in contrast to the fairly rapid dark decomposition in pyridine bears some parallel to the stability properties of 
the pheophytin monolayers. On low pH substrates both ph $\underline{\text { a and }}$ ph b monolayers displayed fienificantly greater chemical stability than on high pH substrates. At high pH's or in pyridine solutions, faixly rapid decomposition occurred that appeared to involve primarily oxidative altere ion of the cyclopentenone ring. 
APPENDIX B

VISIBLE ABSORPTIOY SPICTRA OF THE CHLOROPHYLLS AND SEVERAL DERIVATIVES IN VARIOUS SOLVENTS 


\section{INTRODUCTION}

Some of the results of the apectroscopic measurements have been discussed above in connection with characterization of the compounds and evaluation of their absolute purity. Since it was found that the samples of this work were of high purity, it was of interest to determine their spectra in a number of common solvents. The data obtained are useful for characterization of the compounds in different solvents, and provide information of value for the eventual detailed interpretation of the spectra. Thile the data are limited in scope, they give insight into the problems that appear to exift in the present theoretical interpretation, and reveal interesting variations in solvent effects for the different coupounds.

It has been suggested (reference [2], p. 646) that determination of the integrated oscillator (f) and dipole (D) strengths would be of value in characterizing band intensity changes occurring with variation of solvent. The integrated intensities are also of value in characterizing substituent effects particularly for the low intensity bands where band halfwidths can not be determined. $†$ 'Consequently these values were

${ }^{\dagger} \mathrm{s}$ a rough approxination $f$ values can be calculated from band half-widths and molar extinction coefficients [267. 
obtained for number of the systems studied. It does not appear that these quantities have been determined before for most of the systems studied in this work.

In recent years J.R. Platt [57] and later M. Gouterman [53], [59], [60] have put forward interpretations of the porphyrin spectra which have had good qualitative success with the more simply substituted compounds. The chlorophylls and their intact ring derivatives (which are actually chlorins ${ }^{\dagger}$ ) represent very complexly substituted porphyrins and continue to present difficulties in the detailed interpretation of their spectra. Problens may reside not only in the possibility that the substituent effects are not independent of each other, but also in the possibility that transitions polarized along different axes in the chlorin ring are not independent of each other $[53]$.

The essential features of the interpretations are as follows. Because the porphyrin rine is planar, with the conjugated $\pi$-electron system extended in two dimensions, electronic transitions can occur along two different, mutually perpendicular axes in the plane of the ring. Where substitution patterns are identical along each axis, the transitions are degenerate. Differences in substituent pattern remove the degeneracy. The absorption bands extending from the red through the green region

tReduction in one of the pyrrole rings (i.e. hydrogenation of the 7-8 double bond) is treated as a substituent perturbation $[58]$. 
of the spectrum are assigned to two nearly degenerate electronic transitions, along the two different axes in the molecule, that are weak in intensity because of the large change in electronic angular momentum on transition. The occurrence of more than two bands is ascribed to the fact that vibrational sub-bands can be associated with each transition. Four distinct bands are usually found in the spectra of the porphyrins with simple substituent patterns. Change of substituent pattern will result in variations in band intensities, and changes in the relative positions of the bands. Some specific predictions are mentioned subsequently and compared with experimental findings. Because of the near degeneracy of the transitions and the presence of vibrational sub-bands, it is suggested that rather complicated interdigitation of the bands can occur with some loss of individual band identity. Such overlapping might be expected for the low intensity bands in the orange through green region of the spectrum.

The bands in the blue and violet region of the spectrum are assigned to two nearly degenerate electronic transitions, along the two different axes, that have high intensity because of the small change in electronic angular momentum on transition. No specific assignments have been made for the bands in the ultraviolet. These bands do not show as clearly defined 
structure as those in the visible. ${ }^{\dagger}$. The assigned electronic transitions are considered to be singlet-singlet $\pi-\pi$ transitions; $n-\pi$ transitions are too weak in intensity and charge transfer transitions have been considered to be too high in energy to lie in the visible and near ultraviolet regions.

Study of the effect of change of solvent on the positions and intensities of the various bands might be expected to provide some insight as to which bands are related in direction of polarization. For example, related vibrational bands belonging to the same transition should experience nearly the same perturbation in a given solvent, so that variations in position and intensity should be very similar with change of solvent. If, for a given solvent, specific effects were predominant along a given axis, then it is possible that, with change of solvent, the transitions in the upper and lower energy systems polarized along that axis would both show larger (or smaller) variations in relation to those transitions polarized along a different axis. Thus, the orders of sizes of band changes, with change of solvent, might reveal relationships in regards to direction of polarization. If solvent effects were not specific, or if transitions polarized along different axes were not independent, ${ }^{+}+$the effect of change of solvent might not be significantly

It has been suggested that the blurring of structure can arise from the great speed $\left(-0.3 \times 10^{-13}\right.$ sec.) of the radiationless transitions between higher excited states, which can produce an uncertainty or diffuseness in the region of absorption between bands (reference [57], p. 88).

ttIt has been suggested [587 that some substituents can cause interaction between differently polarized transitions and thus render them dependent. 
different for bands of different polerization. If bands belonging to different transitions overlapped extensively, broadness and lack of symmetry in the mutual regions of absorption would be expected, and determination of jaak positions would be uncertain. A change of solvent might reveal such a complication by differential variations of band positions in the overlap region. 
RESULTS AND DISCUSSION

The results of the measurements are given in Tables 27, $29,30,32,33$, and 36 . Determinations were made on $1.0 \times 10^{-5} \mathrm{M}$ solutions at $25^{\circ} \mathrm{C}$. The systems studied were as follows:

1) chl a-thyl ether $(E)$, 2) chl a-acetone (Ac),

3) chl a-methanol (MeOH), 4) chl a-l $1 / 2$ volume per cent pyridine in low boiling $\left(30^{\circ}-60^{\circ} \mathrm{C}\right)$ petroleum ether ( $11 / 2$ percent py-pet), 5) chl a-pyridine (py), 6) chl a-dry, pure benzene (bz-D), 7) chl a-pure benzene with $\geq 10^{-5} \mathrm{M}$ water $\left.\left(\mathrm{bz}-\mathrm{H}_{2} \mathrm{O}\right), 8\right) \operatorname{chl}$ a-dry, pure carbon tetrachloride $\left.\left(\mathrm{CCl}_{4}-\mathrm{D}\right), 9\right) \mathrm{chl}$ a-pure carbon tetrachloride with $\geq 10^{-5}$ water $\left(\mathrm{CCl}_{4}-\mathrm{H}_{2} \mathrm{O}\right)$, 10) chl a-dry, pure cyclohexane (cyclo-D), II) chl a-pure cyclohexane with about $10^{-5} \mathrm{M}$ water $\left.\left(\mathrm{cyclo}-\mathrm{H}_{2} \mathrm{O}\right), 12\right) \mathrm{chl}$ a-pure, dry cyclohexane with from $10^{-6}$ to $10^{-5} \mathrm{M}$ benzene $\left(\right.$ cyclo-D + bz), $\left.{ }^{\dagger} 13\right) \mathrm{chl}$ a-pure cyclohexane with about $10^{-5} \mathrm{M}$ water and from $10^{-6} \mathrm{M}$ to $10^{-5} \mathrm{M}$ benzene $\left(\right.$ cyclo- $\left.\left.\mathrm{H}_{2} \mathrm{O}+\mathrm{bz}\right),{ }^{+}{ }_{14}\right) \mathrm{chl}$ b-ethyl ether, 15) chl bacetone, 16) chI b-pyridine, 17) chl b-dry, pure benzene, 18) $\operatorname{chl}$ b-pure benzene with $\left.\geq 10^{-5} \mathrm{M} \mathrm{H}_{2} \mathrm{O}, 19\right)$ al chl a-ethyl ether, 20) al chl a-pyridine, 21) al chl a-dry pure benzene,

TIncrease of the concentration of the benzene in these cyclohexane solutions up to 0.2 volume per cent effected no further change in the spectra. 
22) al chl a-pure benzene with $\geq 10^{-5}$ water, 23) ph a-ethyl ether, 24) ph a-pyridine, 25) ph a-benzene with $\geq 10^{-5} \mathrm{M}$ water, ${ }^{+}$ 26) ph a-ethyl ether saturated with dry HCl gas (HHCl), 27) al ph a-ethyl ether, 28) al ph a-pyridine, 29) al ph a-pure benzene with $\geq 10^{-5} \mathrm{M}$ water, 30) al ph a-ethyl ether saturated with dry HCl gas, 31) ph b-ethyl ether, 32) ph b-pyridine, and 33) ph b-ethyl ether saturated with dry $\mathrm{HCl}$ gas. Intercomparisons of corresponding bands of the different systems are given in Tables 28, 31, 34, and 35.

\section{Table 27}

The estimated probable errors in detesmination of the band peak positions given in Table 27 are as follows:

1) far red $\left.(F R) \cdots \pm 30 \mathrm{cmll}^{-1}, 2\right)$ red $(\Omega)- - \pm 15 \mathrm{~cm}^{-1}, 3$ ) orange $\left(\mathrm{O}_{1}\right.$ and 0$\left.)-\cdots \pm 16 \mathrm{~cm}^{-1}, 4\right)$ yellow $\left.(\mathrm{Y})- - \pm 18 \mathrm{~cm}^{-1}, 5\right)$ first green $\left.\left(G_{1}\right)- - \pm 19 \mathrm{~cm}^{-1}, 6\right)$ second green $\left(G_{2}\right)-\cdots \pm 20 \mathrm{~cm}^{-1}$, 7) third green $\left.\left(G_{3}\right)-\cdots \pm 2 I \mathrm{~cm}^{-I}, 3\right)$ blue $(B)-\cdots \pm 24 \mathrm{~cm}^{-1}$, 9) blue satellite (BS) $-- \pm 51 \mathrm{cn}^{-1}$, and 10) the ultraviolet binds $\left(\mathrm{UV}_{1}, \mathrm{WV}, \mathrm{UV}_{3}\right.$, and $\left.\mathrm{WV}_{4}\right) \cdots \pm 34 \mathrm{~cm}^{-1}$. In general determination of band peals positions was unambiguous, even where band overlap created asymetry in band shapes. Although changes of band-overlap were encountered, it seems unlikely that spurious

tPheophytin a was also studied in dry, pure benzene. The visible absorption spectrum was essentially identical to that in wet benzene, in contrast to the changes occurring with the magnesium containing compounds. This observation is consistent with the findings in past work (e.e. reference [2], pp. 648, 772). 
Table 27

Band Peak Wavelengths and Wave Numbers of the Chlorophylls and Several Derivatives in Various Solvents

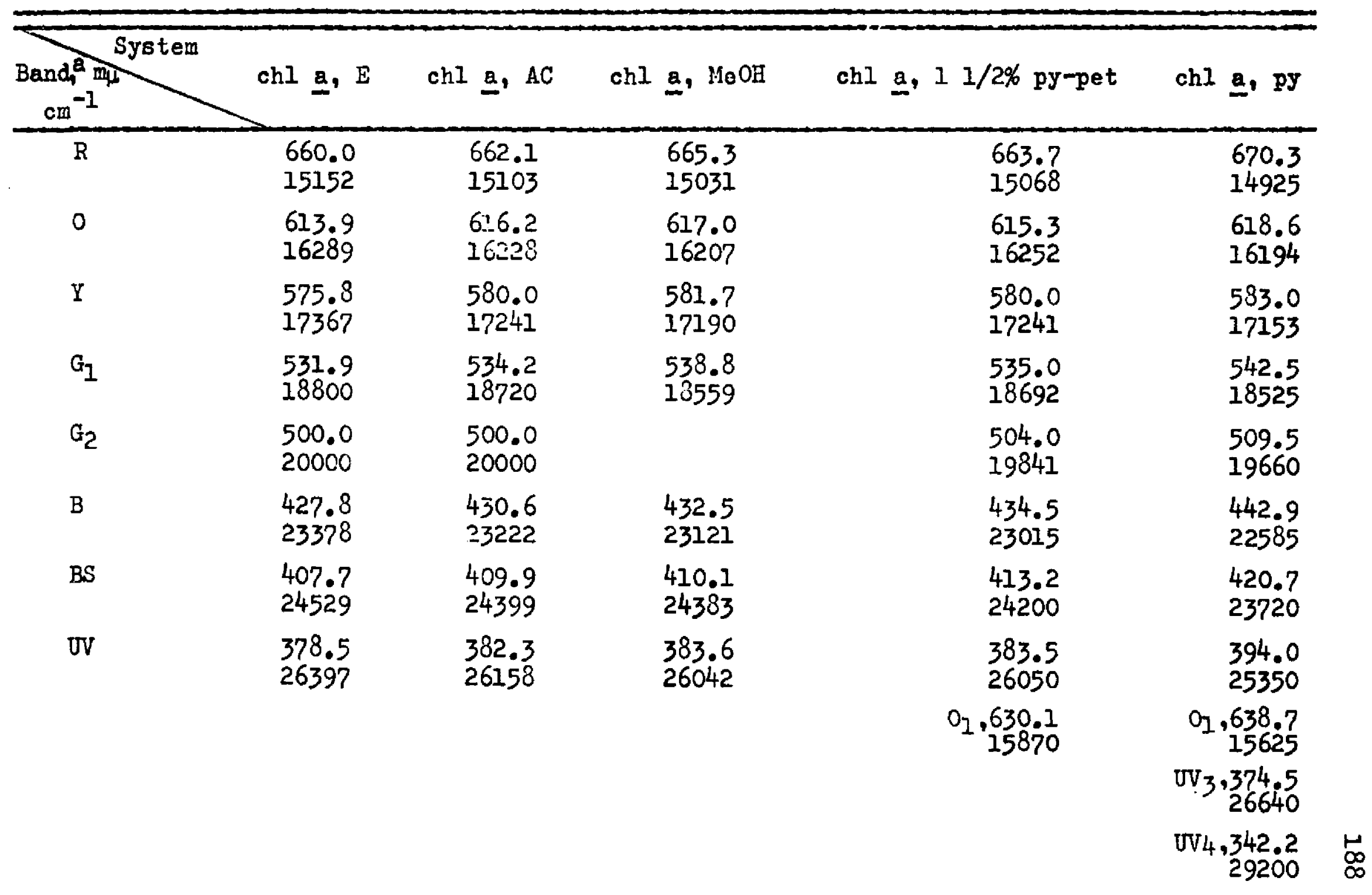


Table 27 (Contd.)

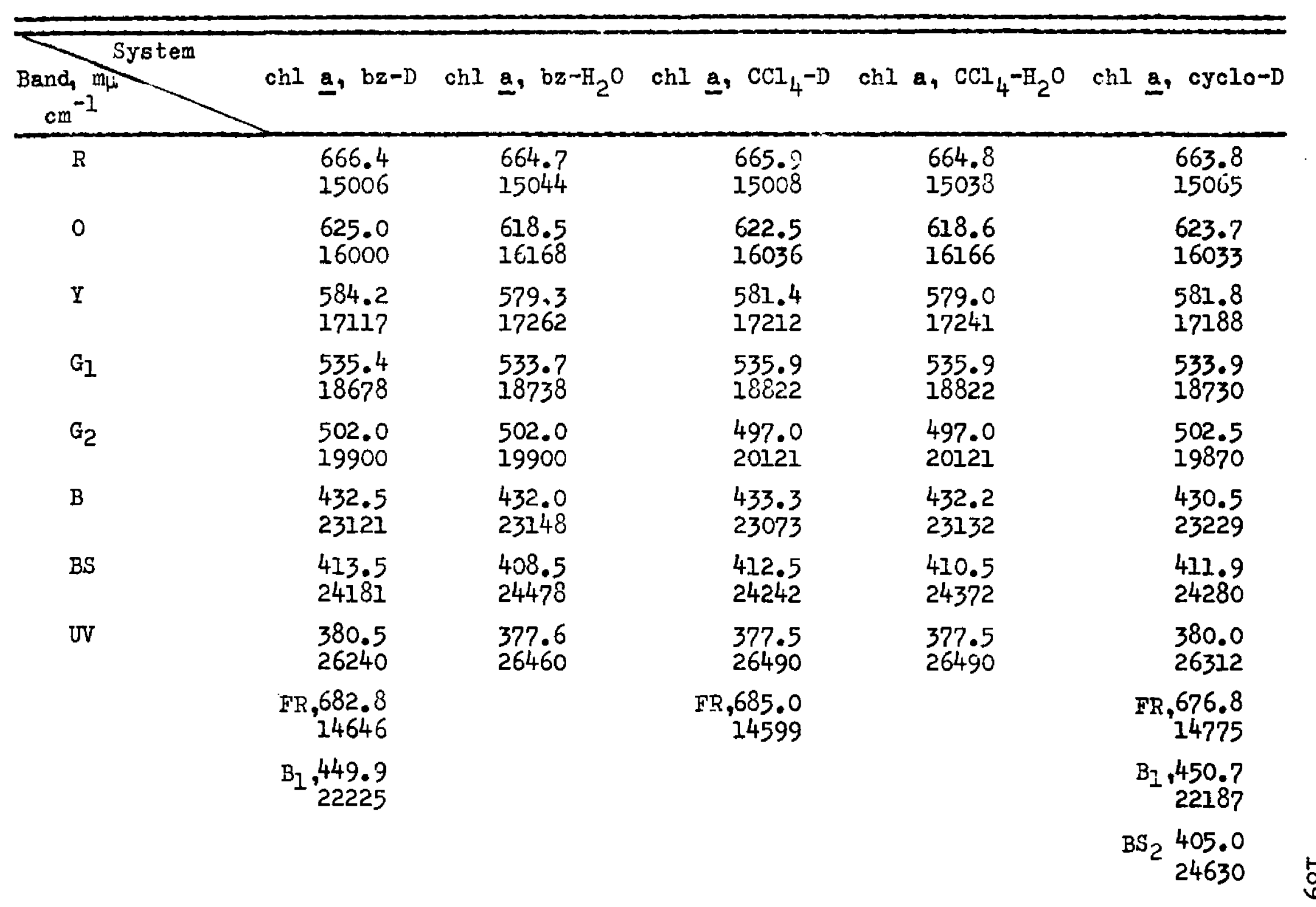


Table 27 (Contd.)

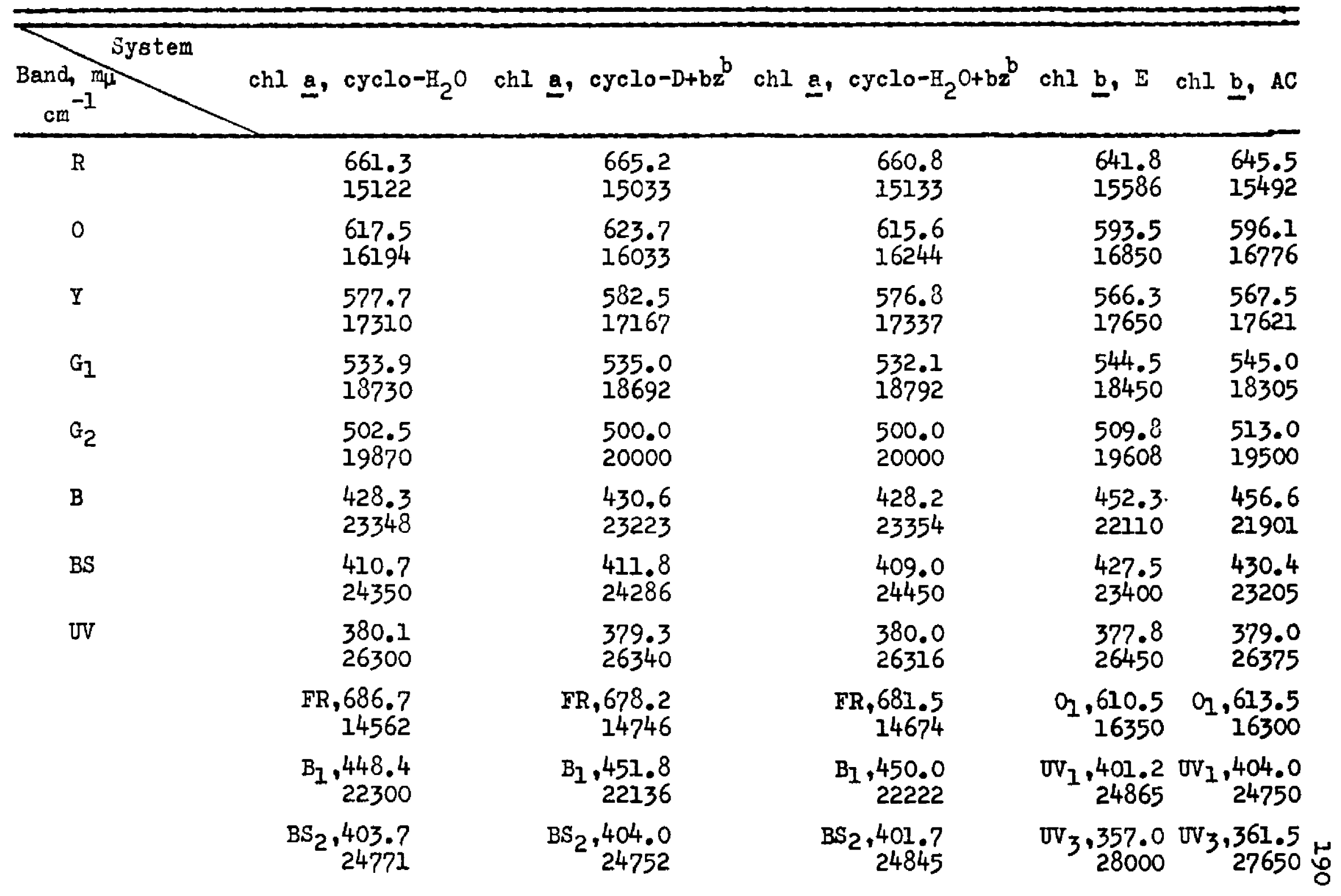


Table 27 (Contd.)

\begin{tabular}{|c|c|c|c|c|c|}
\hline $\mathrm{cm}^{-1}$ & $\mathrm{chl} \underline{\mathrm{b}}, \mathrm{py}$ & $\operatorname{chl} \underline{b}, b z-D$ & $\operatorname{chl} \underline{b}, b z-H_{2} \mathrm{O}$ & al chl $a, E$ & al chl a, py \\
\hline $\mathrm{R}$ & $\begin{array}{l}655.2 \\
15265\end{array}$ & $\begin{array}{l}646.3 \\
15473\end{array}$ & $\begin{array}{l}646.2 \\
15475\end{array}$ & $\begin{array}{l}653.0 \\
15315\end{array}$ & $\begin{array}{l}661.1 \\
15126\end{array}$ \\
\hline 0 & $\begin{array}{l}603.3 \\
16565\end{array}$ & $\begin{array}{l}601.1 \\
16636\end{array}$ & $\begin{array}{l}597.5 \\
16736\end{array}$ & $\begin{array}{l}608.3 \\
16425\end{array}$ & $\begin{array}{l}622.0 \\
16077\end{array}$ \\
\hline$\Psi$ & & $\begin{array}{l}570.0 \\
17544\end{array}$ & $\begin{array}{l}568.6 \\
17588\end{array}$ & $\begin{array}{l}566.6 \\
17675\end{array}$ & $\begin{array}{l}585.0 \\
17065\end{array}$ \\
\hline$G_{1}$ & $\begin{array}{l}557.1 \\
17930\end{array}$ & $\begin{array}{l}548.9 \\
18218\end{array}$ & $\begin{array}{l}546.8 \\
18288\end{array}$ & $\begin{array}{l}523.1 \\
29100\end{array}$ & $\begin{array}{l}538.0 \\
18587\end{array}$ \\
\hline$G_{2}$ & $\begin{array}{l}515.0 \\
19420\end{array}$ & $\begin{array}{l}503.8 \\
i 9850\end{array}$ & $\begin{array}{l}503.8 \\
19850\end{array}$ & $\begin{array}{l}488.9 \\
20+40\end{array}$ & $\begin{array}{l}505.0 \\
19802\end{array}$ \\
\hline B & $\begin{array}{l}474.0 \\
21195\end{array}$ & $\begin{array}{l}459.5 \\
21763\end{array}$ & $\begin{array}{l}457.9 \\
21839\end{array}$ & $\begin{array}{l}417.0 \\
23985\end{array}$ & $\begin{array}{l}430.0 \\
23256\end{array}$ \\
\hline BS & $\begin{array}{l}445.4 \\
22450\end{array}$ & $\begin{array}{l}431.2 \\
23192\end{array}$ & $\begin{array}{l}430.1 \\
23250\end{array}$ & $\begin{array}{l}387.5 \\
25800\end{array}$ & $\begin{array}{l}404.5 \\
24691\end{array}$ \\
\hline \multirow[t]{3}{*}{ UV } & $\begin{array}{l}389.8 \\
25625\end{array}$ & $\begin{array}{l}383.5 \\
26062\end{array}$ & $\begin{array}{l}382.5 \\
26160\end{array}$ & $\begin{array}{l}363.5 \\
27485\end{array}$ & $\begin{array}{l}370.0 \\
27000\end{array}$ \\
\hline & $\begin{array}{r}\mathrm{wV}_{1}, 417.0 \\
23975\end{array}$ & $\begin{array}{r}\mathrm{FR}, 665.5 \\
15025\end{array}$ & $\begin{array}{r}0_{1}, 614.6 \\
16271\end{array}$ & $\begin{array}{r}\mathrm{uv}_{3}, 353.5 \\
28290\end{array}$ & \\
\hline & $\begin{array}{r}\mathrm{w}_{3}, 372.3 \\
26825 \\
\mathrm{wV}_{4}, 347.0 \\
28800\end{array}$ & $\begin{array}{r}0_{1}, 615.4 \\
16250 \\
B_{1}, 485.0 \\
20600 \\
\mathrm{wV}_{3}, 367.5 \\
27211\end{array}$ & $\begin{array}{r}\mathrm{UV}_{1}, 405.5 \\
24700 \\
\mathrm{UV}_{3}, 363.5 \\
27499\end{array}$ & & \\
\hline
\end{tabular}


Table 27 (Contd.)

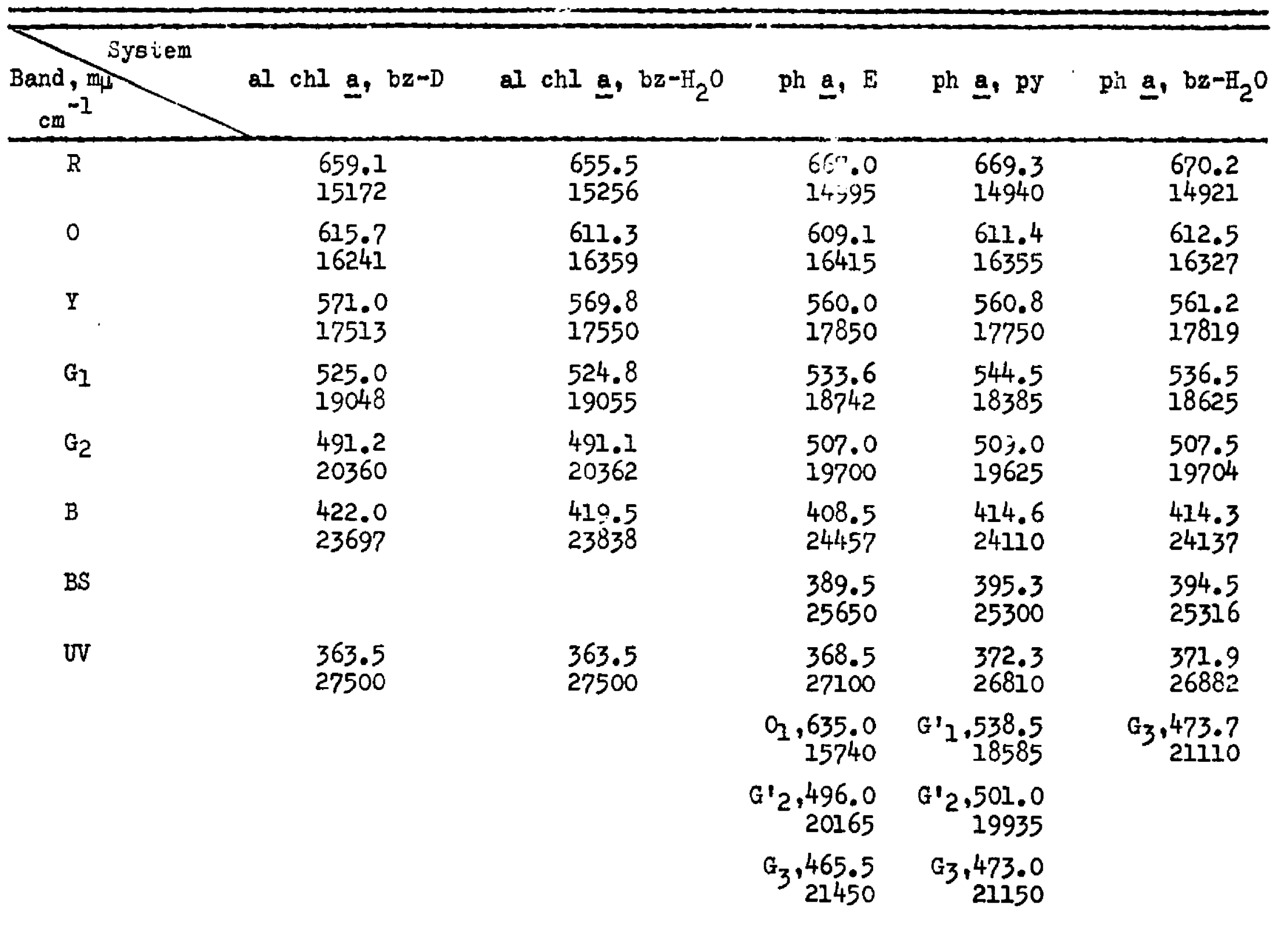


Table 27 (Contd.)

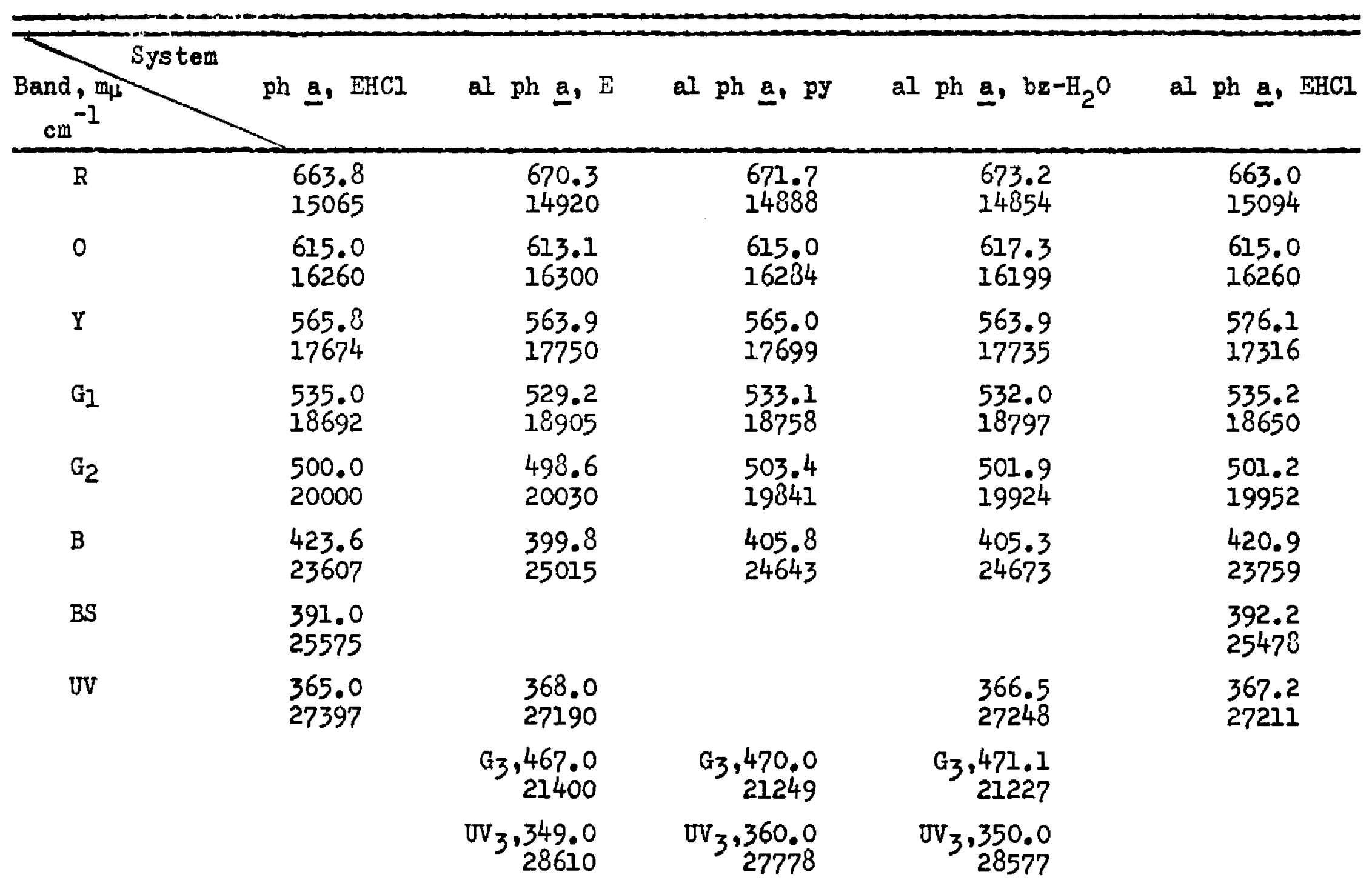


Table 27 (Contd.)

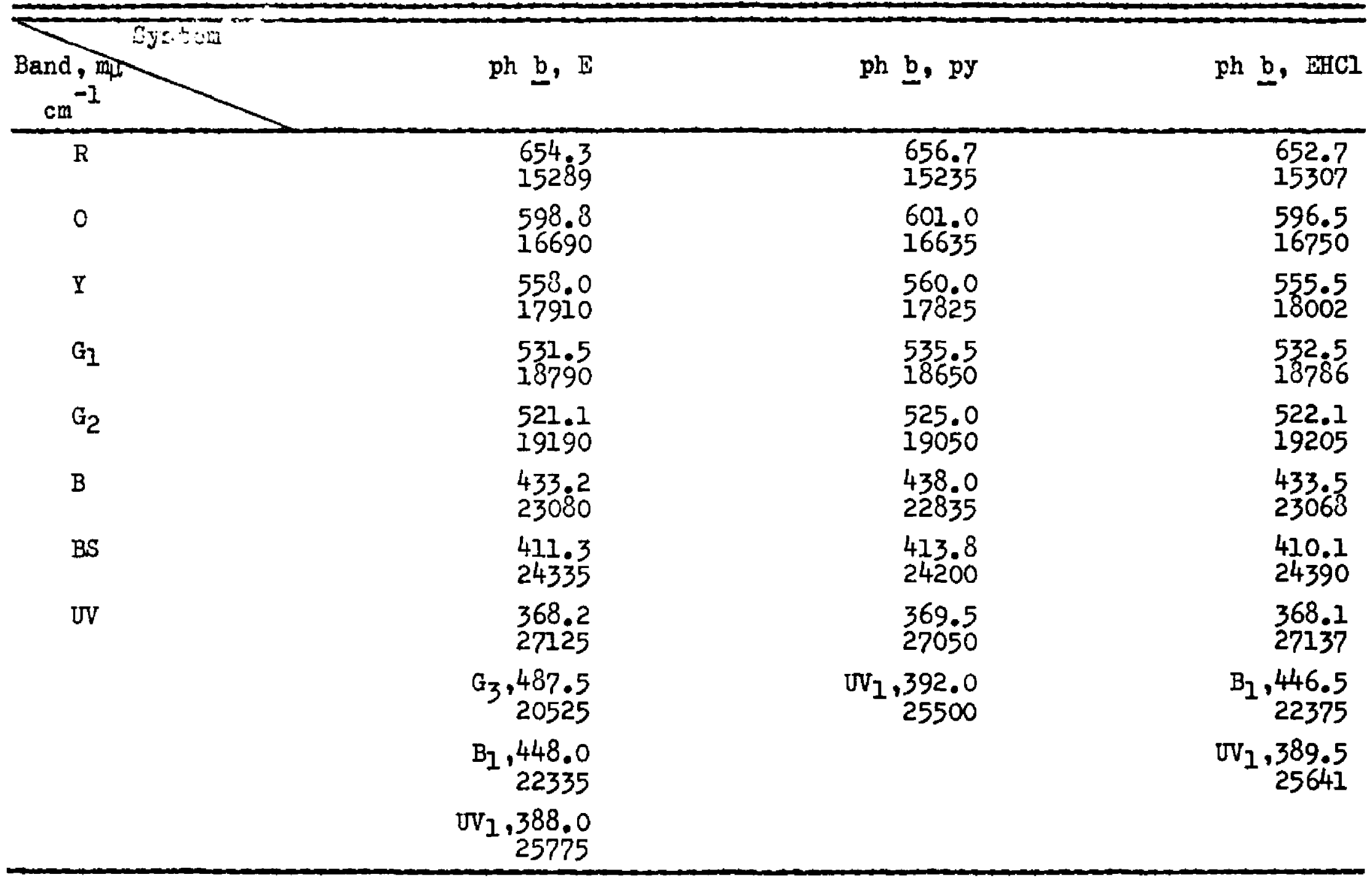

additional bands, present in some systems, are tabulated after the UV band, and designated by the letter preceding the wavelength value.

bery small amounts $\left(1.0 \times 10^{-6}\right.$ to $\left.2.0 \times 10^{-5} \mathrm{M}\right)$ of pure, dry benzene were added to 
identification of band positions were made. Thus it did not appear that the problem of complex interdigitation of oands was encountered where band identity was lost.

Most of the systems studied showed at least five distinct bands $\left(R, O, Y, G_{1}, G_{2}\right)$ in the red through the green region of the spectruin, and at least three bands $(B, B S$, UV) in the blue through the near ultraviolet region. Variations occurred as a result of change of solvent and change of substitupat pattern. For chl a the following major variations in the structure of the spectrun were observed with change of solvent. In methanol all bands were broadened and the peak position of the $G_{2}$ band becaine uncertain. Pyridine caused a splitting of the $O$ band and gave increased structure in the near ultraviolet region. In dry, nonpolar solvents such as $\mathrm{CCl}_{+}$, benzene, and cyclohexane the $R$ band was eplit, and in the latter two solvents a small protuberance $\left(B_{1}\right)$ was observed on the long wavelength side of the $B$ band. All bands were broadened with some loss of distinctness of structure throughout the spectrum. ${ }^{\dagger}$ It

There is evidence that dimeric aggregation of the chlorophylls can occur in dry, pure nonpolar solvents [61]. Dimeric aggregation can be expected to produce different effects on bands polarized along different axes, and consequently can be viewed as a special type of solvent effect. If the dimer absorbed as a unit, structure in the dry spectra could occur that could not be explained in terms of band overlap of the monomeric unit. The general broadening of all bands accompanied by splitting of the $R$ band, which occurs only in the dry nonpolar solvents, suggestr the possibility that there may be a superposition of the spectrum of the dimer on the perturbed spectrum of the monomer.

Also see--A.F.H. Anderson and II. Calvin, Arch. Biochem. Biophys., 107,251 (1964). 
was still possible to determine peals positions clearly. In cyclohexane the BS band was also split. Addition of water to cyclohexane, in contrast to $\mathrm{CCl}_{4}$ and benzene, did not entirely remove band splitting. The presence of a small amount of benzene in the wet cyclohexane solution did not diminish the residual band splitting. Addition of a small amount of benzene to the dry cyclohexane solution did not change the splitting of the bands, but produced red shifts in the $R, Y$, and $G_{1}$ bands. In the eolvents where band sp? itting of chl a did not occur, and with the exception of methanol, the $O, Y$, and $G$ bands were quite cymmetrical with well defined peaks. In methanol the $O, Y$, and $G$ bands lost symmetry with a resulting lack of definition of minima between bands. In pyridine, in addition to the 0 band splitting, there was loss of symmetry in the $Y$ and $G$ bands. The blurring eifects of pyridine and methanol appeared to arise pritarily from thermal broadening of existing bands, due to the motions of loosely attached solvent molecules (e.g. reference $[57]$, p. 83 ).

Chl b, in contrast to chl a, showed splitting of the 0 band in all solvents studied except in pyridine, and was characterized by more band structure in the UV region. In pyridine the $G_{1}$ band appeared to shift to the extent of completeIy overlapping the $\mathrm{X}$ band. The large red shift effect of pyridine caused the appearance of an additional band in the region of the UV scanned. The effect of dry nonpolar solvents on chl b was very similar to that on $\operatorname{chl}$ a. In acetone, ether, 
and wet benzene, where splitting of the $O$ band was observed, the $Y$ and $G$ bands showed a lack of symmetry. In pyridine the $O$ and $G$ bands were broadened but more symmetrical, while the $R$ band lost shape symmetry on the ehort wavelength side.

No band splitting was observed for al chl. a in the solvents studied. In dry benzeno most bands showed a shift to the red as compared to wet benzene, but there was no splitting of the $R$ band and no snearing out of the spectium as occurred for chl a and chl b. In dry and wet benzene a BS band could not be distinguished. In ether and pyridine the BS band was nanifested by a slight protuberance near the si. ort wavelength side of the main blue band. In wet benzenc and ether the $O, Y$, and $G$ bands of al chl a, like those of chl a, were quite symmetrical in sinape with well defined peaks. In fyridine, however, the synmetry of these bands was reduced.

In ethyl ether, a suatl additional $O$ band could be distinguished for ph a near the $R$ band. This did not resemble the $O$ band splitting obsarved for chl a and chl b. Ph $a$, in comparison to the chlorophylls, had an additional band in the green region, which, however, could not be distinguished in the EHCl solvent. In ether the second green band showed splitting, while both $G_{I}$ and $G_{2}$ were split in pyridine. The $O$ and $Y$ bands of ph a had well defined peak positions but did not show much symmetry in shape. In benzene, where splitting of the $G_{2}$ band could not be defined, there was distinct asymmetry of shape suggesting the close overlapping of two bands. 
AI ph a, like ph a, had a third band in the green region. No band splitting was observed in any of the solvents. A BS band could be distinguished only in the EHCl solvent in which the third green band could not be discerned. In pyrieine and EHCl only one UV band could be distinguished, while two bands were observed in ether and wet benzene. In benzene, ether, and pyridine, the $O$ and $Y$ bands of al ph a were less symmetrical than those of ph a; the G bands, however, showed more symmetry with no evicence of splitting.

$\mathrm{Ph} \mathrm{b}$ showed two UV bands, and a third sreen band which could be distinguished only in ether. The $G_{1}$ and $G_{2}$ bands lay much closer together than in ph $a$ and al ph $\underline{B}$. In ether and EICI, but not in pyridine, there was a protuberance on the long wavelength side of the $B$ band. No band splitting was observed. The $O$ band of ph $\underline{b}$ was quite symmetrical, whereas the $Y$ band, lying rather close to the $G_{1}$, was not.

$\operatorname{Chl} a, \operatorname{chl} \underline{b}$, and al $\operatorname{chl} \underline{a}$, but not ph $\underline{a}$, in the dry nonpolar solvents showed a marked ( $10-f o l d)$ decrease in fluorescence intensity as observed visually. This is consistent with earlier observations in dry nonpolar solvents (reference [2], pp. 766-772). Ph a and al ph a, but not ph $\underline{b}$, in EHCl showed significant decreases in fluorescence intensity.

Table 28

Table 28 shows the change of band peak wave number, and the percentage change with respect to the energy of the 
Table 28

The Change of Band Peak Wave Numbers with Change of Solvent in Reference to Ethyl Ether

\begin{tabular}{|c|c|c|c|c|c|c|c|c|c|}
\hline $\begin{array}{l}\text { Solvent and } \\
\text { Compound } \\
\text { Band } \\
\delta \mathrm{cm}^{-1} \\
\text { Change }\end{array}$ & $\stackrel{\mathrm{AC}}{\mathrm{chl}}$ & $\begin{array}{l}\mathrm{MeOH} \\
\mathrm{chl} \mathrm{a}\end{array}$ & $\begin{array}{l}\text { I 1/2\% } \\
\text { py-pet, } \\
\text { chI a }\end{array}$ & $\begin{array}{c}\text { py, } \\
\text { chl a }\end{array}$ & $\begin{array}{l}b z-D \\
c h l \underline{a}\end{array}$ & $\begin{array}{c}\mathrm{bz}-\mathrm{H}_{2} \mathrm{O}, \\
\mathrm{chl} \text { a }\end{array}$ & $\begin{array}{c}\mathrm{CCl}_{4}-\mathrm{D} \\
\mathrm{chl} \underline{\mathrm{a}}\end{array}$ & $\begin{array}{c}\mathrm{CCl}_{4}-\mathrm{H}_{2} \mathrm{O} \\
\mathrm{chl} \stackrel{a}{a}\end{array}$ & $\begin{array}{c}\text { cyclo-D } \\
\text { chl }\end{array}$ \\
\hline $\mathrm{R}$ & $\begin{array}{r}49 \\
0.32\end{array}$ & $\begin{array}{l}121 \\
0.80\end{array}$ & $\begin{array}{r}84 \\
0.55\end{array}$ & $\begin{array}{r}227 \\
1.50\end{array}$ & $\begin{array}{l}146 \\
0.96\end{array}$ & $\begin{array}{l}108 \\
0.71\end{array}$ & $\begin{array}{r}144 \\
0.95\end{array}$ & $\begin{array}{r}144 \\
0.75\end{array}$ & $\begin{array}{r}87 \\
0.57\end{array}$ \\
\hline 0 & $\begin{array}{r}61 \\
0.37\end{array}$ & $\begin{array}{r}82 \\
0.50\end{array}$ & $\begin{array}{r}37 \\
0.23\end{array}$ & $\begin{array}{r}95 \\
0.58\end{array}$ & $\begin{array}{r}289 \\
1.78\end{array}$ & $\begin{array}{r}121 \\
0.74\end{array}$ & $\begin{array}{r}253 \\
1.56\end{array}$ & $\begin{array}{l}123 \\
0.76\end{array}$ & $\begin{array}{r}256 \\
1.57\end{array}$ \\
\hline$Y$ & $\begin{array}{l}126 \\
0.73\end{array}$ & $\begin{array}{r}177 \\
1.02\end{array}$ & $\begin{array}{l}126 \\
0.73\end{array}$ & $\begin{array}{r}214 \\
1.23\end{array}$ & $\begin{array}{r}250 \\
1.44\end{array}$ & $\begin{array}{r}205 \\
1.18\end{array}$ & $\begin{array}{l}155 \\
0.89\end{array}$ & $\begin{array}{l}126 \\
0.73\end{array}$ & $\begin{array}{r}179 \\
1.03\end{array}$ \\
\hline $\mathrm{G}_{1}$ & $\begin{array}{r}80 \\
0.43\end{array}$ & $\begin{array}{r}241 \\
1.28\end{array}$ & $\begin{array}{l}108 \\
0.56\end{array}$ & $\begin{array}{r}275 \\
1.46\end{array}$ & $\begin{array}{r}122 \\
0.65\end{array}$ & $\begin{array}{r}62 \\
0.33\end{array}$ & $\begin{array}{r}+22 \\
+\quad 0.12\end{array}$ & $\begin{array}{r}+22 \\
+\quad 0.12\end{array}$ & $\begin{array}{r}70 \\
0.37\end{array}$ \\
\hline $\mathrm{G}_{2}$ & $\begin{array}{l}100 \\
0.50\end{array}$ & & $\begin{array}{r}259 \\
1.29\end{array}$ & $\begin{array}{r}440 \\
2.19\end{array}$ & $\begin{array}{c}200 \\
1.0\end{array}$ & $\begin{array}{l}200 \\
1.0\end{array}$ & $\begin{array}{r}+121 \\
+0.61\end{array}$ & $\begin{array}{r}+121 \\
+0.61\end{array}$ & $\begin{array}{r}200 \\
1.00\end{array}$ \\
\hline B & $\begin{array}{r}156 \\
0.67\end{array}$ & $\begin{array}{r}257 \\
1.10\end{array}$ & $\begin{array}{r}363 \\
1.55\end{array}$ & $\begin{array}{r}793 \\
3.40\end{array}$ & $\begin{array}{r}257 \\
1.10\end{array}$ & $\begin{array}{r}230 \\
0.99\end{array}$ & $\begin{array}{r}305 \\
1.31\end{array}$ & $\begin{array}{r}246 \\
1.05\end{array}$ & $\begin{array}{r}149 \\
0.64\end{array}$ \\
\hline BS & $\begin{array}{l}130 \\
0.53\end{array}$ & $\begin{array}{l}146 \\
0.60\end{array}$ & $\begin{array}{r}329 \\
1.34\end{array}$ & $\begin{array}{r}809 \\
3.30\end{array}$ & $\begin{array}{r}348 \\
1.42\end{array}$ & $\begin{array}{l}0 \\
0\end{array}$ & $\begin{array}{r}287 \\
1.17\end{array}$ & $\begin{array}{r}157 \\
0.64\end{array}$ & $\begin{array}{r}249 \\
1.02\end{array}$ \\
\hline UV & $\begin{array}{r}239 \\
0.91\end{array}$ & $\begin{array}{r}355 \\
1.35\end{array}$ & $\begin{array}{r}347 \\
1.32\end{array}$ & $\begin{array}{l}1047 \\
3.96\end{array}$ & $\begin{array}{r}157 \\
0.59\end{array}$ & $\begin{array}{l}0 \\
0\end{array}$ & $\begin{array}{l}0 \\
0\end{array}$ & $\begin{array}{l}0 \\
0\end{array}$ & $\begin{array}{l}0 \\
0\end{array}$ \\
\hline
\end{tabular}


Table 28 (Contd.)

\begin{tabular}{|c|c|c|c|c|c|c|c|c|c|}
\hline 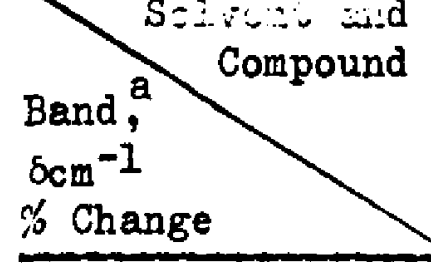 & $\begin{array}{l}\text { cyclo- } \\
\mathrm{H}_{2} \mathrm{O}, \\
\mathrm{chl} a\end{array}$ & $\begin{array}{l}\text { cyclo- } \\
\mathrm{D}+\mathrm{bz} \\
\mathrm{chl} \underline{\mathrm{a}}\end{array}$ & $\begin{array}{c}\text { cyclo- } \\
\mathrm{H}_{2} \mathrm{O}+\mathrm{bz} \\
\mathrm{chl} \underline{\mathrm{a}}\end{array}$ & $\begin{array}{c}\mathrm{AC}, \\
\mathrm{chl} \mathrm{b}\end{array}$ & $\begin{array}{c}\text { py, } \\
\text { chl b }\end{array}$ & $\begin{array}{l}\mathrm{bz}-\mathrm{D}, \\
\mathrm{chl} \underline{\mathrm{b}}\end{array}$ & $\begin{array}{l}\mathrm{bz}-\mathrm{H}_{2} \mathrm{O} \\
\mathrm{chl} \underline{\mathrm{b}}\end{array}$ & $\begin{array}{l}\text { py, } \\
\text { al chl a }\end{array}$ & $\begin{array}{c}\text { bz-D, } \\
\text { al chl a }\end{array}$ \\
\hline$R$ & $\begin{array}{r}30 \\
0.20\end{array}$ & $\begin{array}{r}119 \\
0.79\end{array}$ & $\begin{array}{r}19 \\
0.13\end{array}$ & $\begin{array}{r}94 \\
0.60\end{array}$ & $\begin{array}{r}321 \\
2.06\end{array}$ & $\begin{array}{r}113 \\
0.73\end{array}$ & $\begin{array}{l}111 \\
0.71\end{array}$ & $\begin{array}{r}189 \\
1.23\end{array}$ & $\begin{array}{r}143 \\
0.93\end{array}$ \\
\hline 0 & $\begin{array}{r}95 \\
0.58\end{array}$ & $\begin{array}{r}256 \\
1.57\end{array}$ & $\begin{array}{r}45 \\
0.28\end{array}$ & 0.74 & $\begin{array}{r}285 \\
1.69\end{array}$ & $\begin{array}{r}214 \\
1.27\end{array}$ & $\begin{array}{l}114 \\
0.68\end{array}$ & $\begin{array}{r}348 \\
2.11\end{array}$ & $\begin{array}{r}184 \\
1.12\end{array}$ \\
\hline$Y$ & $\begin{array}{r}57 \\
0.33\end{array}$ & $\begin{array}{r}200 \\
1.15\end{array}$ & $\begin{array}{l}30 \\
0.37\end{array}$ & 0.29 & & $\begin{array}{l}106 \\
0.60\end{array}$ & $\begin{array}{r}62 \\
0.35\end{array}$ & $\begin{array}{r}610 \\
3.46\end{array}$ & $\begin{array}{l}162 \\
0.92\end{array}$ \\
\hline$G_{1}$ & $\begin{array}{r}70 \\
0.37\end{array}$ & $\begin{array}{r}108 \\
0.57\end{array}$ & $\begin{array}{l}0 \\
0\end{array}$ & $\begin{array}{r}145 \\
0.79\end{array}$ & $\begin{array}{r}520 \\
2.82\end{array}$ & $\begin{array}{r}232 \\
1.26\end{array}$ & $\begin{array}{r}162 \\
0.88\end{array}$ & $\begin{array}{r}513 \\
2.68\end{array}$ & $\begin{array}{r}52 \\
0.27\end{array}$ \\
\hline $\mathrm{G}_{2}$ & $\begin{array}{r}200 \\
1.00\end{array}$ & $\begin{array}{r}100 \\
0.50\end{array}$ & $\begin{array}{r}100 \\
0.50\end{array}$ & $\begin{array}{r}108 \\
0.55\end{array}$ & $\begin{array}{r}188 \\
0.96\end{array}$ & $\begin{array}{r}+242 \\
+1.23+\end{array}$ & $\begin{array}{r}+242 \\
+\quad 1.23\end{array}$ & $\begin{array}{r}638 \\
3.11\end{array}$ & $\begin{array}{r}80 \\
0.39\end{array}$ \\
\hline B & $\begin{array}{r}30 \\
0.13\end{array}$ & $\begin{array}{l}155 \\
0.66\end{array}$ & $\begin{array}{l}0 \\
0\end{array}$ & $\begin{array}{l}209 \\
0.95\end{array}$ & $\begin{array}{r}915 \\
4.14\end{array}$ & $\begin{array}{r}347 \\
1.57\end{array}$ & $\begin{array}{r}271 \\
1.23\end{array}$ & $\begin{array}{r}729 \\
3.04\end{array}$ & $\begin{array}{r}288 \\
1.20\end{array}$ \\
\hline BS & $\begin{array}{r}179 \\
0.73\end{array}$ & $\begin{array}{r}243 \\
0.99\end{array}$ & $\begin{array}{r}79 \\
0.32\end{array}$ & $\begin{array}{l}195 \\
0.83\end{array}$ & $\begin{array}{r}950 \\
4.06\end{array}$ & $\begin{array}{r}258 \\
1.10\end{array}$ & $\begin{array}{r}200 \\
0.35\end{array}$ & $\begin{array}{l}1109 \\
4.30\end{array}$ & \\
\hline \multirow[t]{2}{*}{ UV } & $\begin{array}{l}0 \\
0\end{array}$ & $\begin{array}{l}0 \\
0\end{array}$ & $\begin{array}{l}0 \\
0\end{array}$ & $\begin{array}{l}0 \\
0\end{array}$ & $\begin{array}{r}825 \\
3.12\end{array}$ & $\begin{array}{r}388 \\
1.47\end{array}$ & $\begin{array}{r}290 \\
1.10\end{array}$ & $\begin{array}{r}485 \\
1.76\end{array}$ & $\begin{array}{l}0 \\
0\end{array}$ \\
\hline & & & & $\begin{array}{c}01 \\
50 \\
0.31 \\
0 V_{1} \\
115 \\
0.46 \\
0 V_{3} \\
350 \\
1.25\end{array}$ & $\begin{array}{r}\mathrm{wV}_{1} \\
890 \\
3.58 \\
\mathrm{wV}_{3} \\
1175 \\
4.2\end{array}$ & $\begin{array}{r}0_{1} \\
100 \\
0.61 \\
W_{3} \\
789 \\
2.82\end{array}$ & $\begin{array}{c}0_{1} \\
79 \\
0.48 \\
0 V_{1} \\
165 \\
0.66 \\
W_{3} \\
501 \\
1.79\end{array}$ & & \\
\hline
\end{tabular}




\section{Table 28 (Contd.)}

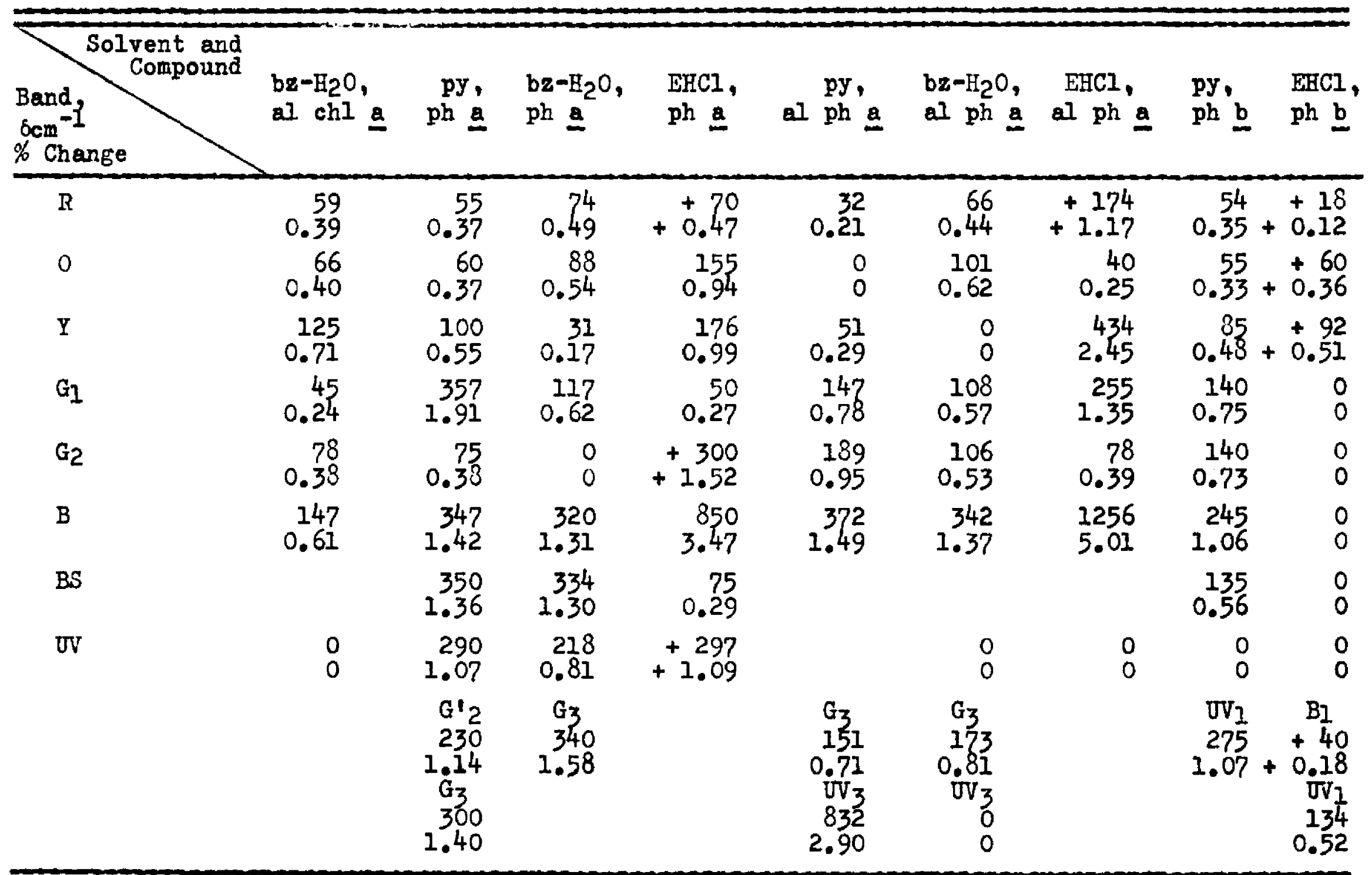

a Changes less than the estimated probable error (see text) are omitted. Changes tabuwithout aign are negative, that is shifts to the red; changes with plus aigns are positive. 
transition, with change of solvent in reference to ethyl ether. Shifts are to the red unless accompanied by a plus sign which signifies a blue shift. Ethyl ether was chosen as reference solvent since it is one of the most commonly used solvents in the study of the chlorophylls and their derivatives. The main red and blue band peaks are at shorter wave lengths than in other solvents, and the red band half-widths $\left(R_{1 / 2}\right)$ and nost of the blue band half-widths $\left(B_{1 / 2}\right)$ are smaller (see Table 32 ). These phenonena indicate that the solvent perturbations in ethyl ether are somewhat less than in the other solvents.

In general, it can be scen that for a given compound the sizes of the individual band shifts change markedly with different solvents. There is no general tendency for any particular band, or group of bands, to show precominantly the largest percentage change, altiough the largest absolute band shifts occur primarily in tine upper energy system. For a given oolvent change, bands at corresponding positions in the spectrum shift differently for each compourd. In pyridine, for example, the bands of the magnesiun containing compounds in general show greater changes than the bands of the corresponding pheophytins. Not only is there a variation in the magnitude of a particular shift, but also the order of the sizes of the shifts changes from system to system. These patterns of variation clearly indicate the occurrence of specific solvent interactions that differ for each system. In general the observed changes support the view that there are bands representing transitions of 
different polarization in both the upper and lower energy Bys tems.

For the chl a, chl $\underline{b}$, and al chl a systems there is no consistent change of the same per cent, within probable error ( $\leq 0.1$ per cent for the $R$ through the $B$ bands, $\leq 0.2$ per cent for the BS band, and $\leq 0.3$ per cent for the UV bands), in any of the neighboring bands, nor in next neighbor bands. Consistently similar changes for two or more bands would be good evidence that those bands were related vibrational sub bands belonging to the same transition.

In comparing the orders of sizes of band shifts in the upper and lower energy systems no consistent relationship between upper and lower bands is apparent. As example for chl a, in many of the instances when the B band shows a larger (or smaller) shift than the BS band, the $R$ band shows a larger (or smaller) shift than the $O$ band. However, this relationship between upper and lower bands is not consistent for all bolvent changes. There remains some uncertainty, therefore, in drawing a conclusion from these data about which bands may be polarized along the same axis. The difficulty may lie in the possibility that a substituent has effect on transitions polarized along different axes. Interaction of a solvent molecule at such a substituent could therefore have significant effects along two axes. Since the electron distributions in the different chlorin orbitals are not expected to be the same [53], the effects produced by a solvent molecule would in general not be identical along each 
axis, and could vary in relative size depending on the specific nature of the interaction.

In contrast to chl $a$, the shifts in the $R$ and $O$ bands and in the $B$ and BS bands for ph a in benzene and pyridine are consistent in size. This raises the possibility that the $R$ and $O$ bands, and the $B$ and $B S$ bands might be related vibrational bands belonging to the same transition. However, the relative variations in intensities, discussed subsequently, do not support this possibility. Moreover the relationship for the $R$ and the $O$ bands is not preserved for al ph a in benzene and pyridine.

In the EHCl solvent the $R$ and the $O$ bands of ph a shift in opposite directions, there is a comparatively large red shift of the $B$ band, and the $G_{1}$ and $G_{2}$ bands shift in opposite directions. The net result is that the positions of the band peaks tend to be close to those of the corresponding bands of chl a in ether. These changes are consistent with the suggestion that salt formation occurs with entry of protons into the center of the chlorin ring. Thus, in EHCl the effect is essentially a change in substituent pattern to one resembling that of chl a. There is a similar, though less close correspondence between the band positions of al ph a in EHCl and those of al chl a in ether. Only the $R$ and $O$ bands of ph $b$ in EHCl shift toward the positions of the corresponding bands of chl $b$ in ether. The overall changes in the spectrum for ph $b$ in EHCl are small compared to those for $\mathrm{ph}$ a and al ph a. This suggests that the 
extent of salt formation was less for ph $\underline{b}$, in the particular solvent used.

For chl a in polar solvents the larger percentage shifts are predominantly in the high energy system. In the more inert solvents, either dry or with traces of water, the low energy bands tend to show the larger shifts, and the UV band consistently shows little or no change. In the dry solvents, the o band consistently shows the largest percentage changes. Pyridine produced the greatest band shifts, while cyclohexane with traces of benzene and water gave the least.

The upper energy bands of chl b consistently show the larger shifts, the greatest being in the $U_{3}$ band. The $O$ band in dry benzene undergoes a significantly larger shift than the $R$ band, which resembles the behavior for chl $a$. The $Y$ band of chl $b$, however, shows a smaller shift than that of chl a. Pyridine produced the largest changes and acetone the least. The order of size of band shifis of al chl a in wet benzene closely resembles that of chl a in the same solvent. The actual size of the shifts for al chl a, hovever, are about one-half those for chl a. There is less correspondence in orders of size for al chl a and chl a in dry benzene and pyridine. In pyridine the $Y$ band of al chl a shows a large shift while the UV band shift is relatively swall. The reverse is true for chl a in pyridine. If the bands of the two compounds, at corresponding points throughout the spectrum, represent transitions with the same polarization in the chlorin ring, then it would appear that 
the differences in effect for a given solvent change must be directly related to the alteration of the isocyclic ring. Thus, alteration of the isocyclic ring may result in change of opecific interactions with it, or change in the interactions with another substituent that is not independent of the isocyclic ring. In the latter case the substituent might be the magnesium atom.

In comparing the effects of a given solvent change for ph a vs al rh a, differences in the sizes of particular band shifts and in the order of sizes are also observed. In pyridine the shifts of the B bands are very similar, but shifts in the lower energy bands and the UV bands differ considerably. In wet benzene, band shifts are more nearly alike, large differences occurring only in the $G_{2}, G_{3}$, and UV band shifts. In EHCl, significant differences exist in all band shifts. The $R, Y, G_{1}$, and $B$ bands of al ph a show larger shifts than in ph a, while the shifts in the $O$ and $G_{2}$ bands of ph a are larger. These results also reflect the influence of the differences in the isocyclic rings of ph $\underline{a}$ and al ph a on solvent effects. The differences in the effects between pyridine and benzene on the one hand, and EHCl on the other sugGest that not only are direct interactions with the isocyclic ringe important, but also that the structure of the isocyclic ring can have significant influence on the substituents in the center of the chlorin ring, and thus on the solvent interactions occurring there. For the pheophytins the B bands consistently show large 
shifts with solvent change, except for ph $b$ in EHCl where all spectral changes were relatively small. The $R, O$, and $Y$ bands undergo relatively smaller shifts, except for the $Y$ band of al ph a in EHCl. The G bancis show rather wide variations in sizes of shifts depending on the solvent and the compound. For a given solvent change, the effects on the bands of the pheophytins are generally smaller than those for the magnesium containing compounds. This suggest that specific solvent interactions at ihe cagnesium atom can occur with relatively strong perturbing effect.

Tables 29, 30, and 31

In Table 29 are given the oscillator strengths (f) and band widths ${ }^{j}$ for the individual bands of a number of the systems studied. The dipole strengths (D) and their square-roots are shown in Table 30 . In Table 31 are given the changes in $f$ and D witin change of solvent with respect to ethyl ether. Changes less than probable error (Ece Table 6) are neglected.

For chl a and al chl a the strengths of the transitions in the lower energy band decreasc consistently in the order $R, O, Y, G_{1}$, and $G_{2}$. For chl $b$ the order of strengths is changed only in that $G_{1}$ precedes $Y$. Where $O$ band splitting occurs, the strengths are about equal for chl a, but not for chl $b$ where the

The numbers tabulated represent the distances between band cut offs which were in many instances well defined minima between bands. Actual band widths, which are larger than distances between cut offs, are obscured by band overlap. 
Oscillator Strengths (f) of the Chlorophylls and Several Derivatives in Various Solvents

\begin{tabular}{|c|c|c|c|c|c|c|}
\hline $\begin{array}{c}\text { Band, } a, b \text { Width System } \\
\left(\mathrm{cm}^{-1}\right)\end{array}$ & $\operatorname{chl} a, E$ & $\operatorname{chl} \stackrel{a}{A C}$ & $\begin{array}{l}\text { chl a, } \\
\text { NeOHr }\end{array}$ & $\operatorname{chl}$ a, I $1 / 2 \%$ py-pet & $\operatorname{chl} \mathrm{a}, \mathrm{py}$ & $\operatorname{chl} \underline{a}, b z-D$ \\
\hline $\mathrm{R}$ & $\begin{array}{r}1627 \\
0.170\end{array}$ & $\begin{array}{l}1613 \\
0.167\end{array}$ & $\begin{array}{r}1987 \\
0.173\end{array}$ & $\begin{array}{l}1595 \\
0.159\end{array}$ & $\begin{array}{r}1475 \\
0.170\end{array}$ & $\begin{array}{r}836 \\
0.116\end{array}$ \\
\hline 0 & $\begin{array}{r}1165 \\
0.049\end{array}$ & $\begin{array}{r}1161 \\
0.055\end{array}$ & $\begin{array}{r}1070 \\
0.062\end{array}$ & $\begin{array}{r}981 \\
0.036\end{array}$ & $\begin{array}{r}795 \\
0.038\end{array}$ & $\begin{array}{r}1192 \\
0.063\end{array}$ \\
\hline$Y$ & $\begin{array}{r}1320 \\
0.027\end{array}$ & $\begin{array}{l}1333 \\
0.031\end{array}$ & $\begin{array}{r}1400 \\
0.032\end{array}$ & $\begin{array}{r}1154 \\
0.018\end{array}$ & $\begin{array}{r}1405 \\
0.022\end{array}$ & $\begin{array}{r}1555 \\
0.035\end{array}$ \\
\hline$G_{1}$ & $\begin{array}{r}1313 \\
0.015\end{array}$ & $\begin{array}{l}1393 \\
0.015\end{array}$ & $\begin{array}{l}2583^{c} \\
0.018\end{array}$ & $\begin{array}{r}1284 \\
0.013\end{array}$ & $\begin{array}{r}1185 \\
0.019\end{array}$ & $\begin{array}{l}2509^{c} \\
0.016\end{array}$ \\
\hline $\mathrm{G}_{1}$ & $\begin{array}{r}1741 \\
0.009\end{array}$ & $\begin{array}{r}1529 \\
0.008\end{array}$ & & $\begin{array}{r}1483 \\
0.008\end{array}$ & $\begin{array}{r}1575 \\
0.009\end{array}$ & \\
\hline B & $\begin{array}{r}2771 \\
0.515\end{array}$ & $\begin{array}{r}2823 \\
0.463\end{array}$ & $\begin{array}{r}2837 \\
0.368\end{array}$ & $\begin{array}{r}2830 \\
0.523\end{array}$ & $\begin{array}{r}2525 \\
0.516\end{array}$ & $\begin{array}{r}1670 \\
0.416\end{array}$ \\
\hline BS & $\begin{array}{r}1590 \\
0.410\end{array}$ & $\begin{array}{l}1627 \\
0.413\end{array}$ & $\begin{array}{r}1550 \\
0.369\end{array}$ & $\begin{array}{r}1700 \\
0.399\end{array}$ & $\begin{array}{r}1435 \\
0.336\end{array}$ & $\begin{array}{r}1755 \\
0.387\end{array}$ \\
\hline
\end{tabular}


Table 29 (Contd.)

\begin{tabular}{|c|c|c|c|c|c|c|}
\hline $\begin{array}{l}\text { Band, },^{a, b} \text { Width } \\
\left(\mathrm{cm}^{-1}\right) \\
f\end{array}$ & $\operatorname{chl}$ a, : & $\operatorname{chl}$ a, $\mathrm{AC}$ & chl a, & chl a, 1 1/2\% py-pet & $\operatorname{chl} \underline{a}, \mathrm{py}$ & $\operatorname{chl} a, b z-D$ \\
\hline \multirow[t]{4}{*}{ UV } & $\begin{array}{r}2861 \\
0.444\end{array}$ & $\begin{array}{r}2957 \\
0.476\end{array}$ & $\begin{array}{r}3351 \\
0.560\end{array}$ & $\begin{array}{r}3046 \\
0.403\end{array}$ & & $\begin{array}{r}2996 \\
0.452\end{array}$ \\
\hline & & & & $\begin{array}{r}0,468 \\
0.023\end{array}$ & $\begin{array}{r}0_{1}, 525 \\
0.035\end{array}$ & $\begin{array}{r}\mathrm{FR}, 1151 \\
0.063\end{array}$ \\
\hline & & & & & $\begin{array}{r}\mathrm{JV}+\mathrm{WV} 3.2740 \\
0.391\end{array}$ & $\begin{array}{r}B_{1}, 1108 \\
0.024\end{array}$ \\
\hline & & & & & $\begin{array}{r}\mathrm{Nr}_{4}, 2653 \\
0.301\end{array}$ & \\
\hline First Cut off $\left(\mathrm{cm}^{-1}\right)$ & 14183 & 14135 & 13793 & 14035 & 13990 & 13699 \\
\hline Last Cut off $\left(\mathrm{cm}^{-1}\right)$ & 28571 & 28571 & 28571 & 28571 & 30303 & 28571 \\
\hline Total f & 1.640 & 1.628 & 1.589 & 1.572 & 1.840 & 1.570 \\
\hline & & & & & $(1.635)$ & \\
\hline
\end{tabular}


Table 29 (Contd.)

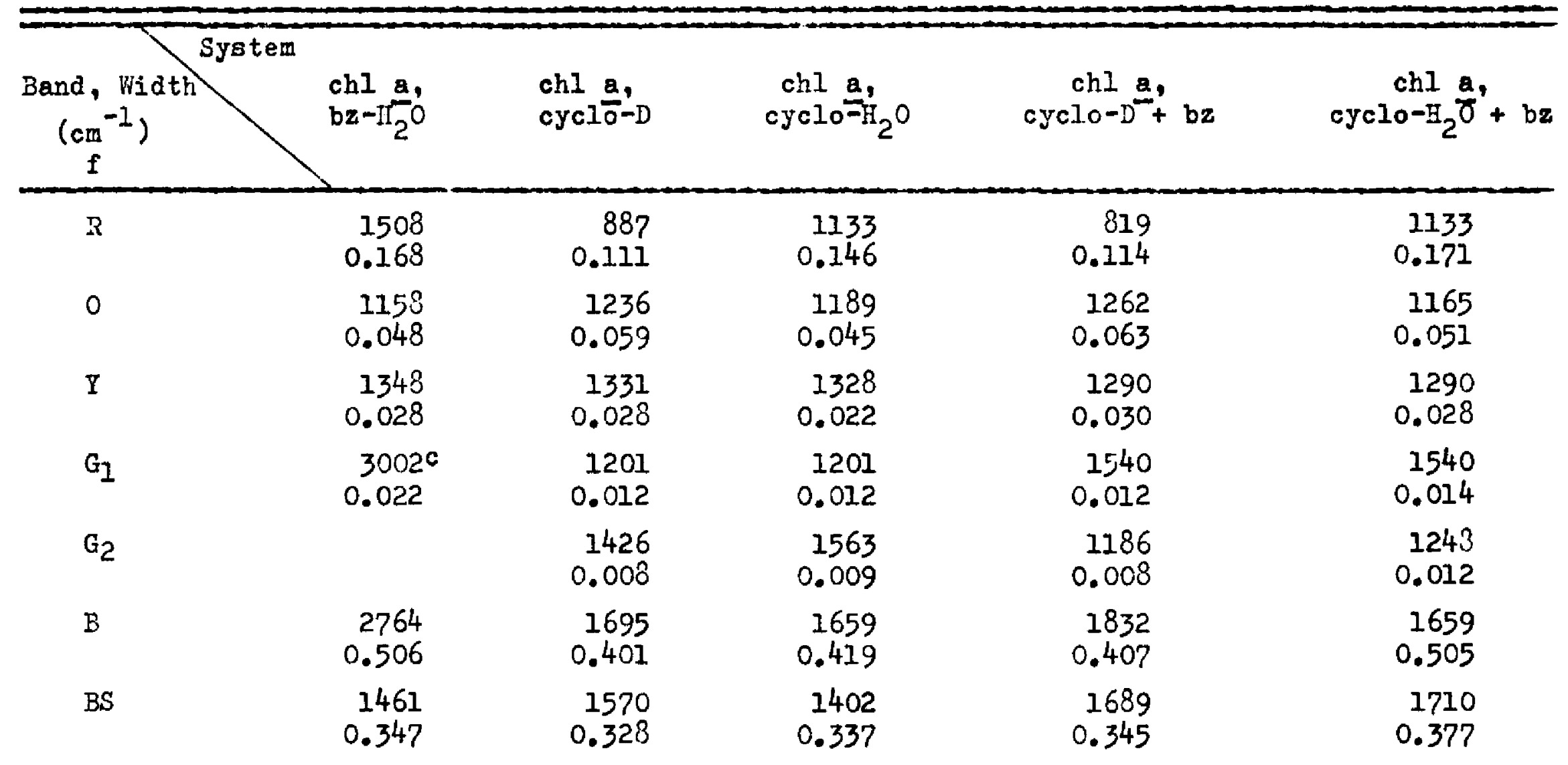


Table 29 (Contd.)

\begin{tabular}{|c|c|c|c|c|c|}
\hline $\begin{array}{c}\text { Band, Wj.dth } \\
\left(\mathrm{cmb}^{-1}\right)\end{array}$ & $\frac{c h l}{b z-y_{2}}$ & chl a, & $\underset{\operatorname{cycl}}{\operatorname{chl}}=\mathrm{H}_{2} \mathrm{O}$ & $\operatorname{chl}_{\text {cyclo- }}^{a}+b z$ & $\underset{\operatorname{cycl} 0-\mathrm{H}_{2}}{\mathrm{a}}{ }^{\mathrm{a}}+\mathrm{bz}$ \\
\hline \multirow[t]{4}{*}{ UV } & $\begin{array}{r}3146 \\
0.437\end{array}$ & $\begin{array}{r}3021 \\
0.450\end{array}$ & $\begin{array}{r}3090 \\
0.453\end{array}$ & $\begin{array}{r}2931 \\
0.434\end{array}$ & $\begin{array}{r}2765 \\
0.503\end{array}$ \\
\hline & & $\begin{array}{r}F R, 1162 \\
0.057\end{array}$ & $\begin{array}{r}F R, 824 \\
0.013\end{array}$ & $\begin{array}{r}F R, 1244 \\
0.069\end{array}$ & $\begin{array}{r}F R, 836 \\
0.015\end{array}$ \\
\hline & & $B_{1}, 1343$ & $B_{1}, 1341$ & $B_{1}, 1129$ & $B_{1}, 1384$ \\
\hline & & 0.033 & 0.015 & 0.034 & 0.018 \\
\hline First cut off $\left(\mathrm{cm}^{-1}\right.$ & $\Rightarrow 14184$ & 13699 & $1384 I$ & 13650 & 13841 \\
\hline Last Cut off $\left(\mathrm{cm}^{-1}\right)$ & 28571 & 23571 & 23571 & 28571 & 28571 \\
\hline Total f & 1.560 & 1.488 & 1.481 & 1.567 & 1.699 \\
\hline
\end{tabular}


Table 29 (Contd.)

\begin{tabular}{|c|c|c|c|c|}
\hline $\begin{array}{c}\text { Band, Width } \\
\left(\mathrm{cm}^{-1}\right) \\
f\end{array}$ & $\operatorname{chl} \underline{b}, E$ & $\operatorname{chl} \underline{b}, A c$ & $\operatorname{chl} \underline{b}, p y$ & $\operatorname{chl} \underline{b}, b z-D$ \\
\hline $\mathrm{R}$ & $\begin{array}{r}1845 \\
0.107\end{array}$ & $\begin{array}{r}1699 \\
0.104\end{array}$ & $\begin{array}{r}1795 \\
0.113\end{array}$ & $\begin{array}{r}968 \\
0.090\end{array}$ \\
\hline 0 & $\begin{array}{r}985 \\
0.033\end{array}$ & $\begin{array}{r}0_{1}+0,1252 \\
0.043\end{array}$ & $\begin{array}{r}01+0,1385 \\
0.049\end{array}$ & $\begin{array}{r}897 \\
0.035\end{array}$ \\
\hline$Y$ & $\begin{array}{r}610 \\
0.016\end{array}$ & $\begin{array}{r}627 \\
0.015\end{array}$ & $\begin{array}{r}\mathrm{y}+\mathrm{G}_{1}, 1615 \\
0.032\end{array}$ & $\begin{array}{r}648 \\
0.016\end{array}$ \\
\hline $\mathrm{G}_{1}$ & $\begin{array}{l}2365^{\circ} \\
0.035\end{array}$ & $\begin{array}{l}2082^{c} \\
0.035\end{array}$ & & $\begin{array}{r}1275 \\
0.026\end{array}$ \\
\hline $\mathrm{G}_{2}$ & & & $\begin{array}{r}625 \\
0.009\end{array}$ & $\begin{array}{r}448 \\
0.008\end{array}$ \\
\hline$B$ & $\begin{array}{r}2800 \\
0.633\end{array}$ & $\begin{array}{r}2777 \\
0.673\end{array}$ & $\begin{array}{r}2500 \\
0.662\end{array}$ & $\begin{array}{r}2420 \\
0.663\end{array}$ \\
\hline BS & $\begin{array}{l}1350 \\
0.213\end{array}$ & $\begin{array}{r}\mathrm{BS}+\mathrm{UV}_{1}, 2439 \\
0.279\end{array}$ & $\begin{array}{r}1425 \\
0.206\end{array}$ & $\begin{array}{r}\mathrm{BS}+\mathrm{OV}_{1}, 2183 \\
0.238\end{array}$ \\
\hline WV & $\begin{array}{r}1550 \\
0.105\end{array}$ & $\begin{array}{r}1694 \\
0.120\end{array}$ & $\begin{array}{r}1400 \\
0.094\end{array}$ & $\begin{array}{r}1833 \\
0.142\end{array}$ \\
\hline
\end{tabular}


Table 29 (Contd.)

\begin{tabular}{|c|c|c|c|}
\hline $\begin{array}{c}\text { Band, Width } \\
\left(\mathrm{cm}^{-1}\right) \\
f\end{array}$ & $\operatorname{chl} \underline{b}, A c$ & $\operatorname{cin} 1 \underline{b}, p y$ & $\operatorname{chl} \underline{t}, b z-D$ \\
\hline $0_{1} .255$ & $\mathrm{UV}_{3}, 1240$ & $W_{1}, 1000$ & $\mathrm{FR}, 1342$ \\
\hline 0.008 & 0.116 & 0.058 & 0.033 \\
\hline $\begin{array}{r}\mathrm{wV}_{1}, 900 \\
0.056\end{array}$ & & $\begin{array}{r}W_{3}, 1400 \\
0.128\end{array}$ & $\begin{array}{r}0 ., 334 \\
0.015\end{array}$ \\
\hline $\mathrm{UV}_{3}, 1571$ & & $\mathrm{WV}_{4}, 2775$ & 51,705 \\
\hline 0.142 & & 0.308 & 0.037 \\
\hline & & & $\begin{array}{r}\mathrm{JV}_{3}, 1,032 \\
0.108\end{array}$ \\
\hline First Cut off $\left(\mathrm{cm}^{-1}\right) 14340$ & $144: 0$ & 14280 & 13793 \\
\hline Last Cut off $\left(\mathrm{cm}^{-1}\right) 23571$ & 28250 & 30200 & 27878 \\
\hline Total f $\quad 1.395$ & 1.385 & $\begin{array}{l}1.658 \\
(1.473)^{d}\end{array}$ & 1.412 \\
\hline
\end{tabular}


mable 29 (Contd.)

\begin{tabular}{|c|c|c|c|c|}
\hline $\begin{array}{c}\text { Band widt } \\
\left(\mathrm{cm}^{-1}\right) \\
f\end{array}$ & $\operatorname{chl} \underline{b}, \quad b z-H_{2} O$ & al $\operatorname{chl} a, E$ & al $\operatorname{chl} a, b z-\mathrm{H}_{2} \mathrm{O}$ & ph $\underline{a}, \bar{I}$ \\
\hline $\mathrm{R}$ & $\begin{array}{r}1812 \\
0.113\end{array}$ & $\begin{array}{l}1995 \\
0.136\end{array}$ & $\begin{array}{r}2300 \\
0.144\end{array}$ & $\begin{array}{l}1250 \\
0.103\end{array}$ \\
\hline 0 & $\begin{array}{r}940 \\
0.033\end{array}$ & $\begin{array}{r}1200 \\
0.036\end{array}$ & $\begin{array}{r}1167 \\
0.035\end{array}$ & $\begin{array}{l}1300 \\
0.027\end{array}$ \\
\hline$Y$ & $\begin{array}{r}684 \\
0.017\end{array}$ & $\begin{array}{r}1220 \\
0.018\end{array}$ & $\begin{array}{r}1249 \\
0.020\end{array}$ & $\begin{array}{r}1055 \\
0.011\end{array}$ \\
\hline $\mathrm{G}_{1}$ & $\begin{array}{r}1433 \\
0.026\end{array}$ & $\begin{array}{r}1540 \\
0.017\end{array}$ & $\begin{array}{l}2748^{c} \\
0.024\end{array}$ & $\begin{array}{r}905 \\
0.023\end{array}$ \\
\hline$G_{2}$ & $\begin{array}{r}750 \\
0.009\end{array}$ & $\begin{array}{r}1305 \\
0.008\end{array}$ & & $\begin{array}{r}775 \\
0.229\end{array}$ \\
\hline 3 & $\begin{array}{r}2605 \\
0.634\end{array}$ & $\begin{array}{r}4055 \\
0.766\end{array}$ & $\begin{array}{r}B+B S, 5152 \\
0.959\end{array}$ & $\begin{array}{r}3050 \\
0.700\end{array}$ \\
\hline BS & $\begin{array}{r}B S+W_{1}, 2570 \\
0.246\end{array}$ & $\begin{array}{r}1365 \\
0.244\end{array}$ & & $\begin{array}{l}1075 \\
0.350\end{array}$ \\
\hline \multirow[t]{2}{*}{ WV } & $\begin{array}{r}1333 \\
0.003\end{array}$ & $\begin{array}{r}1235 \\
0.155\end{array}$ & $\begin{array}{r}U V+V_{3}, 2255 \\
0.252\end{array}$ & $\begin{array}{l}2271 \\
0.390\end{array}$ \\
\hline & $\begin{array}{r}0,320 \\
0.011\end{array}$ & $\begin{array}{r}\mathrm{UV}_{3}, 1120 \\
0.108\end{array}$ & & $\begin{array}{r}0.375 \\
0.007\end{array}$ \\
\hline
\end{tabular}


Table 29 (Contd.)

\begin{tabular}{|c|c|c|c|c|}
\hline $\begin{array}{l}\text { Band Width } \\
\left(\mathrm{cm}^{-1}\right)\end{array}$ & b. $\mathrm{bz}_{2}-\mathrm{H}_{2} \mathrm{O}$ & al $\operatorname{chl}$ a, $E$ & a] $c=1$ a, bz- $\mathrm{H}_{2} \mathrm{O}$ & ph \\
\hline & $\begin{array}{r}\mathrm{UV}_{3}, 1450 \\
0.129\end{array}$ & & & $\begin{array}{r}G 1,730 \\
0.023 \\
G_{3}, 425 \\
0.024\end{array}$ \\
\hline First Cut off $\left(\mathrm{cm}^{-1}\right)$ & 14286 & 13990 & 13700 & 14300 \\
\hline Last Cut off $\left(\mathrm{cm}^{-1}\right)$ & 28183 & 29025 & 20571 & 23571 \\
\hline Total $f$ & 1.357 & $\begin{array}{c}1.488 \\
(1.450)^{\mathrm{d}}\end{array}$ & 1.434 & 1.700 \\
\hline
\end{tabular}


Table 29 (Contd.)

\begin{tabular}{|c|c|c|c|c|}
\hline $\begin{array}{l}\text { Band Widt } \\
\left(\mathrm{cm}^{-1}\right) \\
f\end{array}$ & ph $\underline{a}, p y$ & $\mathrm{ph} a, \mathrm{bz}-\mathrm{H}_{2} \mathrm{O}$ & al pha, $\mathrm{E}$ & al ph $\underline{a}, b z-H_{2} \mathrm{O}$ \\
\hline$R$ & $\begin{array}{r}1800 \\
0.113\end{array}$ & $\begin{array}{r}1637 \\
0.115\end{array}$ & $\begin{array}{r}1800 \\
0.090\end{array}$ & $\begin{array}{r}2043 \\
0.103\end{array}$ \\
\hline 0 & $\begin{array}{r}1385 \\
0.031\end{array}$ & $\begin{array}{r}1357 \\
0.026\end{array}$ & $\begin{array}{r}1340 \\
0.016\end{array}$ & $\begin{array}{l}1221 \\
0.016\end{array}$ \\
\hline$Y$ & $\begin{array}{r}815 \\
0.012\end{array}$ & $\begin{array}{r}923 \\
0.009\end{array}$ & $\begin{array}{r}2100 \\
0.006\end{array}$ & $\begin{array}{r}1156 \\
0.010\end{array}$ \\
\hline $\mathrm{G}_{1}$ & $\begin{array}{r}475 \\
0.009\end{array}$ & $\begin{array}{r}990 \\
0.024\end{array}$ & $\begin{array}{r}1070 \\
0.018\end{array}$ & $\begin{array}{r}988 \\
0.018\end{array}$ \\
\hline$G_{2}$ & $\begin{array}{r}760 \\
0.028\end{array}$ & $\begin{array}{r}1594 \\
0.050\end{array}$ & $\begin{array}{r}1752 \\
0.04+0\end{array}$ & $\begin{array}{r}1512 \\
0.037\end{array}$ \\
\hline B & $\begin{array}{r}3125 \\
0.709\end{array}$ & $\begin{array}{r}2978 \\
0.652\end{array}$ & $\begin{array}{r}4490 \\
0.941\end{array}$ & $\begin{array}{r}4750 \\
1.035\end{array}$ \\
\hline BS & $\begin{array}{r}1300 \\
0.420\end{array}$ & $\begin{array}{r}1129 \\
0.373\end{array}$ & & \\
\hline UV & $\begin{array}{r}2321 \\
0.410\end{array}$ & $\begin{array}{r}2597 \\
0.484\end{array}$ & $\begin{array}{l}1365 \\
0.267\end{array}$ & $\begin{array}{r}1482 \\
0.230\end{array}$ \\
\hline & $\begin{array}{r}G_{1}, 590 \\
0.020\end{array}$ & $\begin{array}{r}G_{3}, 1193 \\
0.018\end{array}$ & $\begin{array}{r}G_{3}, 925 \\
0.010\end{array}$ & $\begin{array}{r}G_{3}, 990 \\
0.012\end{array}$ \\
\hline
\end{tabular}


Table 29 (Contd.)

\begin{tabular}{|c|c|c|c|}
\hline $\begin{array}{c}\text { Band hidth } \\
\left(\mathrm{cm}^{-1}\right) \\
f\end{array}$ & $\mathrm{ph} \underline{\mathrm{a}}, \mathrm{bz}-\mathrm{H}_{2} \mathrm{O}$ & al ph $\underline{e}, \mathrm{E}$ & al ph $\underline{a}, b z-H_{2} \mathrm{O}$ \\
\hline$G_{2}, 775$ & & $\mathrm{Uv}_{3}, 1545$ & $\mathrm{UV}_{3}, 1353$ \\
\hline 0.023 & & 0.180 & 0.172 \\
\hline $\begin{array}{r}G_{3}, 1225 \\
0.022\end{array}$ & & & \\
\hline First Cut off, $\left(\mathrm{cm}^{-1}\right) 14000$ & 14184 & 14000 & 13830 \\
\hline Last Cut off, $\left(\mathrm{cm}^{-1}\right) 28571$ & 28571 & 29400 & 29325 \\
\hline Total $\mathrm{f} \quad 1.797$ & 1.752 & $\begin{array}{l}1.568 \\
(1.490)^{d}\end{array}$ & 1.634 \\
\hline
\end{tabular}


Table 29 (Contd.)

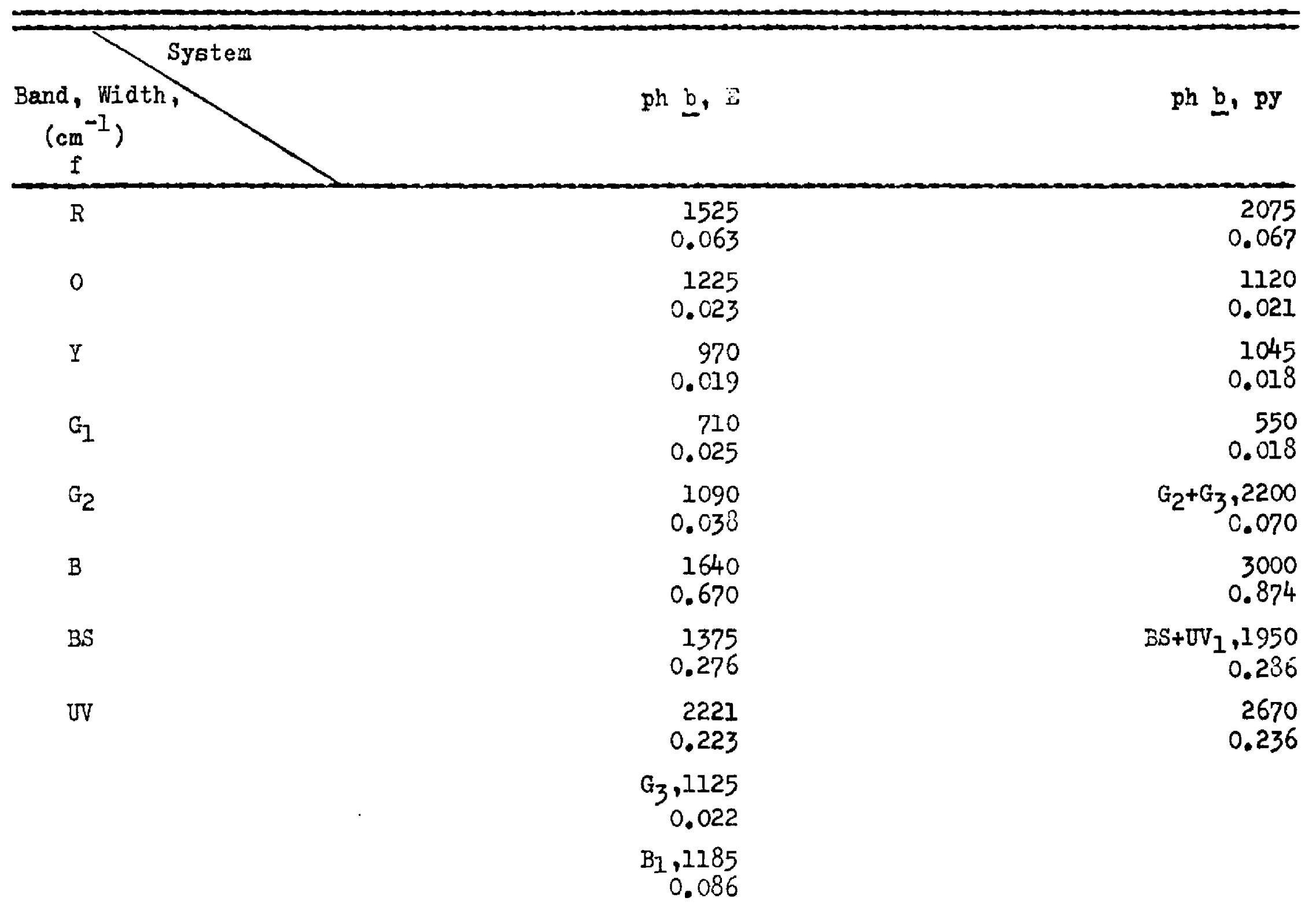


Table 29 (Contd.)

\begin{tabular}{|c|c|c|}
\hline $\begin{array}{c}\text { Band, Width, } \\
\left(\mathrm{cm}^{-1}\right) \\
f\end{array}$ & ph $\underline{b}, E$ & ph $\underline{b}, p y$ \\
\hline & $\mathrm{UV}_{1}, 975$ & \\
\hline & 0.103 & \\
\hline First Cut off $\left(\mathrm{cm}^{-1}\right)$ & 14530 & 13950 \\
\hline Last Cut off $\left(\mathrm{cm}^{-1}\right)$ & 28571 & 28571 \\
\hline Total $f$ & 1.547 & 1.593 \\
\hline
\end{tabular}

The band ridth is the distancs between minima, or band cut offs.

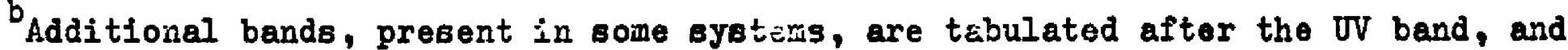
designated by the letter preceding tile band width value.

$c_{\text {Total green band. }}$

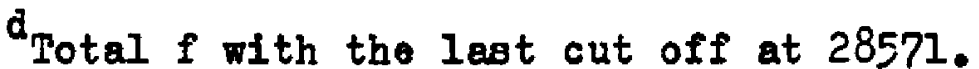


Table 30

Dipole Strengths (D) of the Chlorophylls and Several

Derivatives in Various Solvente

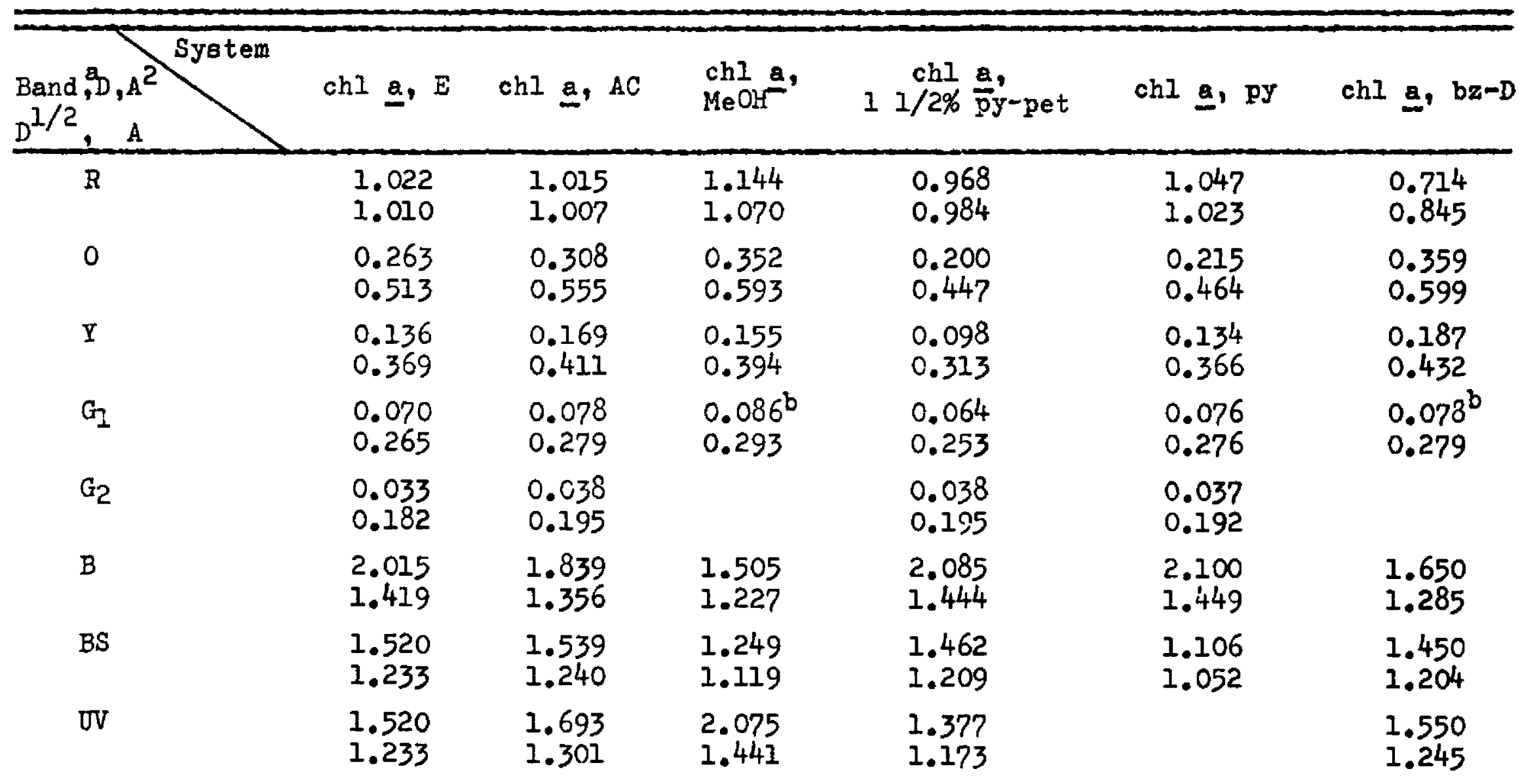


Table 30 (Contd.)

\begin{tabular}{|c|c|c|c|c|c|c|}
\hline 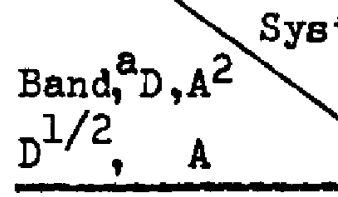 & $\operatorname{chl} a, E$ & $\operatorname{chl} \mathrm{a}, \mathrm{AC}$ & $\begin{array}{l}\mathrm{chl} a \\
\mathrm{MeOH}^{-}\end{array}$ & $1 \stackrel{\text { chl }}{1 / 2 \%} \frac{a}{p y-p e t}$ & $\operatorname{chl} \mathbf{a}, \mathrm{py}$ & $\operatorname{chl} \underline{a}, b z-D$ \\
\hline & & & & $\begin{array}{r}0_{1}, 0.132 \\
0.363\end{array}$ & $\begin{array}{r}0,0.206 \\
0.454\end{array}$ & $\begin{array}{r}\mathrm{FR}, 0.398 \\
0.631\end{array}$ \\
\hline & & & & & $\begin{array}{r}\mathrm{UV}+\mathrm{UV}_{3}, 1.511 \\
1.229\end{array}$ & $\begin{array}{r}B_{1}, 0.200 \\
0.316\end{array}$ \\
\hline & & & & & $\begin{array}{r}\mathrm{UV}_{4}, 0.925 \\
0.962\end{array}$ & \\
\hline Total $D, A^{2}$ & 6.580 & 6.580 & 6.566 & 6.425 & $\begin{array}{l}7.357 \\
(6.750)^{\mathrm{c}}\end{array}$ & 6.486 \\
\hline Total $D^{1 / 2}, A$ & 6.244 & 6.344 & 6.137 & 6.381 & 7.467 & 6.836 \\
\hline
\end{tabular}


Table 30 (Contd.)

\begin{tabular}{|c|c|c|c|c|c|}
\hline $\begin{array}{l}\text { Band, } D, A^{2} \\
D^{1 / 2}, A\end{array}$ & $\operatorname{chl} \frac{a}{b 2-H_{2}}$ & chl a, & cyclo $\stackrel{\mathrm{a}}{2}_{2} 0$ & $\operatorname{chl} \underline{b}, E$ & $\operatorname{chl} \underline{b}, A c$ \\
\hline $\mathrm{R}$ & $\begin{array}{l}1.025 \\
1.012\end{array}$ & $\begin{array}{l}0.676 \\
0.822\end{array}$ & $\begin{array}{l}0.890 \\
0.943\end{array}$ & $\begin{array}{l}0.653 \\
0.808\end{array}$ & $\begin{array}{l}0.621 \\
0.788\end{array}$ \\
\hline 0 & $\begin{array}{l}0.268 \\
0.518\end{array}$ & $\begin{array}{l}0.329 \\
0.574\end{array}$ & $\begin{array}{l}0.255 \\
0.504\end{array}$ & $\begin{array}{l}0.185 \\
0.430\end{array}$ & $\begin{array}{r}0_{1}+O_{2}, 0.238 \\
0.488\end{array}$ \\
\hline$Y$ & $\begin{array}{l}0.148 \\
0.385\end{array}$ & $\begin{array}{l}0.147 \\
0.383\end{array}$ & $\begin{array}{l}0.118 \\
0.344\end{array}$ & $\begin{array}{l}0.081 \\
0.285\end{array}$ & $\begin{array}{l}0.080 \\
0.283\end{array}$ \\
\hline $\mathrm{G}_{1}$ & $\begin{array}{l}0.083^{b} \\
0.288\end{array}$ & $\begin{array}{l}0.059 \\
0.243\end{array}$ & $\begin{array}{l}0.059 \\
0.243\end{array}$ & $\begin{array}{l}0.171^{b} \\
0.414\end{array}$ & $\begin{array}{l}0.171^{b} \\
0.414\end{array}$ \\
\hline$G_{2}$ & & $\begin{array}{l}0.038 \\
0.195\end{array}$ & $\begin{array}{l}0.043 \\
0.207\end{array}$ & & \\
\hline B & $\begin{array}{l}2.019 \\
1.421\end{array}$ & $\begin{array}{l}1.600 \\
1.265\end{array}$ & $\begin{array}{l}1.666 \\
1.290\end{array}$ & $\begin{array}{l}3.005 \\
1.733\end{array}$ & $\begin{array}{l}2.821 \\
1.679\end{array}$ \\
\hline BS & $\begin{array}{l}1.290 \\
1.136\end{array}$ & $\begin{array}{l}1.225 \\
1.107\end{array}$ & $\begin{array}{l}1.269 \\
1.126\end{array}$ & $\begin{array}{l}0.846 \\
0.920\end{array}$ & $\begin{array}{r}B S+W V_{1}, 1.080 \\
1.039\end{array}$ \\
\hline \multirow[t]{2}{*}{ UV } & $\begin{array}{l}1.483 \\
1.218\end{array}$ & $\begin{array}{l}1.543 \\
1.242\end{array}$ & $\begin{array}{l}1.557 \\
1.247\end{array}$ & $\begin{array}{l}0.367 \\
0.606\end{array}$ & $\begin{array}{l}0.420 \\
0.648\end{array}$ \\
\hline & & $\begin{array}{r}F R, 0.355 \\
0.596\end{array}$ & $\begin{array}{r}F R, 0.074 \\
0.272\end{array}$ & $\begin{array}{r}0,0.043 \\
0.207\end{array}$ & $\begin{array}{r}\mathrm{NV}_{3}, 0.387 \\
0.622\end{array}$ \\
\hline
\end{tabular}


Table 30 (Contd.)

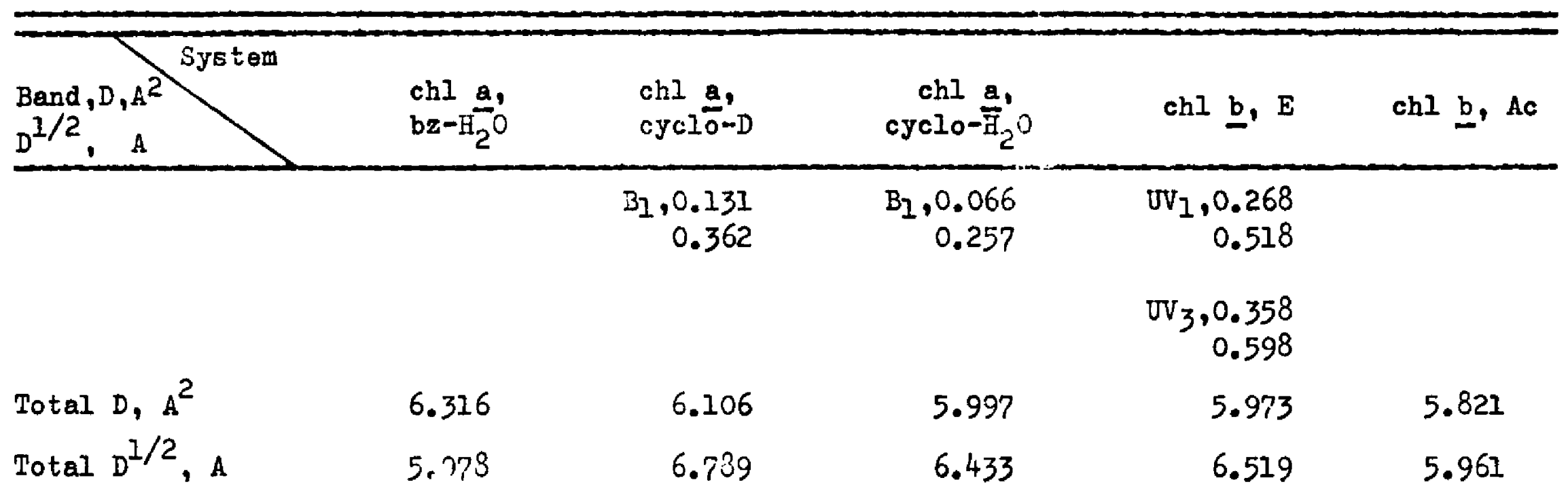


Table 30 (Contd.)

\begin{tabular}{|c|c|c|c|c|}
\hline $\begin{array}{l}\text { Band, } D, A^{2} \\
D^{1 / 2}, A\end{array}$ & $\operatorname{chl} \underline{b}, b z-D$ & $\operatorname{chl} \mathrm{b}, \mathrm{bz}-\mathrm{H}_{2} \mathrm{O}$ & al $\operatorname{chl} E, E$ & al chl $\underline{a}, b z-H_{2} O$ \\
\hline$R$ & $\begin{array}{l}0.534 \\
0.731\end{array}$ & $\begin{array}{l}0.675 \\
0.822\end{array}$ & $\begin{array}{l}0.825 \\
0.908\end{array}$ & $\begin{array}{l}0.876 \\
0.936\end{array}$ \\
\hline 0 & $\begin{array}{l}0.193 \\
0.439\end{array}$ & $\begin{array}{l}0.179 \\
0.423\end{array}$ & $\begin{array}{l}0.200 \\
0.447\end{array}$ & $\begin{array}{l}0.196 \\
0.443\end{array}$ \\
\hline $\mathrm{Y}$ & $\begin{array}{l}0.086 \\
0.293\end{array}$ & $\begin{array}{l}0.092 \\
0.303\end{array}$ & $\begin{array}{l}0.095 \\
0.308\end{array}$ & $\begin{array}{l}0.105 \\
0.324\end{array}$ \\
\hline$G_{1}$ & $\begin{array}{l}0.128 \\
0.358\end{array}$ & $\begin{array}{l}0.108 \\
0.329\end{array}$ & $\begin{array}{l}0.081 \\
0.285\end{array}$ & $\begin{array}{l}0.113^{b} \\
0.336\end{array}$ \\
\hline$G_{2}$ & $\begin{array}{l}0.036 \\
0.190\end{array}$ & $\begin{array}{l}0.046 \\
0.214\end{array}$ & $\begin{array}{l}0.034 \\
0.184\end{array}$ & \\
\hline B & $\begin{array}{l}2.842 \\
1.680\end{array}$ & $\begin{array}{l}2.704 \\
1.645\end{array}$ & $\begin{array}{l}2.913 \\
1.707\end{array}$ & $\begin{array}{r}B+B S, 3.638 \\
1.907\end{array}$ \\
\hline BS & $\begin{array}{r}B S+U V_{1}, 0.793 \\
0.891\end{array}$ & $\begin{array}{r}\mathrm{BS}+\mathrm{WV}_{1}, 1,126 \\
1.061\end{array}$ & $\begin{array}{l}0.866 \\
0.931\end{array}$ & \\
\hline \multirow[t]{2}{*}{ UV } & $\begin{array}{l}0.504 \\
0.710\end{array}$ & $\begin{array}{l}0.306 \\
0.553\end{array}$ & $\begin{array}{l}0.523 \\
0.723\end{array}$ & \multirow[t]{2}{*}{$\begin{array}{r}U V+U_{3}, 0.852 \\
0.923\end{array}$} \\
\hline & $\begin{array}{r}F R, 0.208 \\
0.456\end{array}$ & $\begin{array}{r}0_{1}, 0.063 \\
0.251\end{array}$ & $\begin{array}{r}\mathrm{vV}_{3}, 0.350 \\
0.592\end{array}$ & \\
\hline
\end{tabular}


Table 30 (Contd.)

\begin{tabular}{|c|c|c|c|c|}
\hline $\begin{array}{l}\text { Band, } D, A^{2} \\
D^{1 / 2}, A\end{array}$ & $\operatorname{chI} \underline{b}, b z-D$ & $\operatorname{chl} \mathrm{b}, \mathrm{bz}-\mathrm{H}_{2} \mathrm{O}$ & al chl $a, E$ & al $\operatorname{chl} \mathrm{a}, \mathrm{bz}-\mathrm{H}_{2} \mathrm{O}$ \\
\hline & $\begin{array}{r}0,0.087 \\
0.295\end{array}$ & $\begin{array}{r}\mathrm{wN}_{3}, 0.432 \\
0.657\end{array}$ & & \\
\hline & $\begin{array}{r}B_{1}, 0.143 \\
0.378\end{array}$ & & & \\
\hline & $\begin{array}{r}U V_{3}, 0.364 \\
0.603\end{array}$ & & & \\
\hline Total $D, A^{2}$ & 5.918 & 5.730 & $\begin{array}{l}5.888 \\
(5.762)^{c}\end{array}$ & 5.783 \\
\hline Total $D^{1 / 2}, A$ & 7.030 & 6.258 & 6.285 & 4.869 \\
\hline
\end{tabular}


Table 30 (Contd.)

\begin{tabular}{|c|c|c|c|c|}
\hline $\begin{array}{l}\text { Band, } D, A^{2} \\
D^{1 / 2}, A\end{array}$ & $\mathrm{ph}$ a, $E$ & ph a, py & $p h \underline{a}, b z-H_{2} O$ & al ph $\underline{a}, E$ \\
\hline $\mathrm{R}$ & $\begin{array}{l}0.629 \\
0.793\end{array}$ & $\begin{array}{l}0.698 \\
0.835\end{array}$ & $\begin{array}{l}0.707 \\
0.840\end{array}$ & $\begin{array}{l}0.561 \\
0.749\end{array}$ \\
\hline 0 & $\begin{array}{l}0.151 \\
0.389\end{array}$ & $\begin{array}{l}0.175 \\
0.418\end{array}$ & $\begin{array}{l}0.152 \\
0.390\end{array}$ & $\begin{array}{l}0.108 \\
0.329\end{array}$ \\
\hline$Y$ & $\begin{array}{l}0.057 \\
0.239\end{array}$ & $\begin{array}{l}0.054 \\
0.232\end{array}$ & $\begin{array}{l}0.045 \\
0.212\end{array}$ & $\begin{array}{l}0.034 \\
0.184\end{array}$ \\
\hline$G_{1}$ & $\begin{array}{l}0.117 \\
0.342\end{array}$ & $\begin{array}{l}0.054 \\
0.232\end{array}$ & $\begin{array}{l}0.120 \\
0.346\end{array}$ & $\begin{array}{l}0.086 \\
0.293\end{array}$ \\
\hline$G_{2}$ & $\begin{array}{l}0.134 \\
0.366\end{array}$ & $\begin{array}{l}0.131 \\
0.362\end{array}$ & $\begin{array}{l}0.234 \\
0.484\end{array}$ & $\begin{array}{l}0.182 \\
0.427\end{array}$ \\
\hline B & $\begin{array}{l}2.639 \\
1.624\end{array}$ & $\begin{array}{l}2.671 \\
1.634\end{array}$ & $\begin{array}{l}2.511 \\
1.585\end{array}$ & $\begin{array}{l}3.511 \\
1.874\end{array}$ \\
\hline BS & $\begin{array}{l}1.234 \\
1.111\end{array}$ & $\begin{array}{l}1.462 \\
1.209\end{array}$ & $\begin{array}{l}1.344 \\
1.160\end{array}$ & \\
\hline \multirow[t]{4}{*}{ WV } & $\begin{array}{l}1.175 \\
1.084\end{array}$ & $\begin{array}{l}1.278 \\
1.130\end{array}$ & $\begin{array}{l}1.651 \\
1.285\end{array}$ & $\begin{array}{l}0.898 \\
0.948\end{array}$ \\
\hline & $\begin{array}{r}01,0.042 \\
0.205\end{array}$ & $\begin{array}{r}G^{\prime} 1,0.095 \\
0.308\end{array}$ & $\begin{array}{r}G_{3}, 0.079 \\
0.281\end{array}$ & $\begin{array}{r}G_{3}, 0.039 \\
0.197\end{array}$ \\
\hline & $\begin{array}{r}G^{\prime} 2,0.105 \\
0.324\end{array}$ & $\begin{array}{r}G^{\prime}, 0.108 \\
0.329\end{array}$ & & $\begin{array}{r}\mathrm{UV}_{3}, 0.5 \mathrm{v} 0 \\
0.762\end{array}$ \\
\hline & $\begin{array}{r}G_{3}, 0.100 \\
0.316\end{array}$ & $\begin{array}{r}G_{3}, 0.094 \\
0.307\end{array}$ & & \\
\hline Total $D, A^{2}$ & 6.390 & 6.819 & 6.844 & $\begin{array}{l}5.990 \\
(5.705)^{c}\end{array}$ \\
\hline Total $D^{1 / 2}, A$ & 6.793 & 6.996 & 6.583 & 5.763 \\
\hline
\end{tabular}


Table 30 (Contd.)

\begin{tabular}{|c|c|c|c|}
\hline $\begin{array}{l}\text { Band, } D, A^{2} \\
D^{1 / 2}, A\end{array}$ & al ph $\underline{a}, b z-H_{2} \mathrm{O}$ & ph b, E & $\mathrm{ph} \underline{b}, \mathrm{py}$ \\
\hline$R$ & $\begin{array}{l}0.634 \\
0.796\end{array}$ & $\begin{array}{l}0.387 \\
0.622\end{array}$ & $\begin{array}{l}0.408 \\
0.639\end{array}$ \\
\hline 0 & $\begin{array}{l}0.088 \\
0.297\end{array}$ & $\begin{array}{l}0.100 \\
0.316\end{array}$ & $\begin{array}{l}0.115 \\
0.339\end{array}$ \\
\hline $\mathrm{I}$ & $\begin{array}{l}0.055 \\
0.235\end{array}$ & $\begin{array}{l}0.079 \\
0.281\end{array}$ & $\begin{array}{l}0.090 \\
0.300\end{array}$ \\
\hline$G_{1}$ & $\begin{array}{l}0.090 \\
0.300\end{array}$ & $\begin{array}{l}0.139 \\
0.373\end{array}$ & $\begin{array}{l}0.087 \\
0.295\end{array}$ \\
\hline$G_{2}$ & $\begin{array}{l}0.173 \\
0.416\end{array}$ & $\begin{array}{l}0.173 \\
0.416\end{array}$ & $\begin{array}{r}G_{2}+G_{3}, 0.330 \\
0.574\end{array}$ \\
\hline B & $\begin{array}{l}3.658 \\
1.912\end{array}$ & $\begin{array}{l}2.671 \\
1.634\end{array}$ & $\begin{array}{l}3.399 \\
1.844\end{array}$ \\
\hline BS & & $\begin{array}{l}1.104 \\
1.051\end{array}$ & $\begin{array}{r}\mathrm{BS}+\mathrm{WV}_{1}, 1.064 \\
1.032\end{array}$ \\
\hline WV & $\begin{array}{l}0.784 \\
0.885\end{array}$ & $\begin{array}{l}0.760 \\
0.872\end{array}$ & $\begin{array}{l}0.979 \\
0.989\end{array}$ \\
\hline
\end{tabular}




\section{Table 30 (Contd.)}

\begin{tabular}{|c|c|c|c|}
\hline $\begin{array}{l}\text { Band }, D, A^{2} \text { Syst } \\
D^{1 / 2}, A\end{array}$ & al ph $\mathrm{a}, \mathrm{b}=-\mathrm{H}_{2} \mathrm{O}$ & $\mathrm{ph} \underline{\mathrm{b}}, \mathrm{E}$ & ph $\underline{b}$, py \\
\hline & $\begin{array}{r}G_{3}, 0.052 \\
0.228\end{array}$ & $\begin{array}{r}G_{3}, 0.099 \\
0.315\end{array}$ & \\
\hline & $\begin{array}{r}\mathrm{UV}_{3}, 0.517 \\
0.719\end{array}$ & $\begin{array}{r}B_{1}, 0.430 \\
0.656\end{array}$ & \\
\hline & & $\begin{array}{r}u v_{1}, 0.364 \\
0.603\end{array}$ & \\
\hline Total D, $A^{2}$ & 6.048 & 6.310 & 6.474 \\
\hline Total $D^{1 / 2}, A$ & 5.788 & 7.139 & 6.012 \\
\hline
\end{tabular}

additional bands, present in scre systems, are tabulated after the $\mathrm{W}$ band, and designated by the letter preceding the $D$ value.

botal green band.

cotal D with the last cut off at 28571. 
Table 31

Changes in Oscillator and Dipole Strengthe with Change of Solvent in Reference to Ethyl Ether

\begin{tabular}{|c|c|c|c|c|c|c|c|c|c|}
\hline $\begin{array}{l}\text { Band, of Solvent and } \\
\% \text { Change } \\
\text { SD } \\
\% \text { Change }\end{array}$ & Ac, & $\begin{array}{l}\mathrm{MeOH}, \\
\mathrm{chl} \text { a }\end{array}$ & $\begin{array}{l}11 / 2 \% \\
\text { py-pet, } \\
\text { chl a }\end{array}$ & $\begin{array}{c}\text { py, } \\
\text { chl' }\end{array}$ & $\begin{array}{l}\mathrm{bz}-\mathrm{D}, \\
\mathrm{chl} \underline{\mathrm{a}}\end{array}$ & $\begin{array}{l}\mathrm{bz}-\mathrm{H}_{2} \mathrm{O} \\
\mathrm{chl} \underline{\mathrm{a}}\end{array}$ & $\begin{array}{l}\text { cyclo- } \\
\text { D, } \\
\text { chl } a\end{array}$ & $\begin{array}{l}\text { cyclo- } \\
\mathrm{B}_{20} \\
\mathrm{chI}\end{array}$ & $\begin{array}{l}\text { cyclo- } \\
\text { D+be, } \\
\text { chl a }\end{array}$ \\
\hline$R+F R$ & $\begin{array}{l}0 \\
0 \\
0 \\
0\end{array}$ & $\begin{array}{l}+0.008 \\
+4.7 \\
+0.122 \\
+11.9\end{array}$ & $\begin{array}{l}-0.011 \\
-6.5 \\
-0.054 \\
-5.3\end{array}$ & $\begin{array}{l}0 \\
0 \\
0 \\
0\end{array}$ & $\begin{array}{l}+0.009 \\
+5.3 \\
+0.090 \\
+8.8\end{array}$ & $\begin{array}{l}0 \\
0 \\
0 \\
0\end{array}$ & $\begin{array}{l}0 \\
0 \\
0 \\
0\end{array}$ & $\begin{array}{l}-0.011 \\
-6.5 \\
-0.058 \\
-10.7\end{array}$ & $\begin{array}{l}+0.013 \\
+7.6\end{array}$ \\
\hline$o_{1}+0$ & $\begin{array}{l}+0.006 \\
+12.2 \\
+0.045 \\
+17.1\end{array}$ & $\begin{array}{l}+0.013 \\
+26.5 \\
+0.089 \\
+33.8\end{array}$ & $\begin{array}{l}+0.010 \\
+20.4 \\
+0.069 \\
+26.2\end{array}$ & $\begin{array}{l}+0.024 \\
+49.0 \\
+0.158 \\
+60.0\end{array}$ & $\begin{array}{l}+0.014 \\
+28.6 \\
+0.096 \\
+36.5\end{array}$ & $\begin{array}{l}0 \\
0 \\
0 \\
0\end{array}$ & $\begin{array}{l}+0.010 \\
+20.4 \\
+0.066 \\
+25.1\end{array}$ & $\begin{array}{l}-0.004 \\
-8.2 \\
0 \\
0\end{array}$ & $\begin{array}{l}+0.014 \\
+28.6\end{array}$ \\
\hline+ & $\begin{array}{l}+0.004 \\
+14.8 \\
+0.030 \\
+22.1\end{array}$ & $\begin{array}{l}+0.005 \\
+18.5 \\
+0.019 \\
+14.0\end{array}$ & $\begin{array}{l}-0.009 \\
-33.3 \\
-0.038 \\
-28.0\end{array}$ & $\begin{array}{c}-0.005 \\
-18.5 \\
0 \\
0\end{array}$ & $\begin{array}{l}+0.008 \\
+29.6 \\
+0.051 \\
+37.5\end{array}$ & $\begin{array}{l}0 \\
0 \\
+0.012 \\
+8.8\end{array}$ & $\begin{array}{l}0 \\
0 \\
+0.011 \\
+8.1\end{array}$ & $\begin{array}{l}-0.005 \\
-18.5 \\
-0.018 \\
-13.2\end{array}$ & $\begin{array}{l}+0.003 \\
+11.1\end{array}$ \\
\hline$G($ Total $)$ & $\begin{array}{l}0 \\
0 \\
+0.013 \\
+12.6\end{array}$ & $\begin{array}{l}-0.006 \\
-25.0 \\
-0.017 \\
-16.5\end{array}$ & $\begin{array}{c}-0.003 \\
-12.5 \\
0 \\
0\end{array}$ & $\begin{array}{l}+0.004 \\
+16.7 \\
+0.010 \\
+9.7\end{array}$ & $\begin{array}{l}-0.008 \\
-33.3 \\
-0.025 \\
-24.3\end{array}$ & $\begin{array}{l}-0.002 \\
-8.3 \\
-0.020 \\
-19.4\end{array}$ & $\begin{array}{l}-0.004 \\
-16.7 \\
-0.006 \\
-5.8\end{array}$ & $\begin{array}{c}-0.003 \\
-12.5 \\
0 \\
0\end{array}$ & $\begin{array}{l}-0.004 \\
-16.7\end{array}$ \\
\hline
\end{tabular}


Table 31 (Contd.)

\begin{tabular}{|c|c|c|c|c|c|c|c|c|c|}
\hline $\begin{array}{l}\text { Band, of Solvent and } \\
\% \text { Change } \\
\text { CD } \\
\% \text { Change }\end{array}$ & Ac, & $\begin{array}{l}\mathrm{MeOH}, \\
\mathrm{chl} a\end{array}$ & $\begin{array}{l}11 / 2 \% \\
\text { py-pet, } \\
\text { chl } \underline{ }\end{array}$ & chI' & $\begin{array}{l}\mathrm{bz}-\mathrm{D}, \\
\operatorname{chl} \underline{a}\end{array}$ & $\begin{array}{l}\mathrm{bz}-\mathrm{H}_{2} \mathrm{O}, \\
\mathrm{chl} \text { a }\end{array}$ & $\begin{array}{l}\text { cyclo- } \\
\text { D, } \\
\text { chl } a\end{array}$ & $\begin{array}{l}\text { cyclo- } \\
\mathrm{H}_{2} \mathrm{O} \text {, } \\
\mathrm{chl}\end{array}$ & $\begin{array}{l}\text { cyclo- } \\
\text { D+bz, } \\
\text { chl a }\end{array}$ \\
\hline$B_{1}+B$ & $\begin{array}{l}-0.052 \\
-10.1 \\
-0.176 \\
-8.7\end{array}$ & $\begin{array}{l}-0.147 \\
-28.5 \\
-0.510 \\
-25.3\end{array}$ & $\begin{array}{l}0 \\
0 \\
0 \\
0\end{array}$ & $\begin{array}{l}0 \\
0 \\
0 \\
0\end{array}$ & $\begin{array}{l}-0.075 \\
-14.6 \\
-0.265 \\
-13.2\end{array}$ & $\begin{array}{l}0 \\
0 \\
0 \\
0\end{array}$ & $\begin{array}{l}-0.081 \\
-15.7 \\
-0.284 \\
-14.1\end{array}$ & $\begin{array}{l}-0.081 \\
-15.7 \\
-0.283 \\
-14.1\end{array}$ & $\begin{array}{l}-0.074 \\
-14.4\end{array}$ \\
\hline BS & $\begin{array}{l}0 \\
0 \\
0 \\
0\end{array}$ & $\begin{array}{l}-0.041 \\
-10.0 \\
-0.271 \\
-17.8\end{array}$ & $\begin{array}{l}0 \\
0 \\
0 \\
0\end{array}$ & $\begin{array}{l}-0.074 \\
-18.1 \\
-0.414 \\
-27.2\end{array}$ & $\begin{array}{l}0 \\
0 \\
0 \\
0\end{array}$ & $\begin{array}{l}-0.063 \\
-15.4 \\
-0.230 \\
-15.1\end{array}$ & $\begin{array}{l}-0.082 \\
-20.0 \\
-0.295 \\
-19.4\end{array}$ & $\begin{array}{l}-0.073 \\
-17.8 \\
-0.251 \\
-16.5\end{array}$ & $\begin{array}{l}-0.065 \\
-15.9\end{array}$ \\
\hline UV (Total) & $\begin{array}{l}+0.032 \\
+7.2 \\
+0.173 \\
+11.4\end{array}$ & $\begin{array}{l}+0.116 \\
+26.1 \\
+0.555 \\
+36.5\end{array}$ & $\begin{array}{l}-0.041 \\
-9.2 \\
-0.143 \\
-9.4\end{array}$ & $\begin{array}{l}+0.043 \\
+9.7 \\
+0.309 \\
+20.3\end{array}$ & $\begin{array}{l}0 \\
0 \\
0 \\
0\end{array}$ & $\begin{array}{l}0 \\
0 \\
0 \\
0\end{array}$ & $\begin{array}{l}0 \\
0 \\
0 \\
0\end{array}$ & $\begin{array}{l}0 \\
0 \\
0 \\
0\end{array}$ & $\begin{array}{l}+0.040 \\
+9.0\end{array}$ \\
\hline
\end{tabular}


Table 31 (Contd.)

\begin{tabular}{|c|c|c|c|c|c|c|c|c|}
\hline $\begin{array}{l}\text { Band, of } \\
\% \text { Change } \\
5 D \\
\% \text { Change }\end{array}$ & $\begin{array}{l}\text { cyclo- } \\
\mathrm{H}_{2} \mathrm{O} \\
+\mathrm{bz}, \\
\text { chl a }\end{array}$ & $\begin{array}{c}A c, \\
\text { chl } b\end{array}$ & $\begin{array}{c}\text { py, } \\
\text { chl b }\end{array}$ & $\begin{array}{l}\mathrm{bz}-\mathrm{D}, \\
\mathrm{chl} \mathrm{b}\end{array}$ & $\begin{array}{c}\mathrm{bz}-\mathrm{H}_{2} \mathrm{O} \\
\mathrm{chl} \text {, }\end{array}$ & $\begin{array}{r}\mathrm{bz}-\mathrm{H}_{2} \mathrm{O}, \\
\text { al } \operatorname{chl} a\end{array}$ & $\begin{array}{l}\text { py, } \\
\text { ph a }\end{array}$ & $\begin{array}{c}\mathrm{bz}-\mathrm{H}_{2} \mathrm{O} \\
\text { ph } \mathrm{a}\end{array}$ \\
\hline$R+F R$ & $\begin{array}{l}+0.016 \\
+9.4\end{array}$ & $\begin{array}{l}0 \\
0 \\
-0.032 \\
-4.9\end{array}$ & $\begin{array}{l}+0.006 \\
+5.6\end{array}$ & $\begin{aligned}+0.016 \\
+15.0 \\
+0.089 \\
+13.6\end{aligned}$ & $\begin{array}{l}+0.006 \\
+5.6 \\
+0.022 \\
+3.4\end{array}$ & $\begin{array}{l}+0.008 \\
+5.9 \\
+0.051 \\
+6.2\end{array}$ & $\begin{array}{l}+0.010 \\
+9.7 \\
+0.069 \\
+11.0\end{array}$ & $\begin{array}{l}+0.012 \\
+11.7 \\
+0.078 \\
+12.4\end{array}$ \\
\hline $\mathrm{O}_{1}+0$ & $\begin{array}{l}0 \\
0\end{array}$ & $\begin{array}{l}0 \\
0 \\
+0.010 \\
+4.4\end{array}$ & $\begin{array}{l}+0.008 \\
+19.5\end{array}$ & $\begin{array}{r}+0.009 \\
+22.0 \\
+0.052 \\
+22.8\end{array}$ & $\begin{array}{l}+0.003 \\
+7.3 \\
+0.014 \\
+6.1\end{array}$ & $\begin{array}{l}0 \\
0 \\
0 \\
0\end{array}$ & $\begin{array}{l}-0.003 \\
-8.8 \\
-0.018 \\
-9.3\end{array}$ & $\begin{array}{l}-0.008 \\
-23.5 \\
-0.041 \\
-21.2\end{array}$ \\
\hline$Y$ & $\begin{array}{l}0 \\
0\end{array}$ & $\begin{array}{l}0 \\
0 \\
0 \\
0\end{array}$ & $\begin{array}{c}Y+G_{1}+G_{2} \\
-0.010 \\
-19.6\end{array}$ & $\begin{array}{l}0 \\
0 \\
+0.005 \\
+6.2\end{array}$ & $\begin{array}{l}0 \\
0 \\
+0.011 \\
+13.6\end{array}$ & $\begin{array}{l}+0.002 \\
+11.1 \\
+0.010 \\
+10.5\end{array}$ & $\begin{array}{l}0 \\
0 \\
-0.003 \\
-5.3\end{array}$ & $\begin{array}{l}-0.002 \\
-18.2 \\
-0.012 \\
-21.0\end{array}$ \\
\hline$G($ Total $)$ & $\begin{array}{l}+0.002 \\
+8.3\end{array}$ & $\begin{array}{l}0 \\
0 \\
0 \\
0\end{array}$ & & $\begin{array}{l}0 \\
0 \\
-0.007 \\
-4.1\end{array}$ & $\begin{array}{l}0 \\
0 \\
-0.017 \\
-10.0\end{array}$ & $\begin{array}{l}0 \\
0 \\
0 \\
0\end{array}$ & $\begin{array}{l}0 \\
0 \\
+0.026 \\
+5.7\end{array}$ & $\begin{array}{l}-0.012 \\
-11.5 \\
-0.023 \\
-5.1\end{array}$ \\
\hline $\mathrm{B}_{1}+\mathrm{B}$ & $\begin{array}{l}0 \\
0\end{array}$ & $\begin{array}{l}0 \\
0 \\
-0.184 \\
-6.1\end{array}$ & $\begin{array}{l}0 \\
0\end{array}$ & $\begin{array}{l}0 \\
0 \\
0 \\
0\end{array}$ & $\begin{array}{c}0 \\
0 \\
-0.301 \\
-10.0\end{array}$ & $\begin{array}{c}B+B S \\
-0.051 \\
-5.1 \\
0 \\
0\end{array}$ & $\begin{array}{l}0 \\
0 \\
0 \\
0\end{array}$ & $\begin{array}{l}-0.048 \\
-6.9 \\
-0.128 \\
-4.9\end{array}$ \\
\hline
\end{tabular}


Table 31 (Contd.)

\begin{tabular}{|c|c|c|c|c|c|c|c|c|}
\hline $\begin{array}{l}\text { Band, } \delta f \\
\% \text { Change } \\
\text { 6D } \\
\% \text { Change }\end{array}$ & $\begin{array}{l}\text { cyclo- } \\
\mathrm{H}_{2} \mathrm{O} \\
+\mathrm{bz} \\
\text { chl a }\end{array}$ & Ac, & $\begin{array}{c}\text { py } \\
\text { chl } 0\end{array}$ & $\begin{array}{l}\mathrm{bz}-\mathrm{D} \\
\mathrm{chl} \mathrm{b}\end{array}$ & $\begin{array}{c}\mathrm{bz}=\mathrm{H}_{2} \mathrm{O} \\
\mathrm{chl} \mathrm{b}\end{array}$ & $\begin{array}{r}\mathrm{bz}-\mathrm{H}_{2} \mathrm{O}, \\
\text { al chl a }\end{array}$ & $\begin{array}{l}\text { py, } \\
\text { ph a }\end{array}$ & $\begin{array}{c}\mathrm{bz}_{2}-\mathrm{H}_{2} \mathrm{O} \\
\mathrm{ph} \mathbf{2}\end{array}$ \\
\hline BS & $\begin{array}{l}-0.033 \\
-8.1\end{array}$ & $\begin{array}{l}B S+U V_{1} \\
0 \\
0 \\
0 \\
0\end{array}$ & $\begin{array}{l}0 \\
0\end{array}$ & $\begin{array}{l}\mathrm{BS}+\mathrm{JV}_{1} \\
-0.031 \\
-11.5 \\
-0.321 \\
-28.8\end{array}$ & $\begin{array}{l}\mathrm{BS}+\mathrm{OV}_{1} \\
-0.023 \\
-8.5 \\
0 \\
0\end{array}$ & & $\begin{array}{l}+0.062 \\
+17.3 \\
+0.228 \\
+18.5\end{array}$ & $\begin{array}{l}0 \\
0 \\
+0.110 \\
+8.9\end{array}$ \\
\hline UV (Total) & $\begin{array}{l}+0.064 \\
+14.4\end{array}$ & $\begin{array}{l}\text { UV } \\
+0.015 \\
+14.3 \\
+0.053 \\
+14.4\end{array}$ & $\begin{array}{l}+0.100 \\
+33.0\end{array}$ & $\begin{array}{l}\text { UV } \\
+0.037 \\
+35.2 \\
+0.137 \\
+37.4\end{array}$ & $\begin{array}{l}\text { UV } \\
-0.017 \\
-16.2 \\
-0.061 \\
-16.7\end{array}$ & $\begin{array}{l}+0.027 \\
+12.0 \\
+0.105 \\
+14.0\end{array}$ & $\begin{array}{l}0 \\
0 \\
+0.103 \\
+8.8\end{array}$ & $\begin{array}{l}+0.094 \\
+24.1 \\
+0.476 \\
+40.5\end{array}$ \\
\hline
\end{tabular}


Table 31 (Contd.)

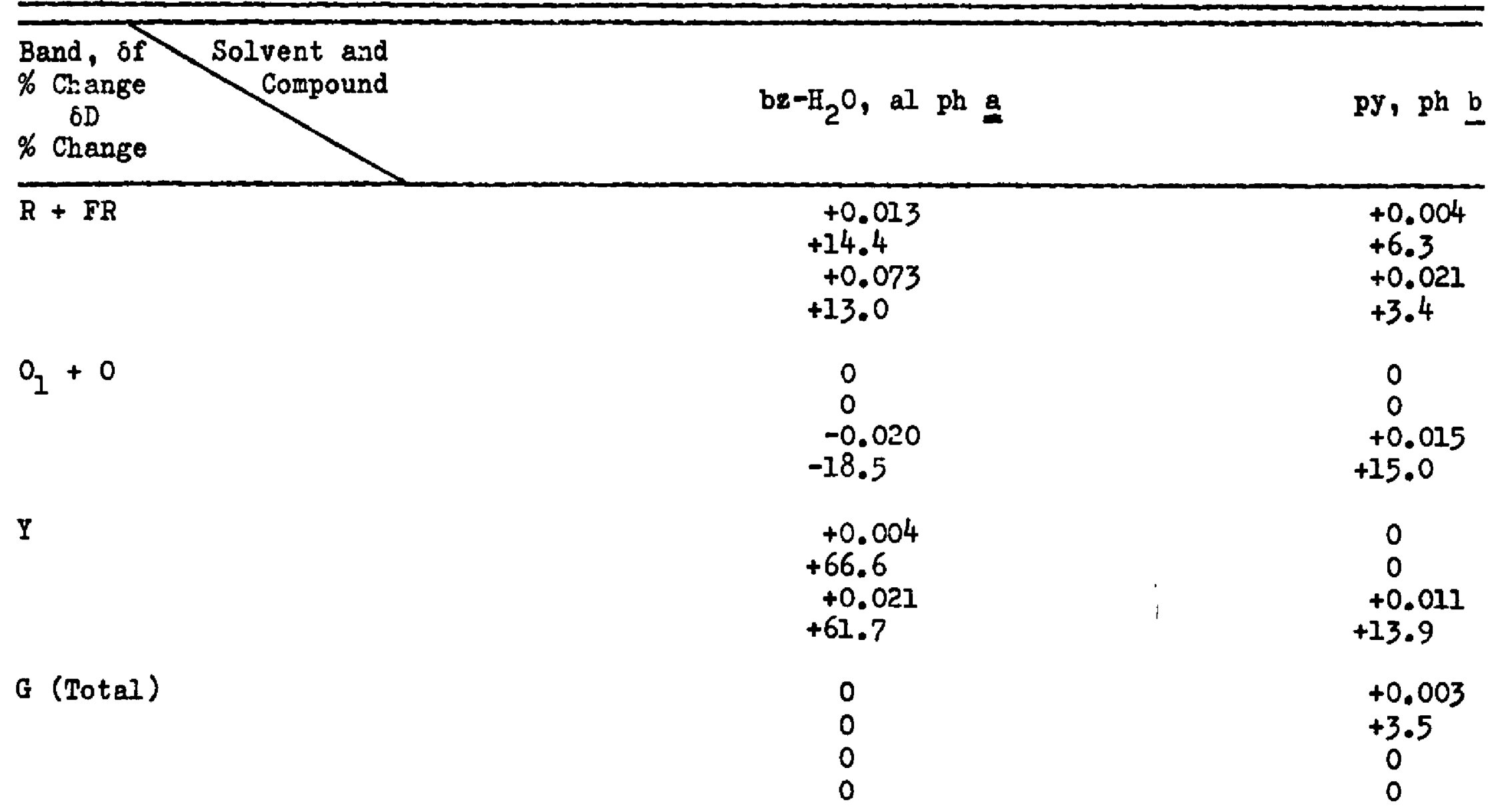


Table 31 (Contd.)

\begin{tabular}{|c|c|c|}
\hline $\begin{array}{l}\text { Band, of } \\
\% \text { Ch ange } \\
\text { 6D } \\
\% \text { Change }\end{array}$ & $\mathrm{bz}-\mathrm{H}_{2} \mathrm{O}$, al ph $\underline{a}$ & py, ph b \\
\hline$B_{1}+B$ & $\begin{array}{l}+0.094 \\
+10.0 \\
+0.147 \\
+4.2\end{array}$ & $\begin{array}{l}+0.118 \\
+15.6 \\
+0.298 \\
+9.6\end{array}$ \\
\hline BS & & $\begin{array}{c}\mathrm{BS}+\mathrm{UV}_{1} \\
-0.093 \\
-24.6 \\
-0.404 \\
-27.5\end{array}$ \\
\hline UV (Total) & $\begin{array}{l}-0.045 \\
-10.1 \\
-0.177 \\
-12.0\end{array}$ & $\begin{array}{l}\text { ov } \\
0 \\
0 \\
+0.219 \\
+28.8\end{array}$ \\
\hline
\end{tabular}

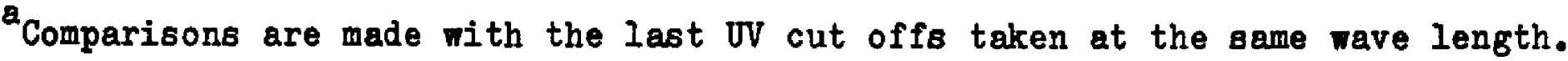


strength of the first band is about one half that of the second.

For chl a the strength of the $B$ bend is consistently greater than that of the BS band except in methanol where they become nearly equal. There is no corresponding change in the Low energy band system in methanol; the strength of the UV band is significantly larger than in the other solvents. In solvents where it can be distinguished, the BS band of al chl a shows significantly less intensity than that of chl a. In solvents where the $B$ band is presumably overlapping the BS band in al chl a, the combined intensity is greater than the sum of the $B$ and $B S$ band intensities of chl a. The $B$ band intensity of chl $\underline{b}$ is significantly greater than tinat of chl a, while the BS band intensity is significantly smaller.

In tire pheophytins the increased strengths in the $G$ bands remarkably alter the aipearance of the spectruin and give the following order of decreasing gtrengths in the low energy region: $R, G_{2}+G^{\prime}, G_{1} \sim 0, G_{3}$, and $Y$. The B band intensity of ph a is significantly larger than that of chl a, while the BS band intensity is smaller. The distances between the BS and $B$ band peaks are about the same for both compounds. As a consequence there is not a well defined minimum between the B and BS bands in ph a as in chl a. In al ph a the BS band is either entirely overlapped by the $B$ band or is of very low intensity, since there is no indication of a peak on the short wavelength side of the $B$ band. The intensity of the $B$ band of al ph $a$ is less than the combined intensities of the $B$ and $B S$ bands of ph $a$ in 
ether, but nearly equal in wet benzene. The combined intensity of the $B$ and $B_{1}$ bands in ph $\underline{b}$ is larger than that of the $B$ band in chl b, and the BS band intensity is larger than that of chl b. Ph $\underline{b}$ shows a well defined minimum between the $B$ and BS bands like chl b.

In EHCl, the strengths of the G bands of ph a and al ph $\underline{a}^{\dagger}$ decrease to the magnitude of those of chI a and al chl a respectively. The order of decrease of band strengths thus reverts to that of the magnesium containing compounds with the exception that the strength of the $Y$ band is less than that of the $G_{1}$ bend, as for chl b. A similar chenge for ph b in EHCl was not found, which corresponds to the relatively small changes in peak positions observed.

The variations of the total $f$ and $D$ values, given at the bottoins of Tables 29 ard 30 , reflect the overall effects of solvent or substituert change on intensity in the spectra. For chl a the most remarkable effect is the increase of total strength when a small amount of benzene is added to the dry and wet chclohexane solutions. It is interesting to note that the decrease of strength in going from chl a to al chl a is quite similar to the decrease in going from ph a to al ph a. In both instances nearly every band undergoes a significant change with the alteration of the isocyclic ring. Thus it appears that the

The $f$ and $D$ values were not determined in EHCl. The data given in Tables 32 and 33 provide for the determination of the optical densities and show the decrease of intensities of the $\mathrm{G}$ bands. 
perturbations arising from the isocyclic ring can influence transitions polarized along different axes in the chlorin plane. The comparisons given in Table 31 show that the strengths of individual bands for a given compound can vary considerably with change of solvent. The $R, O, Y$, and $G$ bands of chl a and the UV band of chl b, for example, undergo both increases and decreases of intensity. For a given solvent change, the bands of the different compounds, at correspondine positions in the spectrui, lisualiy show difforences in intensity changes. In some instances changes of the opposite sign occur. As example, for the BS bands of $\operatorname{chl} a, \operatorname{chl} \underline{b}$, pi $\underline{a}$, and ph $\underline{b}$, in the change from ether to pyridine, the changes in $f$ values are -0.074 , 0 , +0.062 , and -0.093 respectively. In general, one or more of the bancis in the vpper energy region of each system show the largest absolute changes in intensity. In terms of per cent change, however, these are a number of systems in which bands in the lower energy region (predominantly the $Y$ and $O$ bands) show the largest change, for example, the $Y$ band of al ph a in wet benzene, and the 0 bands of chl a in pyridine and dry benzene. The order of the sizes of band strength changes varies from system to system. These results give further indication of the differences in specific solvent interactions for each system.

The order of sizes of band strength changes is consistently different from the order of sizes of band peak shifts for a given system. While individual bands sometimes show the 
aame relative sizes of peak shift and intensity change, there are number of instances where a large band peak shift is accompanied by little or no change in band strength, and vice versa. As example, the B bands of chl a and chl b show large red shifts in the change from ether to pyridine but the intensities remain unchanged. On the other hand, the BS band of chl a and the $\mathrm{Y}$ band of al chl a in the change to wet benzene, and the UV band of chl $\underline{b}$ in the change to acetono show changes in intensity but not in band position. These results suggest that solvent interactions can produce several types of perturbations. Where band position only is altered, a coulombic (or inductive) effect is probably predominant with little influence on the magnitude of the transition moment. Where bind intensity only is altered, a conjugative (or migrational) effect is likely to be predominant with influence primarily on the magnitude of the transition moment. Finally, when position and intensity of a band are changed, both conjugative and coulombic effects are probably occurring.

As shown in Table 31 the intensity changes of neighboring bands and of next neighbor bands are, in most instances, different. For chl $a, \operatorname{chl} \underline{b}$, and ph $\underline{a}$, where changes in two or more solvents can be compared, it can be seen that the differences in changes between neighboring bands and between next neighbor bands usually vary from solvent to solvent. These observations again are consistent with the notion that transitions of different polarization are present in both the upper 
and lower energy systems. However, the lack of similarity in the intensity changes of neighboring bands, or of next neighbor bands, does not appear consistent with the suggestion that certion bands are related as vibrational sub-bands of the same transition. For example, the similarity of peak ahifts for the $R$ and $O$ bands, and for the $B$ and $B S$ bands of $p h$ a raised the possibility of relationships between these bands. However, the intensity changes of the $R$ and the $O$ bands are different in sign, and those of the $B$ and $B S$ bancis differ in magnitude. This seems to be indicative of differences in band polarization.

For chl a, the B and BS bands consistently show fairly large decreases in intencity where changes occur. In pyridine and wet benzene the relative sizes of peak shifts and intensity changes for the B and BS bands show particularly poor correspondence. In dry and wet cyclohexane and benzene the UV band shows no intensity change, which corielates well with the absence of band peak shifts. When changes occur, the UV band shows predominantly small intensity increases which do not correspond well with the relative sizec of the peak shifts. The 0 band, where changes occur, shows large per cent increases in intensity except in wet cyclohexane where nearly all bands show intensity decreases. The relative sizes of the peak shifts and intensity changes for the $O$ band correspond well in the dry inert solvents, but not in the others. The majority of the intensity changes of the $R$ band are small increases which correspond fairly well with the relative sizes of the peak shifts. 
The behavior of the $Y$ band is perhaps the most erratic, both Iarge Increases and large decreases of intensity occurring. The total G inteneity shows both increases and decreases, but the decreases are predominant.

For chl b, the larger intensity changes are consiotently in the UV region, with both increases and decreases occurring. The $B$ and BS bands show either no change or relatively small decreases of intensity. The relative sizes of the peak shifta and the intinity changes for the $B$ band do not correspond, although there is correspontence for the BS band in wet and dry benzene. Where changes occlir, the o band consistently shows increases of intensity, which are larger than the increases of the $R$ band. This correletes with the relativo sizes of the band shifts in dry benzene but not in the otier solvents. Except in pyridine, where the $G_{1}$ band has apparently shified to cover up the $Y$ rand, the $Y$ and $G$ bands show little cr no change in intensity.

Although there is close correspondence in the orders of size of band shifts for chl a and al chl a in wet benzene, the intensity changes are not closely related. Al chl a shows intensity increases in the $R$ and $U V$ bands, and a decrease in the $B$ band, while there is no change in those bands for chl a. In comparing ph a vs al ph a in wet benzene significant differences are also observed. While the $R$ bands show comparable increases, the $Y, B$, and UV bands of the two compounds change in opposite directions. 
Comparison of the chlorophylls and the pheophytins in regards to the correlation of orders of bizes of band peak shifts and of intensity changes shows that the overall consistency (or lack of consistency) is about the same for both types of compounds. For the chlorophylls the O, BS, and UV bands tend to show the poorest correlation in relative sizes of changes, while for the pheophytins the $Y$ and $G$ bands tend to show the least correlation. The absolute magnitudes of intensity changes for corresponding bands of the chlorophylls and the pheophytins are about the same (although usually not for the same oolvent change). There are some differences in direction of change however. For ph $a_{\text {, the }} \mathrm{O}$ band consistently shows a decrease in Inteneity in contrast to the usual increases for the chlorophylls. Intensity increases occur in the BS band of ph $\underline{a}$, and in the $\mathrm{B}$ bands of al $\mathrm{ph} \underline{a}$ and $\mathrm{ph} \underline{b}$, while these bands show decreases in the chlorophylis.

Tables 32, 33, 34, and 35

Table 32 lists the peak molar extinction coefficients and the half-widths for the main red and blue bands, the absorbance ratio of the red band peak and the minimum in the green region, the wavelength of the green minimum, and the ratio of the absorbance of the red band peak and that at the wavelength corresponding to the position of the second green band of the pheophytin. These parameters are commonly used for characterization of the compounds. When there is a decrease in molar 
Table 32

Spectroscopic Parameters of the Chlorophylls and Several

Derivatives in Various Solvents

\begin{tabular}{|c|c|c|c|c|c|c|c|}
\hline System & $\begin{array}{l}\varepsilon_{R} \times 10^{-4}, \\
\text { liters per } \\
\text { mole } \mathrm{cm}\end{array}$ & $\begin{array}{l}\varepsilon_{\mathrm{B}} \times 10^{-4}, \\
\text { liters per } \\
\text { mole cm }\end{array}$ & $\begin{array}{c}R_{1 / 2} \\
m_{\mu}\end{array}$ & $\underset{1 / 2}{B_{1 / 2}}$ & $\mathrm{R} / \min$ & $\lambda \min _{\mathrm{m}_{\mu}}$ & $R / 505^{a}$ \\
\hline $\operatorname{chl} a, E$ & 8.68 & 11.17 & 17.0 & 38.0 & 109 & 467.5 & 55 \\
\hline $\operatorname{chl} \bar{a}, A c$ & 7.74 & 9.41 & 19.0 & 44.3 & 85 & 474.9 & 43 \\
\hline $\operatorname{chl} a, \mathrm{MeOH}$ & 6.72 & 6.40 & 22.7 & 87.1 & 95 & 476.7 & 44 \\
\hline $\operatorname{chl} a, 11 / 2 \%$ py-pet & 8.52 & 9.96 & 16.6 & 41.0 & 94 & 476.3 & 47 \\
\hline $\operatorname{chl} a$, py & 7.97 & 10.62 & 19.4 & 39.5 & 114 & 483.0 & 57 \\
\hline $\operatorname{chl} a, b z-D$ & 5.53 & 7.83 & 30.8 & 69.6 & 78 & 477.5 & 46 \\
\hline $\operatorname{chl} a, b z-\mathrm{H}_{2} \mathrm{O}$ & 7.88 & 10.07 & 18.6 & 40.1 & 156 & 475.0 & 65 \\
\hline $\operatorname{chl} \mathrm{a}, \mathrm{CCl}_{4}-\mathrm{D}$ & 6.34 & 8.46 & 24.1 & 65.6 & 57 & 478.9 & 40 \\
\hline $\operatorname{chl} \underline{a}, \mathrm{CCl}_{4}-\mathrm{H}_{2} \mathrm{O}$ & 7.30 & 9.14 & 18.6 & 45.0 & 72 & 476.9 & 45 \\
\hline chl a, cyclo-D & 4.94 & 7.35 & 31.8 & 70.4 & 54 & 477.5 & 29 \\
\hline $\operatorname{chl} a, \operatorname{cyclo}-\mathrm{H}_{2} \mathrm{O}$ & 6.09 & 7.83 & 18.4 & 45.3 & 86 & 474.4 & 32 \\
\hline $\operatorname{chl} \underline{a}, \operatorname{cyclo}-\bar{D}+b z$ & 5.28 & 7.46 & 30.7 & 74.8 & 52 & 476.4 & 29 \\
\hline chl a, cyclo- $\mathrm{H}_{2} \mathrm{O}+\mathrm{bz}$ & 7.67 & 9.99 & 17.6 & 42.1 & 51 & 475.0 & 32 \\
\hline $\operatorname{ch} 1 b, E$ & 5.09 & 14.31 & 16.1 & 21.2 & 23 & 497.5 & 18 \\
\hline $\operatorname{chl} \underline{b}, A c$ & 4.24 & 12.01 & 20.1 & 25.9 & 17 & 510.0 & 17 \\
\hline
\end{tabular}


Table 32 (Contd.)

\begin{tabular}{|c|c|c|c|c|c|c|c|}
\hline System & $\begin{array}{c}\varepsilon_{R} \times 10^{-4} \\
\text { liters per } \\
\text { mole } \mathrm{cm}\end{array}$ & $\begin{array}{l}\varepsilon_{B} \times 10^{-4} \\
\text { liters per } \\
\text { mole } \mathrm{cm}\end{array}$ & $\begin{array}{c}R_{1 / 2} \\
\mathbf{m}_{4}\end{array}$ & $\underset{1 / 2}{\mathrm{~B}_{\mu}}$ & $\mathrm{R} / \min$ & $\lambda_{m_{\mu}}^{\min }$ & $\mathrm{R} / 505^{\mathrm{a}}$ \\
\hline $\operatorname{chl} b, p y$ & 4.18 & 12.80 & 23.0 & 25.4 & 12 & 526.2 & 14 \\
\hline $\operatorname{chI} b, b z-D$ & 3.37 & 9.79 & 37.1 & 34.9 & 10 & 519.5 & 10 \\
\hline $\operatorname{chl} \underline{b}, b z-H_{2} \mathrm{O}$ & 5.18 & 13.71 & 17.2 & 21.8 & 20 & 512.1 & 19 \\
\hline al chl a, E & 5.08 & 10.08 & 21.6 & 36.6 & 50 & 470.0 & 29 \\
\hline al $\operatorname{chl} a, p y$ & 4.74 & 10.63 & 24.7 & 29.1 & 30 & 480.00 & 22 \\
\hline al $\operatorname{chl} a, b z-D$ & 4.21 & 9.11 & 23.8 & 38.0 & 42 & 473.6 & 26 \\
\hline al chl a, bz- $\mathrm{H}_{2} \mathrm{O}$ & 4.52 & 9.62 & 23.4 & 37.2 & 45 & 472.5 & 25 \\
\hline ph $a, E$ & 5.30 & 10.74 & 16.6 & 51.2 & 18 & 452.5 & 5.2 \\
\hline ph a, py & 4.85 & 10.73 & 20.4 & 44.9 & 13 & 457.5 & 4.7 \\
\hline $\mathrm{ph} \underline{a}, \mathrm{bz}-\mathrm{H}_{2} \mathrm{O}$ & 5.42 & 11.02 & 18.4 & 47.9 & 19 & 455.7 & 5.0 \\
\hline ph a, EHCl & 4.14 & 12.29 & 27.9 & 37.8 & 28 & 474.2 & 10.4 \\
\hline al ph a, $\mathrm{E}$ & 3.69 & 10.20 & 20.5 & 40.7 & 19 & 454.4 & 6.5 \\
\hline al ph $a, p y$ & 3.19 & 9.66 & 24.4 & 39.6 & 8.3 & 458.7 & 4.5 \\
\hline al $\mathrm{ph} a, b z-\mathrm{H}_{2} \mathrm{O}$ & 3.48 & 10.01 & 22.6 & 39.8 & 16 & 459.5 & 4.3 \\
\hline al $\mathrm{ph}$ a, $\mathrm{BHCl}$ & 2.74 & 9.58 & 30.8 & 33.8 & 17 & 481.3 & 8.8 \\
\hline ph $\underline{b}, \vec{E}$ & 3.18 & 15.56 & 16.0 & 16.2 & 7.3 & 472.1 & 3.0 \\
\hline $\mathrm{ph} \underline{\mathrm{b}}, \mathrm{py}$ & 2.66 & 13.01 & 20.6 & 25.2 & 5.0 & 484.0 & 2.4 \\
\hline $\mathrm{ph} \overline{\bar{b}}, \mathrm{ERCl}$ & 2.65 & 13.54 & 23.0 & 29.2 & 5.5 & 487.5 & 3.0 \\
\hline
\end{tabular}

$a_{\text {For the }} \mathrm{b}$ compounds, the ratio $\mathrm{R} / 520$ is given. 
Table 33

Ratios of Peak Absorbances (d), Oscillator Strengths ( $f$ ), and Dipole Strengths (D)

\begin{tabular}{|c|c|c|c|c|c|c|c|c|c|}
\hline $\begin{array}{l}\text { Ratio, } d / d \text { System } \\
f / f^{\prime} \\
D / D !\end{array}$ & $\operatorname{chl}_{E}$, & $\underset{A c}{\operatorname{chl}} a$ & $\frac{\operatorname{chl} a,}{\text { MeOH }}$ & $\begin{array}{l}\text { chl a, } \\
11 / 2 \% \\
\text { py-pet }\end{array}$ & $\underset{\mathrm{py}}{\mathrm{chl}} \underline{\mathrm{a}}$ & $\underset{b z=D^{c h l}}{a}$ & $\underset{b z-H_{2}}{c h l} a$ & $\operatorname{chl}_{4}=\frac{a}{b}$ & $\operatorname{chl}_{4}-\mathrm{H}_{2} \mathrm{O}$ \\
\hline $\mathrm{B}_{\mathrm{T}}$ & $\begin{array}{l}1.29 \\
3.03 \\
1.97\end{array}$ & $\begin{array}{l}1.22 \\
2.78 \\
1.81\end{array}$ & $\begin{array}{l}0.95 \\
2.07 \\
1.32\end{array}$ & $\begin{array}{l}1.17 \\
3.29 \\
2.16\end{array}$ & $\begin{array}{l}1.33 \\
3.04 \\
2.01\end{array}$ & $\begin{array}{l}1.42 \\
2.46 \\
1.57\end{array}$ & $\begin{array}{l}1.28 \\
3.02 \\
1.97\end{array}$ & 1.33 & 1.25 \\
\hline $\mathrm{B}_{\mathrm{T}} / \mathrm{BS}$ & $\begin{array}{l}1.57 \\
1.26 \\
1.33\end{array}$ & $\begin{array}{l}1.37 \\
1.12 \\
1.20\end{array}$ & $\begin{array}{l}1.12 \\
1.00 \\
1.21\end{array}$ & $\begin{array}{l}1.33 \\
1.31 \\
1.43\end{array}$ & $\begin{array}{l}1.66 \\
1.54 \\
1.90\end{array}$ & $\begin{array}{l}1.35 \\
1.14 \\
1.21\end{array}$ & $\begin{array}{l}1.55 \\
1.46 \\
1.57\end{array}$ & 1.31 & 1.45 \\
\hline $\mathrm{R}_{\mathrm{T}}$ & $\begin{array}{l}6.75 \\
3.47 \\
3.89\end{array}$ & $\begin{array}{l}5.44 \\
3.04 \\
3.29\end{array}$ & $\begin{array}{l}4.32 \\
2.87 \\
3.25\end{array}$ & $\begin{array}{l}7.03 \\
2.70 \\
2.92\end{array}$ & $\begin{array}{l}6.03 \\
2.33 \\
2.48\end{array}$ & $\begin{array}{l}3.65 \\
2.84 \\
3.10\end{array}$ & $\begin{array}{l}6.40 \\
3.50 \\
3.85\end{array}$ & 4.59 & 5.98 \\
\hline $\mathrm{R}_{\mathrm{T}}$ & $\begin{array}{r}12.5 \\
6.30 \\
7.53\end{array}$ & $\begin{array}{l}9.8 \\
5.39 \\
6.00\end{array}$ & $\begin{array}{l}9.4 \\
5.16 \\
7.39\end{array}$ & $\begin{array}{r}16.5 \\
8.84 \\
9.89\end{array}$ & $\begin{array}{c}13.9 \\
7.73 \\
7.81\end{array}$ & $\begin{array}{l}6.85 \\
5.11 \\
5.95\end{array}$ & $\begin{array}{r}11.3 \\
6.00 \\
6.92\end{array}$ & 9.00 & 11.5 \\
\hline$R_{T} / G_{1}$ & $\begin{array}{l}24.3 \\
11.3 \\
14.6\end{array}$ & $\begin{array}{l}22.6 \\
11.1 \\
13.0\end{array}$ & $\begin{array}{r}24.7 \\
9.9^{\mathrm{a}} \\
13.3^{\mathrm{a}}\end{array}$ & $\begin{array}{l}29.1 \\
12.2 \\
15.1\end{array}$ & $\begin{array}{c}31.6 \\
8.95 \\
13.8\end{array}$ & $\begin{array}{l}19.6 \\
11.2^{\mathrm{a}} \\
14.3^{\mathrm{a}}\end{array}$ & $\begin{array}{c}26.9 \\
7.64^{a} \\
12.3^{\mathrm{a}}\end{array}$ & 18.0 & 20.6 \\
\hline$R_{T} / G_{2}$ & $\begin{array}{l}56.8 \\
18.9 \\
31.0\end{array}$ & $\begin{array}{l}44.6 \\
20.9 \\
26.7\end{array}$ & & $\begin{array}{l}46.9 \\
19.9 \\
35.4\end{array}$ & $\begin{array}{l}41.3 \\
18.9 \\
27.6\end{array}$ & 19.9 & 28.3 & 38.6 & 46.6 \\
\hline
\end{tabular}


Table 33 (Contd.)

\begin{tabular}{|c|c|c|c|c|c|c|c|c|c|}
\hline $\begin{array}{l}\text { Ratio, } d / d>\text { System } \\
f / f^{\prime} \\
D / D^{\prime}\end{array}$ & $\begin{array}{l}\text { chl } a, \\
\text { cyclo- }\end{array}$ & $\begin{array}{l}\operatorname{chl} a \\
\operatorname{cycl}=- \\
\mathrm{H}_{2} \mathrm{O}\end{array}$ & $\begin{array}{l}\operatorname{chl} a, \\
\text { cyclo- } \\
D+b z\end{array}$ & $\begin{array}{l}\operatorname{chl} \frac{a}{1} \\
\operatorname{cyclo-} \\
\mathrm{H}_{2} \mathrm{O+bz}\end{array}$ & $\operatorname{chl}_{E} \stackrel{b}{-}$ & $\mathrm{chl} b$ & chl by & $\begin{array}{l}\mathrm{chl} b, \\
b z-D^{-}\end{array}$ & $\underset{\mathrm{bz}-\mathrm{H}_{2} \mathrm{~b}}{\mathrm{c}}$ \\
\hline $\mathrm{B}_{\mathrm{T}} / R_{\mathrm{T}}$ & $\begin{array}{l}1.49 \\
2.58 \\
1.68\end{array}$ & $\begin{array}{l}1.29 \\
2.74 \\
1.80\end{array}$ & $\begin{array}{l}1.41 \\
2.41\end{array}$ & $\begin{array}{l}1.30 \\
2.81\end{array}$ & $\begin{array}{l}2.31 \\
6.38 \\
4.60\end{array}$ & $\begin{array}{l}2.85 \\
6.48 \\
4.55\end{array}$ & $\begin{array}{l}3.10 \\
5.86\end{array}$ & $\begin{array}{l}2.90 \\
5.69 \\
4.02\end{array}$ & $\begin{array}{l}2.67 \\
6.05 \\
4.01\end{array}$ \\
\hline $\mathrm{B}_{\mathrm{T}} / \mathrm{BS}$ & $\begin{array}{l}1.36 \\
1.32 \\
1.42\end{array}$ & $\begin{array}{l}1.33 \\
1.29 \\
1.37\end{array}$ & $\begin{array}{l}1.30 \\
1.28\end{array}$ & $\begin{array}{l}1.414 \\
1.39\end{array}$ & $\begin{array}{l}2.71 \\
3.21 \\
3.56\end{array}$ & $\begin{array}{l}2.52 \\
2.41^{b} \\
2.61^{b}\end{array}$ & $\begin{array}{l}2.54 \\
3.22\end{array}$ & $\begin{array}{l}2.48 \\
2.94^{b} \\
3.77^{b}\end{array}$ & $\begin{array}{l}2.81 \\
2.78^{\mathrm{b}} \\
2.41^{\mathrm{b}}\end{array}$ \\
\hline $\mathrm{R}_{\mathrm{T}} / \mathrm{O}_{\mathrm{T}}$ & $\begin{array}{l}3.54 \\
2.85 \\
3.14\end{array}$ & $\begin{array}{l}5.69 \\
3.52 \\
3.79\end{array}$ & $\begin{array}{l}3.52 \\
2.90\end{array}$ & $\begin{array}{l}5.88 \\
3.64\end{array}$ & $\begin{array}{l}5.42 \\
2.51 \\
2.46\end{array}$ & $\begin{array}{l}4.40 \\
2.42 \\
2.61\end{array}$ & $\begin{array}{l}3.68 \\
2.32\end{array}$ & $\begin{array}{l}3.21 \\
2.46 \\
2.65\end{array}$ & $\begin{array}{l}6.36 \\
2.57 \\
2.79\end{array}$ \\
\hline $\mathrm{R}_{\mathrm{T}} / \mathrm{I}$ & $\begin{array}{l}6.8 \\
6.00 \\
7.02\end{array}$ & $\begin{array}{r}11.6 \\
7.22 \\
8.20\end{array}$ & $\begin{array}{l}6.9 \\
6.10\end{array}$ & $\begin{array}{c}10.8 \\
6.65\end{array}$ & $\begin{array}{l}8.40 \\
6.69 \\
8.08\end{array}$ & $\begin{array}{l}7.3 \\
6.93 \\
7.76\end{array}$ & & $\begin{array}{l}5.57 \\
7.69 \\
8.63\end{array}$ & $\begin{array}{l}8.21 \\
6.65 \\
7.35\end{array}$ \\
\hline$R_{T} / G_{1}$ & $\begin{array}{l}17.5 \\
14.0 \\
17.5\end{array}$ & $\begin{array}{l}21.5 \\
13.3 \\
15.1\end{array}$ & $\begin{array}{l}18.0 \\
15.2\end{array}$ & $\begin{array}{l}22.1 \\
13.3\end{array}$ & $\begin{array}{l}9.60 \\
3.06^{a} \\
3.82^{a}\end{array}$ & $\begin{array}{l}8.5 \\
2.97^{\mathrm{a}} \\
3.64^{\mathrm{a}}\end{array}$ & 7.05 & $\begin{array}{l}6.19 \\
4.73 \\
5.80\end{array}$ & $\begin{array}{l}9.43 \\
4.35 \\
6.25\end{array}$ \\
\hline$R_{T} / G_{2}$ & $\begin{array}{l}30.6 \\
21.0 \\
27.2\end{array}$ & $\begin{array}{l}33.5 \\
17.7 \\
20.7\end{array}$ & $\begin{array}{l}34.6 \\
22.9\end{array}$ & $\begin{array}{l}39.1 \\
15.5\end{array}$ & 28.0 & 17.4 & $\begin{array}{r}9.55 \\
12.5\end{array}$ & $\begin{array}{l}5.40 \\
15.4 \\
20.6\end{array}$ & $\begin{array}{l}20.3 \\
12.6 \\
14.7\end{array}$ \\
\hline
\end{tabular}


Table 33 (Contd.)

\begin{tabular}{|c|c|c|c|c|c|c|c|c|c|}
\hline $\begin{array}{l}\text { Ratio, d/d } \\
f / f^{\prime} \\
D / D\end{array}$ & al ${ }_{E}^{\mathrm{chl}}$ & $\therefore$ al ${ }_{\mathrm{py}}^{\mathrm{chl}} \underline{\mathrm{a}}$ & $\underset{b z-D}{a l} \operatorname{chl} a$ & $\underset{\mathrm{bz}-\mathrm{H}_{2} \mathrm{O}}{\mathrm{O}} \stackrel{\mathrm{a}}{-}$ & $\underset{E}{2},{ }^{p h}$ & $\mathrm{py}^{\mathrm{ph}}$ & $\frac{\mathrm{ph}}{\mathrm{bz}-\mathrm{H}_{2} \mathrm{O}}$ & $\begin{array}{l}\text { ph a, } \\
\text { EHCI }\end{array}$ & al $\underset{E}{p h} a$ \\
\hline $\mathrm{B}_{\mathrm{T}} / \mathrm{R}_{\mathrm{T}}$ & $\begin{array}{l}2.00 \\
5.64 \\
3.53\end{array}$ & 2.25 & 2.16 & $\begin{array}{l}2.13 \\
6.65^{c} \\
4.14^{c}\end{array}$ & $\begin{array}{l}2.03 \\
6.80 \\
4.20\end{array}$ & $\begin{array}{l}2.21 \\
6.27 \\
3.83\end{array}$ & $\begin{array}{l}2.03 \\
5.67 \\
3.56\end{array}$ & 2.97 & $\begin{array}{c}2.77 \\
10.5 \\
6.25\end{array}$ \\
\hline $\mathrm{B}_{\mathrm{T}} / \mathrm{BS}$ & $\begin{array}{l}2.31 \\
3.14 \\
3.37\end{array}$ & 2.30 & & & $\begin{array}{l}1.34 \\
1.96 \\
2.14\end{array}$ & $\begin{array}{l}1.32 \\
1.69 \\
1.83\end{array}$ & $\begin{array}{l}1.38 \\
1.75 \\
1.87\end{array}$ & 2.50 & \\
\hline$R_{T} / O_{T}$ & $\begin{array}{l}5.66 \\
3.78 \\
4.12\end{array}$ & 4.10 & 5.3 & $\begin{array}{l}5.3 \\
4.12 \\
4.47\end{array}$ & $\begin{array}{l}6.56 \\
3.03 \\
3.26\end{array}$ & $\begin{array}{l}5.46 \\
3.64 \\
3.99\end{array}$ & $\begin{array}{l}6.8 \\
4.42 \\
4.66\end{array}$ & 5.20 & $\begin{array}{l}8.90 \\
5.62 \\
5.20\end{array}$ \\
\hline$R_{T T} / Y$ & $\begin{array}{c}10.8 \\
7.55 \\
8.69\end{array}$ & 7.59 & 10.2 & $\begin{array}{l}9.3 \\
7.20 \\
8.35\end{array}$ & $\begin{array}{l}17.5 \\
9.36 \\
11.1\end{array}$ & $\begin{array}{c}12.6 \\
9.40 \\
12.9\end{array}$ & $\begin{array}{l}20.7 \\
12.8 \\
15.7\end{array}$ & 10.3 & $\begin{array}{l}24.3 \\
15.0 \\
16.5\end{array}$ \\
\hline $\mathrm{R}_{\mathrm{T}} / \mathrm{G}_{1}+\mathrm{G}_{1}^{\prime}$ & $\begin{array}{c}14.7 \\
8.00 \\
10.2\end{array}$ & 16.8 & 14.4 & $\begin{array}{c}14.5 \\
6.0^{\mathrm{a}} \\
7.75^{\mathrm{a}}\end{array}$ & $\begin{array}{l}5.20 \\
3.68 \\
5.38\end{array}$ & $\begin{array}{l}4.71 \\
3.90 \\
4.69\end{array}$ & $\begin{array}{l}5.7 \\
4.79 \\
5.90\end{array}$ & 10.3 & $\begin{array}{l}6.52 \\
5.00 \\
6.54\end{array}$ \\
\hline$R_{T T} / G_{2}+G_{2}^{\prime}$ & $\begin{array}{l}29.4 \\
17.0 \\
24.2\end{array}$ & 52.2 & 20.8 & 28.0 & $\begin{array}{l}4.52 \\
1.98 \\
2.63\end{array}$ & $\begin{array}{l}4.26 \\
2.22 \\
2.92\end{array}$ & $\begin{array}{l}4.98 \\
2.30 \\
3.02\end{array}$ & 18.6 & $\begin{array}{l}4.56 \\
2.25 \\
3.09\end{array}$ \\
\hline
\end{tabular}


Table 33 (Contd.)

\begin{tabular}{|c|c|c|c|c|c|c|}
\hline $\begin{array}{l}\text { Ratio, d/d System } \\
f / f, \\
D / D\end{array}$ & al ph a, & $\underset{b z-H_{2}}{a}$ & al $\underset{E H C l}{\mathrm{ph}}$ a, & $\underset{E}{p h} \underline{b}$ & ph $\stackrel{\mathrm{b}}{\mathrm{py}}$ & $\begin{array}{l}\text { ph b, } \\
\text { EHCI }\end{array}$ \\
\hline $\mathrm{B}_{\mathrm{T}} / \mathrm{R}_{\mathrm{T}}$ & 3.02 & $\begin{array}{c}2.87 \\
10.0 \\
5.77\end{array}$ & 3.48 & $\begin{array}{r}4.89 \\
12.00 \\
8.02\end{array}$ & $\begin{array}{r}4.90 \\
13.10 \\
8.33\end{array}$ & 5.12 \\
\hline $\mathrm{B}_{\mathrm{T}} / \mathrm{BS}$ & & & 2.78 & $\begin{array}{l}2.46 \\
2.74 \\
2.81\end{array}$ & $\begin{array}{l}2.33 \\
3.06^{b} \\
3.19^{b}\end{array}$ & 2.46 \\
\hline $\mathrm{R}_{\mathrm{T}} / \mathrm{O}_{\mathrm{T}}$ & 5.96 & $\begin{array}{l}7.5 \\
6.44 \\
7.20\end{array}$ & 3.94 & $\begin{array}{l}4.44 \\
2.74 \\
3.87\end{array}$ & $\begin{array}{l}4.17 \\
3.19 \\
3.55\end{array}$ & 3.36 \\
\hline $\mathrm{R}_{\mathrm{T}} / \mathrm{Y}$ & 9.30 & $\begin{array}{l}18.2 \\
10.3 \\
11.5\end{array}$ & 5.34 & $\begin{array}{l}5.08 \\
3.32 \\
4.90\end{array}$ & $\begin{array}{l}3.82 \\
3.72 \\
4.53\end{array}$ & 3.75 \\
\hline$R_{T} / G_{1}$ & 4.45 & $\begin{array}{l}4.86 \\
5.72 \\
7.04\end{array}$ & 8.78 & $\begin{array}{l}3.03 \\
2.52 \\
2.79\end{array}$ & $\begin{array}{l}2.74 \\
3.72 \\
4.69\end{array}$ & 3.01 \\
\hline$R_{T} / G_{2}$ & 3.47 & $\begin{array}{l}3.60 \\
2.78 \\
3.66\end{array}$ & 13.6 & $\begin{array}{l}2.98 \\
1.66 \\
2.24\end{array}$ & $\begin{array}{l}2.46 \\
0.96^{\mathrm{d}} \\
1.24^{\mathrm{d}}\end{array}$ & 3.12 \\
\hline
\end{tabular}

a The ratio is $R_{T} / G_{T}$. $\quad b_{T h e}$ ratio is $B_{T} / B S+U V_{1}$.

The ratio is $B_{T}+B S / R_{T^{*}}$. $d_{T h e}$ ratio is $R_{T} / G_{2}+G_{3}$ 
Table 34

The Change of Band Peak Wave Numbers with Change of Substituent in the Same Solvent

\begin{tabular}{|c|c|c|c|c|c|c|c|c|c|}
\hline $\begin{array}{l}\text { Compound vs } \\
\text { Compound } \\
\text { Band } \\
5 \mathrm{~cm}^{-1} \\
\% \text { Change }\end{array}$ & $\begin{array}{l}\operatorname{chl} b \\
\text { vs } \\
\operatorname{chl} a, \\
E\end{array}$ & $\begin{array}{c}\text { vs } b \\
\text { chl } a \\
\text { py }\end{array}$ & $\begin{array}{l}\operatorname{chl} b \\
v s- \\
\operatorname{chl} a \\
b z-H_{2}\end{array}$ & $\begin{array}{l}\text { al } \operatorname{chl}_{\mathrm{vs}} \mathrm{a} \\
\operatorname{chl} \mathrm{a} \\
\mathrm{E}\end{array}$ & $\begin{array}{c}\text { al } \operatorname{chl}_{\mathrm{v}}- \\
\mathrm{chl} a \\
\mathrm{py}^{-}\end{array}$ & $\begin{array}{l}\text { al } \operatorname{chl} a \\
\text { vs } \\
\text { chl a, } \\
\text { ba- } \mathrm{H}_{2} \bar{\sigma}\end{array}$ & $\begin{array}{l}\operatorname{ph} \frac{a}{v \bar{s}} \\
\operatorname{chl} \frac{a}{E}=\end{array}$ & $\begin{array}{l}\text { ph } \frac{a}{v \bar{s}} \\
\operatorname{chl} a, \\
\text { py }\end{array}$ & $\begin{array}{l}\mathrm{ph} a \\
\mathrm{vs} \\
\mathrm{chl} a, \\
\mathrm{bz}-\mathrm{H}_{2} \mathrm{O}\end{array}$ \\
\hline $\mathrm{R}$ & $\begin{array}{l}+434 \\
+2.86\end{array}$ & $\begin{array}{l}+340 \\
+2.28\end{array}$ & $\begin{array}{l}+431 \\
+2.87\end{array}$ & $\begin{array}{l}+163 \\
+1.08\end{array}$ & $\begin{array}{l}+201 \\
+1.35\end{array}$ & $\begin{array}{l}+212 \\
+1.41\end{array}$ & $\begin{array}{l}157 \\
1.04\end{array}$ & $\begin{array}{l}0 \\
0\end{array}$ & $\begin{array}{l}123 \\
0.82\end{array}$ \\
\hline 0 & $\begin{array}{l}+561 \\
+3.45\end{array}$ & $\begin{array}{l}+371 \\
+2.29\end{array}$ & $\begin{array}{l}+568 \\
+3.52\end{array}$ & $\begin{array}{l}+136 \\
+0.83\end{array}$ & $\begin{array}{l}117 \\
0.72\end{array}$ & $\begin{array}{l}+191 \\
+1.18\end{array}$ & $\begin{array}{l}+126 \\
+0.77\end{array}$ & $\begin{array}{l}+161 \\
+1.0\end{array}$ & $\begin{array}{l}+159 \\
+0.98\end{array}$ \\
\hline$Y$ & $\begin{array}{l}+283 \\
+1.63\end{array}$ & & $\begin{array}{l}+326 \\
+1.89\end{array}$ & $\begin{array}{l}+308 \\
+1.77\end{array}$ & $\begin{array}{c}89 \\
0.51\end{array}$ & $\begin{array}{l}+288 \\
+1.67\end{array}$ & $\begin{array}{l}+483 \\
+2.78\end{array}$ & $\begin{array}{l}+597 \\
+3.48\end{array}$ & $\begin{array}{l}+557 \\
+3.23\end{array}$ \\
\hline$G_{1}$ & $\begin{array}{l}350 \\
1.86\end{array}$ & $\begin{array}{l}595 \\
3.21\end{array}$ & $\begin{array}{l}450 \\
2.40\end{array}$ & $\begin{array}{l}+300 \\
+1.60\end{array}$ & $\begin{array}{c}+62 \\
+0.33\end{array}$ & $\begin{array}{l}+317 \\
+1.69\end{array}$ & $\begin{array}{c}58 \\
0.31\end{array}$ & $\begin{array}{l}140 \\
0.76\end{array}$ & $\begin{array}{l}113 \\
0.60\end{array}$ \\
\hline$G_{2}$ & $\begin{array}{l}392 \\
1.96\end{array}$ & $\begin{array}{l}240 \\
1.22\end{array}$ & $\begin{array}{c}50 \\
0.25\end{array}$ & $\begin{array}{l}+440 \\
+2.20\end{array}$ & $\begin{array}{l}+142 \\
+0.72\end{array}$ & $\begin{array}{l}+462 \\
+2.32\end{array}$ & $\begin{array}{l}300 \\
1.50\end{array}$ & $\begin{array}{c}35 \\
0.18\end{array}$ & $\begin{array}{l}196 \\
0.98\end{array}$ \\
\hline B & $\begin{array}{l}1268 \\
5.42\end{array}$ & $\begin{array}{l}1390 \\
6.15\end{array}$ & $\begin{array}{l}1390 \\
5.65\end{array}$ & $\begin{array}{l}+607 \\
+2.60\end{array}$ & $\begin{array}{l}+671 \\
+2.97\end{array}$ & $\begin{array}{l}+690 \\
+2.98\end{array}$ & $\begin{array}{r}+1079 \\
+4.51\end{array}$ & $\begin{array}{l}+1525 \\
+6.75\end{array}$ & $\begin{array}{l}+989 \\
+4.26\end{array}$ \\
\hline BS & $\begin{array}{l}1129 \\
4.60\end{array}$ & $\begin{array}{l}1270 \\
5.35\end{array}$ & $\begin{array}{l}1228 \\
5.00\end{array}$ & $\begin{array}{l}+1271 \\
+5.18\end{array}$ & $\begin{array}{l}+971 \\
+4.09\end{array}$ & & $\begin{array}{l}+1121 \\
+4.57\end{array}$ & $\begin{array}{l}+1625 \\
+6.85\end{array}$ & $\begin{array}{l}+838 \\
+3.42\end{array}$ \\
\hline UV & $\begin{array}{l}0 \\
0\end{array}$ & $\begin{array}{l}+275 \\
+1.09\end{array}$ & $\begin{array}{l}300 \\
1.13\end{array}$ & $\begin{array}{l}+1088 \\
+4.11\end{array}$ & $\begin{array}{l}+1650 \\
+7.06\end{array}$ & $\begin{array}{l}+1040 \\
+3.93\end{array}$ & $\begin{array}{l}+703 \\
+2.66\end{array}$ & $\begin{array}{l}+1460 \\
+5.75\end{array}$ & $\begin{array}{l}+422 \\
+1.60\end{array}$ \\
\hline
\end{tabular}


Table 34 (Contd.)

\begin{tabular}{|c|c|c|c|c|c|c|c|c|c|}
\hline $\begin{array}{l}\text { Band, } \\
6 \mathrm{~cm}^{-1} \\
\% \text { Change }\end{array}$ & $\begin{array}{l}\text { al } \mathrm{ph}_{\text {vo }} \mathrm{a} \\
\mathrm{chl} \mathrm{a},\end{array}$ & $\begin{array}{l}\text { al ph a } \\
\text { vs } \\
\text { chl } \frac{a}{p y} \\
p \bar{y}\end{array}$ & $\begin{array}{l}\text { al ph } a \\
v_{B} \\
\operatorname{chl} a_{1} \\
b z-H_{2} 0\end{array}$ & $\begin{array}{c}\mathrm{ph} b \\
\mathrm{vs} \\
\mathrm{chl} a \\
\mathrm{E}\end{array}$ & $\begin{array}{c}\mathrm{ph} \mathrm{b} \\
\mathrm{v} \boldsymbol{b} \\
\mathrm{chl} \\
\mathrm{py}\end{array}$ & $\begin{array}{c}\mathrm{ph} b \\
\mathrm{vE} \\
\mathrm{chl} b \\
E\end{array}$ & $\begin{array}{l}\mathrm{ph} \mathrm{b} \\
\mathrm{vs} \\
\mathrm{chl} \mathrm{b} \\
\mathrm{py}\end{array}$ & $\begin{array}{c}\text { ph } b-E H C I \\
\text { vs } \\
\text { chI } b \\
E\end{array}$ & $\begin{array}{r}\text { al } \mathrm{ph} a \\
\mathrm{v8} \\
\text { al } \mathrm{chl} a \\
\mathrm{E}\end{array}$ \\
\hline R & $\begin{array}{l}232 \\
1.53\end{array}$ & $\begin{array}{c}37 \\
0.25\end{array}$ & $\begin{array}{l}190 \\
1.26\end{array}$ & $\begin{array}{l}+137 \\
+0.91\end{array}$ & $\begin{array}{l}+310 \\
+2.08\end{array}$ & $\begin{array}{l}297 \\
1.91\end{array}$ & $\begin{array}{c}30 \\
0.20\end{array}$ & $\begin{array}{l}279 \\
1.79\end{array}$ & $\begin{array}{l}395 \\
2.58\end{array}$ \\
\hline 0 & $\begin{array}{l}0 \\
0\end{array}$ & $\begin{array}{c}+90 \\
+0.56\end{array}$ & $\begin{array}{c}+31 \\
+0.19\end{array}$ & $\begin{array}{l}+401 \\
+2.46\end{array}$ & $\begin{array}{r}+441 \\
+2.73\end{array}$ & $\begin{array}{l}160 \\
0.95\end{array}$ & $\begin{array}{r}+70 \\
+0.42\end{array}$ & $\begin{array}{l}100 \\
0.60\end{array}$ & $\begin{array}{l}125 \\
0.76\end{array}$ \\
\hline$Y$ & $\begin{array}{l}+383 \\
+2.21\end{array}$ & $\begin{array}{l}+546 \\
+3.18\end{array}$ & $\begin{array}{l}+473 \\
+2.74\end{array}$ & $\begin{array}{l}+543 \\
+3.13\end{array}$ & $\begin{array}{l}+672 \\
+3.92\end{array}$ & $\begin{array}{l}+260 \\
+1.47\end{array}$ & & $\begin{array}{l}+352 \\
+2.00\end{array}$ & $\begin{array}{c}+75 \\
+0.42\end{array}$ \\
\hline$G_{1}$ & $\begin{array}{l}+105 \\
+0.56\end{array}$ & $\begin{array}{l}+233 \\
+1.26\end{array}$ & $\begin{array}{r}+59 \\
+0.31\end{array}$ & $\begin{array}{l}0 \\
0\end{array}$ & $\begin{array}{l}+125 \\
+0.67\end{array}$ & $\begin{array}{l}+340 \\
+1.84\end{array}$ & $\begin{array}{l}+720 \\
+4.00\end{array}$ & $\begin{array}{l}+336 \\
+1.82\end{array}$ & $\begin{array}{l}195 \\
1.02\end{array}$ \\
\hline$G_{2}$ & $\begin{array}{r}+30 \\
+0.15\end{array}$ & $\begin{array}{l}+181 \\
+0.92\end{array}$ & $\begin{array}{c}+24 \\
+0.12\end{array}$ & $\begin{array}{l}810 \\
4.05\end{array}$ & $\begin{array}{l}610 \\
3.1\end{array}$ & $\begin{array}{l}418 \\
2.13\end{array}$ & $\begin{array}{l}370 \\
1.90\end{array}$ & $\begin{array}{l}403 \\
2.06\end{array}$ & $\begin{array}{l}410 \\
2.00\end{array}$ \\
\hline B & $\begin{array}{l}+1637 \\
+7.0\end{array}$ & $\begin{array}{l}+2050 \\
+9.10\end{array}$ & $\begin{array}{l}+1525 \\
+6.58\end{array}$ & $\begin{array}{l}298 \\
1.28\end{array}$ & $\begin{array}{l}+250 \\
+1.11\end{array}$ & $\begin{array}{l}\div 970 \\
+4.39\end{array}$ & $\begin{array}{l}+1640 \\
+7.75\end{array}$ & $\begin{array}{l}+958 \\
+4.34\end{array}$ & $\begin{array}{l}+1030 \\
+4.30\end{array}$ \\
\hline BS & & $\mathrm{JV}_{3}$ & & $\begin{array}{l}194 \\
0.79\end{array}$ & $\begin{array}{l}+480 \\
+2.02\end{array}$ & $\begin{array}{l}+935 \\
+4.00\end{array}$ & $\begin{array}{l}+1750 \\
+7.80\end{array}$ & $\begin{array}{l}+990 \\
+4.23\end{array}$ & \\
\hline UV & $\begin{array}{l}+793 \\
+3.0\end{array}$ & $\begin{array}{l}+1138 \\
+4.26\end{array}$ & $\begin{array}{l}+1188 \\
+4.49\end{array}$ & $\begin{array}{l}+728 \\
+2.76\end{array}$ & $\begin{array}{l}+1700 \\
+6.70\end{array}$ & $\begin{array}{c}+675 \\
+2.55 \\
U V_{I} \\
+910 \\
+3.66\end{array}$ & $\begin{array}{c}+1435 \\
+5.60 \\
U_{1} \\
+1525 \\
+6.35\end{array}$ & $\begin{array}{c}+687 \\
+2.60 \\
U V_{1} \\
+776 \\
+3.12\end{array}$ & $\begin{array}{l}295 \\
1.07\end{array}$ \\
\hline
\end{tabular}


Table 34 (Contd.)

\begin{tabular}{|c|c|c|c|c|c|c|c|c|}
\hline $\begin{array}{l}\text { Band, } \\
8 \mathrm{~cm}^{-1} \\
\% \text { Change }\end{array} \begin{array}{r}\text { Compound vs } \\
\text { Solvent }\end{array}$ & $\begin{array}{l}\text { ph } a-E H C l \\
\text { vs } \operatorname{chl} \mathrm{a} \\
\text { E }\end{array}$ & $\begin{array}{l}\text { al } \mathrm{ph} \mathrm{a}_{\mathrm{E}} \\
\mathrm{EHCl} \\
\text { vs chl a } \\
\mathrm{E}\end{array}$ & $\begin{array}{c}\text { al ph } a \\
\text { vs } \\
\text { ph } a \\
E-\end{array}$ & $\begin{array}{c}\text { al } \mathrm{ph} a \\
\mathrm{vs} \\
\mathrm{ph} a \\
\mathrm{py}^{-}\end{array}$ & $\begin{array}{c}\text { al ph } \mathrm{a} \\
\text { vo ph } \\
\text { EfICl }\end{array}$ & $\begin{array}{c}\mathrm{ph} b \\
\mathrm{vB} \frac{\mathrm{p} h}{\mathrm{E}} \underline{\mathrm{a}}\end{array}$ & $\underset{\mathrm{py}}{\mathrm{ph} b} \underset{\mathrm{ph}}{\mathrm{a}} \underline{-}$ & 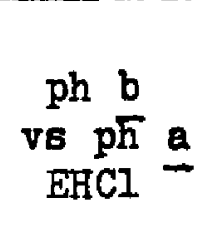 \\
\hline $\mathrm{R}$ & $\begin{array}{c}87 \\
0.57\end{array}$ & $\begin{array}{l}58 \\
0.38\end{array}$ & $\begin{array}{l}75 \\
0.50\end{array}$ & $\begin{array}{c}52 \\
0.35\end{array}$ & $\begin{array}{r}+29 \\
+0,19\end{array}$ & $\begin{array}{l}+294 \\
+1.96\end{array}$ & $\begin{array}{l}+295 \\
+1.98\end{array}$ & $\begin{array}{l}+242 \\
+1.61\end{array}$ \\
\hline 0 & $\begin{array}{c}29 \\
0.18\end{array}$ & $\begin{array}{c}29 \\
0.18\end{array}$ & $\begin{array}{l}115 \\
0.70\end{array}$ & $\begin{array}{c}71 \\
0.43\end{array}$ & $\begin{array}{l}0 \\
0\end{array}$ & $\begin{array}{l}+275 \\
+1.68\end{array}$ & $\begin{array}{l}+280 \\
+1.71\end{array}$ & $\begin{array}{l}+490 \\
+3.02\end{array}$ \\
\hline $\mathbf{Y}$ & $\begin{array}{l}+307 \\
+1.77\end{array}$ & $\begin{array}{c}51 \\
0.29\end{array}$ & $\begin{array}{l}100 \\
0.56\end{array}$ & $\begin{array}{c}51 \\
0.29\end{array}$ & $\begin{array}{l}358 \\
2.03\end{array}$ & $\begin{array}{r}+60 \\
+0.34\end{array}$ & $\begin{array}{r}+75 \\
+0.42\end{array}$ & $\begin{array}{l}+328 \\
+1.86\end{array}$ \\
\hline$G_{1}$ & $\begin{array}{l}108 \\
0.57\end{array}$ & $\begin{array}{l}150 \\
0.80\end{array}$ & $\begin{array}{l}+163 \\
+0.87\end{array}$ & $\begin{array}{l}+373 \\
+2.03\end{array}$ & $\begin{array}{c}42 \\
0.22\end{array}$ & $\begin{array}{c}+48 \\
+0.25\end{array}$ & $\begin{array}{l}+265 \\
+1.44\end{array}$ & $\begin{array}{c}+94 \\
+0.50\end{array}$ \\
\hline$G_{2}$ & $\begin{array}{l}0 \\
0\end{array}$ & $\begin{array}{c}48 \\
0.24\end{array}$ & $\begin{array}{l}+330 \\
+1.67\end{array}$ & $\begin{array}{l}+216 \\
+1.10\end{array}$ & $\begin{array}{c}48 \\
0.24\end{array}$ & $\begin{array}{l}510 \\
2.59\end{array}$ & $\begin{array}{l}575 \\
2.93\end{array}$ & $\begin{array}{l}795 \\
3.97\end{array}$ \\
\hline B & $\begin{array}{l}+229 \\
+0.98\end{array}$ & $\begin{array}{l}+381 \\
+1.63\end{array}$ & $\begin{array}{l}+558 \\
+2.28\end{array}$ & $\begin{array}{l}+533 \\
+2.21\end{array}$ & $\begin{array}{l}+152 \\
+0.64\end{array}$ & $\begin{array}{l}1377 \\
5.62\end{array}$ & $\begin{array}{l}1275 \\
5.29\end{array}$ & $\begin{array}{l}539 \\
2.28\end{array}$ \\
\hline BS & $\begin{array}{l}+1046 \\
+4.26\end{array}$ & $\begin{array}{l}+947 \\
+3.86\end{array}$ & & & $\begin{array}{c}97 \\
0.39\end{array}$ & $\begin{array}{l}1315 \\
5.12\end{array}$ & $\begin{array}{l}1100 \\
4.35\end{array}$ & $\begin{array}{l}1185 \\
4.63\end{array}$ \\
\hline WV & $\begin{array}{l}+1000 \\
+3.79\end{array}$ & $\begin{array}{l}+814 \\
+3.08\end{array}$ & $\begin{array}{c}+90 \\
+0.33 \\
G_{3} \\
50 \\
0.23\end{array}$ & $\begin{array}{c}G_{3} \\
+99 \\
+0.47\end{array}$ & $\begin{array}{l}+186 \\
+0.68\end{array}$ & $\begin{array}{l}0 \\
0 \\
G_{3} \\
925 \\
4.30\end{array}$ & $\begin{array}{l}+240 \\
+0.89\end{array}$ & $\begin{array}{l}260 \\
0.95\end{array}$ \\
\hline
\end{tabular}

${ }^{a}$ Changes less than the estimated probable error are omitted. Changes tabulated without sign are negative, that is shifts to the red; changes with plus signs are positive. 
Changes in Oscillator and Dipole Strengths with Change of Substituent in Ethyl Ether

\begin{tabular}{|c|c|c|c|c|c|c|c|c|c|}
\hline $\begin{array}{l}\text { Band } \\
\text { of } \\
\% \text { Change } \\
\text { oD } \\
\% \text { Change }\end{array}$ & $\begin{array}{c}\text { chl b } \\
\text { vs } \\
\text { chl a } \\
E\end{array}$ & $\begin{array}{l}\text { al } \operatorname{chl} a \\
\text { vB }_{B} \operatorname{chl} \frac{a}{} \\
E\end{array}$ & $\begin{array}{c}\text { ph } \mathrm{a} \\
\mathrm{vs} \operatorname{chI} \\
\mathrm{E}\end{array}$ & $\begin{array}{c}\text { al ph a } \\
\text { vs chl a } \\
\mathrm{E}\end{array}$ & $\frac{\mathrm{ah} b}{\mathrm{vs} \operatorname{chI} \mathrm{a}}=$ & $\begin{array}{c}\text { ph } \mathrm{b} \\
\mathrm{E} \\
\mathrm{E}\end{array}$ & $\begin{array}{l}\text { al } \mathrm{ph} a \\
\text { va } \mathrm{ph} \frac{\mathrm{a}}{\mathrm{E}}\end{array}$ & $\begin{array}{l}\mathrm{ph} b \\
\mathrm{vs} \overline{\mathrm{ph}} \mathrm{a}\end{array}$ & $\begin{array}{l}\text { al } \operatorname{ph}_{v_{B}}- \\
\text { al } \mathrm{chl}^{\mathrm{a}} \mathrm{a}\end{array}$ \\
\hline $\mathrm{R}$ & $\begin{array}{l}-0.063 \\
-37.1 \\
-0.369 \\
-36.1\end{array}$ & $\begin{array}{l}-0.034 \\
-20.0 \\
-0.197 \\
-19.2\end{array}$ & $\begin{array}{l}-0.067 \\
-39.4 \\
-0.393 \\
-38.4\end{array}$ & $\begin{array}{l}-0.080 \\
-47.0 \\
-0.461 \\
-45.0\end{array}$ & $\begin{array}{l}-0.107 \\
-63.0 \\
-0.635 \\
-62.0\end{array}$ & $\begin{array}{l}-0.044 \\
-41.1 \\
-0.266 \\
-40.7\end{array}$ & $\begin{array}{l}-0.013 \\
-12.6 \\
-0.068 \\
-10.7\end{array}$ & $\begin{array}{l}-0.040 \\
-38.8 \\
-0.242 \\
-38.5\end{array}$ & $\begin{array}{l}-0.046 \\
-33.8 \\
-0.264 \\
-32.0\end{array}$ \\
\hline $\mathrm{O}_{1}+0$ & $\begin{array}{l}-0.003 \\
-16.3 \\
-0.0 .5 \\
-13.3\end{array}$ & $\begin{array}{l}-0.013 \\
-26.5 \\
-0.063 \\
-24.0\end{array}$ & $\begin{array}{l}-0.015 \\
-30.6 \\
-0.070 \\
-27.6\end{array}$ & $\begin{array}{l}-0.033 \\
-67.3 \\
-0.155 \\
-59.0\end{array}$ & $\begin{array}{l}-0.026 \\
-53.0 \\
-0.175 \\
-66.5\end{array}$ & $\begin{array}{l}-0.018 \\
-44.0 \\
-0.128 \\
-56.0\end{array}$ & $\begin{array}{l}-0.018 \\
-53.0 \\
-0.085 \\
-44.0\end{array}$ & $\begin{array}{l}-0.011 \\
-32.3 \\
-0.093 \\
-48.4\end{array}$ & $\begin{array}{l}-0.020 \\
-55.5 \\
-0.092 \\
-46.0\end{array}$ \\
\hline$Y$ & $\begin{array}{l}-0.011 \\
-40.7 \\
-0.055 \\
-40.5\end{array}$ & $\begin{array}{l}-0.009 \\
-33.3 \\
-0.041 \\
-30.2\end{array}$ & $\begin{array}{l}-0.016 \\
-59.3 \\
-0.079 \\
-63.9\end{array}$ & $\begin{array}{l}-0.021 \\
-77.8 \\
-0.102 \\
-75.0\end{array}$ & $\begin{array}{l}-0.008 \\
-29.6 \\
-0.081 \\
-59.5\end{array}$ & $\begin{array}{c}+0.003 \\
+18.7 \\
0 \\
0\end{array}$ & $\begin{array}{l}-0.005 \\
-45.5 \\
-0.023 \\
-40.3\end{array}$ & $\begin{array}{l}+0.008 \\
+72.8 \\
+0.022 \\
+38.6\end{array}$ & $\begin{array}{l}-0.012 \\
-66.6 \\
-0.061 \\
-64.2\end{array}$ \\
\hline$G($ Total $)$ & $\begin{array}{l}+0.011 \\
+45.8 \\
+0.068 \\
+66.0\end{array}$ & $\begin{array}{c}0 \\
0 \\
+0.012 \\
+11.6\end{array}$ & $\begin{array}{c}+0.080 \\
+333.0 \\
+0.353 \\
+343.0\end{array}$ & $\begin{array}{c}+0.044 \\
+183.0 \\
+0.204 \\
+198.0\end{array}$ & $\begin{array}{c}+0.061 \\
+252.0 \\
+0.308 \\
+299.0\end{array}$ & $\begin{array}{c}+0.050 \\
+143.0 \\
+0.240 \\
+140.0\end{array}$ & $\begin{array}{l}-0.036 \\
-34.6 \\
-0.149 \\
-32.6\end{array}$ & $\begin{array}{l}-0.019 \\
-18.3 \\
-0.045 \\
-9.9\end{array}$ & $\begin{aligned}+0.043 \\
+172.0 \\
+0.192 \\
+167.0\end{aligned}$ \\
\hline $\mathrm{B}_{1}+\mathrm{B}$ & $\begin{array}{l}+0.168 \\
+32.6 \\
+0.990 \\
+49.0\end{array}$ & $\begin{array}{l}+0.251 \\
+48.8 \\
+0.898 \\
+44.5\end{array}$ & $\begin{array}{l}+0.185 \\
+36.0 \\
+0.624 \\
+31.0\end{array}$ & $\begin{array}{c}+0.426 \\
+83.0 \\
+1.496 \\
+105.3\end{array}$ & $\begin{array}{c}+0.241 \\
+46.8 \\
+1.086 \\
+54.0\end{array}$ & $\begin{array}{c}+0.073 \\
+10.7 \\
0 \\
0\end{array}$ & $\begin{array}{l}+0.241 \\
+34.4 \\
+0.872 \\
+33.1\end{array}$ & $\begin{array}{l}+0.056 \\
+8.0 \\
+0.462 \\
+17.5\end{array}$ & $\begin{array}{c}+0.175 \\
+22.8 \\
+0.598 \\
+20.6\end{array}$ \\
\hline
\end{tabular}


Table 35 (Conta.)

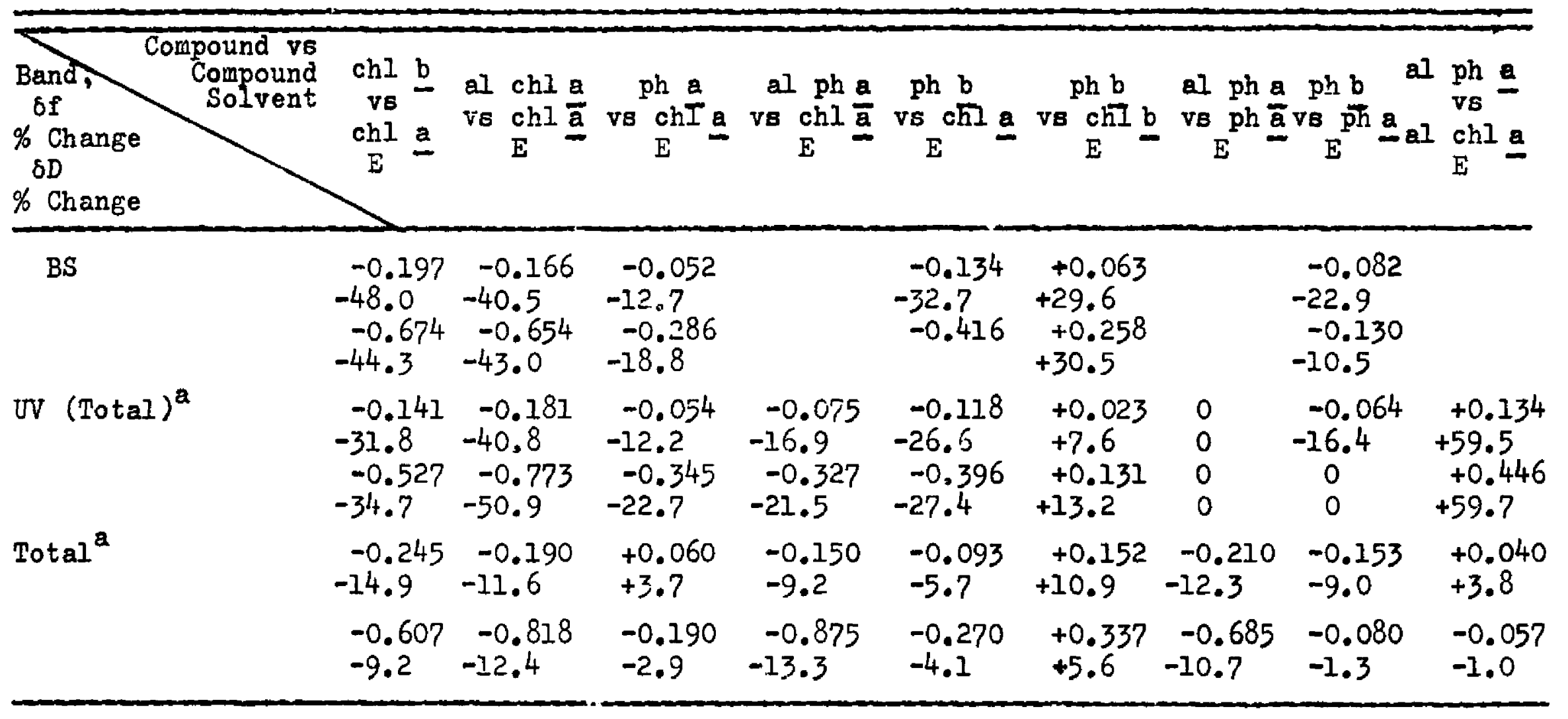

a Comparisons are made with the last UV cut offs taken at the same wave length. 
extinction coefficient of the peak with change of solvent, an increase in band half-width usually occurs. Only by examining Table 29 or Table 30 can it be determined if the actual strength of the transition is changed, or if the band is broadened thermally by the motions of loosely coupled solvent molecules. For example the $B$ band of chl a has a smaller peak molar extinction coefficient and greater half-width both in acetone and in wet benzene than in other. In acetone the band strength is decreased while in wet benzene it is unchanged.

In Table 33 are given ratios of peak absorbances, oscillator strengths, and dipole strengths characterizing the relationships of band intensitios for the lower energy band system and the B and BS bands. The subscript "s" with the letters designating the bands means tirat the total $f$ or $D$ value has been used either where band splitting occurred or where the separation between bands was not distinguished. With the peak absorbance ratios and the molar $e^{*}$ inction coefficients of Table 32, the corresponding cuefficients of the $0, Y, G_{1}, G_{2}$, and BS band peaks can be calculated.

The integrated intensity ratios provide an accurate appraisal of relative band intensity changes in comparison to the peak absorbance ratios. While these latter ratios tend to change in the same direction as the former, particularly where large changes of intensity occur, there are instances where the peak absorbance ratios are quite misleading. As example, for 
chl a in going from ethyl ether to petroleum ether with

$11 / 2$ per cont pyridine the absorbance ratios for $B_{T} / R_{T}$ and $B_{\mathrm{T}} / \mathrm{BS}$ indicate decreases while the integrated intensity ratios show increases.

The $\mathrm{B}_{\mathrm{T}} / \mathrm{R}_{\mathrm{T}}$ ratios undergo quite significant variations with change of solvent. These, in general, differ from compound to compound for a given solvent change, illustrating again the variations in specific solvent effects. Rather striking examples can be seen in comparing $\mathrm{chl}$ a and $\mathrm{chl} b$ in going from ethyl ether to pyridine where the ratio for $\operatorname{chl}$ a remains conetant but decreases significantly for $\mathrm{chl} \underline{b}$, and in comparing chl $\underline{a}$, ph $a$, and al ph a in the change from ethyl ether to wet benzene where the ratio remains escentially constant for chl a and al ph a but decreases significantly for ph a. The variations of the sizes of the $\mathrm{B}_{\mathrm{T}} / \mathrm{BS}, \mathrm{R}_{\mathrm{T}} / \mathrm{O}_{\mathrm{T}}$, and $R_{T} / Y$ ratios with change of solvent again reflect the lack of relatedness between the corresponding bands. A more or less constant ratio would indicate en equivalency of perturbation change.

Table 34 shows the change of band peak energy with change of substituent in a given solvent. The plus signs refer to shifts to higher energies; otherwise the changes are to lower energies. The shifts and per cents are in reference to the second compound listed. While the comparisons reflect the patterns of band peak shifts with change of substituent, they also clearly emphasize the dependence of the pattern on solvent. As 
example, for al chl a vs chl a in going from ether to pyridine the $O$ and the $Y$ bands shift to the red instead of to the blue, and for ph $b$ ve chl $a$ in going from ether to pyridine the $B$ and BS bands shift to the blue instead of to the red.

In Table 35 are shown the changes in the $f$ and $D$ values of the individual bands with change of substituent pattern. The solvent in all cases is ethyl ether; the tabulated values were obtained by subtracting the particular value of the second listed compound from that of the first. The percentage changes are in reference to the second listed compound.

In comparing the bands of the chlorophylls and the pheophytins (Tables 34 and 35), in the red through the green region of the spectrum, correspondence between the various bands is assumed. This is not entirely in line with the present theory of the spectra. While the $R$ bands always should correspond, it has been suggested for the chlorins (reference [58]) that, in comparing the free base with the metal substituted compound, the orange through green bands do not. Thus in the chlorophylls the $O$ bands are assumed to represent transitions polarized aiong a different axis than that of the $R$ bands, and presumably overlap the first vibrational sub bands related to the $R$ bands. The $Y$ and $G$ bands would therefore represent overlapping vibrational sub bands associated with both the $R$ and $O$ transitions. As a consequence of the interdigitation of bands in the chlorophylls, absorption in the orange through the green region would be expected to be characterized by very little symmetry and 
lack of distinctness of peak positions. The $G_{1}$ bands of the pheophytins are presumed to correspond to the $O$ bands of the chlorophylls, and the $G_{2}$ bands are supposedly the first vibrational sub bands related to the $G_{1}$ bands. The 0 bands, and possibly the $Y$ bands, of the pheophytins are presumably vibrational sub bands related to the $R$ bands. Thus the substituent change of pheophytinization in essence is oupposed to have shifted a band system from the orange to the green region of the spectrum.

The presently available data offer some support for the notion of the relatedness between the $O$ bands of the chlorophylls and the $G_{I}$ bands of the pheophytins, however certain empirical difficulties appear. Comparizon of the pheophytins with the corresponding chlorophylls in Table 35 shows that intensity increases of the G bands are always accompanied by intensity decreases of the $O$ bands and in two instances by intensity decreases of the $\mathrm{Y}$ bands. However, intensity decreases of the $O$ bands are accompanied also by decreases in the $R$ bands. Further, intensity decrease of the 0 band occurs in other substituent changes (chl b vs chl a, al chl a vs chl a) with little or no increase of $G$ band intensity. The $G_{2}$ bands of the pheophytins are always greater in intensity than the $G_{1}$ bands, whereas the $O$ bands of the chlorophylls are olways greater than

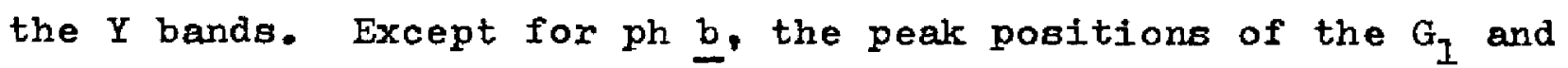
$G_{2}$ bands of the pheophytins are roughly equivalent to the 
positions of the $G_{1}$ and $G_{2}$ bands of the corresponding chlorophylls. Thus the increase of $G$ band intensity in the pheophytins could be visualized as intensification of already existing bands in the chlorophylls corresponding to the same transitions, rather than the shift of an entire band system from one spectral region to another. In general, the band symmetries for the chlorophylls, in the orange through the green region, did not give the appearance of complex interdigitation of band system; the pheophytins, in fact, showed somewhat less symmetry in the $O, Y$, and $G$ bands. The occurrence of splitting of the 0 bands of chl a and chl b might be interpreted as the partial resolution of band system interdigitation. However, there is a somewhat similar splitting of the $G$ bands of ph a in a region where no interdigitation is supposed to occur. Such splittings are absent for al chl a and al ph a, which suggests that the intact cyclopentanone ring may play a role in band splitting. The comparisons in Table 34 ehow the following characteristic variations in the lower (red through green) band system. For chl b vs chl a there is a general moving together of the bands, although an increase occurs between the $R$ and the $O$ banda. A similar moving together is observed in ph b vs ph a, but the distances between the $R$ and the 0 bands remain about equal. These changes result from the change of substituent from a $-\mathrm{CH}_{3}$ group (for the a compoands) to a -CHO group (for the $\mathrm{b}$ compounds) at the 3-position on the chlorin ring. According to the present theory of substituent effects 
(reference [58]), the presence of a -CHO group at the 3-position is expected to reduce the relative intensity and the relative energy differences between the two band systems in the visible that are polarized along different axes in the chlorin ring. The observed moving together of the red through green bands seems to be in general agrement with theory. A difficulty would appear to be the separation of the $R$ and the $O$ bands for $c h l \underline{b}$ vs chl a. Comparison of the $R / O, R / Y$, and $R / G$ intensity ratios in Table 33 shows that there are substantial decreases (except in $R / Y$ for chl $b$ vs chl a) in going fron the $a$ to the $\underline{b}$ compounds, which is in goneral agreenent with the prediction of reduction of intensity cifferences.

For al chl a vo chl $\bar{a}_{\text {: }}$ the general shift to the blue is accompanied by a separation of the $R$ and $G$ bands and the $O$ and $Y$ bands, with the $O-R$ and $G_{1}-Y$ distances showing relatively little change (except in pyridine). For al ph a vs ph a, while there is only a blue shift of the G bands, spearations of the $R$ and $G$ bands, the $Y$ and $G$ bands, and the $O$ and $Y$ bands occur, with the $O-R$ distance undergoing a decrease. These variations result from the alteration of the cyclopentanone ring that occurs with allomerization. The differences in changes of al chI a vs chl a and al ph a vs ph a suggest that the substituent effects of the magnesium atom and the isocylcic ring may not be entirely independent.

For ph a vs chl a there is separation between the $R$ and the $G_{1}$ bands, the $O$ and the $R$ bands, and the $O$ and the $Y$ bands, 
with a decrease in the $G_{1}-Y$ distance. Comparison between al ph a and al chl a shovi a similar patterr of shange. For ph b ve chl b similar variations are observed except that there is a slight increase in $G_{1}-Y$ rather than a decrease. These changes result from the replacement of the magnesium atom by two hydrogen atoms in the center of the chlorin ring.

In the present theory of the porphyrin spectra (references [57] and [58]) it is suggested that substituent perturbaticis can increase intensity in the lower band system by mixing the highly allowed states of the upper band system with those of the nearly forbidden lower band system. Thus, in effect, intensity is borrowed from the allowed transitions. Theory accounts only for the mising of transitions polarized along the same axis. If transitions polarized along different axes are independent of each other, and if a given substituent change hes offect predominantly along only one axis, a simple relationship between intensity changes in the upper and lower band systems might be observed. A possibility is that a certain band in the upper system might consistently show increases when a certain band in the lower system consistently decreases (or vice versa), while little change occurred in other sets of bands. In Table 35 the following can be observed. Chl a has the strongest absorption for the R, O, Y, BS, and UV bands. The pheophytins have the strongest absorption in the $G$ bands, and ph $b$ has the atrongest absorption in the $B$ band. A change in substitution that results in decresse of intensity of the $R$ band 
also results in intensity decreases in the 0 and $Y$ bands, except in comparing ph $\underline{b}$ with chl $\underline{b}$, and ph $\underline{b}$ with ph a where there are increases in intensity in the $Y$ band. The $R$ band fairly consistently shows larger absolute (though not per cent) decreases in intensity than the $Y$ and the $O$ bands. Decreases of intensity in the $R$, $O$, and $Y$ bands are consistently accompanied by an increase of intensity in the $B$ band, and a decrease in intensity in the BS band, except in comparing ph $\underline{b}$ and chl $\underline{b}$ where an increase in the BS band as well as in the B band occurs. These concurrent changes may represent a correlation in support of present theory in that mixing of upper and lower states can occur. Because of the fact that none of the band intensities remain constant for a particular substituent change, no simple relationship between a given upper band and a given lower band is apparent. The concurrent changes in the various bands clearly indicates that the substituent changes considered have effects along more than one axis in the chlorin ring.

In Table 31, showing the effect of solvent change, there are several instances where an intensity increase in the $R$ band is accompanied by a decrease in the $B$ band. Examples are chl a-MeOH and ph a-wet benzene. These effects, though smaller than the effects of substituent change, may represent examples where solvent perturbations can influence the mixing of upper and lower states.

Referring to Tables 34 and 35 the following empirical relationships are observed. An intensity decrease of the $R$ band 
is accompanfed by a blue shift for chl $\underline{b}$ vo $\operatorname{chl} a, a l \operatorname{chl} a$ vs chl $a$, ph $\underline{b}$ ve chl $a$, and ph $\underline{b}$ vo ph $\underline{a}$, but by a red shift for ph a vs chl a, al ph a vs chl a, al ph a ve al chl a, ph $\underline{b}$ vs $\operatorname{chl} \underline{b}$, and al ph a vs ph a. Decreases of intensity in the 0 and $Y$ bands are accompanied fairly consistently by blue shifts except for the $O$ bands of $\mathrm{ph} \underline{b} \mathrm{vs} \operatorname{chl} \underline{b}$ and al ph a vo al chI a in ether. Increase of intensity of the $B$ band and decrease of intensity of the BS band are accompanied by red shifts for chl $\underline{b}$ vo chl a and ph $\underline{b}$ vs chl a in ether, but by blue shifts in the other systems.

As shown in Table 33, change of substituent pattern that results in a relative increase (or decrease) of $\mathrm{B}_{\mathrm{T}} / \mathfrak{T}_{\mathrm{T}}$ is also accompanied, predominantly, by corresponding increases (or decreases) of $B / B S$ and $R / Y$ ( $R / O$ shows the same number of increases as decreases). For some of the solvent changes with respect to ethyl ether for a given compound, there is a similar relation between the changes of $B_{T} / R_{T}, B / B S$, and $R / Y$. The systems showing this are chl a-Ac, chl a-MeOH, chl a-1 $1 / 2$ per cent py-pet, chl a-bz-D, and ph b-py. This again suggests the possibility that changes in oolvent perturbations can have a similar (though weaker) effect as chanee in substituent perturbation in mixing upper and lower energy states.

Table 36

In Table 36 are shown the distances, in $\mathrm{cm}^{-1}$, between neighboring band peaks, and the distances between various bands 
Table 36

Distances Between Band Peaks

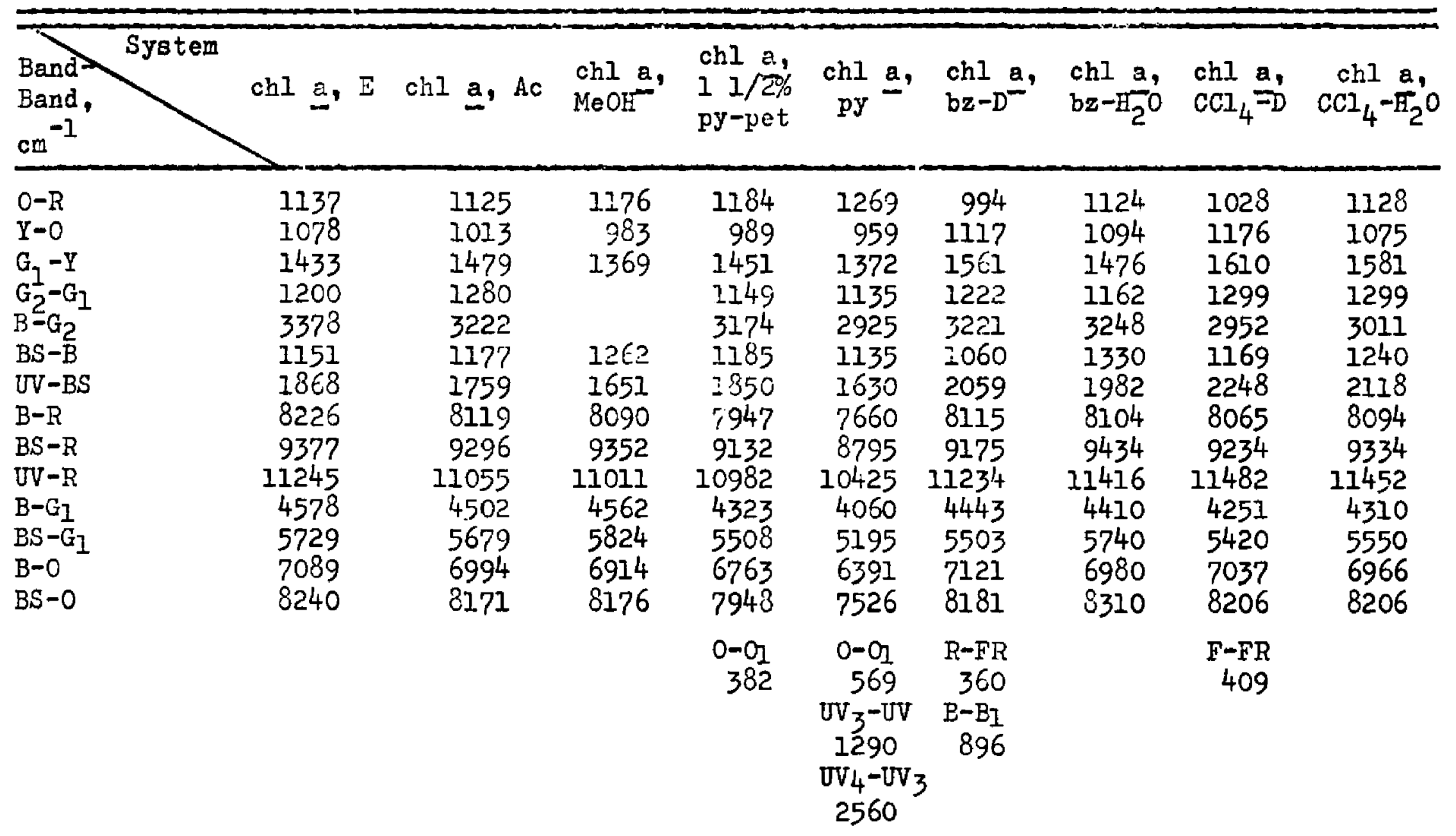


Table 36 (Contd.)

\begin{tabular}{|c|c|c|c|c|c|c|c|c|c|}
\hline $\begin{array}{l}\text { Band System } \\
\text { Band, } \\
\mathrm{cm}^{-1}\end{array}$ & $\begin{array}{l}\text { chl } a, \\
\text { cyclo- }\end{array}$ & $\underset{\operatorname{cyclo}}{\operatorname{chl}}=\mathrm{H}_{2} \mathrm{O}$ & $\begin{array}{l}\text { chl a, } \\
\text { cyclo- } \\
D+b z\end{array}$ & $\begin{array}{l}\operatorname{chl} a, \\
\text { cyclo: } \\
\mathrm{H}_{2} \mathrm{O+bz}\end{array}$ & $\operatorname{chl}_{E} b$, & $\mathrm{chl}_{\mathrm{Ac}} \underline{\mathrm{b}}$ & chl by & $\begin{array}{l}\operatorname{chl} b, \\
b z-D^{-}\end{array}$ & $\begin{array}{l}\mathrm{chl} b \text {, } \\
\mathrm{bz}-\mathrm{H}_{2} \mathrm{O}\end{array}$ \\
\hline \multirow[t]{3}{*}{$\begin{array}{l}O-R \\
Y-0 \\
G_{1}-Y \\
G_{2}-G_{1} \\
B-G_{2} \\
B S-B \\
O V-B S \\
B-R \\
B S-R \\
U V-R \\
B-G_{1} \\
B S-G_{1} \\
B-0 \\
B S-0\end{array}$} & $\begin{array}{r}968 \\
1155 \\
1542 \\
1170 \\
3359 \\
1051 \\
2032 \\
8164 \\
9215 \\
11247 \\
4499 \\
5550 \\
7196 \\
8247\end{array}$ & $\begin{array}{r}1072 \\
1116 \\
1420 \\
1170 \\
3478 \\
1002 \\
1950 \\
8226 \\
9228 \\
11178 \\
4618 \\
5620 \\
7154 \\
8156\end{array}$ & $\begin{array}{r}1000 \\
1134 \\
1525 \\
1308 \\
3223 \\
1063 \\
2054 \\
8190 \\
9253 \\
11307 \\
4531 \\
5594 \\
7190 \\
8253\end{array}$ & $\begin{array}{r}1111 \\
1093 \\
1455 \\
1208 \\
3354 \\
1096 \\
1866 \\
3221 \\
9317 \\
11183 \\
4562 \\
5653 \\
7110 \\
8206\end{array}$ & $\begin{array}{r}1264 \\
800 \\
800 \\
1158 \\
2502 \\
1340 \\
3050 \\
6524 \\
7864 \\
10864 \\
3660 \\
5000 \\
5260 \\
6600\end{array}$ & $\begin{array}{r}1284 \\
845 \\
684 \\
1195 \\
2401 \\
1304 \\
3170 \\
6409 \\
7713 \\
10883 \\
3596 \\
4900 \\
5125 \\
6429\end{array}$ & $\begin{array}{r}1490 \\
1775 \\
1255 \\
3175 \\
5930 \\
7185 \\
10360 \\
3265 \\
4520 \\
4630 \\
5885\end{array}$ & $\begin{array}{r}1263 \\
908 \\
674 \\
1632 \\
1913 \\
1429 \\
2872 \\
6290 \\
7719 \\
10589 \\
3545 \\
4974 \\
5127 \\
6556\end{array}$ & $\begin{array}{r}1261 \\
852 \\
700 \\
1562 \\
1989 \\
1411 \\
2910 \\
6364 \\
7775 \\
10685 \\
3551 \\
4962 \\
5103 \\
6514\end{array}$ \\
\hline & $\begin{array}{r}R-F R \\
290\end{array}$ & $\begin{array}{c}R-F R \\
562\end{array}$ & $\begin{array}{r}\mathrm{R}-\mathrm{FR} \\
287\end{array}$ & $\begin{array}{r}R-F R \\
459\end{array}$ & $\begin{array}{r}0-0_{1} \\
500\end{array}$ & $\begin{array}{l}0-0_{7} \\
476\end{array}$ & $\begin{array}{c}w V-w V_{1} \\
1650\end{array}$ & $\begin{array}{c}R-F R \\
448\end{array}$ & $\begin{array}{r}0-0_{1} \\
465\end{array}$ \\
\hline & $\begin{array}{c}\mathrm{B}-\mathrm{B}_{1} \\
1042 \\
\mathrm{BS}_{2}-\mathrm{BS} \\
350\end{array}$ & $\begin{array}{c}\mathrm{B}-\mathrm{B}_{1} \\
1043 \\
\mathrm{BS}_{2}-\mathrm{BS} \\
421\end{array}$ & $\begin{array}{c}\mathrm{B}-\mathrm{B}_{1} \\
1087 \\
\mathrm{BS}_{2}-\mathrm{BS} \\
466\end{array}$ & $\begin{array}{c}\mathrm{B}-\mathrm{B}_{1} \\
1132 \\
\mathrm{BS}-\mathrm{BS} \\
395\end{array}$ & $\begin{array}{l}w V-W V_{1} \\
1585 \\
w V_{3}-w V \\
1550\end{array}$ & $\begin{array}{l}w v-w v_{1} \\
1625 \\
w v_{3}-w V \\
1275\end{array}$ & $\begin{array}{c}\mathrm{WV}_{3}-\mathrm{UV} \\
1200 \\
\mathrm{UV}_{4}-\mathrm{WV}_{3} \\
1975\end{array}$ & $\begin{array}{c}0-O_{1} \\
386 \\
B-B_{1} \\
1163 \\
\mathrm{Wv}_{3}-\mathrm{UV} \\
1149\end{array}$ & $\begin{array}{c}w V-U V_{1} \\
1460 \\
W V_{3}-U V \\
1339\end{array}$ \\
\hline
\end{tabular}


Table 36 (Contd.)

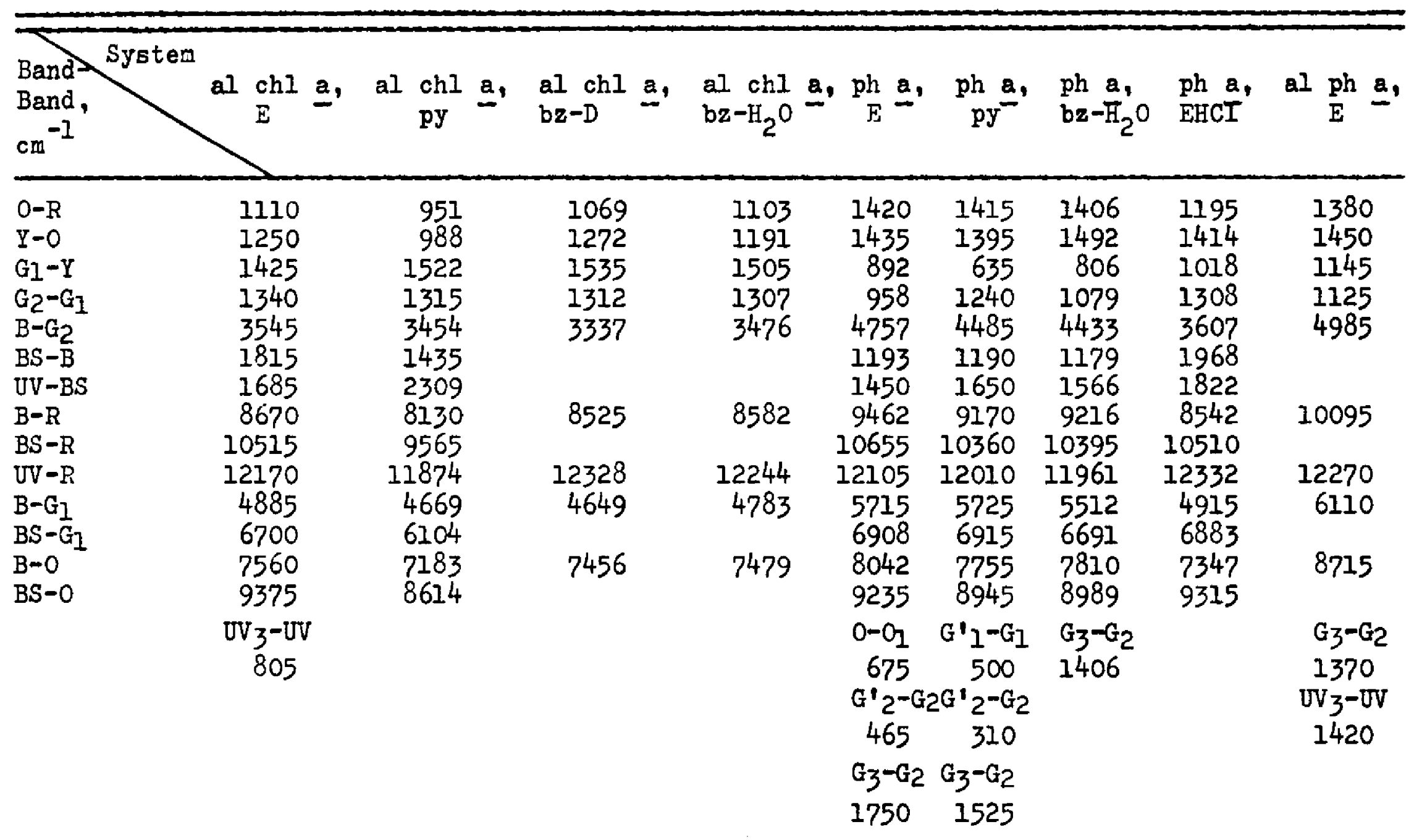


Table 36 (Contd.)

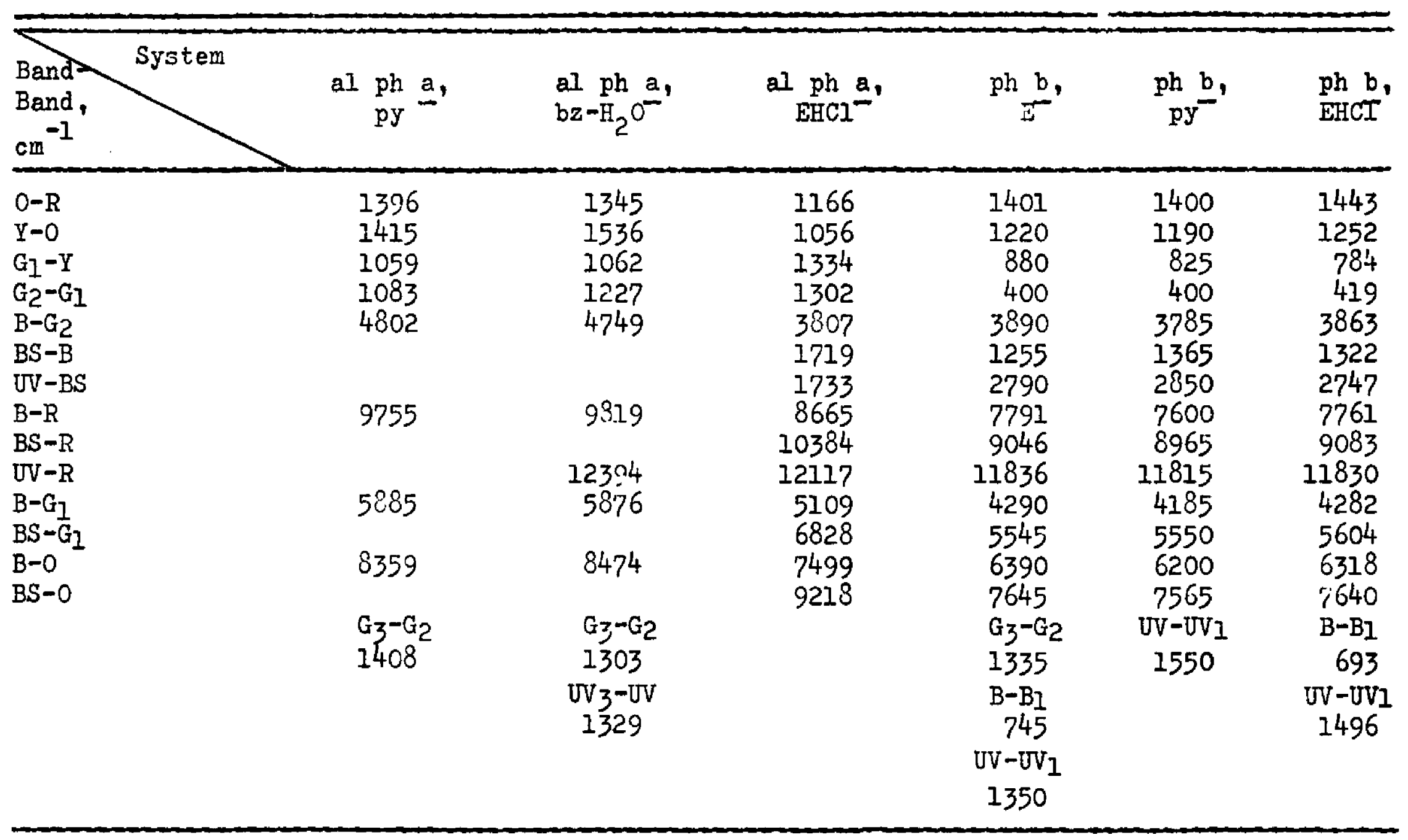


in the upper and lower energy systems which characterize their relative separation with variation of solvent. For the solvent change from ether to pyridine, the chlorophylls show greater variations In separations between the upper and lower bands than the pheophytins, while in going from ether to wet benzene ph a and al ph a generally show larger changes. Ph a and al ph $a$, in the change from ether to EHCl, show the lergest changes in the $B-R$ distance.

Tile distances between neighboring bands for a given compound in general show fairly significant variations with change of solvent. This is again indicative of lack of relatedness between bands, which for the $R$ and $O$ bands of the chlorophylis is in agreement with theory. Some exceptions are the $O-R$ and BS-B distances for $p h \underline{a}$, and the $O-R$ and $G_{2}-G_{1}$ distances for ph b. It was pointed out above that the intensity change relationships for the $O, R$, and $B S, B$ bands for ph a did not appear consistent for band relatedness. The $R$ and $O$ bands of ph b show nearly the same chenges in intensity. This, with the relative constancy of $O-R$, suggests that the bands may be related, in agreement with theory. The magnitude of the $G_{2}-G_{1}$ distance for ph $\underline{b}$, however, seems too small to represent a vibrational mode of the rigid chlorin ring. Similarly the $O-\mathrm{O}_{1}, \mathrm{R}-\mathrm{FR}$, and $\mathrm{BS}_{2}-\mathrm{BS}$ distances of the chlorophylls, and the G'-G distances of ph a appear too small to pertain to vibrations of the chlorin ring. The $G_{2}-G_{1}$ distances for ph a and al ph a 
show variations with change of solvent that are as large as those occurring for the chlorophylls, and differ significantly from each other in a given solvent. These sioervations indicate that the $G_{1}$ and $G_{2}$ vands are not related vibrational subbands as suggested by theory.

In an early interpretation of the chl a spectrum (reference [2], p. 630) it was suggestad that the $R, 0, Y, G_{1}$, and $G_{2}$ bancs were all related vibrational bands belonging to the same Ejectronic transition. The differences in distances between succeesive neighboring band pairs for a given solvent, as well as the varizitions with change of colvent would clearly seem to rule out this interpretation. Similar observations, for the other compounds, on neighboring band pair relationships, offer support for the present theoretical interpretation in that the visible band systems mist comprise at least two differently polarized transitions.

Compaision between djfferent compounds shows that a given interband distance is usually characteristically different for each compound. In ethyl ether, the distances between neighboring band peaks show the following relative size relationships. For the 0-R distance, $\mathrm{ph} \underline{\mathrm{a}} \approx \mathrm{ph} \underline{\mathrm{b}}>\mathrm{al}$ ph $\underline{a}>\operatorname{chl} \underline{\mathrm{b}}>\operatorname{chl} \underline{\mathrm{a}} \approx$ al chl a; for the $O-Y$ distance, al $\mathrm{ph} a=\mathrm{ph} a$ ph $\underline{b}>\operatorname{chl} \underline{a}>\operatorname{chl} \underline{b} ;$ for the $G_{1}-Y$ distance, chl $\underline{a}=a l$ chl $\underline{a}>$ al ph $\underline{a}>\mathrm{ph} \underline{a} \approx \mathrm{ph} \underline{\mathrm{b}}>\operatorname{chl} \underline{\mathrm{b}}$; for the $\mathrm{G}_{2}-\mathrm{G}_{1}$ distance, al $\operatorname{chl} \underline{a}>\operatorname{chl} a>\operatorname{chl} \underline{b}>$ al ph $\underline{a}>$ ph $\underline{a}>$ ph $\underline{b}$; for the BS-B 
distance, al $\operatorname{chl} \underline{a}>\operatorname{chl} \underline{b}>\operatorname{ph} \underline{b}>\operatorname{ph} \underline{a} \sim \operatorname{chl} \underline{a}:$ and for the UV-BS distance, $\operatorname{chl} \underline{b}>\operatorname{ph} \underline{b}>\operatorname{chl} \underline{a}>$ al $\operatorname{chl} \underline{a}>\operatorname{ph} \underline{a}$ As a consequence of the variations is specific solvent effects there is a marked dependency on the solvent in which the comparisons are made. For example, in comparing al chl a with chl a the difference in the UV-BS distances varies from $-183 \mathrm{~cm}^{-1}$ in ether to $+679 \mathrm{~cm}^{-1}$ in pyridine, and the difference in the $0-R$ distances valies from $-27 \mathrm{~cm}^{-1}$ to $-313 \mathrm{~cm}^{-1}$.

Precont theory of the effect of change of substituents suggests a corretation between intensity changes in the bands of the lower energy eystem and their separation from the bands of corresponding polarination in the upper energy system (reference [58]). Increase (or decrease) of intensity should be accompenied by increase (or decrease) of separation. It has been implied (refezence [59]) that in the chlorophylls, the 0 band corresponds with the $B$ band and the $R$ band corresponds with the BS bend. Therefore, in the pheophytins the $\mathrm{G}_{1}$ band presumably should correspond to the $B$ band in polarization. If substituent effects are independent, and if stetes of different polarization are not mixing, then the following simple relationships might be expected: I) a decrease of the $R$ band intensity should be accompanied by dccrease of BS-R in both the pheophytins and the chlorophylls, 2) a decrease in $O$ band intensity should be accompanied by a decrease in B-O for the chlorophylls, and 3) a decrease in $G$ band intensity should be accompanied by a decrease in $B-G_{1}$ in the pheophytins. 
Referring to Tables 36 and 35, the following are observed. For chl b vs chl a the intensities of the $R$ and $O$ bands decrease, and the $B S-R$ and $B-O$ distances decrease, in agreement with theory. For al chl a vs chl a the intensities of the $R$ and 0 bands decrease, but $B S-R$ and $B-O$ increase which is not in agreement with theory. For ph a ve chl a $R$ bend intensity jecreases, but BS-R increases, in disagreement with theory. However, the increase of $G$ band intensity is accompanied by an increase of $B-G_{1}$ in areadent with theory. Similar relationships occur for ph b vs chI b and for al ph a vs al chl a. In the lattor instance, it is assimed that the BS band of al ph $A$ ras essentially coalesced with the $B$ band, and the $B-R$ distance is found to be smaller than the BS-R distance of al chl a. For ph $\mathrm{b}$ vs gh $a$, the intensities of the $R$ and $G$ bands decrease and $B S-R$ and $G-G_{1}$ decrease, in agreement with theorv. For al ph 2 vs ph a, the intensities of the $R$ and $G$ bands decrease. The BS-R distance of ph a j.s larger than the B-R distance of al ph $a$, in agreement with theory. The $B-G_{1}$ dietance of al ph a is greater than that of $\mathrm{ph}$ a which is in disagreement with theory. From these comparisons, it appears that the substituent change effects, corresponding to pheophytinization and allomerization, still pose problems for theoretical consideration.

Similar comparisons, referring to Tables 36 and 31 , between changes in band intensities and interband distances arising from solvent changes for a given compound show that, 
in 21 instances out of 28 , intensity increases (or decreases) are accompanied by interband distance decreases (or incroases). Empirically these changes, which are not in accord with theory, resemble tlose occurring for pheophytinization and allomerization. This ouggests the possibility that specific oolvent interactions may be predominant at the center of the chlorin ring and/or the isocyclic ring. 


\section{SUMMARY}

Quantitative determination was made of the absorption spectre, in the visible through the near ultraviolet, of chl a, $\operatorname{chl} b, a l \operatorname{chl} a, p h a$, al thr $a$, and $p h \underline{b}$ in a number of common solvents. Band peak energies and interband separations are Biven for 33 systems, the oscillator strengths of the individual bands for 25 systems, and the dipole strengths for 22 systems. These data characierize in detail the variations in absorption of the compounds, and reveal interesting differences in solvent effects. Whils the data are limited in scope, they provide information of value for the eventusl detailed interpretation of the spectra. The current theoretical interpretations of the porphyrin spectr! are briefly summarized and comparisons are made between certain predictions and experimental observations.

For each compound, the effects of solvent changes on the individual band positions and the integrated band intensities are examined. Comparisons are made with ethyl ether as the reference solvent. In almost every system, both the change in band position and the change in band intensity differ significantly for different bands. Thus the data, in general, do not provide evidence that any of the neighboring bands, or next 
neighborlng bands, are related as vibrational sub bands belonging to the same electronic transition. Inis is in partial agreement with present theory in the prediction that there are two independent transitions, polarized along different axes in the chlorin ring, in both the upper and lower energy band systems. The observations do not support present theory in that, for the lower energy system, certain pairs of bands have been assigned as companion vibrational bands belonging to the same electronic transitions. It may be that more than two electronic transitions are prosent in the lower band system, a possibility not accounted for in present theory.

For the different compounds in a given solvent, comparisons are made of peak positions and intenfities of the various bands at corresponding positions in the spectrum. Each substituent change, corresponding to the intercomparison of two different compounds, shows significant effects, in nearly every case, on all of the bands, and thus on transitions polarized along different axes. The variations observed for the substituent change from a $-\mathrm{CH}_{3}$ group to a -CHO group at the 3-position on the chlorin ring (i.e. from the a derivative to the b derivative) are in general agreement with the effects predicted by theory. The substituent changes corresponding to allomerization and pheophytinization, however, produce some variations that are not in accord with present theory.

For the substituent changes studied, it is found that intensity decreases in the $R, O$, and $Y$ bands (in the lower 
energy system) are consistently accompanied by an increase of intensity in the $B$ band (in the upper energy system), and, in most instances, by decrease of intensity in the BS band (in the upper energy system). These concurrent changes may represent a correlation is support of present theory in the prediction that intensity may be gained in the lower energy band system from the urper band system through the perturbational mixing effects of substituents. Several ingtances are observed where change of solvent causes an intensity increese of the $R$ band accompanied by a decrease of intensity in the $B$ bend. These effects suggest that solvent perturbations can influence the mixing of upper and lower states.

The observed effects of substituent and solvent changes on band intensities and positions do not sugge日t definitive relationships between upper and lower bands in regards to the directions of polarization of the transitions in the chlorin ring. Irus, consistently similar variations of a certain upper band and a certain lower band, in relationship to the other bands, are not found. In the case of substituent effects, concurrent changes in nearly all the bands obscure a relationship. With different solvent changes for a given compound, the orders of sizes of band changes differ from system to system and a consistent pattern is not observed. The absence of definite relationships may arise from substituent effects not being independent of each other, or from the lack of independence of transitions polarized along difforent axes. 
The ranges of per cent change observed are as follows: for solvent effects on band peak positions $0-5.1$ per ceni with an average of about 1.0 per cent, for solvent effects on band intensities $0-66.6$ per cent with an average of about 10 per cent, for substituent effects on band peak positions $0-9.1$ per cent with an average of about 2.1 per cent, and for substituent effects on band intensities $0-333.0$ per cent with an average of about 50 per cent. As might be expected substituent effects are on the average significantly larger than bolvent effects although both effocts show wide variaticns in size.

The effect of the solvent, ethyl ether saturated with dry HCl gas, on $\mathrm{ph}$ a and al ph a was to make their spectra resemble those of $\mathrm{chl}$ a and al chl a, respectively. Fluorescence intensity was significantly reduced, as was observed for the chlorophylis in pure, ary nonpolar solvents. Inis indicates that protons were introduced into the centers of the chlorin rings of the pheophytins procucing oubstituent patterns like those of the corresponding chlorophylls.

Small amounts of benzene in both dry and wet cyclohexane caused significant increases of intensity throughout the spectra of chl a. This indicates that specific solvent interactions are important in producing spectral changes, and suggests that a systematic study of the various compounds in mixtures of inert and active solvents would provide useful information toward understanding the various solvent effects.

Comparison of the effects of a given solvent variation for 
a] chl a vs ohl a and for al ph a vs ph o shows lnat alteration of the icocyclis ring leads to signjificent differences in spectral changes. This indicates that specific solvent interactions occur at the isocyclic ring. The changes for al chl a vs chl a are different from those for al ph a vs ph a, ouggesting that the substituent perturbations of the magnesium atom ard of the isocyclic ring may not be independent.

In comparing the effects of a given solvent change on the chlorophylls and on the corresponding pheophyiins, significantly different changos for corresponding bends are usually observed. With intensity variations, diffeiennss in direction of change occur in some instancca. The changes in band peak positions for the chlorophylls are grineraily Jarger than for the pheophytins. These observations suggcst that specific solvent interactions at the magnesium atoms in the chlcrophylls are important. In several aspects the effects of change of solvent were observed to be similar to the effects of substituent change. Thus there are a number of instances where solvent change resulted in an increase of the band intensity ratio $B / R$ accompanied by increases in the intensity ratios $B / B S$ and $R / Y$. In three-fourths of the observed solvent effects, increases (or decreases) of intensity of certain bands in the lower energy system (i.e. the $R$ band for both the chlorophylls and the pheophytins, the $O$ band for the chlorophylls, and the $G_{1}$ band for the pheophytins) were accompanied by decreases (or increases) in the distances between certain corresponding upper and lower 
bands (i.e. BS-R for the chlorophylls and the phesphytins, B-O for the chlorophylls, and $B-G_{1}$ for the pheophytins). These concurrent changes resemble the variations occurring with pheophytinization and allomerication, and suggest the possibility that specific solvent interactions may be predomiant at the center of the chlorin ring and/or the isocyclic ring. Splitting of the $R$ and $O$ bands of $\operatorname{chl} a$ and $\operatorname{chl} \underline{b}$, and the $G$ bands of ph a was observed in certain solvents. No splitting, however, was seen in the corresponding allomerized compounds. This suggests that the perturbations of the unaltered isocyclic ring flay an essential role in the splitting. 


\section{BIBLIOGRAPHY}

1. Broolthaven Symposia in Eiology, No. II, "The Photochemical Apparatus -- Its Structure and Function," 1958 , Wolken, J.J., p. 87 , Sager, R., p. 101 .

2. Rabinowitch, E.I., "Photosynthesis," Interscience Publishers Inc. New York, 1945-56, pp. 1714-1740.

3. See reference $[1]$, p. 303.

4. Colmano, G., Biochim. Biophys. Acta 47454 (1961).

5. Bellamy, W.D., Gaines, G.L., Jr., and Tweet, A.G., J. Chem. Phys. 392528 (1963).

6. Sjoerdsma, W., Nature 138405 (1936).

7. Hughes, A., Proc. Roy. Soc. Al55 710, (1936).

8. Langmuir, I., and Schaefer, V.J., JACS 592075 (1937).

9. Alexander, A.E., J. Chom. Soc. 1813 (1937).

10. Hanson, E.A., Rec. Trav. Botan. Neerl. 36180 (1939).

11. Jacobs, E.E., Vatter, A.E., and Holt, A.S., Arch. Biochem. Biophys. 53228 (1954).

12. Jacobs, E.E., Holt, A.S., and Rabinowitch, E., J. Chem. Phys. 22142 (1954).

13. Jacobs, E.E., Holt, A.S., Kromhout, R., and Rabinowitch, E., Arch. Biochem. Blophys. 72495 (1957).

14. Trurnit, H.J., and Colmano, G., Biochim. Biophys. Acta 31434 (1959).

15. 'Pweet, A.G., Gains, G.L., Jr., and Bellamy, W.D., J. Chem. Phys. 402596 (I964).

16. Tweet, A.G., Gaines, G.I., Jr., and Bellamy, W.D., J. Chem. Phys. 411008 (1964). 
BIBIIOGRAPHY (Contr.)

17. Gä́nes, G.I., Ir., Bellamy, W.D., and I'weet, A.G., J. Chem. Phys. 41538 (1964).

13. Tweet, A.G., Bellamy, W.D., and Gaines, G.I., Jr., J. Chem. Phys. 412068 (1964).

19. Gaines, G.I., Jr., Tweet, A.G., and Bellamy, W.D., J. Chem. Phys. 422193 (1965).

20. Langmuir, I., J. Chem. Phys. 1756 (1933).

21. Rosoff, M., and Aron, C., J. Phys. Chem. 6921 (1965).

22. "Technique for Organic Chemistry" Vol. I, part IV, 3rd Edition, Ed. by Weissberger, A., Interscience Publ. Inc., New York (1960), pp. 3302-3303.

23. See Reference [22] pp. 2990-2993, and Liebhafsiky, H.A., and Winslow, E.H., JACS 682734 (1946).

24. See Reference [22] pp. 2990-2993, and von Wartenberg, H., Z. Electrochem. 36295 (1930).

25. Holt, A.S., Can. J. Biochem. Physiol. 36439 (1958).

26. Mulliken, R.S., J. Chem. Phys. 714 (1939).

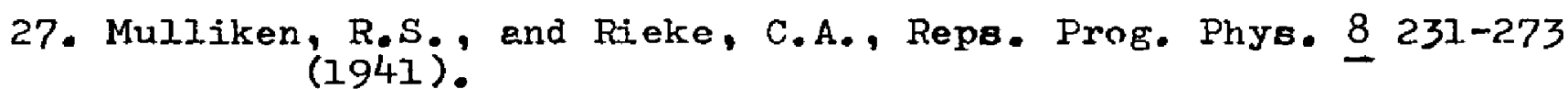

28. Zscheile, F.P., and Comar, C.I., Botan. Gaz. IO2 463 (1941).

29. Harris, D.G., and Zscheile, F.P., Botan, Gaz. 104515 (1943).

30. Wilhelmy, L., Ann. Physik. 119177 (1863).

31. Harkins, W.D., "The Physical Chemistry of Surface Films", pp. 121-124 (1952), Reinhold Publishing Corp.

32. Yamins, H.G., and Zisman, W.A., J. Chem. Phys. I 656 (1933).

33. Adamson, A.W., "Physical Chemistry of Surfaces", p. 119 (1960), Interscience Publishers, Inc., N.Y.

34. Guyot, M.J., Ann. Phys. 2506 (1924).

35. Chambers, J.F., Austrialian J. Chem. 16180 (1963). 


\section{BIBLIOGRAPHY (Contd.)}

36. Daviea, J.T., and Rideal, E. K. , "Interfacial Phenomena," p. 37, (1961), Academic Frees, New York.

37. Larry, J., private communication.

38. Strain, H.H., Thomas, M.R., and Katz, J.J., Biochim. Biophys. Acta 75306 (1963).

39. Smith, J.H.C., and Benitez, A., in Paech, K., and Tracey, M.V., "Modern Metlods of Plant Analysis" Vol. 4, Springer Verlag, p. 142, (1955).

40. Perkins, H.J., and Roberts, D.W.A., Diochim. Biophys. Acta $7920(1964)$.

41. Holt, A.S., and Jacots, E.E., Am. J. Bot. 41710 (1954).

42. Strain, H.H., Thomas, M.R., Crespi, H.L., Blake, M.I., and Katz, J.J., Ann. N.Y, Acad. Sci. 84617 (1960).

43. Kutyurin, V.M., and Knyazev, V.P., Dokl. Akad. Nauk. SSSR 149 (2) 456-9 (1963), (C.A. 59, 4206b (1963)).

44. Goodrich, F.C., in "Proceedings of the Second International Congress of Surface Activity," p. 85, (1957), Academic Press Inc., New York.

45. Adam, N.K., "The Physics and Chemistry of Surfaces," 3rd Edition, p. 38, (1941), Oxford University Press, London.

46. Moelwyn-Hughes, E.A., "Physical Chemistry", p. 919 (1957), Pergamon Press, New York.

47. Dorough, G.D., and Huennekens, F.M., JACS 743974 (1952).

48. Neuberger, A., and Scott, J., Proc. Roy. Soc. (A) 213 307 (1952).

49. Davies, J.T., in "Surface Phenomena in Chemiatry and Biology," p. 55 (1958), Edited by Danielli, J.F., Pankhurst, K.G.A., and Riddiford, A.C., Pergamon Presa, New York.

50. Böttcher, C.J.F., "Theory of Electric Polarisation," p. 13 (1952), Elsevier Publishing Co., New York.

51. Crisp, D.J., J. Colloid Sci. I 49 (1946). 


\section{BIBLIOGRAPHY (Contd.)}

52. Kirkwood, J.G., "Surface Chemistry," Publication of the American Association for the Advancement of Science, No. 21, p. 157 (1943).

53. Claes, H., Biochim. Biophys. Res. Comm. 3585 (1960).

54. Claes, H., and Nakayama, T., Nature 1831053 (1959).

55. Woodward, R.B., and Skaric, V., JACS 834677 (1961).

56. Miller, J.R., and Dorough, G.D., JACS 743977 (1952).

57. Platt, T.R., in "Radiation Biology," Vol. III, Chap. 2, Edited by Hollaender, A., McGraw-Hill Book Company, New York (1956).

58. Gouterman, M., J. Molecular Spectroscopy 6 138-163 (1961).

59. Gouterman, M., J. Molecular Spectroscopy I1 108-127 (1963).

60. Gouterman, M., J.: Molecular Spectroscopy 16 415-450 (1965).

61. Rappaport, G., PhD Thesis, 1966, The Ohio State University. 